Universiteit

Leiden

The Netherlands

\title{
The EU-Canada strategic partnership: challenges and opportunities
}

Verdun, A.C.; Ferreira-Pereira, L.C.; Smith, M.

\section{Citation}

Verdun, A. C. (2021). The EU-Canada strategic partnership:

challenges and opportunities. In L. C. Ferreira-Pereira \& M. Smith (Eds.), The European Union's Strategic Partnerships: Global Diplomacy in a Complex and Contested World (pp. 121-148). London, UK.: Routledge. doi:10.1007/978-3-030-66061-1

Version: Publisher's Version

License: $\quad$ Leiden University Non-exclusive license

Downloaded from: $\quad$ https://hdl.handle.net/1887/3249815

Note: To cite this publication please use the final published version (if applicable). 


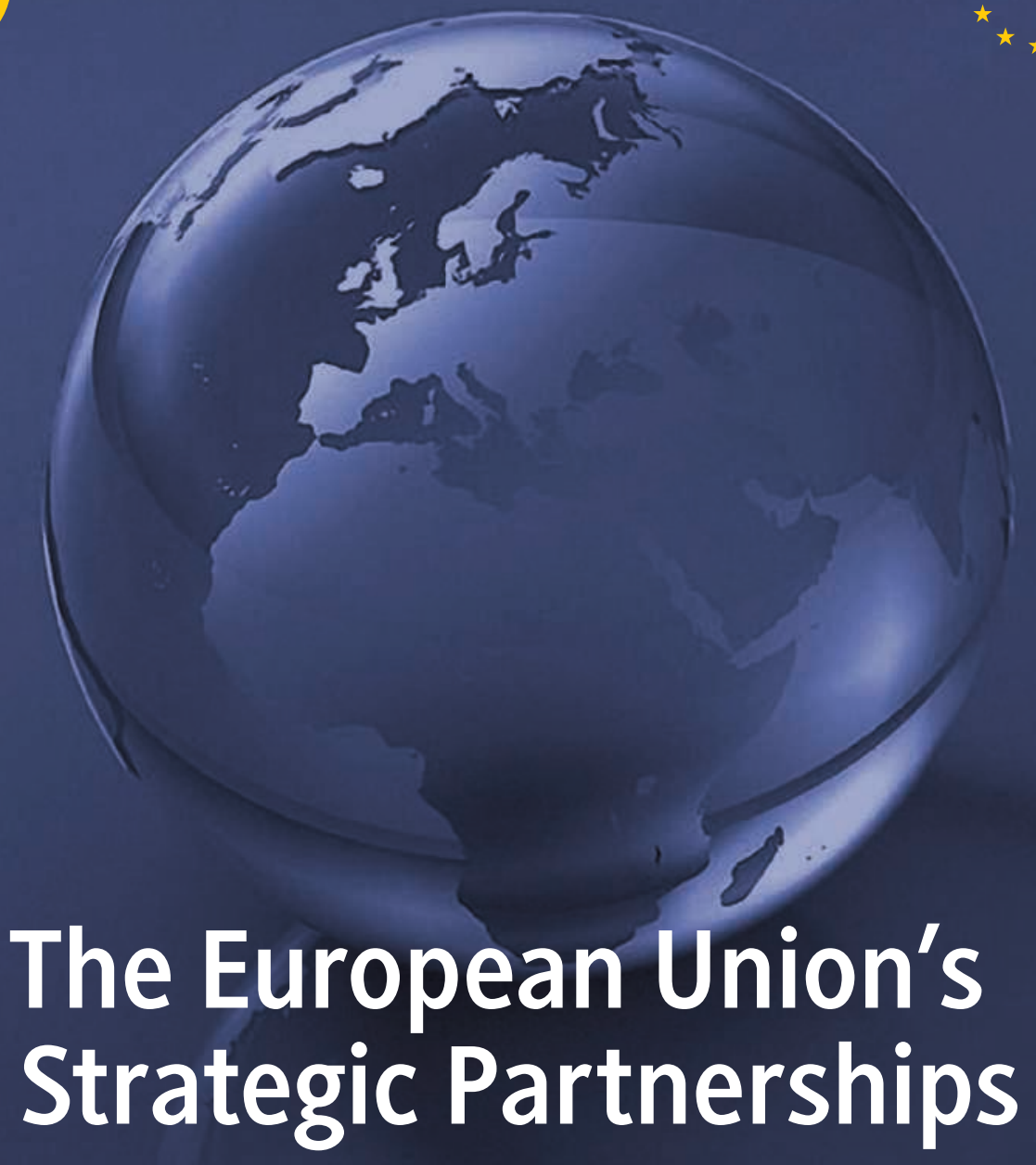

Global Diplomacy in a Contested World

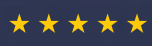

Edited by

Laura C. Ferreira-Pereira

Michael Smith 
The European Union in International Affairs

\author{
Series Editors \\ Sebastian Oberthür \\ Vrije Universiteit Brussel \\ Brussels, Belgium \\ Knud Erik Jørgensen \\ Aarhus University \\ Aarhus, Denmark \\ Philomena B. Murray \\ University of Melbourne \\ Parkville, Australia \\ Sandra Lavenex \\ University of Geneva \\ Geneva, Switzerland
}


This Book Series aims to be a central resource for the growing community of scholars and policy-makers who engage with the evolving interface between the EU and international affairs. It provides in-depth, cutting edge and original contributions of world-class research on the EU in international affairs by highlighting new developments, insights, challenges and opportunities. It encompasses analyses of the EU's international role, as mediated by its own Member States, in international institutions and in its strategic bilateral and regional partnerships. Books in the Series examine evolving EU internal policies that have external implications and the ways in which these are both driven by, and feed back into, international developments. Grounded in Political Science, International Relations, International Political Economy, Law, Sociology and History, the Series reflects a commitment to interdisciplinary scholarship. We welcome book proposals relating to the changing role of the EU in international affairs across policies and the Union's relations with different parts of the world, as well as relations with states and multilateral institutions. We are interested in research on values and norms, interests and global governance and welcome both theory-informed studies and studies comparing the EU with other major global actors. To submit a proposal, please contact Commissioning Editor Ambra Finotello ambra.finotello@palgrave.com. This series is indexed by Scopus.

More information about this series at http://www.palgrave.com/gp/series/14438 


\section{Laura C. Ferreira-Pereira $\cdot$ Michael Smith Editors}

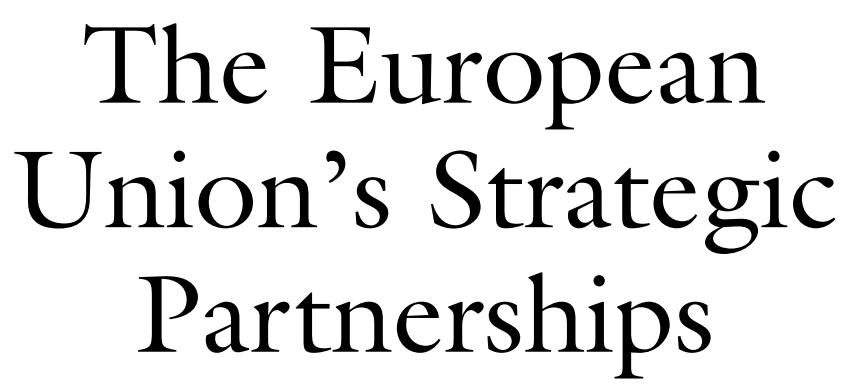

Global Diplomacy in a Contested World 


\section{Editors}

Laura C. Ferreira-Pereira

Department of Political Science and Research Center in Political Science (CICP-UMinho)

University of Minho

Braga, Portugal
Michael Smith

PAIS

University of Warwick

Coventry, UK

ISSN 2662-5911

ISSN 2662-592X (electronic)

The European Union in International Affairs

ISBN 978-3-030-66060-4 ISBN 978-3-030-66061-1 (eBook) https://doi.org/10.1007/978-3-030-66061-1

(C) The Editor(s) (if applicable) and The Author(s), under exclusive license to Springer Nature Switzerland AG 2021

This work is subject to copyright. All rights are solely and exclusively licensed by the Publisher, whether the whole or part of the material is concerned, specifically the rights of translation, reprinting, reuse of illustrations, recitation, broadcasting, reproduction on microfilms or in any other physical way, and transmission or information storage and retrieval, electronic adaptation, computer software, or by similar or dissimilar methodology now known or hereafter developed.

The use of general descriptive names, registered names, trademarks, service marks, etc. in this publication does not imply, even in the absence of a specific statement, that such names are exempt from the relevant protective laws and regulations and therefore free for general use.

The publisher, the authors and the editors are safe to assume that the advice and information in this book are believed to be true and accurate at the date of publication. Neither the publisher nor the authors or the editors give a warranty, expressed or implied, with respect to the material contained herein or for any errors or omissions that may have been made. The publisher remains neutral with regard to jurisdictional claims in published maps and institutional affiliations.

Cover credit: Image Source/Getty Images

This Palgrave Macmillan imprint is published by the registered company Springer Nature Switzerland AG

The registered company address is: Gewerbestrasse 11, 6330 Cham, Switzerland 
To my Mother, Maria Emilia Ferreira, with much love.

- Laura C. Ferreira-Pereira

To Kate, Caroline, Nick and Thea-a family to be proud of.

- Michael Smith 


\section{Contents}

1 Introducing the European Union's Strategic

Partnerships: Global Diplomacy in a Contested World

Laura C. Ferreira-Pereira and Michael Smith

Part I Strategic Partnerships in the European Union's Diplomatic Practice: Evolution and Analysis

2 Strategic Partnerships in European Union External Action: Evolution and Analysis of a Developing Policy Instrument

Laura C. Ferreira-Pereira and Michael Smith

3 Institutional Perspectives on the EU's Strategic Partnerships: Where Is the Focus and Authority?

Daniel Schade

4 Soft Power in the European Union's Strategic Partnership Diplomacy: The Erasmus Plus Programme

Laura C. Ferreira-Pereira and João Mourato Pinto 
Part II The Transatlantic Partners: The United States and Canada

5 The European Union and the United States:

Competition, Convergence and Crisis in a Strategic Relationship

Michael Smith

6 The EU-Canada Strategic Partnership: Challenges and Opportunities Amy Verdun

Part III Strategic Partnerships with the BRICS

7 European Union-Brazil Relations: A Strategic Partnership in Suspended Animation

Laura C. Ferreira-Pereira

8 The End of Ambiguity: Excavating the Remains of the EU-Russia 'Strategic Partnership' Hiski Haukkala

9 The European Union and India: A Reluctant Partnership Between Aspiring Global Powers Emilian Kavalski

10 The European Union and China: Partnership in Changing Times

Andrew Cottey

11 The European Union-South Africa Strategic Partnership: Aligning Interests in a Multi-Layered Environment

Talitha Bertelsmann-Scott 
Part IV Reaching Out for Strategic Partnerships Beyond the BRICS

12 The EU and Mexico: The Strategic Partnership in the Context of the Global Agreement

Roberto Dominguez

13 The EU's Strategic Partnerships with Japan and South Korea: A Comparative Analysis of the Drivers, Outcomes and Limitations

Elena Atanassova-Cornelis and Bruno Hellendorff

14 Conclusions: The Rise and Fall of an Idea Thomas Renard 


\section{Notes ON CONTRibutors}

Elena Atanassova-Cornelis is a Senior Lecturer in International Relations of East Asia. She teaches in the Department of Politics, University of Antwerp (UA), and the School of Political and Social Sciences, Université Catholique de Louvain (UCL), both in Belgium. She is concurrently a Visiting Professor at the Brussels School of International Studies (BSIS) of the University of Kent, as well as an Associate Fellow, Global Fellowship Initiative, at the Geneva Centre for Security Policy (GCSP) in Switzerland. Her research interests and expertise include international relations in the Asia-Pacific region with an emphasis on security. She focuses, in particular, on Japanese foreign and security policy; alignments and major power relations in the Asia-Pacific region; security and geopolitics of the Taiwan Strait and the Korean Peninsula, as well as regional security cooperation in Asia and EU-Asia relations. Atanassova-Cornelis has authored more than 50 academic articles, book chapters, briefing papers and reports covering various topics related to Asian-Pacific politics and security, and AsiaEurope relations. She has delivered more than 80 lectures and presentations at conferences, high-level expert meetings and universities in both Europe and Asia.

Talitha Bertelsmann-Scott is a regional integration, trade policy and EU-Southern Africa expert and worked as a consultant on a variety of projects in this regard. She started her research career at the South African Institute of International Affairs (SAIIA) in 1997-1998, examining the ongoing negotiations between the EU and South Africa on the creation 
of their first free trade agreement, the Trade, Development and Cooperation Agreement (TDCA). This research naturally extended into Southern Africa's relationship with the EU through the Lomé Conventions and then later the Economic Partnership Agreements (EPA). She has written extensively on the regional integration agenda of the Southern African Development Community (SADC), the Southern African Customs Union (SACU) and the East African Community (EAC) and the overlap issues with the Common Market for Eastern and Southern Africa (COMESA). After a long period as an independent consultant working with various donors on the implementation aspects of regional integration as well as on several Mid-Term and Final Evaluations, Talitha rejoined SAIIA in 2015 to head the Economic Diplomacy Programme. This later incorporated the Regional Observatory, which was an initiative to bring futures analysis into policy analysis and policy anticipation in Southern Africa.

Andrew Cottey is EU Jean Monnet Chair in European Political Integration and Senior Lecturer, Department of Government and Politics, University College Cork, Ireland. He previously worked in the Department of Peace Studies, University of Bradford, as well as for the EastWest Institute, Saferworld, and the British American Security Information Council (BASIC) and has been a NATO Research Fellow, a Research Associate at the International Institute for Strategic Studies (IISS) and a Visiting Researcher at the Stockholm International Peace Research Institute (SIPRI). His research focuses on European security, as well as peacekeeping, intervention and conflict management; civilmilitary relations and the roles of armed forces; and Sino-European relations and Chinese foreign policy. His publications include Security in 21st Century Europe (Palgrave Macmillan, 2nd edition 2013), Understanding Chinese Politics: An Introduction to Government in the People's Republic of China (co-authored with Neil Collins, Manchester University Press, 2012) and Reshaping Defence Diplomacy: New Roles for Military Cooperation and Assistance (co-authored with Anthony Forster, Oxford University Press/IISS, 2004), as well as articles in Journal of Common Market Studies, International Affairs, Armed Forces \& Society, Contemporary Security Policy, European Security, Armed Forces \& Society, Contemporary Politics and European Foreign Affairs Review.

Roberto Dominguez is Professor of International Relations at Suffolk University in Boston, Massachusetts. He was Jean Monnet Fellow at the 
European University Institute in Florence and Researcher at the European Union Center of Excellence of University of Miami. He holds a doctoral degree from University of Miami. His current research interest is on comparative regional security governance and security governance in Latin America and European Union-Latin American Relations. Some of his publications include: EU Foreign Policy Towards Latin America (Palgrave, 2015); "Global Governance in the United States" (in Global Governance from Regional Perspectives: A Critical View, Anna Triandafyllidou, ed., Oxford University Press, 2017); "External Powers in Asia" (with Bjørnar Sverdrup-Thygeson in EU Security Relations with Asian Powers, Thomas Christiansen, Emil J. Kirchner, and Tan See Seng, eds., Palgrave, 2021); and Resilience in the Modernization of the EU-Mexico Global Agreement (Carolina Foundation, 2020). Currently, he is one of the senior editors of the upcoming Encyclopedia of European Union Politics (Oxford University Press, 2021). He has also contributed as a consultant for projects for the European Parliament, the European Commission, Transparency International and the US Library of Congress.

Laura C. Ferreira-Pereira is Professor of Political Science and International Relations at the University of Minho and Visiting Professor of the University of São Paulo (since 2012). She is the editor of Portugal in the European Union: Assessing Twenty-Five Years of Integration Experience and a co-editor of The European Union's Fight Against Terrorism: The CFSP and Beyond (both London: Routledge, 2014). She has acted as the leading guest editor of the Special Issue of Cambridge Review of International Affairs 'The Strategic Partnerships of the European Union: Conceptual Insights, Cases and Lessons' (2016). She has published extensively on EU's Foreign Policy (CFSP/CSDP) and Portuguese Foreign Policy in the journals International Politics, Journal of Common Market Studies, Journal of European Integration, Cooperation and Conflict, Global Society, European Politics and Society and European Security, among others, and in several edited volumes. Her current research explores the nature and significance of the EU's strategic partnership diplomacy, Europeanization within and beyond Europe, comparative regional integration (with an emphasis on security and defence), Euroscepticism and European differentiation, and Luso-Chinese relations. She is a member of the editorial board of the journals Contemporary Politics and European Review of International Studies (ERIS). She is 
a founding member of the European International Studies Association (EISA).

Hiski Haukkala is currently a Professor of International Relations in the Faculty of Management and Business, Tampere University, Finland, and a non-resident Policy Expert at the Center for the Governance of AI at the Future of Humanity Institute, University of Oxford. Until summer 2018, he was the Secretary General and Chief of the Cabinet at the Office of the President of the Republic of Finland and Foreign Policy Adviser to the President. Previously, he has held positions at the Universities of Turku and Tampere, the Finnish Ministry for Foreign Affairs, the Finnish Institute of International Affairs as well as visiting positions at the College of Europe in Natolin (Warsaw), the EU Institute of Security Studies (Paris), the IISS (London) and the University of Stirling (Scotland). He is the author of numerous books and articles on EU foreign policy, Russia and International Relations. His recent books are The European Union and Russia (Palgrave, 2016, together with Tuomas Forsberg) and Trust in International Relations. Rationalist, Constructivist and Psychological Approaches (Routledge, 2017, co-editor together with Carina van de Wetering and Johanna Vuorelma). He is an accomplished public speaker who takes a growing interest in questions of bringing order and governance into increasingly turbulent world politics.

Bruno Hellendorff joined the Belgian Ministry of Foreign Affairs in 2020. He teaches as guest lecturer at the Université Catholique de Louvain (UCL). Prior to that, he was Joint Research Fellow at the Egmont Institute and European Policy Centre (EPC) between 2018 and 2020. He is an Associate Researcher at the IR centre of the Université Catholique de Louvain (CECRI), at the East Asian Studies centre (EASt) of the Université Libre de Bruxelles and at the Group for Research and Information on Peace and Security (GRIP), a Brussels-based independent research centre. His research focuses on the geo-economics and security dimensions of China's Belt and Road Initiative, as well as on defence and security issues in Europe-Asia relations (non-proliferation, maritime security).

Emilian Kavalski is the Li Dak Sum Chair Professor in China-Eurasia Relations and International Studies at the University of Nottingham Ningbo, China. He is also the Book Series Editor for Routledge's "Rethinking Asia and International Relations" series. His work explores 
the interconnections between the simultaneous decentring of International Relations by post-Western perspectives and non-anthropocentric approaches. He is the author of four books, most recently: The Guanxi of Relational International Theory (Routledge, 2018), and he is the editor of eleven volumes, including World Politics at the Edge of Chaos (State University of New York Press, 2016).

João Mourato Pinto graduated in International Relations at the University of Coimbra (Portugal) and holds a master's degree in International Relations and European Studies from both this university and Sciences Po Bordeaux (France). Currently, he is a Ph.D. candidate based at the University of Minho studying the global actorness of the European Union, especially toward Brazil and South America. He was a member of a research project on the EU's Strategic Partnerships funded by the Portuguese Foundation of Science and Technology (FCT) and has worked at the European Research Council (European Commission). Additionally, he is a former President of the Erasmus Student Network (2017-2019), where he has worked to increase access to and the quality of higher education student mobility worldwide. João Pinto is a member of the Research Center in Political Science at the University of Minho and collaborates with the Foundation for European Progressive Studies. His main research interests are EU external action, Brazilian foreign policy, South American regionalism, public diplomacy and democratic participation and citizenship in the EU.

Thomas Renard is Senior Research Fellow at the Egmont Institute, a think tank in Brussels and Adjunct Professor at the Vesalius College (Belgium). His research focuses on international security, notably terrorism and cyber-security, as well as on the EU's foreign policy and more specifically EU strategic partnerships. In 2012-2016, he was project leader of the European Strategic Partnerships Observatory (ESPO), a joint project of FRIDE and the Egmont Institute. He published a number of reports and articles on EU strategic partnerships (notably published in Cambridge Review of International Affairs, European Foreign Affairs Review, European Politics and Society and Studia Diplomatica). He is also the co-editor (with Sven Biscop) of the book The European Union and Emerging Powers in the 21st Century: How Europe Can Shape a New Global Order (Ashgate, 2012). 
Daniel Schade is a Visiting Assistant Professor in the Department of Government at Cornell University. He holds a Ph.D. in International Relations from the London School of Economics and Political Science (LSE) and has previously worked as a Postdoctoral Researcher at the Vienna School of International Studies, as well as the Otto von Guericke University Magdeburg. His research is primarily concerned with the role of institutions in the EU's external relations, as well as the increasing politicization of EU policy-making. He is the author of The EU in Association Agreements: Challenges to Complex Policy Coordination (Routledge, 2020) and has published widely on his areas of expertise in journals such as International Politics, the British Journal of Politics and International Relations and The Political Quarterly. Beyond academic research, he is also active in policy outreach and advice, serving as a fellow at the Berlinbased think tank Das Progressive Zentrum. He also provides insights into Brexit as an academic member of a parliamentary enquiry committee on the consequences of Brexit in the legislature of Germany's most populous state, North Rhine-Westphalia.

Michael Smith is Honorary Professor in European Politics at the University of Warwick and Emeritus Professor of European Politics at Loughborough University. Previously, he was Professor in European Politics in the Department of Politics and International Studies, Warwick University (2014-2018), and Professor of European Politics and Jean Monnet Chair at Loughborough University (1994-2015), where he also was Co-Director of the Centre for the Study of International Governance and of a Jean Monnet Centre of Excellence. In 2010, he was the recipient of a Lifetime Achievement Award from the University Association for Contemporary European Studies (UACES). He has published extensively on EU external policies and on EU diplomacy, on the EU and world order, on EU-US relations and on EU-Asia relations. Among his major monographs (books) are: The European Union's Roles in International Politics: Frameworks and Analysis (edited with Ole Elgström) (Routledge, 2006); The European Union and the United States: Competition and Convergence in the Global Arena (co-authored with Steven McGuire, Palgrave Macmillan, 2008; second edition in preparation); International Relations and the European Union (co-edited with Christopher Hill and Sophie Vanhoonacker, Oxford University Press, third edition 2017); and The Diplomatic System of the European Union: Evolution, Change and Challenges (co-edited with Sophie Vanhoonacker and Stephan Keukeleire, 
Routledge 2016). He has also edited special issues of the Journal of Common Market Studies and the Journal of European Public Policy as well as contributing articles to those and to a range of other leading journals.

Amy Verdun is Professor of Political Science, the founding Director of the European Studies Program at the University of Victoria, and served as Chair of the Department of Political Science (2010-2013). While on leave from 2018 to 2020, she served as Professor of European Politics and Political Economy at Leiden University (NL). She held postdoctoral fellowships (University of Essex [1995-1996] and the European University Institute (EUI) [1997]) —and she also holds a Ph.D. (1995) from the EUI. She has published in Acta Politica, British Journal of Politics and International Relations, Canadian Public Administration, European Political Science, European Union Politics, International Studies Review, JCMS: Journal of Common Market Studies, Journal of European Integration, Journal of European Public Policy, Journal of Public Policy, Review of International Political Economy and World Politics. She has been (co)editor or (co)author of more than twenty books, including European Union Governance and Policy Making: A Canadian Perspective with E. Brunet-Jailly and A. Hurrelman; Decision-Making in the EU before and after the Lisbon Treaty with M. Hosli, A. Kreppel and B. Plechanavová (London: Routledge); Ruling Europe: The Politics of the Stability and Growth Pact (Cambridge University Press) with M. Heipertz; and The Transatlantic Divide: Foreign and Security Policies in the Atlantic Alliance from Kosovo to Iraq, with O. Croci. (Manchester University Press). 


\section{AbBreviations}

ACP

ARF

ASEAN

ASEM

BASIC

BIT

BJP

BLNS

$\mathrm{BM}$

BRI

BRIC

BRICS

$\mathrm{CAB}$

CAI

CELAC

CETA

CFSP

COAFR

COASI

COEST

COHOM

COMESA

COTRA

COVID-19

CSCE

CSDP
African, Caribbean and Pacific

ASEAN Regional Forum

Association of Southeast Asian Nations

Asia-Europe Meeting

Brazil, South Africa, India and China

Bilateral Investment Treaty

Bharatiya Janata Party

Botswana, Lesotho, Namibia and Swaziland

Ballistic Missile

Belt and Road Initiative

Brazil, Russia, India and China

Brazil, Russia, India, China and South Africa

Citizenship Amendment Bill

Comprehensive Agreement on Investment

Community of Latin American and Caribbean States

Comprehensive Economic and Trade Agreement

Common Foreign and Security Policy

Council Working Party on Africa

Council Working Party on Asia and Oceania

Council Working Party on Eastern Europe and Central Asia

Council Working Party on Human Rights

Common Market for Eastern and Southern Africa

Council Working Party on Transatlantic Relations

Coronavirus Disease 2019 caused by SARS-CoV-2

Conference on Security and Cooperation in Europe

Common Security and Defence Policy 
CSDS

CSR

DFQF

DG

DGDEVCO

DGEAC

DGNEAR

DGTRADE

DPRK

EAC

EBA

EBRD

ECLAC

EEAS

EEC

EESC

EFTA

EMU

ENP

EP

EPA

ESDP

ESN

ESS

EU

EUD

EUGS

EUNAVFOR

FA

FPA

FPI

FTA

FTAA

G7

G20

GA

GATT

GDP

GHG

HEI

HLD
Centre for Strategic Defence Studies

Common Strategy on Russia

Duty Free Quota Free

Directorate-General

Directorate-General for International Cooperation and Development

Directorate-General for Education, Audiovisual and Culture

Directorate-General for European Neighbourhood and Enlargement Negotiations

Directorate-General for Trade

Democratic People's Republic of Korea (North Korea)

East African Community

Everything But Arms

European Bank for Reconstruction and Development

Economic Commission for Latin America and the Caribbean

European External Action Service

European Economic Community

European Economic and Social Committee

European Free Trade Association

Economic and Monetary Union

European Neighbourhood Policy

European Parliament

Economic Partnership Agreement

European Security and Defence Policy

Erasmus Student Network

European Security Strategy

European Union

EU Delegation

European Union Global Strategy

European Union Naval Force

Framework Agreement

Framework Participation Agreement

Service for Foreign Policy Instruments

Free Trade Agreement

Free Trade Area of the Americas

Group of Seven industrial nations

Group of Twenty largest economies

Global Agreement

General Agreement on Tariffs and Trade

Gross Domestic Product

Greenhouse Gases

Higher Education Institution

High-Level Dialogues 
HR

HRVP/HR/VP

IBSA

ICG

ICM

ICS

IEPA

IGI

IMF

JCC

JPC

LAC

LDC

MENA

MEP

MES

MINUSTAH

MRA

NAFTA

NATO

ODA

OECD

OJEU

P4M

PCA

PESCO

PfP

PI

PPC

PRC

$\mathrm{RIO}+20$

ROK

SA

SACU

SADC

SADC

SDSP

SLOC

SME

SP

SPA
High Representative of the European Union for Foreign Affairs and Security Policy

High Representation for Foreign Affairs and Security Policy/Vice-President of the Commission

India, Brazil and South Africa

International Contact Group

International Credit Mobility

Investment Court System

Interim Economic Partnership Agreement

Global Impunity Index

International Monetary Fund

Joint Cooperation Committee

Joint Parliamentary Committee

Latin America and Caribbean

Least Developed Countries

Middle East and North Africa

Member of the European Parliament

Market Economy Status

United Nations Mission for Stability in Haiti

Mutual Recognition Agreement

North American Free Trade Agreement

North Atlantic Treaty Organisation

Official Development Assistance

Organisation for Economic Cooperation and Development

Official Journal of the European Union

Partnership for Modernisation

Partnership and Cooperation Agreement

Permanent Structured Cooperation

(NATO) Partnership for Peace

Partnership Instrument

Permanent Partnership Council

People's Republic of China

The United Nations Conference on Sustainable Development

Republic of Korea (South Korea)

South Africa

Southern African Customs Union

South American Defence Council

Southern African Development Community

Sector Dialogues Support Facility

Sea Lines of Communication

Small and Medium Enterprise

Strategic Partnership

Strategic Partnership Agreement 
TDCA

TEMPUS

THAAD

TIEA

TPC

TPP

TTIP

UK

UN

UNASUR

UNCLOS

UNESCO

UNGA

UNSC

US/USA

USMCA

USSR

WMD

WTO
Trade, Development and Cooperation Agreement

Trans-European Mobility Programme for University Studies

Terminal High Altitude Area Defence

Trade and Investment Enhancement Agreement

Trade Policy Committee

Trans-Pacific Partnership

Transatlantic Trade and Investment Partnership

United Kingdom

United Nations

Union of South American Nations

United Nations Convention on the Law of the Sea

United Nations Education, Scientific and Cultural Organization

United Nations General Assembly

United Nations Security Council

United States/United States of America

United States-Mexico-Canada Agreement

Union of Soviet Socialist Republics

Weapons of Mass Destruction

World Trade Organisation 


\section{List OF Figures}

Fig. 4.1 Number of students and staff (academic and non-academic) participating in Erasmus+ exchanges between Erasmus+ Programme Countries and Brazil (2015-2019) (Source European Commission 2020a)

Fig. 4.2 Number of students and staff (academic and non-academic) participating in Erasmus+ exchanges between Erasmus+ Programme Countries and Russia (2015-2019) (Source European Commission 2020b)

Map 14.1 The strategic partnerships of global powers (Source Data was retrieved from the following websites' administrations: US department of States, US White House, Russian MFA, Chinese MFA, Furthermore, data was collected and updated from: Hamilton [2014], Zhongping and Huang [2014], Costa Vas [2014], and Renard [2011]) 


\section{List OF TABLES}

Table 1.1 The EU's strategic partnerships: Summary information

Table 6.1 Canada-EU agreements (1959-2016) (selection)

Table 11.1 Timeline of EU-South and Southern African negotiations and Summits 


\title{
Introducing the European Union's Strategic Partnerships: Global Diplomacy in a Contested World
}

\author{
Laura C. Ferreira-Pereira and Michael Smith
}

The willingness to shape an ever more intrusive process of globalization and complex global governance by influencing some of its major contours has been a leitmotiv for the European Union's (EU) endeavours to increase its leverage in the contemporary international arena. The constitutional process launched by the Laeken Declaration on the Future

Laura C. Ferreira-Pereira acknowledges that this study was conducted at the Research Center in Political Science (UIDB/CPO/00758/2020), University of Minho/University of Évora, and was supported by the Portuguese Foundation for Science and Technology and the Portuguese Ministry of Education and Science through national funds.

L. C. Ferreira-Pereira $(\bowtie)$

Department of Political Science and Research Center in Political Science (CICP-UMinho), University of Minho, Braga, Portugal e-mail: lpereira@eeg.uminho.pt

(C) The Author(s), under exclusive license to Springer Nature

Switzerland AG 2021

L. Ferreira-Pereira et al. (eds.), The European Union's Strategic

Partnerships, The European Union in International Affairs, https://doi.org/10.1007/978-3-030-66061-1_1 
of Europe of December 2001 and concluded with the entry into force of Lisbon Treaty in 2009 was informed by the ambition of the EU to expand its foreign policy reach and reinforce its international political and security persona. In the meantime, multiple efforts undertaken by the EU at the politico-diplomatic, institutional and operational levels to assert itself as a global actor have had tangible implications in terms of the external perception(s) of its image and role (Lucarelli and Fioramonti 2010; Martin and Kaldor 2009; Chaban and Holland 2019). Prominent among such efforts has been the institutionalisation of Strategic Partnerships (SPs), by means of which the EU has fostered a network of exclusive bilateral relationships with key major actors, encompassing both established and emerging powers, to advance a common political, economic, commercial and security agenda.

Permeating those privileged rapports with pivotal states, which have received increasing attention by key stakeholders in EU's foreign policy, various references to the global implications of SPs can be found ${ }^{1}$. While reinforcing the status of the EU as an international actor in its own right, the SPs have functioned as equalizing arrangements between the EU and pivotal states. To this extent while being acknowledged as 'strategic partners' of one of the largest trade and economic poles/blocs in the world, such states have been positioned on an equal footing with the EU. At the same time, when ascribing such priority to particular third states, the EU has tended to introduce a hierarchical structure in its international/diplomatic relations. In fact, the strategic partnership policy has created a space for differentiation, thereby drawing a dividing line between those that are acknowledged as strategic partners and those that do not receive this formal recognition (Renard 2011). In promoting the

\footnotetext{
M. Smith

PAIS, University of Warwick, Coventry, UK

e-mail: M.H.Smith@warwick.ac.uk
}

\footnotetext{
${ }^{1}$ Following the 23 May 2009 EU-South Korea summit, it was announced that "The future SP envisaged by the Leaders is expected to contribute greatly not only to KoreaEU bilateral relations but also to the peace and development of the regional and international community". In another geographic region, one can refer to the Joint Executive Action Plan regulating EU-Mexico SP which reads that: "The establishment of a Strategic Partnership between Mexico and the EU reflects the readiness of both players to strengthen coordination on matters of global importance and further intensify their political, economic and cooperation links".
} 
dichotomy between inclusion and exclusion, the EU tends to exert a force of attraction on those who still remain at the margins, but wish to get into the privileged fold of strategic partners for the growth in prestige and leverage it entails.

Therefore, as an evolving multidimensional and multipurpose foreign policy instrument, SPs have impacted not only upon the reputation and influence of the EU as a global political, diplomatic and security player, but also upon the behaviour of third states that eventually agree to get engaged in such a privileged relationship. These states have either demonstrated a disposition to embrace central aspects of the EU's political modus faciendi, or have exhibited compliance with the EU's provisions as a result of a voluntary action towards emulating the EU 'model' (Ferreira-Pereira 2012). Indeed, at least for some partnering states, the status and recognition endowed by a 'strategic partnership' have become vehicles through which they are incentivised to follow the 'right track', in line with EU's standards and best practices in key areas of mutual interest. Ultimately, all this adds to the overall understanding of the global impact of the EU's partnership policy and its ingenious/creative use of selective incentives to promote the emulation of standards in the various substantive areas it operates within (ibidem). Along these lines, it is clear that SPs have been developing themselves as a relevant configuration of the EU's globally oriented presence and governance in operation.

The EU has drawn on a cumulative experience of bilateral rapports with third parties to design its current ten SPs, notably with Brazil, Canada, China, India, Japan, Mexico, South Africa, South Korea, Russia, and the United States. Precedents of SP-driven dynamics in the Common Foreign and Security Policy (CFSP) realm can be found in specific tools which were originally implemented throughout the 1990s in the framework of the EU's post-1989 foreign policy, notably the political dialogue and Common Strategies. Yet, over the last decade and a half roughly, the SPs have gained mounting salience in the EU's pursuit of a credible and influential globally-oriented foreign and security policy. They entered originally into the EU's foreign policy doctrine in the 2003 European Security Strategy which was conditioned by developments stemming from both the 9/11 terrorist attacks and the subsequent Anglo-American military intervention in Iraq. While calling for "effective multilateralism" as a leading comprehensive principle for the post-9/11 world governance, the ESS enumerated a limited number of countries with whom the EU intended to strengthen a strategic relationship. This was the case with 
Canada, China, India, Japan, Russia and the United States. Further SPs were enshrined in the Report on the Implementation of the European Security Strategy approved in 2008, namely with South Africa and Brazil. Furthermore, the EU sealed a SP with Mexico during the same year, while in 2010 South Korea was identified as a strategic partner, thereby completing the list of the current ten members. Table 1.1 details the key aspects of these ten SPs, along with some of their key policy focuses.

The economic and financial crisis that struck Europe as of 2008 and subsequently undermined the external image of EU as a community of prosperity and solidarity, galvanized the importance ascribed to the SPs as a comprehensive foreign policy tool to match the EU's increasingly global ambitions. This became especially noticeable in September 2010, when the Council Conclusions acknowledged that the SPs were a 'useful instrument for pursuing European objectives and interests' (European Council 2010: 2; see also Renard 2011). At the time, the recognition of SPs' salience by such a high-level institution as the European Council then led by Herman Van Rompuy, and the political impetus they also received from the then High Representative of the Union for Foreign Affairs and Security Policy, Catherine Ashton, augured well for the future of SPs.

However, since then, the EU has faced the biggest succession of crises since the inception of the European project. This fact has crystallized the EU's crisis identity, which has gained new salience in the face of growing populism, the decline of democracy in some EU member states and the successive terrorist attacks across Europe. Among those crises, the Brexit process inaugurated by the June 2016 British referendum has posed an unprecedented challenge to the EU's continuity as a regional model with a differentiated global presence. The eventual withdrawal of such a full spectrum global power as the UK characterized by a virtually unmatched political, economic and military leverage has brought with it the prospect of geopolitical tensions and competition at the very heart of continental Europe. Moreover, the future necessity to forge a new customized relationship with the UK as a potential special partner takes the EU into uncharted territory.

On the external front, the EU has been confronting unprecedented and diverse challenges posed by the so-called rising powers which promote contesting views about the reform of global governance as well as the management of globalization both inside and outside the realm of the BRICS (Brazil, Russia, India, China and South Africa). Russia's newly 


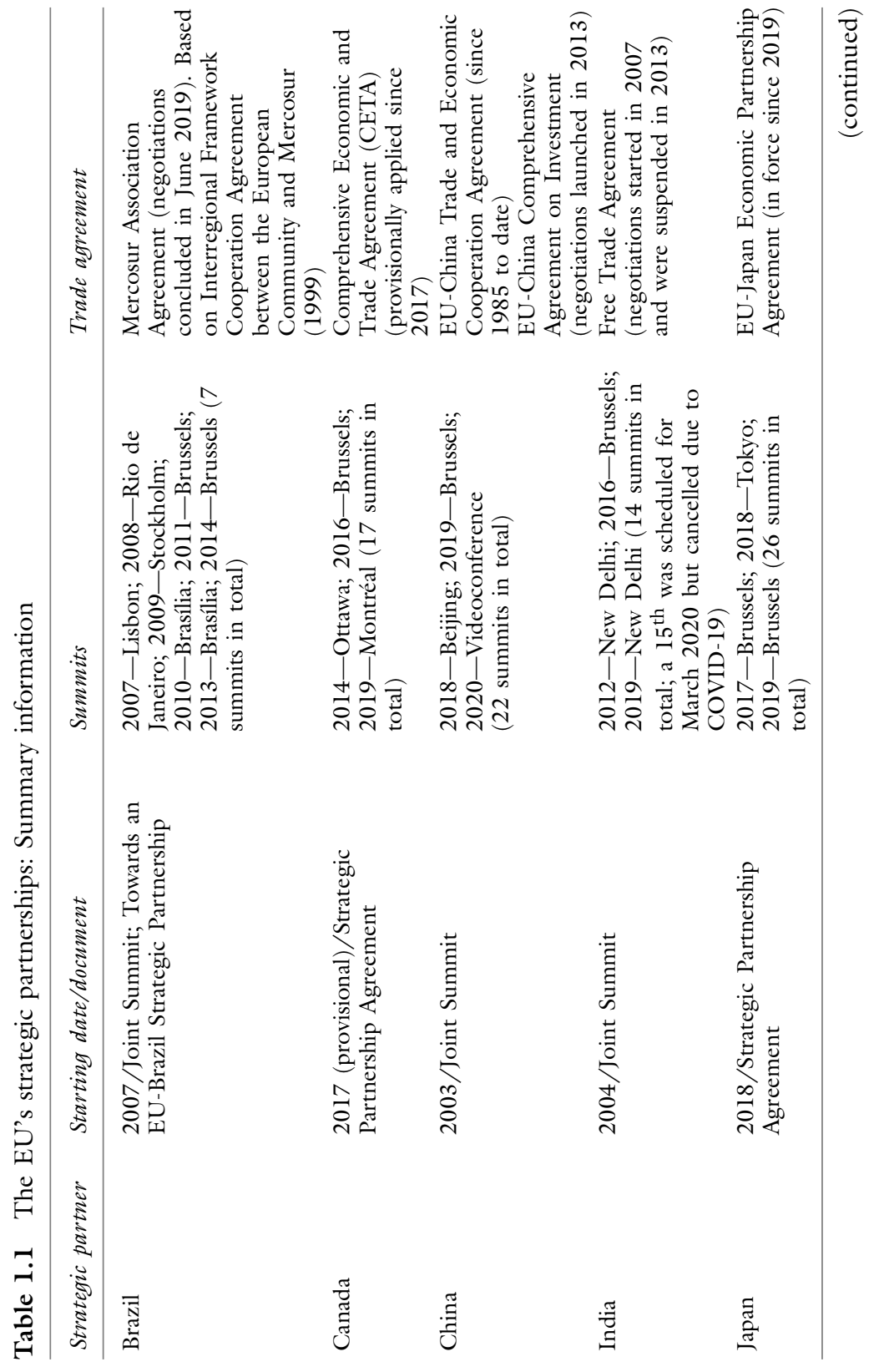




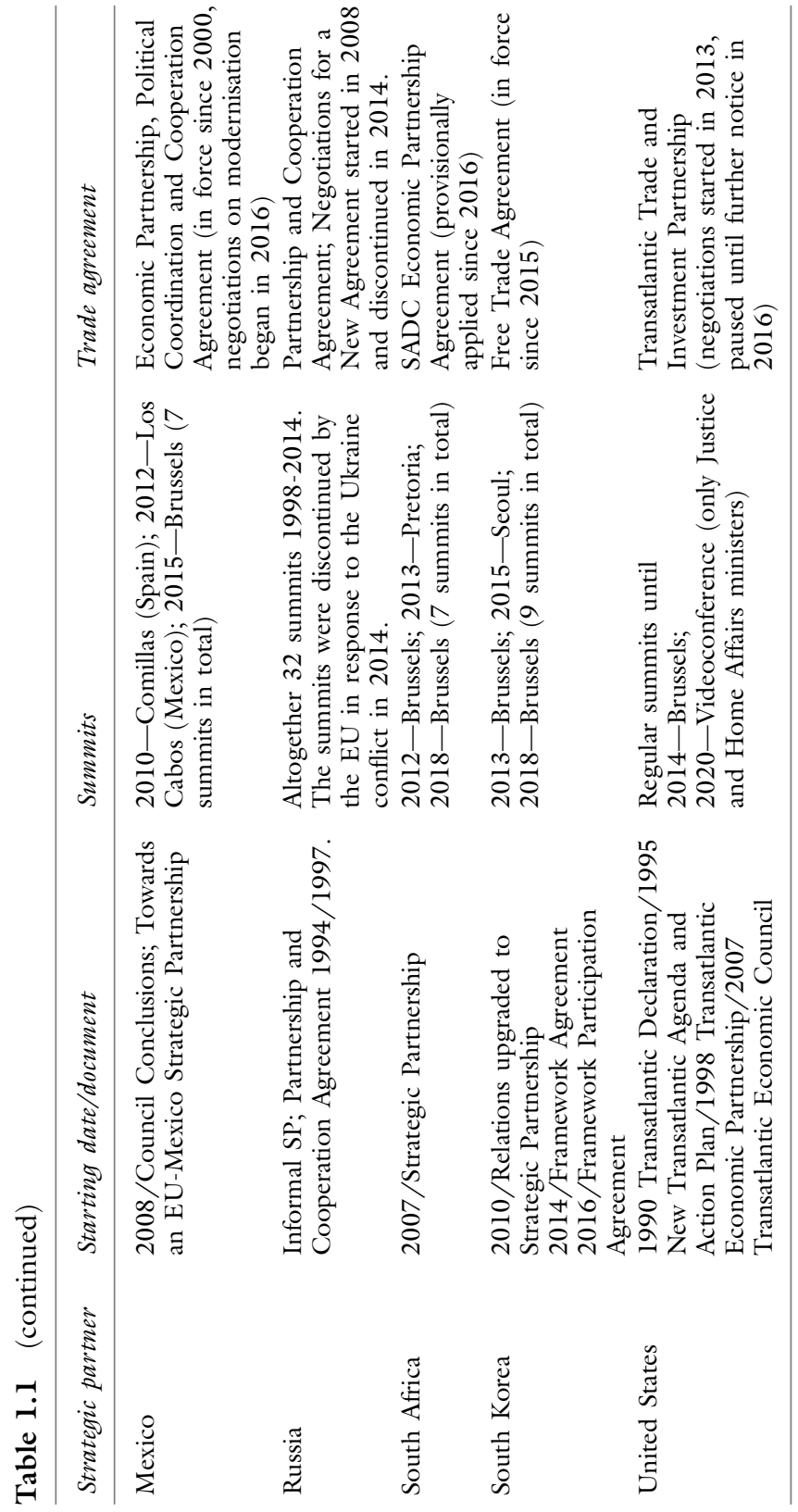


aggressive behaviour as reflected in the annexation of Crimea in March 2014 and its increasing presence in the Middle East have led to a growing perception of this state-once a strategic partner-as a potential threat. To this should be added the wave of aggressive assertiveness of China in the South China Sea alongside its post-imperial nostalgia underlying the 'One Belt, One Road Initiative'; and the perplexing authoritarianism prevailing in Erdogan's Turkey. The general deterioration of international politics and transatlantic relations as a result of the Trump administration's erratic foreign policy, which has been further fuelling both contestation of and mistrust regarding US leadership, completes the complexity of this picture. During 2020, the impact of the COVID-19 coronavirus crisis on all major regions of the world served to highlight many of the tensions and fissures outlined above, with frictions between leading powers and an intense competition to develop means of treating the disease.

Against this backdrop, the consolidation of SPs with pivotal global and regional powers has been further pushed to the top of the EU's foreign policy agenda. This became evident in the EU's Global Strategy launched in June 2016 by the High Representative of the Union for Foreign Affairs and Security Policy, Federica Mogherini. While describing the EU as being "under threat", the new strategic framework document emphasised the need for the organization to invest in its current external partnerships to "partner selectively with players whose cooperation is essential to the provision of global goods and meeting new challenges" (EEAS 2016: 13, 18). Furthermore, it underlined that the EU is willing to share global responsibilities with its partners and contribute to their strengths, on the basis of "win-win solutions". By fostering and supporting "comprehensive agreements rooted in broad, deep and durable regional and international partnerships, the EU aims to contribute to Europe's collective security and achieve sustainable peace" (ibid.: 4, 29).

In this broad context, this book aims to provide a critical analysis of the nature and development of the EU's strategic partnership diplomacy, and of the SPs themselves as a foreign policy modality and an instrument of the EU's external action, in the conditions of the twenty-first century. Our aim in conceiving this project was to link with key aspects of the EU's Global Strategy; to bring together a strong list of experts who could work within a clear framework for analysis; and to deal not only with the substance of the policy, but also with the ways in which the policy as a whole has emerged, is conducted and might develop in the future. 
This collective exercise will bring us one step closer to understanding the SPs' ontology while contributing to the clarification of issues springing from not only their differentiated institutionalization and implementation processes, but also their implications, achievements, setbacks and pitfalls. The establishment of SPs is a relevant fact with manifold repercussions on the evolving assertion of the EU as a global politico-strategic actor and its leadership capacity to advance multilateral solutions in various high order issues related to critical international challenges, such as transnational terrorism, climate change, organized crime and migration, among others. At the same time, it can be also consequential for the regional integration processes in which strategic partners are engaged and in many instances taking a leading role. This is so to the extent that the choice of a given SP and the exclusiveness of the bilateral relationship it entails seem to reflect the EU's outlook on the prevailing hierarchal structure in key regions. The exclusive relationship sealed with an individual country tends to endow this country with a sort of regional powerhood status while generating a more or less accepted followership dynamic on the part of the non-partnering countries in the same region.

SPs have never hitherto been conceptualized in a clear-cut way, nor clarified in the many CFSP declarations (Ferreira-Pereira and Vieira 2016). At the same time, while varying from country to country, the rationale underlying the establishment of a given SP has never been unambiguously stated. Variation has also been noticeable when it comes to the institutionalization of the political dialogue which underpins the SPs. As a result, the latter have evolved in multiple ways and to differing degrees thereby giving ample room for critical voices to depict them as a hollow or empty shell. Hence, when it is not discarded for being totally elusive, the concept of SP is questioned. Metaphorically speaking, it is also prone to be equated with a 'black box', calling for exploration and illumination based on a comprehensive conceptual, theoretical and empirical investigation.

Despite the growing importance attributed to SPs by the Global Strategy, in recent times some could observe that they have not been notably high on the EU agenda and, ultimately, the stage that some SPs have reached nowadays could make some ask: Are the strategic partnerships still alive? Along these lines, an important dimension of this book derives from a critical approach to SPs as it teases out the limitations and constraints underlying their existence, utility/functions and functioning; it discusses the putative relationship between SPs and the EU's 
purported role as a strategic actor; and explores the linkages between different SPs and how they have been played out or used by the EU (or by the strategic partners themselves) in the pursuit of their objectives. As a result, intriguing questions arise. How do bilateral relations with one strategic partner affect those with other partners? For example, considering that the United States National Security Strategy of December 2017 depicted both Russia and China as challengers to American power, how can the bolstering of the EU-China Comprehensive Strategic Partnership of 2003 based on the EU-China 2020 Strategic Agenda for Cooperation be achieved without questioning the long-time transatlantic partnership with the United States? Do strategic partners actually perceive and treat the EU as a strategic actor? In the context of the return of great power rivalry and considering that, theoretically speaking, great powers are among the EU's strategic partners, is the EU shifting its strategic partnership policy from a more idealist view evinced in the 2003 European Security Strategy to a more "Realpolitik" view of the world, as envisaged by the Global Strategy?

\section{The Strategic Partnerships Within THE Field of European Foreign Policy}

In recent years, following diverse developments at the policy level in the context outlined above, a significant number of academics in both universities and think tanks have addressed the topic of the EU's SPs. However, as a distinct research topic in the established specialized field of EU's Foreign Policy, the SPs have seldom been systematically studied to date (for exceptions, see Renard and Biscop 2012; Sautenet 2012). While there has been a significant body of literature focusing on individual EU's SPs, these studies have not been put in immediate juxtaposition to the literature on EU foreign policy. Symptomatic of this, some relevant scholarly works dedicated to European foreign and security policy do not cover the specific topic of the EU's SPs (Jørgensen et al. 2015; Bickerton 2015; Duke 2017). Yet, in the meantime the field of European Foreign Policy has witnessed the emergence of research sub-streams such as 'strategic diplomacy', 'external perceptions of the EU' and 'EU relations with emerging powers', as well as the 'EU's relationship with the UN' (Husar and Maihold 2010; Maihold 2010; Allen and Smith 2012; Lucarelli and Fioramonti 2010; Renard and Hooimaaijers 2011; Smith et al. 2016), which offer contributions potentially relevant to the understanding of the 
EU's SPs. In addition, recent work by Chaban and Holland and their contributors (Chaban and Holland 2019) has provided valuable insights into the ways in which the EU's strategic partners themselves have fed into the shaping of the EU's global strategy and diplomacy, bringing together aspects of the 'strategic diplomacy' and 'external perceptions' literature.

Linked to this, it should be underlined that research on the EU's SPs has been intertwined with a more general academic debate on how the EU is viewed worldwide and perhaps even more so with the EU's own capacity to reinvent its role in contemporary world politics. Research focused on the EU's SPs therefore contributes to the study of the EU's external action and its multifaceted international actorness, mainly as a political, diplomatic, economic and security actor. Some studies have also analysed the EU's ambition to contribute to the overarching goal of strengthening 'effective multilateralism' as the fundamental principle of global governance (see, for example, Bouchard et al. 2014). Others have paid particular attention to the security considerations underlying the EU's SPs, including the identification of common threats and perceived needs related to joint endeavours in the domain of international peacekeeping and peacebuilding (for an overview, see Ferreira-Pereira and Vieira 2016).

As noted above, a number of studies focusing on the dynamics of the EU's SP regarding specific countries have been published. Yet, this genre of literature is highly disparate, with a moderate number of studies covering only few target states, notably Brazil (Gratius 2018; Saraiva 2017; Santander 2016; Ferreira-Pereira 2016; Emerson and Flores 2013), China (Pan 2012; Michalski and Pan 2017; Smith 2016; Li 2016; Maher 2016), Russia (Chizhov 2012; Haukkala 2010; De Wilde and Pellon 2006) and India (Kavalski 2016; Bava 2010; Sachdeva 2009) besides relations with the United States which have been much more widely covered. A less extensive coverage is available for Canada, South Korea, Japan, Mexico and South Africa. To this, it should be added that there are also publications exploring the strategic partnership dynamics embedded in the EU-Africa (Mangala 2013) and EU-ASEAN (Novotny and Portela 2012 ) relations/frameworks. Finally, a separate stream of research has explored the cooperation between the EU and it strategic partners in specific policy areas such as environment, trade (Husar and Maihold 2010) and cyber issues (Renard 2018). 
The literature is thus uneven, for various reasons. Firstly, considering the significant events that took place in recent years, particularly since 2016, such as those referred to above, the available literature exhibits a number of blind spots that need to be overcome. Secondly, the literature has not fully recognized that there are different levels of policy activity towards different countries pertaining to the same region, meaning that on the part of the EU there are no homogeneous policies towards the region of the strategic partners. The cases of Brazil and Mexico, and Japan and South Korea, may be presented as illustrative cases in point. However, very few studies critically analyse and contrast the EU's approach towards the different Asian countries (Song and Wang 2019) and Latin America (Dominguez 2015). Thirdly, bearing in mind the current state of the art of the EU's SPs on the one hand, and the fluid and contested state of world politics on the other, there is a need for further exploration of the impact of change and crisis. To what extent have the Trump administration, the Brexit process, the security crisis originating from both the wave of illegal migrants and refugees arriving in Europe and the terrorist attacks between 2015 and 2017, and also the continuing trade frictions and competing ideas of global governance impacted upon the EU's partnership policy? In the evolving highly intricate and unpredictable international environment, what have been the pay-offs springing from the reinforcement of the EU's partnership policy, and to what extent are they in line with the partners' expectation that "the European Union [should] play a major role, including as a global security provider" (EEAS 2016: 3)? While engaging itself in the establishment, expansion and/or consolidation of its SPs with regional leading powers, is the EU promoting regional orders thereby conditioning regional governance and, ultimately, governance at the global level? Can the official narrative of the EU's SP policy be equated with an attempt to forge a strategic metanarrative or does it simply represent an easy short cut designed to skip much-needed long-term strategic thinking and planning? Has the experience of 20 years or so of a strategic partnership policy confirmed its potential to enable the EU to wield further persuasive and regulatory power on the world stage? If yes, has the partnership policy helped the EU both to transform its relations with major powers and to tame the revisionist and contestation-oriented posture adopted not only by rising powers, notably China and Russia, but also by the United States? Finally, might the variegated portfolio of SP's be useful in developing an exceptional type of partnership with the post-Brexit UK and how might the 
latter impact upon the future EU's partnership diplomacy in an ever-more complex world?

\section{Focus ANd Content of The Volume}

While acknowledging the merits of previous scientific efforts made in the framework of three special issues of well-known journals (i.e. International Affairs, 2013, Cambridge Review of International Affairs, 2016 and International Politics, 2017) - two of which have particularly contributed to evaluating the state of the art with respect to the EU's partnership policy while outlining an agenda for future research-this volume aims to present an updated and integrated reading of the EU's SPs in the context of the current geopolitical and strategic reconfiguration of the global order. In offering an inclusive set of case studies and diverse perspectives, namely comparative perspectives in order to interpret the complexity and multifacetedness of the phenomena, the volume aims to advance both conceptualization and analysis of the implementation of the established SPs.

The appraisal of the EU's partnership policy in times of global power shift and liberal order contestation will highlight four dimensions. Firstly, there is the functional dimension linked to the increasing resort to SPs as a foreign policy instrument to help the EU to thrive in a critical juncture of multilevel crisis. By this reasoning, the establishment and development of SPs can be seen as a milieu-shaping expedient used by the EU to promote stability in an increasingly uncertain/unpredictable international environment while countering/mitigating the effects resulting from the growing affirmation of rising and contesting powers (e.g. Russia and China), as well as from the US drift towards unilateralism. Equally important, the reiterated commitment to the SPs can be eventually equated to a novel meta-narrative that has accompanied the redefinition of the EU's international posture and status-seeking strategy since the launching of the 2003 European Security Strategy and especially with the development of the Global Strategy. Among other aspects, this includes the evolution from the promoter/supporter of "effective multilateralism" to the co-creator of "effective global governance" (EEAS 2016: 36, 43). Secondly, there is the policy dimension which highlights the building up of the SPs as a gradually separated, but not separable policy within CFSP, of which it is an integral part. Thirdly, there is the institutional dimension, on the basis of which the originally declaratory SPs have been consolidated 
and have evolved into a self-preserving institutional platform and soft law contractual basis, allowing for denser and deeper cooperation in various policy areas. Finally, there is the identity/role dimension articulated with a reflection on whether the evolution of the SPs has strengthened the EU's self-conception as an international actor and thus whether the SPs have crystallized into an instrument to enhance the legitimacy of the EU's global role in times of transition. These four themes-functional, policyrelated, institutional and role-related-are key to the chapters that follow and thus to the volume as a whole.

The structure of the volume reflects the arguments put forward in this Introduction, and also the evolution of the SPs as a focus of EU external action. In Part I, the focus is on the evolution and analysis of the SP as a part of EU diplomatic practice. In Chapter 2, Laura Ferreira-Pereira and Michael Smith explore key trends in the development of the SPs, and propose a set of frameworks for considering the SPs as a reflection of different logics and images in EU external action, thus linking closely with the underlying questions about the functions of the SPs, their policy implications and their connections with the EU's international roles. In Chapter 3, Daniel Schade focuses on the institutional aspects of the development and implementation of SPs, and in particular on the ways in which institutional factors shape the focus and the exercise of authority within the SP process. In Chapter 4, Laura Ferreira-Pereira and João Mourato Pinto explore the role of soft power in the evolution of SPs, with particular reference to the Erasmus+ programme and to the pursuit of educational diplomacy.

Part II of the volume is dedicated to study of two traditional partners for the EU in the global arena: the United States and Canada. Chapter 5, by Michael Smith, assesses the extent to which the EU-US relationship, which is clearly strategic and a core element in the EU's diplomatic activities, can be seen as a 'strategic partnership', and the extent to which recent developments have moved the relationship towards divergence or even divorce. Chapter 6, by Amy Verdun, examines the EU-Canada partnership, and the ways in which it has become formalized not only in a SP agreement but also in a wide-ranging free trade agreement, placing an emphasis on the effects of the differing domestic structures in the EU and Canada and on the forces that promoted or delayed the move towards a formalized SP.

Part III of the volume explores the relationships between the EU and the BRICS countries. This grouping has been central to the development 
of the EU's network of SPs, embodying as it has the idea that such partnerships can help to promote 'effective multilateralism' as a building block for global cooperation. In Chapter 7, Laura Ferreira-Pereira assesses the turbulent course of EU-Brazil relations and the factors that have led to the stagnation of cooperation since 2014, among them domestic political developments and the evolution of the global power structure. Chapter 8 , by Hiski Haukkala, analyses the course of EU-Russia relations, and the extent to which the SP was thrown into crisis by the development of an assertive Russian foreign policy, evident especially in the Ukraine conflict. In Chapter 9, Emilian Kavalski explores the development of EU-India relations, and the ways in which the interaction of EU external action with Indian foreign policy has created real difficulties in the implementation of the SP provisions. Andrew Cottey in Chapter 10 explores the EU-China relationship and evaluates the ways in which the development of China's internal politics as well as its global status have interacted with the EU's efforts to develop the relationship both in economic and in cultural terms. In Chapter 11, Talitha Bertelsmann-Scott assesses the development of the EU-South Africa SP, drawing attention not only to the role of domestic political developments but also to the regional and global dimensions of South Africa's foreign policy and its intersection with the concerns of the EU.

Part IV deals with the development of SPs in two other cases: those of Mexico, and of Japan and South Korea. Roberto Dominguez in Chapter 12 charts the development of the EU-Mexico SP, with reference to the broader EU-Mexico relationship as formalized in the Global Agreement, and explores the interaction between these two areas. Elena Atanassova-Cornelis and Bruno Hellendorff in Chapter 13 analyse the close links between the EU-South Korea and the EU-Japan SPs, and the ways in which they bring together both economic and trade agreements and the more political aspects of SPs in novel forms of partnership.

The final chapter in the volume takes the form of an overall appraisal of the SPs as diplomatic and political-economic agreements. Thomas Renard looks back at the frameworks proposed in Chapter 2 and reviews the key questions posed by the volume in the light of the evidence from the succeeding chapters. This chapter brings together key themes and places them within a broader context, both conceptually and empirically, as a means of reflecting on the ideas and evidence advanced in the volume as a whole. In particular, Renard suggests that strategic partnerships in general reflect a particular conjuncture in the global arena in the early years of 
the new millennium, and that the EU's strategic partnerships in particular arose in a rather untidy way as a response to external opportunities and to the development of partnerships by key international interlocutors such as the United States, China and Russia. This being so, there are important questions to be asked about the continuing rationale for and implementation of such partnerships.

\section{REFERENCES}

Allen, D., \& Smith, M. (2012, February). The EU, Strategic Diplomacy and the BRIC Countries. Diplomatic System of European Union Network, Policy Paper 11. Available at: http://dseu.lboro.ac.uk/Documents/Policy_Papers/ DSEU_Policy_Paper1 1.pdf.

Bava, U. S. (2010). India and the European Union: From Engagement to Strategic Partnership. International Studies, 47(2-4), 373-386.

Bickerton, C. (2015). European Union Foreign Policy: From Effectiveness to Functionality. Basingstoke: Palgrave Macmillan.

Bouchard, C., Peterson, J., \& Tocci, N. (2014). Multilateralism in the 21st Century: Europe's Quest for Effectiveness. London: Routledge.

Chaban, N., \& Holland, M. (Eds.). (2019). Shaping the EU Global Strategy: Partners and Perceptions. Basingstoke: Palgrave Macmillan.

Chizhov, V. (2012). Russia-EU Strategic Partnership: Euro Crisis No Cause for Delay. International Affairs, 58(4), 24-35.

De Wilde, T., \& Pellon, G. (2006). The Implications of the European Neighbourhood Policy (ENP) on the EU-Russian Strategic Partnership. The Helsinki Monitor, 17(2), 119-132.

Dominguez, R. (2015). EU Foreign Policy Towards Latin America. Basingstoke: Palgrave Macmillan.

Duke, S. (2017). Europe as a Stronger Global Actor Challenges and Strategic Responses. Basingstoke: Palgrave Macmillan.

Emerson, M., \& Flores, R. (2013). Enhancing the Brazil-EU Strategic Partnership: From the Bilateral and Regional to the Global. Brussels: CEPS.

European Council. (2010). European Council of 16 September 2010 Conclusions. Brussels. Available at: https://www.consilium.europa.eu/uedocs/cms_data/ docs/pressdata/en/ec/116547.pdf.

European External Action Service. (2016). Shared Vision, Common Action: A Stronger Europe. A Global Strategy for the European Union. Available at: https://eeas.europa.eu/topics/eu-global-strategy_en.

Ferreira-Pereira, L. C. (2012). The European Union as a 'Model Power': Spreading Peace, Democracy and Human Rights in the Wider World. In F. 
Bindi (Ed.), The European Union Foreign Policy: Assessing Europe's Role in the World (pp. 293-305). Washington, DC: Brookings Institution Press.

Ferreira-Pereira, L. C. (2016). The European Union's Partnership Policy Towards Brazil: More Than Meets the Eye. Cambridge Review of International Affairs, 29(1), 55-77.

Ferreira-Pereira, L. C., \& Vieira, A. (2016). Introduction: The European Union's Strategic Partnerships: Conceptual Approaches, Debates and Experiences. Cambridge Review of International Affairs, 29(1), 3-17.

Gratius, S. (2018). Brazil and the EU: From Liberal Interregionalism to Realist Bilateralism. Revista Brasileira de Politica Internacional, 61(1). Retrieved from http://www.scielo.br/scielo.php?script=sci_arttext\&pid=S0034-732920 $18000100203 \& \operatorname{lng}=$ en\&nrm=iso.

Haukkala, H. (2010). The EU-Russia Strategic Partnership: The Limits of PostSovereignty in International Relations. London: Routledge.

Husar, J., \& Maihold, G. (2010). The EU and New Leading Powers: Analytical Approach and Policy Options. In J. Husar, et al. (Eds.), Europe and New Leading Partners: Towards Partnership in Strategic Policy Areas (pp. 11-20). Baden-Baden: Nomos.

Jørgensen, K. E., Aarstad, A. K., Drieskens, E., Laatikainen, K., \& Tonra, B. (Eds.). (2015). SAGE Handbook of European Foreign Policy (Vol. 1 and 2). London: Sage.

Kavalski, E. (2016). The EU-Indian Strategic Partnership: Neither Very Strategic, Nor Much of a Partnership, Special Issue 'The Strategic Partnerships of the European Union: Conceptual Insights, Cases and Lessons'. Cambridge Review of International Affairs, 29(1), 192-208.

Li, M. (2016). China-EU Relations: Rivalry Impedes Strategic Partnership. In J. Wang \& W. Song (Eds.), China, The European Union, and the International Politics of Global Governance (pp. 13-28). New York: Palgrave Macmillan.

Lucarelli, S., \& Fioramonti, L. (2010). External Perceptions of the European Union as a Global Actor. London: Routledge.

Maher, R. (2016). The Elusive EU-China Strategic Partnership. International Affairs, 92(4), 959-976.

Maihold, G. (2010). Leadership Coalitions as a New Element for the EU's External Action. In J. Husar, et al. (Eds.), Europe and New Leading Partners: Towards Partnership in Strategic Policy Areas (pp. 149-156). Baden-Baden: Nomos.

Mangala, J. (2013). Africa and the European Union: A Strategic Partnership. Basingstoke: Palgrave Macmillan.

Martin, M., \& Kaldor, M. (Eds.). (2009). The European Union and Human Security: External Interventions and Missions. London: Routledge.

Michalski, A., \& Pan, Z. (2017). Unlikely Partners? China, the European Union and the Forging of a Strategic Partnership. Singapore: Palgrave Macmillan. 
Novotny, D., \& Portela, C. (2012). EU-ASEAN Relations in the 21st Century: Strategic Partnership in the Making. Basingstoke: Palgrave Macmillan.

Pan, Z. (Ed.). (2012). Conceptual Gaps in China-EU Relations: Global Governance, Human Rights and Strategic Partnerships. Basingstoke: Palgrave Macmillan.

Renard, T. (2011). The Treachery of Strategies: A Call for True EU Strategic Partnerships (Egmont Paper 45). Brussels: Egmont Institute. Available at: http:// www.egmontinstitute.be/content/uploads/2013/09/ep45.pdf?type=pdf.

Renard, T. (2018). EU Cyber Partnerships: Assessing the EU Strateic Partnerships with Third Countries in the Cyber Domain. European Politics and Society. https://doi.org/10.1080/23745118.2018.1430720.

Renard, T., \& Biscop, S. (2012). The European Union and Emerging Powers in the 21st Century. Aldershot: Ashgate.

Renard, T., \& Hooimaaijers, B. (2011). Assessing EU Strategic Partnerships in the UN System. Egmont Security Policy Brief. Available at: http://www.egm ontinstitute.be/papers/11/sec-gov/SPB24-RenardHooimaaijers.pdf.

Sachdeva, G. (2009). India and the European Union: Time to De-Bureaucratize Strategic Partnership. Strategic Analysis, 33(2), 202-207.

Santander, S. (2016). Brazil-EU Relations: Strategic Partner or Competitors? In M. Smith, S. Keukeleire, S. Vanhoonacker (Eds.), The Diplomatic System of the European Union: Evolution, Change and Challenges (pp. 181-196). London: Routledge.

Saraiva, M. (2017). The Brazil-European Union Strategic Partnership, from Lula to Dilma Rousseff: A Shift of Focus. Revista Brasileira de Politica Internacional, 60(1). Available at: http://www.scielo.br/scielo.php?pid=S0034-732 92017000100208\&script=sci_arttext.

Sautenet, A. (2012). The EU's Strategic Partnerships with Emerging Powers: Institutional, Legal, Economic and Political Perspectives. In T. Renard \& S. Biscop (Eds.), The European Union and Emerging Powers in the 21st Century: How Europe Can Shape a New Global Order (pp. 123-146). Aldershot: Ashgate.

Smith, M. (2016). EU Diplomacy and the EU-China Strategic Relationship: Framing, Negotiation and Management. Special Issue 'The Strategic Partnerships of the European Union: Conceptual Insights, Cases and Lessons'. Cambridge Review of International Affairs, 29(1), 78-98.

Smith, M., Keukeleire, S., \& Vanhoonacker, S. (Eds.). (2016). The Diplomatic System of the European Union: Evolution, Change and Challenges. London: Routledge.

Song, W., \& Wang, J. (2019). The European Union in the Asia Pacific: Rethinking Europe's Strategies and Policies. Manchester: Manchester University Press. 
Strategic Partnerships in the European Union's Diplomatic Practice: Evolution and Analysis 


\title{
Strategic Partnerships in European Union External Action: Evolution and Analysis of a Developing Policy Instrument
}

\author{
Laura C. Ferreira-Pereira and Michael Smith
}

\section{INTRODUCTION $^{1}$}

This chapter explores the context, the development and the impact of the European Union's strategic partnerships as part of the Union's external action, and thus provides a broad foundation for the analysis of specific

${ }^{1}$ The first author acknowledges that this study was conducted at the Research Center in Political Science (UIDB/CPO/00758/2020), University of Minho/University of Évora, and was supported by the Portuguese Foundation for Science and Technology and the Portuguese Ministry of Education and Science through national funds.

L. C. Ferreira-Pereira $(\bowtie)$

Department of Political Science and Research Center in Political Science

(CICP-UMinho), University of Minho, Braga, Portugal

e-mail: lpereira@eeg.uminho.pt

M. Smith

PAIS, University of Warwick, Coventry, UK

e-mail: M.H.Smith@warwick.ac.uk

(C) The Author(s), under exclusive license to Springer Nature

Switzerland AG 2021

L. Ferreira-Pereira et al. (eds.), The European Union's Strategic

Partnerships, The European Union in International Affairs, https://doi.org/10.1007/978-3-030-66061-1_2 
partnerships in later chapters of the volume. It locates the initiation of strategic partnerships in the early 2000s with reference to the development of the EU's Common Foreign and Security Policy (CFSP), especially its security strategies and its strategic diplomacy, and charts the key stages in the development of strategic partnerships as practices and institutional forms, through the European Security Strategy (ESS) of 2003, the 2008 review of the security strategy, the Lisbon Treaty, and the framing and implementation of the EU's Global Strategy. It also assesses the ways in which the search for and evolution of strategic partnerships has come into contact with other areas of Union external action. In this context, the chapter explores the potential for a comprehensive approach and joined-up policy-making in relation to strategic partnerships and assesses the potential and actual tensions between different areas of partnership diplomacy. It also focuses on the ways in which a multilevel set of crises and challenges has surrounded the EU's partnership diplomacy for the past fifteen years and suggests ways in which these challenges might have affected the substance of policy.

Following from this empirical exploration, the chapter argues that the phenomenon of strategic partnerships can broadly be analysed and evaluated in terms of three logics of EU external action-the internal logic, the external logic and the identity logic-and three images of the way in which partnerships are initiated: strategic, managerial and reactive. The chapter concludes by relating these analytical devices to questions about the functions and motivations, policy implications, institutionalisation and role implications of strategic partnerships in EU external action, and by briefly discussing the ways in which they might be conceptualised by different approaches in International Relations and European Union studies.

\section{The European Union's Strategic Partnerships: From the European Strategic Security Strategy to the Global Strategy and Beyond}

In the wake of the events of 11 September 2001, the EU came under pressure to take an unprecedented collective stance regarding complex security challenges that called for the promotion of 'effective multilateralism'. The latter required the establishment of new partnerships, in addition to the consolidation of more long-standing ones. The creation 
of a network of SPs would further help European foreign policy to adapt itself to and reflect in its profile the evolving redistribution of power in the international system fostered by the increasing weight of emerging economic powers, such as the BRICs (Brazil, Russia, India and China).

In 2003, a decade after NATO launched its Partnership for Peace (PfP) - a sort of strategic umbrella to attract states originating from the former Soviet Union to its own institutional and functional orbit ${ }^{2}-$ the first EU strategic document, the European Security Strategy (ESS), underlined the importance of developing SPs. In its section "Working with Partners', the document mentioned EU's "balanced partnership" with the United States and listed Canada, China, India, Japan and Russia as the countries with which "special partnerships" should be developed. However, this list was not exclusive in nature since the ESS noted that all those who shared the EU's values and goals and were "prepared to act in their support" could be engaged in the same kind of partnerships (European Council 2003: 13-14).

While it was not explicit about the criteria for considering a third state as a strategic partner, the ESS's content, nonetheless, suggested that the existence of shared goals and values would have a bearing on the decision to establish a SP with a given individual country. This is so to the extent that in order to be elevated to the status of strategic partner, the country in question must endorse the EU's "goals and values" and should be ready to support them. Besides shared principles or values, it is clear that the choice of SPs should also based on convergence of interests or shared objectives. Indeed, as Van Rompuy has observed, "strategic partnerships have to be based on a balance of mutual advantages and commitments" (Van Rompuy 2010: 3; see also Ferreira-Pereira 2012).

In the light of the ESS, therefore, the creation of the SPs constitutes the recognition by the EU that in order to assert itself as a global actor in a multipolar world, it had to cultivate multilateralism grounded on a dynamic network involving both "international organizations and key international actors" (European Council 2003: 13). Dialogue with these constituents of a rapidly changing international power structure was considered essential to address critical global issues. The security dimension was also implicit in the establishment of SPs since this was linked with the Union's quest for a more 'Secure Europe in a Better World' (the

\footnotetext{
${ }^{2}$ The formal establishment of PfP in 1994 was decisive for the reinvention of NATO's identity and role in the post-1989 strategic context and European security architecture.
} 
official title of the ESS). Following this line of reasoning, the EU's partnership thinking can be seen as an additional European doctrinal response to unprecedentedly intricate and unpredictable world politics and security.

In a pro-active endeavour to engage further countries, the EU signed SPs with South Africa, Brazil and Mexico in 2006, 2007 and 2008, respectively. The formal existence of these partnerships was recognised in 2008, in the Report on the Implementation of the European Security Strategy. In 2010, South Korea was added to this exclusive list that eventually encompassed ten strategic partners, and whose importance was stressed in the Conclusions of the European Council of September 2010. This document is of particular significance in the evolving trajectory of the EU's SPs. In the sequence of the worldwide economic and financial crisis which reverberated severely within the Eurozone and in the face of the "emergence of new players with their own world views and interests", it dedicated its first section to "Relations with Strategic Partners'. Such relations are presented as part of a European collective endeavour directed at giving "new momentum to the Union's external relations", and enhancing "the effectiveness of the Union's external policy" (European Council 2010: 1).

It is worth highlighting the contributions made by the EU Council Presidencies of Germany, Portugal, and France to the expansion of the SPs portfolio to embrace Brazil, Mexico and South Africa. Among the initiatives launched by the German Presidency, between January and June 2007, and particularly supported by the Chancellor Angela Merkel, was the Heiligendamm Process, which has institutionalised the highlevel dialogue between G8 and five emerging economies, notably China, Mexico, India, Brazil and South Africa (Fues and Leininger 2010). Such institutionalisation intended to "intensify the political dialogue and foster cooperation with these countries, especially in the fields of innovation and intellectual property, investment conditions including responsible business conduct, energy efficiency and development cooperation" (European Council Conclusions 2007: 17). It was under the Portuguese Presidency during the second semester of the same year that the first ever EU-Brazil Summit took place and a SP with this then rising actor was signed (Ferreira-Pereira 2008, 2016). During the French Presidency, the organisation of high-level meetings with Brazil, India and South Africa contributed to reinforce the French President, Nicolas Sarkozy's vocal endorsement of the expansion of G8 to include these countries alongside China and Mexico (Pilling 2008). 
Viewed from a historical perspective, the emergence of SPs does not date back just to 2003. Its deepest roots can be found in a more longstanding tradition of the EU's rapport with third states and regions in the past, which has been based on a multifaceted tool known as political dialogue. This is recognised as a "quite specific" form of relationship which goes beyond occasional meetings, but cannot be equated to a commitment typical of an alliance (Monar 1997: 264). According to Monar, after several wide and vague references to political dialogues with third parties in the early 1990s, the EU set out three conditions that had to be met so as to enable the establishment of a political dialogue with a given country as a basis for a new relationship. First of all, there must be a formal decision made by the Political Committee and/or the Council to engage in a dialogue. Secondly, there must be a formal agreement with the third state concerned, which could take the form of an informal arrangement between the Presidency and the third state, a common understanding through an exchange of letters, a joint declaration or a formal treaty. Finally, the agreement had to provide for regular political contact at one or several levels, in addition to the normal diplomatic relations (ibid: 263). Over the years, the pattern of political dialogues became more diversified and began to incorporate new instruments, thereby helping the EU to acquire an enhanced political profile.

In 1997, the Amsterdam Treaty represented a turning point in bringing about a new formal instrument to the EU foreign policy portfolio, notably the 'Common Strategies'. The latter were inaugurated in 1999 with documents on Russia and Ukraine (see below) and reinforced in 2000 with a Common Strategy on the Mediterranean region. Interestingly, the post-Cold War relations between the EU and the post-imperial Russia structured round a 'Common Strategy' emerged as a test-bed for the eventual development of the EU's strategic partnership diplomacy. After Russia was for the first time labelled a "strategic partner" in the Presidency Conclusions of the Vienna European Council held in December 1998 (Blanco 2016), the Common Strategy of the European Union on Russia introduced the term 'strategic partnership' into the EU's lexicon when saying that: "The European Council therefore adopts this common strategy to strengthen the strategic partnership between the Union and Russia" (European Council, June 1999). Some observers raised questions based on the Common Strategies' negative interference with well-established policies existing on these countries and regions 
(Spencer 2001); and on the ways in which they might constrain the action of individual EU Presidencies given their exposure to public scrutiny (Eeckhout 2011: 477). Moreover, they became an object of criticism for having achieved little, as for example the Common Strategy on Russia that failed to provide the EU with any leverage on Chechnya (Dover 2007: 250). Not surprisingly, therefore, subsequent Common Strategies, such as the one planned for the Balkans, were simply not brought forward. It can thus be argued that the key characteristics of the Common Strategies, whose implementation by Joint Actions and Common Positions required qualified majority voting, contributed to the eventual disappearance of this instrument (de Baere 2008, 115).

Considering that from 2001 until 2003 Common Strategies faded away, it seems that the disappearance of this CFSP legal instrument for autonomous action created a void that the ESS started to fill by underlining the importance of developing "strategic partnerships" with major interlocutors, such as Canada, China, India, Japan and Russia (Council of the European Union 2003: 14). In addition, the EU initiated other kinds of 'Strategies' such as 'The EU and Africa: Towards a Strategic Partnership' (European Council 2005) and developed new strategic initiatives such as the European Neighbourhood Policy (ENP).

Unlike the 'Common Strategies', the strategic partnerships as a policy instrument have never entered into the treaty-basis of the EU. Yet, the Lisbon Treaty introduced a new framework for EU external action, while creating specific conditions to enhance the framing of SPs. In light of the post-Lisbon EU institutional set up, the European Council has the power to set overall objectives and determine the strategic interests of the Union as a whole, i.e., not only in CFSP matters, but in other aspects of EU foreign policy (Art. 22, l TEU). It is also entitled to "take the decisions which may concern the relations with a specific country or region or be thematic in approach" (Art 22, l TEU). The establishment of a SP would, thus, result from a decision, unanimously adopted upon a recommendation from the European Council. The High Representative/Vice-President (HRVP), the Commission, or both, have the prerogative of submitting proposals to the Council (Art. 22, 2 TEU).

After the entry into force of the Lisbon Treaty, the EU's strategic priorities were placed at the core of a rethink of the EU external relations agenda. The President of the European Council, Herman van Rompuy, started the debate around this developing foreign policy instrument driven by the realisation that the economic strength of developing 
countries was transforming itself into "real political power." Such realisation resulted from the lessons learned during the 2009 Copenhagen climate change conference, during which "there was the perception that the EU was sidelined" (Van Rompuy quoted by Rettman 2010). The work of van Rompuy and the High Representative for Foreign Affairs and Security Policy/Vice-President of the Commission (HRVP), Catherine Ashton, contributed tangibly to the initial consolidation of the ten official SPs as part of their endeavours to make the EU more effective in world affairs. The same can be said regarding the President of the Commission, José Durão Barroso, for whom the SPs helped the EU to punch above its weight within G20 by galvanising relations with key economic and trade players. As he observed in the State of the Union Speech in September 2010: "As the strategic partnerships of the 21st century emerge, Europe should seize the chance to define its future...In our globalized world, the relationships we build with strategic partners determine our prosperity" (Barroso 2010). Yet, overall criticism as to the ill-defined nature and usage of the term 'strategic partnership', and widespread doubts about the strategic partners' perception of the EU as a genuine strategic partner persisted (Rettman 2010; Renard 2011). On the other hand, as Grevi stressed, the lack of definition is a condition for the establishment of a given SP due to the need for flexibility and adaptability (Grevi 2013).

The post-2003 identification of 'strategic partners' generated particular expectations regarding the promotion of symmetric relationships, within which the partners would stand on an equal footing and be granted equal political value. Incidentally, the preamble of the 2010 European Council Conclusions conveyed clearly this idea of 'reciprocity', when stressing "the need for Europe to promote its interests and values more assertively and act in a spirit of reciprocity and mutual benefit" (European Council 2010). However, by developing and intensifying the use of SPs as the highest level platforms of bilateral convergence to deal with major powers in world politics, the EU created new space for further differentiation, thereby drawing a dividing line between those that are positioned inside and outside this exclusive circle.

Despite variations among SPs, they exhibit common aspects, namely concerns with security issues and attempts towards the coordination/harmonisation of political stances in the framework of international fora. To be sure, most of the current SPs incorporate a security agenda, with security being understood in all-encompassing terms so as to comprise matters related to energy, environment and economy. Not 
surprisingly, such a security agenda is adjusted to the specificities of a given strategic partner with some aspects receiving more attention than others. The particular emphasis placed upon environmental security in the EU's relations with both Brazil and the US, and the weight ascribed to the issue of energy security with Russia are paradigmatic examples of this. The introduction of security issues onto the European agendas governing SPs has represented significant progress and therefore it stands as an analytically relevant trait in the present volume.

In fact, while traditional relations with third states have been mainly structured around economic, commercial and technical cooperation issues, the SPs have been founded on a noticeable convergence of positions regarding complex common threats arising from the increasingly complicated post-9/11 security context and the realities of the post-2008 economic crisis. The existence of shared security and strategic concerns between the EU and its partners has, in many instances, reinforced the political dialogue. Yet, such reinforcement did not prevent the suspension of political dialogues as part of the mechanisms of diplomatic crisis management. The temporary suspension of the political dialogue strictu sensu with China in 2011, and with Russia in 2008 and since 2014 are cases in point.

Underlying the architecture of the EU's SPs, there is a commitment to political dialogue, which tends to add an institutional structure to the relationship with partners by defining the areas for cooperation and communication. However, the level of institutionalisation of this specific component varies from case to case. The duration and scope of the political dialogues also vary according to such factors as the historical foundations of the relationship, strategic importance of the partner in its regional context, geopolitical considerations, and economic and trade interests, among others. At the same time, there has been an attempt on the part of the EU to recognise the idiosyncratic features characterising each partner, by offering it a customised political dialogue deemed to mirror its particular requirements and status. In the case of South Africa, for example, the fact that it is the only country with which the EU has sealed a SP in the whole African continent makes it particularly important at both continental and the regional level, and also has implications for the country presenting itself as positive point of reference or role model for other African states.

The EU has developed a form of 'strategic partnership labelling', by means of which specific countries have been recurrently recognised and 
labelled as the organisation's strategic partners. The continued adherence to such rhetorical recognition has contributed to a degree of stability and sustainability in the existing strategic relationships, through which the EU has been able to advance a common political, economic and security agenda when dealing with key players in critical regions of the world. Moreover, the continuous use of the SP 'label' has helped to sustain a commitment of the relevant parties to the pursuit of common goals like those stipulated in the ESS and the Report on the Implementation of the European Security Strategy (European Council 2008), namely the promotion of a well-governed neighbourhood and effective multilateralism. The strategic partnership 'labelling' has also helped to mitigate concerns of both the EU and its partners with the changing balance of power in a world order in transformation. In so doing, the EU aims to enhance the predictably and stability prevailing in its relations with third states-something that is not without resonance for the improvement of the Union's political and security milieu and, ultimately, the international environment.

That being said, the fact that some countries have been acknowledged as 'strategic partners' does not imply any guarantee that this privileged status will endure in the future. The cases of Ukraine and Russia stand out as illustrative examples of this. In 1999, a "strategic partnership between the European Union (EU) and Ukraine based on shared values and common interests" (European Council, December 1999, 7) was formally initiated in the framework of the Common Strategy on Ukraine. But in subsequent years the acknowledgement of the country's condition as a strategic partner ceased to be consistently stated; and to date Ukraine has never entered the list of strategic partners (Ferreira-Pereira and Vieira 2015). On the other hand, the EU dropped the 'strategic partner' label after Russia annexed Crimea in 2014; and in the Global Strategy of 2016, relations with Russia were described as representing a "key strategic challenge" (EEAS 2016: 33). More recently, on 12 March 2019, the European Parliament overwhelmingly approved a resolution stating that Russia "can no longer be considered a 'strategic partner". 3 Equally, China in 2019 was acknowledged as a strategic partner, but also as a commercial and political rival challenging the EU in key areas of interest (European Commission 2019).

\footnotetext{
${ }^{3}$ The resolution has passed with 402 votes in favour, 163 against and 89 abstentions.
} 
Incidentally, reflecting the impact of the unfolding of the post-2014 events in Ukraine as well as of the seminal moment in European integration inaugurated by the British referendum held on 23 June 2016, the EU's Global Strategy further pushed the strategic partnership policy to the top of the CFSP agenda. Against the backdrop of a Union that is "under threat" and of a European project that "is questioned", "partnering" with and within a web of major players seemed to be one of the principal themes of the new framework document (EEAS 2016: 7, 43). In line with this, the Global Strategy recognised that the role of the EU as a "responsible global stakeholder" requires "revamping [our] external partnerships" (ibid: 8). Furthermore, it emphasised that: "Sustainable peace can only be achieved through comprehensive agreements rooted in broad, deep and durable regional and international partnerships" (EEAS 2016: 29). Finally, while presenting the SPs as a key contribution to the Global Strategy's priority of "effective global governance", the document stressed that: "On the vast majority of global governance issues, we will work with the UN....with other core partners such as the US, with regional organisations, and with like-minded and strategic partners in Asia, Africa and the Americas" (ibid: 43, Italics added). Indeed, the achievement of such effective global governance, which is later referred in the 1st Year Report of the Global Strategy as "reformed global governance" (EEAS 2017: 6), makes work with partners in general, and strategic partners in particular, indispensable.

Against the backdrop of the implementation of the Global Strategy, the then HRVP, Federiga Mogherini, further underlined the critical significance of the SPs to the core of the European approach to multilateralism by stating in 2018 that: "This year, the priority of our work will be to strengthen a global network of partnerships for multilateralism. This requires a new mind-set, maybe less focused than before on the traditional bilateral diplomacy. As such, the vision was to foster an "an alliance for multilateralism", founded on a "network of truly like-minded partners" (Mogherini 2018).

\section{Strategic Partnerships in Time of Crisis}

Although various periods of crisis can be found in the annals of the European integration process, since 2008-the year which marked the beginning of the economic recession originating from the United Statescrises have become the order of the day for an increasingly vulnerable EU. 
Such crises have unfolded in various domains, besides the economic one, thereby creating a general picture of what might be termed multilevel crisis. As its first major manifestation, the crisis caused a general recession in the Eurozone, with some more peripheral and fragile economies being subject to (total or partial) international bailouts, such as those that occurred in Ireland, Greece, Portugal, Cyprus and Spain. The recession, which gave rise to severe austerity politics, put into question the traditional image of the EU as 'the club of prosperous democracies', while challenging the well-respected European economic and social model. In contrast, the continuing economic growth of the countries belonging to the BRIC grouping, such as Brazil and China, only intensified the perceived decline of the European project while paving the way for these countries to contest the existing international order and offer alternative solutions (Saraiva 2018: 8).

Equally important, in view of the geographical location of the eye of the economic storm, internal breaches between the North of Europe that continued to exhibit economic growth, employment and competitiveness, and the South of Europe afflicted by sovereign debt challenges, unemployment and social unrest became very visible. Such breaches exposed a deep crisis in European economic and social solidarity that became more pronounced upon the impact of the refugee crisis that overflowed into Europe from war and misery in Syria, Afghanistan, Pakistan, Iraq and Eritrea, as well as other countries in sub-Saharan Africa. In the Summer of 2015, the refugee crisis transformed into the deepest humanitarian crisis since the World War II and further revealed the normative 'capability-expectations' gap between the EU's rhetorical defence of principles such as 'human security', 'responsibility to protect' and 'responsible sovereignty' on the one hand; and its inability to translate them into practice, as a collective actor, in the management of uncontrolled migration waves, on the other. Diverging views among member states about the implementation of a quota policy to ensure a proportional distribution of migrants/refugees, which was eventually rejected by some countries, aggravated intra-EU divisions, especially between the West and East. At the same time in domestic arenas anti-immigration discourses cultivated particularly by populist leaders and radical parties begun to attract more support.

While putting into question the EU's ability to meet the expectations of its citizens when it comes to the creation of jobs and affluence, the economic crisis has weakened their identification with the ontology 
and teleology of the European integration process inextricably linked to the diffusion of hope, prosperity and security. Disenchantment and even indignation on the part of a growing number of voters resulted in stronger support for anti-EU forces on the far-right and left of the political party spectrum in various European states. Hence, the rising Euroscepticism that became more evident in the June 2014 European Parliament elections and was corroborated, more recently, in the European elections of June 2019. Moreover, the series of terrorist attacks that took place across Europe (e.g. Brussels, Nice, Barcelona, Manchester, among others) since those in Paris, in November 2015, have aggravated the overall sense of insecurity and thus the citizens' discontent with the EU's boasted efforts to foster a 'secure Europe in a better world'. Illustrative of this, the feeling that the EU is a secure place to live has continually decreased since 2011 (European Commission 2017).

On the external front, the experience of economic crisis moved the EU to further reach out towards forging and implementing new strategic partnerships with pivotal states such as Mexico, Japan and South Korea. More importantly, however, the annexation of Crimea by Russia in March 2014 which embodied Russia's aggressive assertiveness was a watershed event in many respects. It led to the deterioration of the European security environment with various international ramifications. Apart from an entrenched and protracted political and military conflict between Ukraine and Russia, this critical episode provoked a split not only in the EU-Russia SP (see Haukkala, this volume), but also in the relationship between United States/NATO and Russia. Eventually, as noted above and recognised by the Global Strategy, Russia came to be approached as "a key strategic challenge" (EEAS 2016: 33) and ceased to be perceived as a strategic partner. In the aftermath of the Russian annexation of Crimea and the subsequent conflict in Ukraine, the EU's increasing focus on its Eastern neighbourhood has taken its toll upon (extra-) European engagements in other more distant regions, and this tendency was reinforced by the priorities of the new Commission installed in 2019.

Furthermore, unforeseen challenges posed to the EU and to transatlantic security by the Trump Administration, reflecting its disaffection regarding the European integration process and doubts raised about the United States' continued commitment to transatlantic solidarity and security in Europe have disrupted the EU-United States strategic relationship (see Smith, this volume). Against this backdrop, the deepening of the 
Common Security and Defence Policy (CSDP) through the implementation of Lisbon Treaty provisions such as Permanent Structured Cooperation (PESCO) can be seen as part of a self-resilience-building strategy to rescue the vitality of the integration process and build up 'strategic autonomy' vis-à-vis the United States and NATO. As a result, during 2017-and in the following years - the mainstreaming of security and defence policy became particularly pronounced, with repeated calls for the creation of a European Security and Defence Union (Ferreira-Pereira 2020).

The prospect of the UK's withdrawal from the EU, opened up by the victory of the 'Leave' vote in the British referendum, magnified the uncertainty and instability within the EU. Ultimately, it has created doubts about the EU's sustainability due to fears about fragmentation and disintegration resulting from other states leaving the EU. As a sort of corollary of the post-2014 crisis path, Brexit constituted a politically tortuous process that diverted the EU's attention and energies from other external action fronts, notably its bilateral cooperation with strategic partners. The first phase lasted three and a half years (June 2016-January 2020) and comprised manifold political and institutional twists and turns, both in London and Brussels, that only started to be settled, in a more predictable way, after the UK general elections of December 2019. Boris Johnson was re-elected with a large majority and the date of the country's departure from the EU was fixed at 31st January 2020-but this was only the prelude to a complex and highly politicised process of negotiation and transition.

The implications of this multiple set of challenges are still working themselves out in the context of the EU's strategic partnerships. The internal challenge of economic and political capacity, the external challenge of assertive and often unpredictable 'powers', and the accompanying challenges to the legitimacy and credibility of EU external action are bound to resonate in its pursuit of partnerships with key external and global actors. At the same time, however, a number of strategic partnerships have been consolidated, extended or reinvented in the period since the Global Strategy was framed, providing some basis for claims of renewed vigour in the EU's approach to its key interlocutors. Reflecting these developments, there appears to be strong evidence of the ways in which internal and external factors have interacted to mould the EU's approach to strategic partnerships in the light of multiple challenges and 
crises, and to shape the EU's position as a global interlocutor. As a consequence, the practices of strategic partnerships have been characterised by a number of co-existing patterns, and these have exerted a formative influence on the effectiveness and impact of the EU's partnership diplomacy. The next part of this chapter puts forward a framework for a more systematic analysis of these processes and for potential evaluation of the EU's responses to the challenges facing it.

\section{Analysing Strategic PARTNERSHIPS: LOGICS AND IMAgES}

Why have strategic partnerships emerged as a key expression of EU external action, and how do they relate to key elements of the EU's broader international strategies? We have already seen that the Global Strategy of 2016 places SPs into a broader framework of international cooperation, that it relates them to the challenges faced by the EU itself in the global arena, and that the effectiveness of EU actions has been challenged in a number of dimensions. But it is important to go further and to provide a way of locating SPs into a broader concept of EU external action, as well as to link them to issues such as those raised by the evolution of EU diplomacy over the past fifteen years and more.

In this section, the focus is first on the logics of strategic partnerships: a set of forces and factors that operate to make SPs a salient and integrative means of organising EU external action, and that generate a number of questions that can order more detailed analysis. The second focus of the section is on the images of strategic partnerships: the ways in which they can be seen as expressing competing or complementary sets of assumptions, priorities and practices. An appreciation of the ways in which logics and images act to shape the EU's approach to strategic partnerships and their associated diplomatic actions can provide the framework within which the evolution and impact of specific partnerships can be evaluated, and the conclusions to the volume will take up this approach as one means of assessing the SPs in a general sense.

\section{Logics}

Three underlying logics can be discerned in EU external action more generally (Smith 2009, 2012). The first is the internal logic: that external action reflects the development of the balance of forces within the EU, 
between Brussels institutions and member states and even within member states themselves. Thus, the changing membership of the Union, the development of domestic politics within old and new member states, and the processes sometimes described as the 'Brusselisation' of EU external action are relevant to this area of analysis. The second logic is the external logic: in other words, the ways in which the changing structures and processes of the global arena impinge upon EU external action, providing opportunities for and challenges to the extension of the Union's international activity. A relevant concept here is that of international opportunity structures-the ways in which the changing shape of global political and economic activity provide openings for and constraints upon the EU's ability to engage effectively with other actors at regional or global levels. The literature of opportunity structures distinguishes between those that are open with respect to a given actor and those that are closed-and of course allows for processes of opening and closing that can radically affect the available spaces for action (Tarrow 1996, 1998; Tilly and Tarrow 2006). The third logic is that of identity: the search for a settled identity reflecting the norms, values, interests and capacities of the Union in a changing world. In this case, external action is a reflection of the ways in which debates about the EU's collective presence and engagement in the global arena are framed by social and political norms, and by the socialization and learning processes that accompany them. It is clear that these three logics are linked, that they intersect and can fluctuate in a complex balance of forces that will condition key aspects of EU external actionand we would expect SPs to be no exception to this. It is also clear that the signs attached to each of the three logics can be positive, neutral or negative, and that the overall balance between them is likely to shape the EU's ability to undertake new initiatives and bring them to fruition in a changing global arena.

What do these three logics imply for the origins, development and impact of SPs? In the first case, we would expect the emergence of SPs as a high-level policy device to reflect internal forces within the Union. It is clear from the 'historical' discussion above that during the late 1990s and early 2000s, there was a set of internal pressures leading towards the development of a more structured EU approach to key international partners. One set of pressures came from the institutional context, with the development of the structures first established in the Maastricht Treaty and then fleshed out further through the Amsterdam and Nice Treatiesthese structures including the CFSP and eventually the CSDP. But the key 
developments were not only to be found in the foreign policy and security domains: the further development of EU external commercial policy, and the introduction of the Euro, created greater internal capacity to undertake broad partnerships in the global arena, which were complemented by external policy developments (see below). At the same time, the extension of EU activity in domains such as global environmental policy and the promotion of international human rights provided further foundations for a more comprehensive engagement with major partners. During the late 1990s and early 2000s, the Union provided itself with at least the outlines of a framework for the introduction and management of strategic partnerships, building on the existing infrastructure of dialogues and policy engagements with key international interlocutors. The 2004 and 2007 enlargements of the Union arguably also strengthened the impetus behind the search for new external action initiatives, by bringing into the Union a number of member states that supported the extension of the EU's international activities and the political and economic 'economies of scale' that this would provide. Finally, the internal crises over the development of the Constitutional Treaty and subsequently the Lisbon Treaty between 2005 and 2009 saw external action in general, and strategic partnerships in particular, gain salience as an 'antidote' to the internal woes of the Union. Although the line of causation is not always clear, it is the case not only in the early 2000s but also in the 2020s that external action can be seen as a way of (re)asserting the vigour of the European project.

Such developments in the internal logic were accompanied by key forces in the external logic. Much attention has been given to the nature of structural shifts in the global arena during the past two decades, and it is clear that these have provided a potent mix of opportunities and challenges for the EU. In the first place, the post-Cold War period from the 1990 s to the early 2000 s provided opportunities for the Union to assert itself at the international level, especially in its guise as a 'normative power' (see also below) and an international conflict manager. Not only this, but the development of the global political economy and its reflection in trade negotiations such as the Uruguay Round and later the Doha Development Round in the context of the World Trade Organization (WTO) provided the basis for strong EU engagement with key partners in the multilateral context-just as the internal development of the Euro and economic and monetary union also provided the basis for a new European engagement with international monetary policy. In many ways, the period from 1995-2003 provided a virtuous circle of opportunities for 
EU extension of its external action, but there were also severe constraints, especially those composed by the lack of 'hard security' capabilities and the lack of full international economic autonomy.

These constraints came home to roost in the mid-2000s, with the shocks provided by the Iraq War and the international financial crisis. Tellingly, these shocks were also reflected in EU internal tensions, both as regarded the CFSP and CSDP, and as related to the development of the Euro and cross-national financial management. At the same time, and as noted in earlier parts of this chapter, the changing power-structure of the global arena, especially symbolised by the emergence of 'rising powers' such as the BRICS, created new challenges and opportunities for the Union (Smith 2013, 2016a). Given the existing infrastructure of political dialogues, high-level summits and common strategies, it is no coincidence that one response to this was the development of the SP idea. First initiated in relations with Russia, elaborated in relations with China and then extended into wider areas, the SP framework thus expressed not only internal pressures but also external opportunities. The opportunities of the 2000s, though, have not always persisted: indeed, the development in the 2010s of new pressures towards unilateralism in terms of trade policy and foreign/security policy, underlined by internal financial and economic crisis and interacting with global power shifts, arguably made SPs both more important and more difficult to achieve. The external logic of the past decade and now the 2020s is in many ways more challenging and more constraining than that of the 2000s, and a key issue is thus whether the momentum of the 2000 s has been maintained and developed since 2010 .

Alongside the internal and the external logics, it is important to consider the identity logic as it relates to strategic partnerships. As noted above, there have been major internal incentives and constraints attending the development of SPs, and these have coincided with key shifts in the external opportunity structure. One constant element, though, has been the linkage between SPs and the desire to promote the EU's international identity-not just as an antidote to internal crisis, but also as a means of furthering the EU's interests and values at the global and regional level. A key aspect of this desire is a form of European exceptionalismreflecting the idea that the Union is a distinctive form of international actor, with distinctive priorities and means of action. One dimension of this exceptionalism has been the fact that the Union has been-and largely remains - a civilian power, without the means of coercion through 
military means. Although recent developments (e.g. PESCO and other innovations) have promised to add to the EU's military capacity, they have not yet come fully to fruition, and may not for a decade. Allied to this quality of EU external action is the idea that the EU is a 'force for good' in the global arena, acting in line with global norms and through the multilateral framework constituted by the UN and its specialised agencies as well as a number of major sectoral bodies. In this context, the notion of strategic partnerships assumes an additional dimension: they are not only a response to internal pressures or to external opportunities, but also an expression of a distinctive European approach to international cooperation and global governance, through which the EU's international identity could be pursued. Thus, the attempts in strategic partnerships to promote multilateralism through trade, financial relations and approaches to such issues as UN peacekeeping have gone alongside attempts to promote democracy, human rights and the roles of partners as 'responsible stakeholders' in the global arena.

As noted earlier in the chapter, however, these elements of the strategic partnership phenomenon have often (and some would say, increasingly) come up against the harsh realities of geopolitics and realpolitik both at the regional and at the global level. One key issue in this area is thus the extent to which and the ways in which SPs reflect the EU's normative power, and the extent to which this can be translated into effective policy impact. From the Global Strategy and other key statements of EU external action, it is clear that the assumption of a distinctive European international presence remains at the core of the Union's aspirations for external action - but it is not always clear how this matches up either with the demands of the external environment or indeed the positions of key EU member states.

\section{Images}

Over the past thirty years, the EU has developed a wide-ranging partnership diplomacy, of which the formalised strategic partnerships are only one dimension. This part of the chapter aims to build on the 'historical' treatment of the SPs conducted thus far, and on the analysis of the underlying logics shaping SPs, and to propose some ways in which the SPs might be evaluated as part of the EU's partnership diplomacy. It focuses in particular on three images of partnership diplomacy in general, and of 
strategic partnership diplomacy in particular, with the aim of clarifying their place in EU external action. ${ }^{4}$

A first image focuses on the building of partnerships as strategy. As noted by many commentators, the EU does not lack strategies (Grevi and de Vasconcelos 2008; Renard 2012, 2016; Smith 2016a). The problem as perceived by some is that it does not have a single overarching strategy, in the tradition of 'grand strategy', that establishes priorities, identifies targets and commits resources. The ESS, it can be argued, was only a partial expression of such an overarching strategic approach, more a statement of challenges and possibilities than a collective statement of approach and priorities. The Global Strategy of 2016 was in part an attempt to go further and to formalise what is often left implicit-the EU approach to key international challenges and commitments. As already noted, the Global Strategy embodied a search for 'strategic autonomy' and a 'comprehensive approach', coupled with a 'joined-up' approach to policy-making, and thus pointed to the deployment of a 'strategic diplomacy' in pursuit of SPs among other forms of external engagement. But what would such a strategic diplomacy imply?

A first issue that would in principle be addressed by a strategic approach would be that of 'target acquisition'. There would be an explicit ordering of priorities, that would provide a guide to the attention to be paid to specific partnerships or groups of partnerships, and a long-term framework both for the pursuit of partnerships and their evaluation. A second issue addressed by a strategic approach would be that of resources: the establishment of reliable, dedicated financial, institutional and human resources with which to pursue the targets identified, and with which to operationalise the principles behind the EU's partnership diplomacy. A third key element would be adaptability: the capacity to adjust to change and challenge, and to take advantage of opportunities, without casting aside the principles and the priorities established through the strategic approach.

The problem is that this kind of strategic approach has not characterised either the establishment or the conduct of the EU's partnership diplomacy to date. The strategic review that preceded the Global Strategy identified this issue in a clearcut form, by pointing to problems of policy direction, flexibility, leverage, coordination and capability that must be

\footnotetext{
${ }^{4}$ The following discussion draws upon work undertaken by one of the present authors in another context: Smith, M. (2017).
} 
overcome in order to produce a fully-fledged strategic approach (EEAS 2015; see also Tocci 2017). The consequence-spelt out in the Global Strategy, and illustrated in the earlier discussion in this chapter-is that EU diplomacy (including partnership diplomacy) is sub-optimal because of institutional and other variations within the EU system (both among the Brussels institutions and between those and member states). While that is clearly a key part of any diagnosis, it is only a part. The nature of external challenges, as recognised elsewhere in the review, is fundamental, but so is the existing structure of the EU's external engagements, reflecting as it does not only a fundamental commitment to partnerships, but also an incremental process which has produced a complex and messy system of strategic partnerships. This system, which produces both awkward contexts and awkward partners, as well as significant elements of path dependency, does not lend itself prima facie to a comprehensive strategic approach or to a comprehensive strategic diplomacy.

A second image of the EU's pursuit of strategic partnerships sees it as a process of management - an image that is in many ways a reaction to the difficulties encountered by a strategic approach. Here, the EU's actions are defined not as a goal-oriented and explicit reflection of a strategy, but much more as a management process (and this is of course how many diplomats themselves would present the activity). The emphasis is not on explicit setting of goals and priorities, but on a process that is continuous, incremental and dedicated to problem-solving rather than to the pursuit of a 'grand strategy'. The emphasis in this approach is on process itself, and in terms of partnership diplomacy on the maintenance of a kind of infrastructure that enables the day to day business of partnership to be transacted. Thus, the whole array of dialogues, management groups, sectoral working parties and specialised codes of conduct that underpin relationships such as those between the EU and the US or the EU and China are central to this image (Smith 2016b; Renard 2016). This kind of low-key institutionalisation, often expressed in joint action plans with a largely technical content, reflects a technocratic vision of diplomacy itself, in which the interests of a wide range of stakeholders need to be taken into account and in which the result is an intensification of day to day interactions.

In general, the managerial image of EU partnership diplomacy responds to a number of the problems confronted by a strategic image, but it does not resolve all of them. It can promise to make diplomacy more of a technocratic, adaptive process, and thus to iron out some of 
the elements that stand in the way of a comprehensive, differentiated and purposeful approach to what is a complex and messy area. But it cannot resolve (at least in the short term) the issues of international structure and high politics that create the demand for strategic approaches in the first place. It also creates potential problems arising from the tensions between the aims and actions of institutional stakeholders, and from different arms of the EU's commercial and political/security diplomacies.

A third image of the EU's search for strategic partnerships sees it as essentially a reactive process. While the first and second images discussed above contain a series of inbuilt tensions and potential frictions between different actors and activities, the third image challenges both of them, and in doing so challenges the notion of an organised or systematic EU partnership diplomacy. It also has important implications for the EU's credibility and legitimacy as a global actor, and for the resilience of its diplomatic system and diplomatic presence. The argument is that there have always been elements of the reactive in the EU's partnership diplomacy, from its earliest manifestations, but that these have been given greater salience by recent external challenges, and by the internal challenges to the legitimacy of the EU's institutions and policies in a range of fields.

The most obvious manifestation of this reactive tendency is the EU's response to external and internal crisis. As noted above, in recent years, there has been a series of external challenges to EU diplomacy in general, and these challenges have also attacked the central pillars of partnership diplomacy. Recent and current crises can thus be seen as a set of challenges to the EU's capacity for strategic or managerial approaches to strategic partnerships, since they have called into question the credibility and the legitimacy of the EU as an international interlocutor. The potential consequence is a retreat from the notion of a settled collective approach, and the (re)emergence of clashing preferences within the EU as to what might be acceptable partners and acceptable types of partnership. This in turn could lead to uncertainty within the EU about the types of commitment that might be entered into or maintained, and about the availability of resources that can be deployed to bolster conceptions of partnership. The eventual outcome might be a retreat from the vision of a stable and rule-governed partnership diplomacy to a reactive and sometimes chaotic EU approach in key regions of its engagement. At the same time, the increasing prevalence of 'strategic partnerships' initiated by some of the EU's major interlocutors, for example the United States and 
China, could also form the basis for a process of competition or emulation, in which the EU would respond to the claiming of new 'territory' by some of its key existing partners.

\section{Themes, Frameworks and Theories}

As noted in the Introduction, this volume is organised essentially around four key themes, which link with the three key logics of EU external action and the three images of the EU's SPs outlined above to constitute a framework for the analysis of strategic partnerships as diplomatic practice. First, there is the question of functions and motivations: Why has the EU sought SPs, do EU member states share the motivations and functions generated at Brussels level, and do partner countries recognise and share the motivations on which the EU initiative is based? This clearly links directly to the argument in this chapter about the different logics of EU external action in general and of the drive towards strategic partnerships in particular. Second, there is the question of policy: How is the nature and extent of a partnership shaped by both the specific negotiations on which it is based and the broader logics (i.e. internal, external and identity) framing EU external policies, not to mention the priorities and actions of the prospective or actual partner? This question links directly with the three images presented earlier, each of which constitutes a specific diagnosis of the characteristics of any given partnership. Third, there is the issue of institutionalisation: How are SPs in general, and individual SPs in particular, given institutional expression, to what extent do the institutions concerned to develop a dynamic of their own and to what extent do they adapt to the changing needs and scope of the partnership(s) as well as to broader claims from stakeholders and outsiders? Again, this question connects closely with the images of SPs as strategic, managerial or reactive, since each contains an implicit set of judgements on the need for and the effects of institutionalisation. Finally, there is the question of role: to what extent do SPs in general, and specific SPs, shape the behaviours demonstrated and roles played by the EU and others involved in them as well as the broader forces operating in the global arena? Clearly, this has strong links with the earlier discussion of the external logic and opportunity structures in the global context, but it also has a strong connection to the ways in which the dynamics of partnership (re)shape the expectations and actions of the partners. 
The approach taken in this volume is deliberately eclectic, but it is important at this point to note the ways in which it intersects with some key approaches in international relations and European integration theory. In the first place, there is a strong intersection with questions of power, and of the EU as a 'power' in international relations. Each of the partnerships under examination is a partnership between a non-state actor (the $\mathrm{EU})$ and a state actor How does this affect the power relations inherent to the partnership, and how does the partnership itself reflect or reframe the power relations in the global arena more generally? As noted above, the resurgence of 'power politics' in the global arena during the past two decades has raised important questions for EU external action and for the Union's ability to exercise power within its key international relationships. At the same time, while developing outside inter-regional cooperation arrangements, the SPs tend to be more in line with realist-driven sensitivities and approaches. All this means that Realist theories are far from irrelevant to the analysis and evaluation of the EU's strategic partnerships.

In a parallel fashion, the relevance of Liberal theories with their emphasis on a variety of international actors (and thus on multiple stakeholders in strategic partnerships), on the building of institutions and on the nature of global governance is clear: the issue is to what extent the key ideas of Liberalism can capture the EU's drive towards strategic partnerships and explain the ways in which those partnerships have been negotiated, have flourished or have decayed. Institutionalist theories more specifically have a strong bearing on the ways in which SPs have been initiated, consolidated and supplied with more or less extensive infrastructures: do they reflect processes of rational choice and utility maximisation, of social learning and adaptation, or of historical evolution through phases of institutionalisation that accumulate to provide a more or less robust structure? Finally, there is clearly a place for reflectivist and Social Constructivist approaches to the understanding of SPs: To what extent do they reflect the generation of strategic narratives and processes of social learning by those involved-and more specifically, on the part of the EU itself? Even these brief references to theory underline the ways in which SPs challenge processes of explanation and understanding as well as generating a wide range of international interactions between the EU and its partners. 


\section{Conclusions}

This chapter set out to review the development and the key characteristics of the EU's strategic partnerships, and to propose some ways in which they might be subjected to systematic analysis and evaluation. By identifying and tracing the roots of the strategic partnership phenomenon, the chapter has raised a number of questions about the EU's capacity and inclination to enter into such arrangements, and about the impact of internal and external challenges or crises on the EU's choices. By proposing that strategic partnerships as an EU integrative policy can be evaluated in terms of their relationship to internal, external and identity logics, in relation to the interaction of those logics, and by reference to the images of EU policy that they shape, the chapter has provided a framework for considering the functions and motivations shaping EU policies, the scope and policy implications of the agreements reached, the extent to which these agreements are institutionalised, and their impact both on the role of the EU and on its partners in the broader world arena. Thus, the chapter has suggested that there are important implications for the development of the EU's strategic diplomacy, as an expression of the EU's international role and as a mechanism for the achievement of policy objectives. In the chapters that follow, the contributors will focus on each of these dimensions in relation to specific partnerships as well as to the aims and practices of EU policy.

\section{REFERENCES}

Barroso, J. M. D. (2010, September 7). President of the Commission, State of the Union 2010, Strasbourg. Available at https://ec.europa.eu/commission/pre sscorner/detail/en/SPEECH_10_411. Accessed 26 April 2020.

Blanco, L. F. (2016, March). The Functions of 'Strategic Partnership' in European Union Foreign Policy Discourse', Special Issue 'The Strategic Partnerships of the European Union: Conceptual Insights, Cases and Lessons'. Cambridge Review of International Affairs, 29(1), 36-54.

de Baere, G. (2008). Constitutional Principles of EU External Relations. Oxford: Oxford University Press.

Dover, R. (2007). The EU's Foreign, Security and Defence Policies. In M. Cini (Ed.), European Union Politics (pp. 237-252). Oxford: Oxford University Press.

Eeckhout, P. (2011). EU External Relations Law. Oxford: Oxford University Press. 
European External Action Service. (2017, January 10). From Shared Vision to Common Action: Implementing the EU Global Strategy-1 Year. https://eeas.europa.eu/topics/eu-global-strategy/49750/eu-global-str ategy-\%E2\%80\%93-year-1_en. Accessed 1 May 2020.

European Commission. (2017). Public Opinion in the European Union-Report, Standard Eurobarometer 88. Available at http://ec.europa.eu/commfrontoff ice/publicopinion/index.cfm. Accessed 18 January 2020.

European Commission. (2019, March 12). EU-China-A Strategic Outlook. Joint Communication to The European Parliament, The European Council and The Council. Brussels. https://ec.europa.eu/commission/sites/beta-pol itical/files/communication-eu-china-a-strategic-outlook.pdf. Accessed I May 2020.

European Council. (1999, June 3-4). Common Strategy of the European Union on Russia, Cologne Available at https://op.europa.eu/en/publication-detail/-/ publication/38943c06-7e5d-4ca3-acc3-c5154bd9c04e/language-en.

European Council. (1999, December 23). European Council Common Strategy of 11 December 1999 on Ukraine (1999/877 CFSP). Official Journal of the European Communities. Available at https://op.europa.eu/en/publicationdetail/-/publication/c9c50ad4-e0a9-4ff9-8e3a-6el4a3e54lbf/language-en/ format-PDF.

European Council. (2003, December 12-13). European Council Presidency Conclusions. A Secure Europe in A Better World: European Security Strategy. Brussels.

European Council. (2005, December 15-16). European Council Presidency Conclusions. The EU and Africa: Towards a Strategic Partnership. Brussels.

European Council. (2007). Brussels European Council, Presidency Conclusions. Available at https://ec.europa.eu/commission/presscorner/detail/en/ DOC_07_2.

European Council. (2008, December 11). Report on the Implementation of the European Security Strategy - Providing Security in a Changing World. Brussels.

European Council. (2010). European Council of 16 September 2010 Conclusions. Brussels. Available at https://www.consilium.europa.eu/uedocs/cms_ data/docs/pressdata/en/ec/116547.pdf.

European External Action Service. (2015). The European Union in a Changing Global Environment: A More Connected, Contested and Complex World. Brussels: EEAS.

European External Action Service. (2016). Shared Vision, Common Action: A Stronger Europe. A Global Strategy for the European Union. Available at https://eeas.europa.eu/topics/eu-global-strategy_en.

Ferreira-Pereira, L. C. (2008). Portugal and the 2007 EU Presidency: A Case of Constructive Bridge-Building. Journal of Common Market Studies, 46(suppl 1), 61-70. 
Ferreira-Pereira, L. C. (2012). The European Union as a 'Model Power': Spreading Peace, Democracy and Human Rights in the Wider World. In F. Bindi (Ed.), The European Union Foreign Policy: Assessing Europe's Role in the World (pp. 293-305). Washington, DC: Brookings Institution Press.

Ferreira-Pereira, L. C. (2016, March). The European Union's Partnership Policy Towards Brazil: More Than Meets the Eye. Special Issue 'The Strategic Partnerships of the European Union: Conceptual Insights, Cases and Lessons'. Cambridge Review of International Affairs, 29(1), 55-77.

Ferreira-Pereira, L. C. (2020). The Mainstreaming of Security and Defense in the European Union Post-2016: Building Resilience in Challenging Times. In B. Weiffen \& D. Nolte (Eds.), Regionalism Under Stress: Europe and Latin America in Comparative Perspective (pp. 98-115). Routledge Global Institutions Series. New York and London: Routledge.

Ferreira-Pereira, L. C., \& Vieira, A. (2015, June). Ukraine in the European Union's Partnership Policy: A Case of Institutionalized Ambiguity. European Politics and Society, 16(2), 143-158.

Fues, T., \& Leininger, J. (Eds.). (2010). Germany and the Heiligendamm Process. In A. F. Cooper \& A. Antkiewicz (Eds.), Emerging Powers in Global Governance Lessons from the Heiligendamm Process (pp. 235-262). Montreal: Wilfrid Laurier University Press.

Grevi, G. (2013). The EU Strategic Partnerships: Processes and Purposes. In M. Telo \& F. Ponjaert (Eds.), The EU's Foreign Policy: What Kind of Power and Diplomatic Action? (pp. 159-174). Aldershot: Ashgate.

Grevi, G., \& de Vasconcelos, A. (Eds.). (2008). Partnerships for Effective Multilateralism: EU Relationships with Brazil, China, India and Russia. Chaillot Paper 109. Paris: European Union Institute for Security Studies.

Mogherini, F. (2018). Opening speech by High Representative/Vice-President at the annual EU Ambassadors Conference 2018, on 3 September 2018. Available at https://eeas.europa.eu/headquarters/headquarters-homepage/ 50025/node/50025_lo. Accessed 27 April 2020.

Monar, J. (1997). Political Dialogue with Third Countries and Regional Political Groupings: The Fifteen as an Attractive Interlocutor. In E. Regelsberger, P. de Schoutheete de Tervarent, \& W. Wessels (Eds.), Foreign Policy of the European Union: From EPC to CFSP and Beyond (pp. 263-274). Boulder: Lynne Rienner.

Pilling, D. (2008, July 9). Club G8 Under Pressure to Expand. Financial Times. Renard, T. (2011). The Treachery of Strategies: A Call for True EU Strategic Partnerships. Egmont Paper 45. Brussels: Egmont Institute. Available at http:// www.egmontinstitute.be/content/uploads/2013/09/ep45.pdf?type=pdf.

Renard, T. (2012). The EU Strategic Partnerships Review: Ten Guiding Principles. Brussels: European Strategic Partnerships Observatory. 
Renard, T. (2016). Partnering for Global Security: The European Union, Its Strategic Partners and Transnational Security Challenges. European Foreign Affairs Review, 21(1), 9-34.

Rettman, A. (2010, September 16). EU HRVP Ashton Designates Six New "Strategic Partners". EUObserver. Available at http://euobserver.com/instit utional/30828. Accessed 26 April 2020.

Saraiva, M. G. (2018). As Relações com a União Europeia (2008-2015). In W. A. Desiderá Neto et al. (Orgs.), Politica Externa Brasileira em Debate: Dimensões e Estratégias de Inserção Internacional no Pós-crise de 2008 (pp. 273-300). Brasilia: Ipea, Funag.

Smith, M. (2009). Between Soft Power and a Hard Place: European Union Foreign and Security Policy Between the Islamic World and the United States. International Politics, 46(5), 596-615.

Smith, M. (2012). Still Rooted in Maastricht: EU External Relations as a "ThirdGeneration Hybrid”. Journal of European Integration, 34(7), 699-716.

Smith, M. (2013). Beyond the Comfort Zone: Internal Crisis and External Challenge in the European Union's Response to Rising Powers. International Affairs, 89(3), 658-671.

Smith, M. (2016a). The EU, Strategic Diplomacy and the BRIC Countries. In M. Smith, S. Keukeleire, \& S. Vanhoonacker (Eds.), The Diplomatic System of the European Union: Evolution, Change and Challenges (pp. 115-129). London: Routledge.

Smith, M. (2016b, March). EU Diplomacy and the EU-China Strategic Relationship: Framing, Negotiation and Management. Cambridge Review of International Affairs, 29(1), 78-98.

Smith, M. (2017, December). The Geopolitics of the European Union's Partnership Diplomacy: Strategic, Managerial or Reactive?. International Politics, 56, 288-303. online first. https://doi.org/10.1057/s41311-017-0127-8.

Spencer, C. (2001). The EU and Common Strategies: The Revealing Case of the Mediterranean. European Foreign Affairs Review, 6(1), 31-51.

Tarrow, S. (1996). States and Opportunities: The Political Restructuring of Social Movements. In D. McAdam, J. McCarthy, \& M. Zald (Eds.), Comparative Perspectives on Social Movements (pp. 41-61). Cambridge: Cambridge University Press.

Tarrow, S. (1998). Power in Movement: Social Movements and Contentious Politics (2nd ed.). Cambridge: Cambridge University Press.

Tilly, C., \& Tarrow, S. (2006). Contentious Politics. Boulder, CO: Paradigm Publishers.

Tocci, N. (2017). Framing the EU Global Strategy: A Stronger Europe in a Fragile World. Basingstoke: Palgrave Macmillan.

Van Rompuy, H. (2010, June 24). Remarks by Herman van Rompuy, President of the European Council, at the press conference before the G8 meeting, Toronto. Available at http://www.consilium.europa.eu/uedocs/cms_Data/ docs/pressdata/en/ec/115488.pdf. 


\title{
Institutional Perspectives on the EU's \\ Strategic Partnerships: Where Is the Focus and Authority?
}

\author{
Daniel Schade
}

\section{INTRODUCTION}

Ten years have passed since then European Council President Herman Van Rompuy bemoaned in a speech that 'Until now, we had strategic partners, now we also need a strategy ![sic]' (Van Rompuy 2010: 1). The speech was held in the aftermath of the EU's transition to its functioning under the Treaty of Lisbon in 2009. While affecting the EU's policy-making system as a whole, the EU's foreign policy was particularly affected: not only were new institutions set up for its coordination, but a carefully balanced institutional setting was disrupted with the changes made.

The purpose of this chapter is to analyse the role that the EU's institutions as currently constituted have played and continue to play in

\author{
D. Schade $(\otimes)$ \\ Department of Government, Cornell University, Ithaca, NY, USA \\ e-mail: daniel.schade@cornell.edu \\ (C) The Author(s), under exclusive license to Springer Nature \\ Switzerland AG 2021 \\ L. Ferreira-Pereira et al. (eds.), The European Union's Strategic \\ Partnerships, The European Union in International Affairs, \\ https://doi.org/10.1007/978-3-030-66061-1_3
} 49 
developing the EU's strategic partnerships. Its focus is thus largely on an elaboration of the internal logic as identified in Chapter 1, which posits that the EU's external action is ultimately shaped by factors internal to the EU.

Identifying the institutional basis of the strategic partnerships is a key challenge given the absence of formality in designating EU strategic partners, formulating goals to be achieved through the strategic partnerships and lastly enacting them. The lack of formality can be illustrated by the difficulty to establish the number of strategic partnerships in place around the time of the transition to the EU's Lisbon Treaty (Renard 2011: 111). This is due to the fact that the rationale for, and development of each also followed radically different trajectories (Renard 2013: 305), with no clearcut definition or criteria to be found (Ferreira-Pereira and Vieira 2016: 4-5). These underlying facts about the EU's strategic partnerships have not changed since their inception and continue to provide the backdrop against which they are assessed. Similarly, the list of the EU's strategic partners has not formally changed and constitutes the universe of cases to be considered here.

This chapter will be concerned primarily not with the issue of strategic partner choice and designation, but with how the institutions have managed and acted upon them since they were established. To paraphrase the call by former European Council President Van Rompuy, have the EU's institutions since developed a strategy for the EU's strategic partnerships, and have they been able to translate this into partnership practice? The first part of the question is ultimately motivated by broader concerns in research on EU foreign policy which seek to understand if and how the EU attempts to bring more strategic thinking to its external relations so as to enhance coherence and effectiveness of its activities (see, for instance, da Conceição-Heldt and Meunier 2014; Furness and Gänzle 2017; Mayer 2013). This is also echoed by the first image introduced in Chapter 1, which considers the building of the partnerships as part of a strategic approach. With regard to the EU's strategic partnerships, this could either relate to addressing the strategic partners collectively as part of a single policy toolkit, or in relation to approaching EU ties towards individual strategic partners coherently across all areas of EU foreign policy activity. The second part of the question is then ultimately concerned with the capacity of the EU's current Brussels-based foreign policy system to leave an imprint on the strategic partnerships in its current set-up. This closely mirrors the second image introduced in 
Chapter 1, which considers whether the EU's approach to the strategic partnerships is ultimately managerial.

The bar for identifying institutional activity towards a more 'strategic' use of the strategic partnerships is ultimately a low one, as around the time of the transition to the Lisbon Treaty after 2009 officials within the European Commission responsible for the EU's ties to its strategic partners were often unaware that theirs was a strategic partner, or how their activity differed from that of colleagues dealing with other third partners (Renard 2013: 308). Nonetheless, for the purpose of offering a structured analysis of institutional activity towards the strategic partnerships, distinct areas in which an answer to the above research questions could be expected need definition.

This is necessary as both the very nature and functioning of strategic partnerships are contested, just as what would constitute 'strategy' in the conduct of these (Grevi 2013: 160-162; Schade 2019b: 376). The first analytical category to be identified ultimately revolves around whether there are genuine priorities and interests identified for the EU's strategic partnerships (Bendiek and Kramer 2010: 455-456), in other words whether the EU has identified a goal to be achieved through its strategic partnerships. Furthermore, secondly, following on from previous analyses of the EU's strategic partnerships (Renard 2013: 308-311), one would expect that a strategic use of the strategic partnerships necessitates for these to be based on specific frameworks enabling structured cooperation. Thirdly and finally, the existence of the strategic partnerships needs to translate into specific institutional provisions internal to the EU which enable its foreign policy system to translate partnership goals into outcomes. The remainder of this chapter is thus structured around these analytical categories, identifying the role and activity of key EU institutions within each.

Such a focus on the institutional underpinnings of the EU's strategic partnerships is necessary, as the EU's policy choices on these are ultimately shaped not just by the pursuit of the EU's aims and interests-as posited by the third logic of identity introduced in Chapter 1 -but by how these are defined, perceived and advocated for by the actors shaping EU foreign policy. These cannot be considered as mere transmission belts of EU interests. Institutionalist literature instead cautions that bureaucratic decision-making processes are themselves shaped by the institutional set-up of a foreign policy bureaucracy, as well as the distinct interests and preferences of each institutional actor involved. Existing 
literature on EU foreign policy-making thus cautions that it has become increasingly necessary to consider the bureaucratic politics of the EU's institutions in this domain, including their changing organization and the role of individuals within them (for an overview of these arguments, see Delreux 2015). A focus on the institutional elements of the EU's strategic partnerships can thus help unearth how much these are an expression of the EU's strategic pursuit of foreign policy goals (strategic image), or a mere expression of the underlying bureaucratic politics (management image).

The institutions to be considered in this context are numerous. This is despite the fact that one of the purposes of the EU's transition to the Lisbon Treaty was to simplify the EU's foreign policy system. Ultimately, this can today be qualified as a 'hybrid' system (Smith 2012), in which old divisions and modes of decision-making continue to survive in a now formally unified foreign policy system. This means that actors involved in the EU's strategic partnerships prior to the Lisbon Treaty, and the European Commission and the Council of the EU, in particular, continue to play a relevant role in the strategic partnerships. To this, one has to add the novel EU High Representative for the Common Foreign and Security Policy (CFSP) and Vice-President of the Commission (HRVP), as well as the affiliated institution, the European External Action Service (EEAS). Given the HRVP's formal responsibility in the conduct of the EU's external relations, and due to the fact that the EU's first post-Lisbon HRVP Catherine Ashton had declared the strategic partnerships as one of her foreign policy priorities (Renard 2016: 24), the analysis of this actor's activity and that of its underpinning institution, the EEAS will be of particular relevance. Lastly, insofar as the adoption of frameworks for the strategic partnerships (see below) involves the conclusion of formal EU international agreements, the European Parliament also has to form part of the analysis. Given the important changes introduced with the Treaty of Lisbon, this chapter's analysis focuses on institutional developments since its inception in 2009.

\section{A Lack of Overarching Goal Formulation for EU Strategic Partnerships}

It is difficult to identify a single set of documents outlining the goals to be achieved with the strategic partnerships, as 'the EU actually produces a lot of strategies' (Smith 2017: 505). It is telling, however, that there is no 
document, in particular, that is devoted to jointly discussing the entire set of the EU's strategic partnerships. Part of this is due to the fact that the strategic partnerships were gradually set up disjointedly with individual partners in increments, without overarching goals in mind. However, this does not explain why no efforts have been made to remedy this situation since their initial set-up.

The EU's main attempt at formulating its foreign policy vision in the post-Lisbon context, the so-called EU Global Strategy of 2016 (EEAS 2016), puts an emphasis on the EU approaching external relations as an exercise involving partnerships. However, the specific strategic partnerships are only mentioned in passing and no explicit reference is made to the strategic partners as a specific foreign policy instrument. Instead, the strategic partners are mentioned alongside other countries in the geographic sections of the Global Strategy as well as when discussing with whom to pursue multilateral cooperation. This is telling as to the relevance of the strategic partnerships as a policy instrument, given that the Global Strategy is ultimately the result of a large-scale consultation process involving all key stakeholders of the EU's foreign policy system (Smith 2017: 509; Tocci 2017: 491-495). Furthermore, it was the novel EEAS under the guidance of the HRVP that was ultimately responsible for its publication, indicating that the strategic partnerships did not form part of this institution's policy priorities at the time.

This is not to say that there haven't been any times when the strategic partnerships were on the agenda of the EU's institutions. Following on from van Rompuy's above-mentioned call for more strategic thinking surrounding the strategic partnerships in September 2010, the European Council mandated the HRVP:

in coordination with the Commission and the Foreign Affairs Council, to evaluate the prospects of relations with all strategic partners, and set out in particular our interests and possible leverage to achieve them. (European Council 2010: 9)

This indeed resulted in some mainly descriptive reports on most of the strategic partnerships being produced, albeit lacking an overall structure to them (Grevi 2013: 170). Since then, there has been little to no collective follow-up by the EU's institutions on these. When it comes to the current formulation of goals for individual EU strategic partnerships, great differences can thus be observed. Whereas there are some strategic 
partnerships which have received regular attention (such as the ones with Canada or China), including the adaptation of an EU goal formulation, this is clearly not the case for most others.

The formulation of a common vision for the EU's strategic partnerships is naturally limited by the important diversity of partners at hand (Renard 2013: 305). While some, such as Canada (see Verdun in this volume), are naturally close to the EU's position on many issues, including aspects such as the protection of democracy and human rights, this is not necessarily the case for all. Russia is a case in point: the strategic partnership with the country had been fraught with difficulties for quite some time (Schmidt-Felzmann 2016). It was the country's involvement in the Ukraine conflict which led to the strategic partnership effectively having been put on hold (Casier 2019: 1; see also Haukkala in this volume).

To illustrate the matter of divergent approaches to the strategic partnerships, the case of the EU-China partnership provides an example for regular and differentiated thought into the overall goal formulation by the EU's institutions (see also Cottey in this volume). In this case, two documents from 2016 provided the basis for the EU's current goal formulation towards the country. The first is a joint document by the European Commission and the HRVP (European Commission and HRVP 2016) analysing developments in China, outlining the EU's position towards these developments, as well as formulating specific aims and goals to be achieved. This document is accompanied by Council conclusions (Council of the EU 2016a) which immediately followed the other document, and which similarly emphasize specific aims to be achieved. This documents an instance in which the core EU institutions acted in sync, providing an overall set of goals for this specific strategic partnership.

To attest to the dynamism of the EU's goal formulation towards the country, the initial strategy by the Commission and the HRVP has since been amended ahead of an EU-China summit in 2019 (European Commission and HRVP 2019a), significantly revising both its analysis of developments in China and the associated goals to be achieved. While the 2016 document still emphasized the potential for cooperation with the country in many areas, the new document now recognizes that 'China is, simultaneously, in different policy areas, a cooperation partner with whom the EU has closely aligned objectives, a negotiating partner with whom the EU needs to find a balance of interests, an economic competitor in the pursuit of technological leadership, and a systemic rival 
promoting alternative models of governance' (European Commission and HRVP 2019a: 4). This is relevant insofar as the document recognizes a rapidly changing environment for the pursuit of the strategic partnership, while also outlining the limits of cooperation with specific strategic partners at hand. As initially suggested by Grevi (2013: 170), this demonstrates an EU capacity to distinguish between the partnerships overall, and partnering on specific policy issues at hand.

The other extreme of the spectrum is EU strategic partnerships which see little to no goal formulation, let alone regular reflection on the matter by the EU's institutions. This can be illustrated through the case of the EU's strategic partnership with Brazil. While the strategic partnership dates back to 2007, the latest overall goal formulation by the EU towards the country dates back to the same year (Schade 2019b: 383).

This is despite the fact that throughout this period negotiations were ongoing with Mercosur on the conclusion of an EU Association Agreement including an FTA with the countries of this regional organization, of which Brazil is by far the largest member. While the ultimate Association Agreement with Mercosur will contain a political pillar which was agreed upon in principle in 2018 (Schade 2020: 110-111), unlike for the trade pillar of the agreement its contents are not in the public domain. In the same vein, no recent goal formulation for ties with either individual countries of said organization or the entire grouping is to be found. Instead, the Commission and the HRVP have opted to draft a new strategy document outlining its strategy towards the entire Latin American and Caribbean region in 2019 (European Commission and HRVP 2019b). While the document emphasizes that the EU considers its ties to the entirety of the region as a strategic partnership, no mention is made of the specific strategic partnership with Brazil or Mexico, the EU's other formal strategic partner in the region.

While goal formulation towards specific strategic partners attests to the EU's institutional ability to analyse its ties to the strategic partners, and to associate the analysis with the pursuit of specific aims, it nonetheless demonstrates the complexity and difficulty in finding and defining these within and between key EU institutions. In the absence of a distinct goal formulation on the EU's side, the very bilateral frameworks setting out cooperation instruments and target areas with strategic partners may also serve a goal formulation function, as discussed below. 


\section{Diverging Frameworks-A Plethora of 'Strategic Partnerships'}

The EU's ability to translate its policy aims towards its strategic partners into practice also ultimately relies on how cooperation with specific strategic partners is structured. This can be achieved through the creation of a framework for cooperation with strategic partners. This section evaluates the existing framework formats and how these were set up. It ultimately finds that while the frameworks developed for specific strategic partners enable EU institutions to pursue EU policy aims, this is not the case across all strategic partnerships at hand.

The conduct of EU strategic partnerships ultimately relies on bilateral cooperation between the EU and individual strategic partners. Usually, this is based on an agreement as to the modalities of cooperation between the EU and its specific strategic partner. It is such a framework that defines the structures which determine the range and intensity of cooperation with strategic partners. These frameworks for the EU's strategic partnerships differ radically and a variety of differing formats are in existence, all affecting the role that the EU's institutions can play in them.

The most extensive kind of framework for such cooperation between the EU and its strategic partners is so-called strategic partnership agreements (SPAs). These are in place with Japan and Canada, as well as a similar 'framework agreement' with a third strategic partner, the Republic of Korea (ROK) (also known as South Korea). Aside from the difference in name, the latter was also somewhat more limited in scope given that its negotiations largely precede the Treaty of Lisbon. There is, however, a similarity in the negotiation of all three, as these occurred in parallel to the conclusion of Free Trade Agreements (FTAs). This follows an overall recent development which has seen the EU formally eschew the increased formal complexity of Association Agreement by signing parallel yet legally separate FTAs and political agreements in its external negotiations (D'Ambrogio 2019: 3-4; Schade 2020: 203). The set-up of these frameworks therefore does not occur in a vacuum and happened as part of a broader negotiation effort involving a plethora of actors on the EU's side.

These agreements ultimately help to set up specific formats for discussion and cooperation across many areas with the EU's strategic partners.

${ }^{1}$ This was also the term used in the initial negotiations with Canada and Japan. 
It has been argued that the added value of the partnerships is in facilitating specific technical exchanges (Vivet and de Lalande 2014:4) between officials on both sides. In many cases, such as for the Republic of Korea, the creation of a framework has led to a significant expansion of the number of dialogues occurring (Chung and Lee 2019: 329-330). These are all contained within an overarching institutional setting. In the case of the SPAs (see, for instance, Council of the EU 2016b: 32-35), this usually provides for regular summits at head-of-state level, meetings between foreign ministers, as well as a so-called Joint Committee. It is the latter that is meant to direct the strategic partnership between both partners. On the EU's side, the highest official is typically notionally the HRVP, thus giving the EEAS a core institutional role at the highest level of the strategic partnership. Nonetheless, a consideration of the areas of cooperation contained within the SPAs makes it obvious that many are within the institutional remit of the European Commission. This creates the potential for bureaucratic and political tensions on the EU's end, as institutional involvement ranges from a (national) executive dominance in the regular summits and ministerial meetings, to the HRVP and the EEAS and ultimately the Commission at different levels, which all have distinct policy goals.

While the SPAs provide for the most coherent and developed framework for the EU's strategic partnerships, there are nonetheless important differences between them. For instance, while the agreement with Canada can be suspended if one party violates fundamental principles that both have agreed to, an inclusion of this has proven highly contentious in the case of the SPA with Japan (D'Ambrogio 2019: 4). Similarly, while the agreement with Canada lists specific areas for cooperation in chapters, the agreement with Japan is significantly less ambitious when it comes to that, and thus ultimately less structured. This shows that while SPAs provide an extensive structure for individual strategic partnerships, they do not help the EU's institutions to address all strategic partners collectively.

To put the SPAs further into perspective, it is also important to note that such agreements are ultimately not limited to the EU's formal strategic partners. The framework agreement with Australia, in particular, closely resembles the Canada SPA and the ROK framework agreement in structure and scope. It also goes beyond the EU-Japan SPA in one crucial area in that it includes an essential elements clause allowing for its suspension if either party violates fundamental principles such as human rights. 
This ultimately raises the question as to whether the particular framework adopted here sets EU strategic partnerships apart from those countries to whom the label has not been applied (Murray 2016).

While SPAs represent the most developed framework for EU strategic partnerships, there are also some which lack any significant underlying framework altogether. This can be illustrated through the case of the EU's strategic partnership with Brazil (for a more focused discussion of this, see Ferreira-Pereira in this volume). While both SPAs and framework agreements are legally binding international treaties which require ratification, no similar framework for the strategic partnership exists with Brazil. Instead, there are a number of outdated bilateral political agreements which predate the strategic partnership. The strategic partnership framework itself is then but a declaratory concluding joint statement from a 2011 EU-Brazil summit (Council of the EU 2011), which sets out areas in which cooperation is to occur. While the 'Joint Action Plan' is structured similarly to the sections of the Canada SPA discussing areas for cooperation, it entirely lacks the overarching legal framework and sections outlining cooperation institutions and modes of decision-making. Since then, further summit conclusions have listed some additional areas for cooperation which are, however, once again devoid of any institutional framework whatsoever (EU-Brazil Summit 2014). In addition to this, much like with most countries across the globe, the EU has signed a number of very specific smaller agreements with the country, such as on civil aviation matters. These are not part of an overall framework, however, and have all been negotiated separately.

This is partly related to the fact that prior to the establishment of the SP with Brazil, the EU's relations with the country were principally structured by the EU's attempts to develop its ties to Mercosur. Since the entry into force of a so-called Framework Cooperation Agreement with this particular regional organization, this has provided a legal basis for ties to the region. The EU-Mercosur Association Agreement, which at the time of writing has been concluded but not yet ratified, would also modernize the basis for political ties to the region in addition to an FTA. However, all Mercosur partners are considered as equal within this agreement, meaning that institutionally speaking the EU's ties to Brazil would be no different from those with Argentina or Paraguay.

This present lack of an institutional framework in the Brazilian and other cases is somewhat problematic, as in addition to the potential lack of aims for the strategic partnerships, it makes for much less structured 
exchanges with the strategic partner at hand. Considering the role of the EU's institutions, the SPAs ultimately set out a hierarchy for the conduct of the strategic partnership, while still necessitating difficult coordination between the EEAS, the Commission and the member states. In the case of less codified strategic partnerships, even a basic agreement on institutional roles and hierarchies is lacking, making the conduct of a strategic partnership potentially much more difficult.

The hugely divergent frameworks for the EU's established strategic partnerships ultimately significantly hinder the EU foreign policy system's capacity to achieve coherence between the conduct of specific partnerships. Even when considering the relatively novel SPA format, the differences between the established ones are striking. These reveal the continued weakness of frameworks for a joined-up EU approach towards its established strategic partnerships. Nonetheless, these types of agreements should enhance the potential for cooperation with individual strategic partners to be more strategic across individual areas of EU foreign policy, as they set out some institutional hierarchies within the EU. The case of Australia then illustrates that the pursuit of this kind of coherence is not limited to the EU's official strategic partners, however. In fact, considering a case such as Brazil, it is easy to find other countries like Ukraine which are not strategic partners of the EU, but with which cooperation frameworks are more developed at present.

\section{INSTITUTIONAL COMPLEXITY AND EU Strategic Partnerships}

While the previous sections have dealt with how (a lack of) goal formulation and frameworks for cooperation with strategic partners shape the possibilities for an EU institutional response, this section considers how the EU's institutional set-up itself determined the EU's cooperation with its strategic partners. This section thus takes a perspective which particularly emphasizes the potential for bureaucratic politics between and within individual institutions involved in the EU's foreign policy-making as a factor determining the EU's approach towards its strategic partners.

The considerations here partly interlink with the observations above, as it is the EU's institutions which are responsible for the negotiation of cooperation frameworks and the elaboration of strategy documents. Lastly, in the absence of such formal provisions, it is also institutional action that can shape strategic partnership policy. The underlying issues 
present in the EU's strategic partnerships manifest themselves in the negotiation setting for frameworks of the EU strategic partnerships, as well as the day-to-day business of partnership policy-making.

The key challenge for strategic institutional activity on the EU's strategic partnerships is the continued survival of different modes of decision-making in EU foreign policy. As mentioned above, despite the Lisbon Treaty changes, it continues to act as a 'hybrid' in which legal provisions from differing sources compete with one another (Smith 2012). Relatedly, the transition to the Lisbon Treaty also ruptured existing formats for intra-institutional and inter-institutional cooperation at the EU level. This is due to the fact that the Lisbon reshufflingmeant to reduce complexity in the EU's foreign policy system-ultimately redrew institutional boundaries given the introduction of the remodelled HRVP and of the EEAS (Schade 2019a: 203-207). While, since then, some informal cooperation and coordination practices have been recreated, this is ultimately an ongoing long-term process (Schade 2019a: 211) and does not solve the underlying problem of the diverse institutional set-up involved in the conduct of the EU's strategic partnerships.

The negotiation of the framework for EU SPAs is illustrative of the complexity involved in setting their modalities. This is ultimately due to these agreements touching on several modes of functioning of the EU's foreign policy system and multiple of the EU's policy areas. As explored above, these therefore contain provisions pertaining to competencies within the exclusive remit of the EU, competencies which are mixed between the EU and its member states, as well as those that the member states formally retain. Furthermore, even in the areas within which the EU has formal competency, the inclusion of clauses pertaining to its CFSP as well as those relating to 'regular' EU policy-making means that different modes of EU decision-making are involved in the negotiations. These difficulties complicate the negotiations for the SPAs as a plethora of actors are involved on the EU side.

This manifests even in negotiations with strategic partners with whom the EU shares most interests and values, such as Canada. The negotiation process for the SPA formally followed those established for any EU international agreement, in which the Council of Ministers mandates an EU institution (and typically the Commission) to negotiate an agreement on behalf of the EU. This institution then negotiates with the third partner on the contents of the agreement based on the negotiation mandate given by the Council and regularly reports back to it. Ultimately, an agreement 
is then signed and ratified once more by the Council, as well as the EP since the Treaty of Lisbon.

However, much like other complex EU agreements spanning multiple modes of decision-making in the EU such as EU Association Agreements (Schade 2020: 58-60), the EU-Canada SPA did not have a single negotiator on the EU's side. Rather, the Council mandated both the Commission and the EU's HRVP to negotiate on different parts of the agreement falling into the responsibility of each (Council of the EU 2010a: 2). In the case of the latter, this is for the EU's CFSP, in particular. Furthermore, as the SPA would also touch on competences remaining with the member states, the Council additionally mandated the Commission to negotiate those provisions on its behalf (Council of the EU 2010b: 2 ). At the same time, a representative of the rotating Council presidency was to be directly involved in those parts of the negotiations, and the relevant Council working group closely informed at all times so as to ensure constant member state supervision of the process.

The negotiation of SPAs thus necessitates the cooperation of multiple EU institutions even in a relatively simple setting. However, most of the time, the political issues at the heart of the EU's strategic partnerships are only a side aspect of wider negotiations for FTAs. This is due to the fact that the EU's foreign policy has historically been dominated by international trade, and this continues to be a major aspect in the post-Lisbon context (Smith 2018). It is thus that the negotiations for all EU SPAs so far were embedded in a wider context of economic negotiations. This enhances the role of the Commission in the overall process, as competencies in the area of international trade remain firmly with its Directorate-General for Trade (DG Trade). Given the prevalence of economic issues, a consideration of the EU's overall strategic partnership policy is unlikely to feature in such negotiations, as evidenced by the stark differences in the SPAs negotiated to date.

Even in the absence of changing the framework of the EU's strategic partnerships, extensive coordination is necessary for their daily conduct and leading up to specific moments such as summits with the strategic partners. However, the set-up of the EU's foreign policy structures is ultimately ill-equipped to consider the strategic partners either collectively or individually across policy areas.

A key problem is that the strategic partnerships are not reflected in the organizational structure of the EEAS, despite the fact that this is the institution tasked with managing the EU's external relations overall. 
Its organizational structure instead largely follows a geographical logic. While there are some cross-cutting thematic divisions in place, none are concerned with the EU's overall strategic partnership policy. This is not surprising overall, as geographic coordination has been a constant feature of the EU's foreign policy system in recent times, while issue-based coordination is weak in the EEAS' institutional set-up (Grevi 2013: 171) due to its origins with the external relations units of the Commission and the Council.

While a geographical logic within the EEAS should ensure that-at least within this institution-activities towards individual strategic partners are coordinated across policy areas, this is not without its problems either. Firstly, the resources devoted to strategic partners within the EEAS are not linked to their strategic partner status, but rather indirectly to the number of political dialogues to be upheld with third countries. This in turn concerns EU strategic partners and non-strategic partners alike, depending on the framework for their ties with the EU (Schade 2019b: 387-388). This lack of visibility of the strategic partners in the institutional resources is not novel and has been observed at the time of the transition to the Lisbon Treaty (Renard 2013: 308, 310) both within the Commission and the EEAS delegations abroad. While today these observations principally concern the EEAS and its delegations, the problem is also pronounced within the Commission, which-despite having been stripped of its foreign policy bureaucracy-retains competencies in policy areas relevant for EU foreign policy-making.

While this geographic logic of the EEAS may ultimately facilitate the coordination of EU activity towards individual strategic partners internally, it is not a guarantee that this institution can lead an efficient coordination process across distinct institutions. Ultimately, the EEAS remains reliant on the Commission for key elements of the EU's foreign policy towards third countries, including the strategic partners. However, for the geographic subdivisions within the EEAS, it is not always easy to identify their counterparts within the distinct hierarchy of Commission Directorates' General (DGs), which may not follow the same geographic logic (Schade 2019a: 206). Furthermore, given that Commission DG aims may differ from those of EEAS officials, and that the ultimate question of hierarchies in EU foreign policy-making remains unresolved, EEAS coordination efforts ultimately rely on the goodwill of their Commission counterparts (Grevi 2013: 171). 
While EEAS-Commission interactions are one core part of the institutional coordination necessary for the EU's strategic partnerships, it is important not to overlook necessary interactions with the Council given the retained member state powers in the area of foreign affairs. Here, the Council of Ministers' internal structure does not facilitate either a collective consideration of the EU's strategic partnerships or one that would focus on ties to individual strategic partners at hand.

Much like in the other institutions considered, there is no specific Council subdivision responsible for ties with the EU's strategic partners as such. Instead, a number of geographically centred bodies within the Council are responsible for following the relations with specific strategic partners. These are notably the Working Party on Transatlantic Relations (COTRA) which follows the EU's ties to Canada and the United States; the Asia-Oceania Working Party (COASI) responsible for the EU's ties to the 4 strategic partners China, India, Japan and South Korea; the Working Party on Latin America and the Caribbean for Brazil and Mexico; the Working Party on Eastern Europe and Central Asia (COEST) for Russia; as well as two working parties in which South Africa is included, namely the Africa Working Party (COAFR) and the Africa, Caribbean and Pacific Working Party (ACP). Last but not least, thematic concerns relating to the strategic partnerships may obviously also be addressed within other specific Council working groups such as the Trade Policy Committee (TPC) or the Working Party on Human Rights (COHOM).

Furthermore, the transition to the Lisbon Treaty reduced the Council's formal role in the EU's foreign policy, with the HRVP and the EEAS gaining some responsibilities that once formed part of the tasks of the rotating Council presidency (Grevi 2013: 172). Ultimately, this has somewhat reduced the incentives for member states to launch initiatives towards third partners during their tenure of the rotating presidency, although the practice has not disappeared entirely.

While the European Parliament plays a relatively minor role in the dayto-day conduct of the EU's strategic partnerships, there is no specific body responsible for the consideration of ties with all strategic partners either. Instead, it maintains specific parliamentary delegations to their counterparts in 9 of the EU's 10 strategic partners. The odd one out in this case is the Republic of Korea, as the EP maintains a parliamentary delegation to the Korean peninsula instead. Furthermore, the delegation to Brazil is a relatively novel addition, as parliamentary ties to the country 
were part of the exclusive remit of the EP's delegation for relations with Mercosur beforehand (Schade 2019b: 386).

The EU's external relations system in the post-Lisbon context thus suffers from a similar problem to the one it experienced beforehand despite its institutional innovations: a lack of authority and focus that could put the EU's strategic partnerships on the agenda. Instead of facilitating the formulation of strategies towards the EU's strategic partnerships collectively or individually, the new role of the EEAS has ensured that matters remain as complex as beforehand. While this institution is now more visible in the conduct of the EU's foreign policy, both the institution and its political head the HRVP lack the authority to guide overall EU activity towards third countries, including the strategic partnerships. While the EEAS might play a role as a facilitator in ensuring coherence between individual policy areas aimed at specific strategic partners, the distinct structures between EEAS, the Commission and the Council do not help this coordination either.

This problem is exacerbated by the fact that the member states no longer dispose of strong incentives to bring initiatives towards strategic partners forward in time for high-level summits, as the political capital arising out of the rotating Council presidency has been somewhat reduced due to the HRVP's more prominent role. Lastly, the organizational structures of the core institutions involved in the EU's strategic partnerships make it difficult to identify from where a more strategic outlook on the EU's strategic partners could occur.

\section{CONCLUSION}

The EU's strategic partnerships offer a paradox for the EU's pursuit of a more coherent foreign policy. The very notion of prioritizing relations to specific partners can be seen as an attempt to overcome the EU's haphazard approach towards third partners without strategy. At the same time, pursuing coherent ties to the EU's strategic partners is hampered firstly by the impossibility to provide a coherent strategy and framework(s) for a very divergent set of strategic partners, and secondly by this attempt going counter to the different modes of decision-making in the EU's foreign policy. While it is an internal logic that dominates this process, the reality of the diversity of the external world has also influenced it.

Ultimately, there is thus very little evidence that the concept of strategic partnerships receives any ongoing and regular institutional 
attention whatsoever, either in the form of formulating goals and aims, providing a framework for cooperation, or by facilitating interinstitutional exchanges on the strategic partnerships. This can principally be attributed to the complex institutional set-up of the EU in the area of its foreign policy, allowing for bureaucratic politics to influence its activity towards the strategic partners.

This perspective is mitigated by the possibility to identify best practices across the dimensions considered. When it comes to a recognition of EU goals and aims, the EU's strategic partnership with China is such a case in point. Here, the three key institutions involved in EU strategic partnership diplomacy, namely the Commission, HRVP/EEAS and the Council of Ministers all regularly consider ties to this specific country. What is more, it is possible to identify a relatively rapid shift in the underlying analysis, reacting to developments in the country-even if this ultimately means that China can no longer be considered a strategic partner.

When it comes to frameworks for cooperation, the EU-Canada SPA provides a blueprint for the policy areas which can form part of EU strategic partnership diplomacy, as well as an institutional framework which allows for more than political dialogues without consequences. Sadly, when it comes to the interaction between the key institutions, no best practice can be identified as to how to consider the strategic partnerships both as a policy tool and in their individual dimensions across policy areas. This is due to the fact that underlying structural issues hinder the development of a best-practice institutional approach towards the strategic partnerships.

Given the low salience that most strategic partnerships appear to have in EU foreign policy-making, it is thus safe to conclude that they have not been used to pursue a more coherent and strategic EU foreign policy overall. In the EU's current foreign policy set-up, there still is no single institution that is ideally placed to take the initiative for providing leadership on the EU's strategic partnerships despite the existence of the EU's HRVP and of the EEAS. While former Council President Herman Van Rompuy's plea for a strategy to underpin the EU's strategic partnerships was well-intentioned, it has simultaneously remained the sole high-level institutional attempt at doing something about said issue. Ultimately, this chapter thus makes the case that an internal logic based on a haphazard managerial approach is paramount in shaping the EU's strategic partnerships. 


\section{REFERENCES}

Bendiek, A., \& Kramer, H. (2010). The EU as a 'Strategic' International Actor: Substantial and Analytical Ambiguities. European Foreign Affairs Review, $15(4), 453-474$.

Casier, T. (2019). Russia and the European Union. In Oxford Research Encyclopedia, Politics. Oxford: Oxford University Press. https://doi.org/10.1093/ acrefore/9780190228637.013.1051.

Chung, S. W., \& Lee, J.-S. (2019). Building the Pillars of the EU-South Korea Strategic Partnership. Asia Europe Journal, 17(3), 327-340. https://doi.org/ 10.1007/s10308-019-00557-z.

Council of the EU. (2010a, November 30). Council Decision Authorising the European Commission and the High Representative of the Union for Foreign Affairs and Security Policy to Negotiate on Behalf of the European Union, the Provisions of a Framework Agreement Between the European Union and Its Member States, of the One Part, and Canada, of the Other Part, That Fall Within the Competence of the European Union. Brussels: Council of the European Union.

Council of the EU. (2010b, November 30). Decision of the Representatives of the Governments of the Member States, Meeting Within the Council, Authorising the European Commission to Negotiate, on Behalf of the Member States, the Provisions of a Framework Agreement Between the European Union and Its Member States, of the One Part, and Canada, of the Other Part, That Fall Within the Competences of the Member States. Brussels: Council of the European Union.

Council of the EU. (2011, October 4). 5th European Union-Brazil Summit Joint Statement. Brussels: Council of the European Union.

Council of the EU. (2016a, July 18). EU Strategy on China. Council conclusions. Brussels: Council of the European Union.

Council of the EU. (2016b, August 5). Strategic Partnership Agreement Between the European Union and Its Member States, of the One Part, and Canada, of the Other Part. Brussels: Council of the European Union.

D'Ambrogio, E. (2019). The EU-Japan Strategic Partnership Agreement (SPA): A Framework to Promote Shared Values. Brussels: European Parliamentary Research Service.

da Conceição-Heldt, E., \& Meunier, S. (2014). Speaking with a Single Voice: Internal Cohesiveness and External Effectiveness of the EU in Global Governance. Journal of European Public Policy, 21(7), 961-979. https://doi.org/ $10.1080 / 13501763.2014 .913219$.

Delreux, T. (2015). Bureaucratic Politics, New Institutionalism and PrincipalAgent Models. In K. E. Jørgensen, Å. K. Aarstad, E. Drieskens, K. Laatikainen, \& B. Tonra (Eds.), The SAGE Handbook of European Foreign Policy (pp. 152-165). London: Sage. 
EEAS. (2016, June 2). Shared Vision, Common Action: A Stronger Europe: A Global Strategy for the European Union's Foreign And Security Policy. Brussels: European External Action Service.

EU-Brazil Summit. (2014, February 24). 7th EU-Brazil Summit Joint Statement. Brussels: Council of the European Union.

European Commission and HRVP. (2016, June 22). Elements for a New EU Strategy on China. Joint Communication to the European Parliament and the Council. Brussels: European Commission, High Representative of the Union for Foreign Affairs and Security Policy.

European Commission and HRVP. (2019a, March 12). EU-China-A Strategic Outlook. Joint Communication to the European Parliament and the Council. Brussels: European Commission, High Representative of the Union for Foreign Affairs and Security Policy.

European Commission and HRVP. (2019b, April 16). European Union, Latin America and the Caribbean: Joining Forces for a Common Future. Joint Communication to the European Parliament and the Council. Brussels: European Commission, High Representative of the Union for Foreign Affairs and Security Policy.

European Council. (2010). European Council Conclusions 16 September 2010. Brussels: General Secretariat of the Council.

Ferreira-Pereira, L. C., \& Vieira, A. V. G. (2016). Introduction: The European Union's Strategic Partnerships: Conceptual Approaches, Debates and Experiences. Cambridge Review of International Affairs, 29(1), 3-17. https://doi. org/10.1080/09557571.2015.1130341.

Furness, M., \& Gänzle, S. (2017). The Security-Development Nexus in European Union Foreign Relations After Lisbon: Policy Coherence at Last? Development Policy Review, 475-492. https://doi.org/10.1111/dpr.12191.

Grevi, G. (2013). The EU Strategic Partnerships: Process and Purposes. In M. Telò \& F. Ponjaert (Eds.), The EU's Foreign Policy: What Kind of Power and Diplomatic Action? (pp. 159-173). Globalisation, Europe, Multilateralism Series. Farnham, Surrey: Ashgate.

Mayer, H. (2013). The Challenge of Coherence and Consistency in EU Foreign Policy. In M. Telò \& F. Ponjaert (Eds.), The EU's Foreign Policy: What Kind of Power and Diplomatic Action? (pp. 105-117). Globalisation, Europe, Multilateralism Series. Farnham: Ashgate.

Murray, P. (2016). EU-Australia Relations: A Strategic Partnership in All but Name? Cambridge Review of International Affairs, 29(1), 171-191. https:// doi.org/10.1080/09557571.2015.1015487.

Renard, T. (2011). The Treachery of Strategies: A Call for True EU Strategic Partnerships. Egmont Paper 45. Brussels: EGMONT.

Renard, T. (2013). The EU and Its Strategic Partners: A Critical Assessment of the EU's Strategic Partnerships. In S. Biscop \& R. G. Whitman (Eds.), 
The Routledge Handbook of European Security (pp. 302-314). Abingdon: Routledge.

Renard, T. (2016). Partnerships for Effective Multilateralism? Assessing the Compatibility Between EU Bilateralism, (Inter-)Regionalism and Multilateralism. Cambridge Review of International Affairs, 29(1), 18-35. https://doi. org/10.1080/09557571.2015.1060691.

Schade, D. (2019a). Fuzzy Roles in EU External Relations Governance: The Difficult Construction of Informal Policy Coordination Frameworks. In L. van Heumen \& M. Roos (Eds.), The Informal Construction of Europe (pp. 199216). Abingdon: Routledge.

Schade, D. (2019b). Of Insiders and Outsiders: Assessing EU Strategic Partnerships in Their Regional Context. International Politics, 56(3), 375-394. https://doi.org/10.1057/s41311-017-0132-y.

Schade, D. (2020). The EU in Association Agreement Negotiations: Challenges to Complex Policy Coordination. Abingdon: Routledge.

Schmidt-Felzmann, A. (2016). The Breakdown of the EU's Strategic Partnership with Russia: From Strategic Patience Towards a Strategic Failure. Cambridge Review of International Affairs, 29(1), 99-127. https://doi.org/10.1080/ 09557571.2015 .1130096$.

Smith, K. E. (2017). A European Union Global Strategy for a Changing World? International Politics, 54(4), 503-518. https://doi.org/10.1057/s41311017-0041-0.

Smith, M. (2012). Still Rooted in Maastricht: EU External Relations as a "ThirdGeneration Hybrid". Journal of European Integration, 34(7), 699-715. https://doi.org/10.1080/07036337.2012.726010.

Smith, M. H. (2018). Does the Flag Still Follow Trade? Agency, Politicization and External Opportunity Structures in the Post-Lisbon System of EU Diplomacy. The Hague Journal of Diplomacy, 13(1), 41-56. https://doi.org/10. $1163 / 1871191 X-13010011$.

Tocci, N. (2017). From the European Security Strategy to the EU Global Strategy: Explaining the Journey. International Politics, 54(4), 487-502. https://doi.org/10.1057/s41311-017-0045-9.

Van Rompuy, H. (2010, September 14). We Have Strategic Partners, Now We Need a Strategy. Transcript of a speech by European Council President Herman Van Rompuy. Brussels: European Council.

Vivet, E., \& de Lalande, V. (2014). EU Strategic Partnerships: Shallow Political Summits, Active Technical Dialogues? Paris: Institute for Research and Education on Negotiation (IRENE). 


\title{
Soft Power in the European Union's Strategic Partnership Diplomacy: The Erasmus Plus Programme
}

\author{
Laura C. Ferreira-Pereira and João Mourato Pinto
}

\section{INTRODUCTION}

In March 2016, a few dozens of higher education students and young graduates from around the world were invited by the European External Action Service (EEAS) and Directorate General for Education, Culture, Youth and Sports (DG EAC) for a meeting in Brussels. They had in common the fact that they had participated in one of the several EUfunded exchange programmes, such as Erasmus or Erasmus Mundus, both of which were combined into the Erasmus+ Programme in 2014.

L. C. Ferreira-Pereira $(\bowtie)$

Department of Political Science and Research Center in Political Science (CICP-UMinho), University of Minho, Braga, Portugal

e-mail: lpereira@eeg.uminho.pt

J. Mourato Pinto

Research Center in Political Science (CICP-UMinho), University of Minho, Braga, Portugal

(C) The Author(s), under exclusive license to Springer Nature

Switzerland AG 2021

L. Ferreira-Pereira et al. (eds.), The European Union's Strategic

Partnerships, The European Union in International Affairs, https://doi.org/10.1007/978-3-030-66061-1_4 
The two-day meeting aimed at harvesting from the participants their understanding of the role that (higher) education could play in the EU's foreign policy. The Erasmus and Erasmus Mundus Alumni, who made it to the acknowledgement list of the Global Strategy, "stressed the important role the European Union plays in securing global peace and prosperity, by strengthening multilateral and bilateral partnerships and standing up for human rights, democracy and rule of law around the world" (EEAS 2016a: parag 2). For Erasmus and Erasmus Mundus Alumni, hereinafter Erasmus Alumni, the EU's soft power emanates from its "commitment to human rights, education and cultural exchange" associated with "a perceived lower security and military profile". Indeed, for them, "The Erasmus+ Programme is a prime example of a desirable soft power tool in which the EU should continue to invest. Its alumni can act as "multipliers" and "opinion leaders" in their respective countries". 1

Although the Global Strategy recognised that "soft power is not enough" (EEAS 2016b: 44), the document asserted that the EU "prided itself on its soft power" and was "the best in this field" (EEAS 2016b: 4). Moreover, it reinforced the Union's soft power toolbox that came to comprise several elements such as engagement with civil society and people-to-people contacts through education and research. Taken together, these elements aim at increasing the credibility of a Union whose ontological and teleological foundations have been shaken by successive crises since 2008 (see Chapter 2 in this volume). As this volume demonstrates in its various chapters, such crises have taken their toll on the EU's strategic partnership policy by eroding the perceived value of the Union as a strong and stable partner in world politics, economics and trade; and affected the external lure and influence of the "Model power Europe" (Ferreira-Pereira 2012) in different regions. Under these circumstances, various SPs lost their momentum, some entered a state of political stagnation and others were brought to a halt.

Despite these challenges, higher education is a domain enshrined in the key documents of the majority of SPs and seems to have remained relatively unaffected by their fluctuations. It also seems to have benefited from the communication channels and resources generated by the institutionalisation of differentiated bilateral relationships. In this regard, Brazil and Russia constitute particularly intriguing case studies for two

${ }^{1}$ Personal email sent by EEAS/DG EAC to João Pinto, 22/04/2016. 
major reasons. On the one hand, in both cases, the SP dynamic has come to a halt at the summitry level: the EU-Brazil SP has been in a state of suspended animation since 2014 (see Ferreira-Pereira in this volume); and the EU-Russia SP has been frozen particularly since it was voted down by the European Parliament in 2015, after the Russian annexation of the Crimean Peninsula (see Haukkala in this volume). On the other hand, as this chapter will illustrate, despite the diplomatic inertia the exchanges of students and university staff/researchers between the EU and these two parties has continued to grow steadily. This seems to demonstrate that, under the umbrella of SP, higher education has developed its own dynamic given the autonomous implementation of EU soft power instruments such as the Erasmus+ Programme. This generates a new insight into the operation of linkages outside the "high politics" of SPs.

Although the Erasmus+ Programme is one of the largest student exchange programmes of its kind, academic research devoted to its role and impact in European Foreign Policy is still scarce. Only a few exploratory studies have investigated the European case, but with a scope mostly limited to the Union's neighbourhood and looking at Erasmus+ as a tool for Europeanisation (Polglase 2013; Perilli 2017). Details and effects of the synergies between the Erasmus+ Programme and the EU's external action, namely its inherent soft power impact upon relations with strategic partners, have not yet received significant attention from the European foreign policy-related literature. ${ }^{2}$ To be sure, within scholarship dedicated to the study and examination of the EU's strategic partnership diplomacy there is no work that points out the significance of the Erasmus+ Programme as a soft power tool in articulation with the EU's relations with its strategic partners. However, rapid and diverse developments have taken place in the field of so-called education diplomacy which means that there is a lot of potential for academic enquiry.

This chapter attempts to fill part of this gap in the literature by exploring the concept of soft power in connection to the area of higher education and more specifically to the communities of alumni built around the Erasmus+ Programme. This exploration will be made against the backdrop of what can be seen as a democratisation of the

${ }^{2}$ For example, in the two-volumes of the SAGE Handbook of European Foreign Policy (2015), there is no single chapter devoted to this educational dimension of European foreign policy. The same applies to the book The Foreign Policy of the European Union by Stephan Keukelaire and Tom Delreux (2014). 
Union's SP, which has started gradually through the engagement of nongovernmental actors in the bilateral dialogues (Blanco 2016: 468). So the focus is on a "bottom up" and not "top down" view of the SPs. This links to this study's underlying argument about the persistence, the vitality and even strengthening of the educational links and networks set against the stagnation and erosion of the SPs in the broader sense.

The present chapter will examine the concept of soft power in juxtaposition to higher education before relating it to the EU context and specifically to the Erasmus+ Programme. Finally, it will examine the life beyond summitry animated by the Erasmus+ Programme in the illustrative cases of Brazil and Russia. This study's conclusion points out the growing role of higher education in sustaining the EU's relations with its strategic partners, especially those relations that with the passing of time ended up "suspended" and even "frozen" at the highest political level as a result of a combination of exogenous and endogenous factors.

Although revisiting some relevant earlier developments for contextualisation purposes, the analysis will focus mainly on the period between 2014 and 2020. The year 2014 saw the inauguration of a new and more robust Erasmus+ Programme, with reinforced funding and enhanced centrality in the EU's external action. It was also the year of the 7th EU-Brazil Summit, marking the end of a promising and celebratory phase of this bilateral relationship (see Ferreira-Pereira, this volume); and the year of the annexation of Crimea by Russia which represented a turning point in EU-Russia relations. The year 2020 corresponds to the end of the 2014-2020 funding cycle of EU programmes, the Erasmus+ Programme included, making it a relevant milestone for taking stock of what has been achieved and reflecting about possible further steps. This study draws not only on secondary sources, but also on empirical sources, notably documents produced by the Erasmus Student Network (ESN) (e.g. ESNsurveys), the European Commission (e.g. Erasmus Impact Studies) and original data collected from semi-structured interviews in Brussels with officials from the DG EAC, EEAS and a former member of the College of Commissioners over the course of 2019 and 2020.

\section{The Erasmus + Programme and the EU's Soft Power Operation in the World}

The existing literature underlines the role of higher education as an element of soft power in foreign policy (Nye 2004; Lima 2007; Atkinson 2010; Amirbek and Ydyrys 2014; Wojciuk et al. 2015). As Joseph S. Nye 
(2004: 12) puts it, "soft power rests on the ability to shape the preferences of others". Through a well-known and coherently implemented set of values, a country - or as a group of countries - can make other countries follow its leadership through their "co-optive power" which is "the ability to shape what others want" through "the attractiveness of one's culture and values" (ibidem). According to Nye, education is one of the many elements that can contribute to this goal, being an element of attraction and influence.

The brief analysis of relevant literature dedicated to the soft power dynamics underlying higher education shows that, there are evident similarities between the international ambitions of key players concerning the projection of education-related soft power and those that have been exhibited by the EU, before and after the launching of its Global Strategy. Chinese strategy for higher education and its links with foreign policy goals is a case in point (Hong 2014; Wojciuk et al. 2015; Bislev 2017). With an impressive number of nearly 970,000 Chinese higher education students ${ }^{3}$ studying abroad in $2017,{ }^{4}$ China sees each student as an element of its soft power strategy and public diplomacy game. While understanding the need to keep contact with these students, a Chinese governmental directive "suggests creating a network integrating domestic and foreign students and experts to propagate knowledge about the development of "the fatherland", thereby casting all Chinese overseas students in the role of potential "people-to-people ambassadors" (Bislev 2017: 82). While major global actors compete to spread their values, higher education is seen as a major vehicle because education is considered as a universal value (Wojciuk et al. 2015: 300), its traditional target (i.e. youth) and its relative affordability, especially when compared to hard power. Against this backdrop, higher education has become part of the battle for gaining influence in a rapidly changing multipolar world. And the EU has been striving to position itself as a forerunner, in a distinctive way.

Despite the absence of a shared understanding of the EU's soft power essence and scope, it is agreed that soft power projection has been a distinctive area of the EU's external action; and that among soft power

\footnotetext{
${ }^{3}$ Data retrieved from UNESCO Institute for Statistics. Table "Education: Outbound Internationally Mobile Students by Host Region".

${ }^{4}$ This includes the special administrative regions of Macao and Hong Kong, nearly 930,000 without them.
} 
resources employed by the EU to enhance its status as an actor of global influence, European culture, identity and its values stand out (Manners 2002). Some observers have already connected soft power dynamics with "the ability of the European Union to educate foreign students, set global constitutional norms and garner a worldwide following for athletic achievements" (Moravcsik 2017: 3). Considering the growing salience of the Erasmus+ Programme as a foreign policy tool, higher education has been a soft power means employed by the EU to boost cooperation and mobility towards its partner countries.

Significantly, the meeting mentioned in the beginning of this chapter culminated with a direct dialogue between the participants and HRVP Federica Mogherini-an Erasmus alumna herself-who "highlighted the crucial role of young people like the Erasmus Generation ${ }^{5}$ in building a foundation for mutual trust and cooperation in times of crisis". As she stressed: "The European Union is above all about people coming together. You play a crucial role in building a Europe that is open to the world" (EEAS 2016a: parag 4). Both the invitation of these students to Brussels and the outcome of their discussions unveil a strategic synergy built between the EEAS and DG EAC. This interinstitutional collaboration was built on the achievements of the Erasmus Programme, which has reached the impressive milestone of 10 million participants in three decades or so.

Since its creation in 1987, Erasmus has grown to become an EU flagship programme and a tangible symbol of its vision for the European country. Several studies, such as the Erasmus Impact Study of 2014 and 2019 have proven that its participants are among the most protective of the European project, are more positive towards the idea of living in another EU country and are more engaged in friendships or love relationships with other EU citizens. They are the European epitome of multiculturalism and the possibilities that the EU has brought to the European people.

What makes the programme particularly interesting is the fact that education is not an EU competence in any of its dimensions. Nevertheless, by adhering to the Erasmus+ Programme, higher education

\footnotetext{
5 The term "Erasmus Generation" does not have a clear definition, but it is widely used by the educational sectors of the European Union to describe a loose group of people, mostly alumni of the programme, who share a common and rather progressive vision for the European project.
} 
institutions (HEIs) in the different member countries must sign the Erasmus+ Charter for Higher Education, which is a shortlist of rules complemented with an extensive guide with plenty of instructions to which they all must abide. Although the EU does not regulate education in the same way it regulates trade, by having created and consistently increased the funding of its educational programme, it has managed to attract over 5000 HEIs to its sphere, thus effectively regulating part of their activity. Besides these, many other institutions are indirectly reached and involved, such as those based in the countries with which the EU has established and developed strategic partnerships.

In 2014, the Programme went through a revolution by absorbing most of the existing EU programmes in the field of education-something that helped to further boost its brand. As result, it is now comprised of six fields - adult education, higher education, school education, sport, vocational education and training, and youth-and also the Jean Monnet Actions. The activities within the newly designated Erasmus+ range from the exchange of students and staff, traineeships and high-level university partnerships to intergovernmental collaboration. Through the 14.7 billion euros assigned for the period 2014-2020, the programme has also funded alliances of universities that allow their students to take the courses they want in any participating institution, thus obtaining an European diploma. For the framework period 2021-2027, the EU is aiming at reaching 12 million participants, ${ }^{6}$ thereby more than doubling the number of Erasmus+ beneficiaries in just seven years. For this reason, Erasmus+ has become an overarching and multifaceted programme with a lot of untapped potential also in terms of impact upon the EU's relations with strategic partners, whose unfolding deserves more attention in the forthcoming years - not only in the political and diplomatic spheres, but also on the academic front.

All EU member states and six other countries-three EFTA members (i.e. Iceland, Norway and Liechtenstein) and three EU candidates (i.e. Serbia, North Macedonia and Turkey)—are full participants of the Programme, and are known as "programme countries". This means that they have access to all abovementioned dimensions and have an Erasmus+ National Agency in their country. Each Erasmus+ National Agency works

\footnotetext{
${ }^{6}$ Both numbers are a sum of the participants of the Erasmus+ Programme and its predecessor programmes.
} 
directly with both DG EAC, the respective national Ministry of Education, and all participating HEIs existing in their country, acting as a bridge between the local, national, and supranational levels. Erasmus+ National Agencies manage the Erasmus+ funding allocated to their country, which comes mostly from the respective EU budget line.

All other countries of the world, among which feature the strategic partners examined in this volume (i.e. the US, Canada, all the BRICS, Mexico, Japan and South Korea), are labelled as "partner countries". Most of these countries do not have direct access to Erasmus+ Programme funding to the extent that they are only able to use it through the establishment of partnerships with a programme country. However, there is a specific budget that enables the EU to work directly with these countries. This funding is the result of a partnership created between the DG European Neighbourhood and Enlargement Negotiations (DG NEAR), DG International Cooperation and Development (DG DEVCO) and DG EAC under the general supervision of the EEAS. This partnership, as an example of what the Global Strategy describes as a "joined-up approach", aims at capitalising on the soft power potential of the Erasmus+ Programme, building on its already existing international sub-programme-Erasmus Mundus. This sub-programme was created in 2003 by the then Commissioner Viviane Reding with the goal of "opening our universities to the world" since in a globalised world there was need for "people to understand each other - at least the intellectuals, at the least the graduates". It was called an "Erasmus Window" and gave the "opportunity to non-European states to create Erasmus agreements with Europe; and the first country that took this opportunity was China". ${ }^{7}$

The Erasmus Mundus programme which targeted mostly master students coming to Europe, quickly expanded into multiple dimensions, such as the Erasmus Mundus Joint Master Degrees, a prestigious action offered to both EU and non-EU citizens in networks of universities around the world. Selected students receive a scholarship "covering tuition, travel, and a living allowance. The programmes last from one to two years during which students study in at least two different European countries, and obtain a joint, double degree, or multiple degree" (European Commission 2020a: 1).

\footnotetext{
${ }^{7}$ Interview with Viviane Reding, Brussels, 2019.
} 
As of 2015, it became possible to undertake a classic Erasmus experience-without needing to complete a full Master's degree-between programme and partner countries, making it easier for students to spend between 3 and 12 months abroad and obtain full recognition for the credits. While the Erasmus Mundus Joint Master Degrees programme has been funded directly by the Erasmus+ Programme budget, the traditional semester or one-year-long exchanges, the so-called International Credit Mobility (ICM) modality, has been funded almost entirely by DG NEAR and DG DEVCO. These DGs have been splitting the funds in accordance with their own priorities after having divided the world into 13 different regions, to match the evolving priorities of the EU's external action. Five of these regions correspond to the European Neighbourhood-South, East, Western Balkans, and Russia (which has a region of its own)-and Central Asia. The countries in the European Neighbourhood have long benefited from the EU-funded Trans-European Mobility Programme for University Studies (TEMPUS), which was integrated into the Erasmus+ Programme in 2014. DG EAC maintains branches in each of these countries, called Erasmus+ Offices. Although having fewer resources and autonomy than the Erasmus+ National Agencies, they ensure a certain level of focus on the partnership with the EU through education. At the same time, they support the countries' HEIs in applying for funding and back up systemic change in the realm of higher education. The abovementioned five regions are funded mostly through budget made available by DG NEAR that uses education to build bridges between young people and universities in the EU and in its neighbourhood. ${ }^{8}$

Most of the other regions are funded primarily by the budget of DG DEVCO, which intends to support developing countries through education. These regions encompass Latin America, including Brazil and Mexico, and most of Asia, including India and China. Sub-Saharan Africa is another wide region, which does not include South Africa as the country constitutes its own Erasmus+ region. The countries in these regions do not have Erasmus+ Offices, which means that all educational matters are treated directly by their EU Delegations (EUD). One of the regions is comprised by the so-called industrialised countries which include some of the EU's strategic partners such as Canada, Japan, South

${ }^{8}$ Interview with DG EAC official in Brussels, 05/11/2019. 
Korea and the United States ${ }^{9}$ and is funded by the EEAS. Along these lines, it is interesting to note that the official ten strategic partners have not been treated as a coherent whole on the basis of a common integrated approach. Instead, they have benefited from different tools and arrangements while being accompanied institutionally by different DGs. This generally mirrors the prevalence of flexibility, not to say diffuseness, in the management of the strategic partnerships that is marked by various levels of selection, prioritisation and differentiation (see Chapter 2 in this volume).

To support its general work with these regions, the EEAS created the Partnership Instrument for Cooperation with Third Countries (PI), which was approved by the European Parliament and European Council in 2014, the first year of the new Erasmus+ Programme. This instrument, which is managed by the Service for Foreign Policy Instruments (FPI), aims at "providing direct support for the Union's external policies, expanding cooperation partnerships and policy dialogues to areas and subjects beyond development cooperation. It builds on the experience gained with industrialised countries and high-income countries and territories" (OJEU Reg. 234/2014, preamble). Building on a previous 2006 regulation, the new PI aims at giving more flexibility on how funding with specific countries can be used, especially beyond the traditional development dimension. Apart from the goals related to international cooperation and trade, the PI aims at "enhancing widespread understanding and visibility of the Union and of its role on the world scene by means of public diplomacy, people-to-people contacts, cooperation in educational and academic matters, think tank cooperation and outreach activities to promote the Union's values and interests" (OJEU Reg. $234 / 2014$, art. $1(2)$ ). To achieve this goal, a significant amount of the PI's $€ 955$ million budget (for the period 2014-2020) is allocated to the Erasmus+ Programme, especially to ICM. Since 2015, an additional amount is allocated specifically to the Jean Monnet Actions.

The PI is also an instrument for the EEAS to achieve the "Joined-Up Union" by fostering synergies between different EU programmes and institutions. At a legacy speech in Brussels, in October 2019, Federica Mogherini recalled that as Vice-President of the Commission, she held

\footnotetext{
${ }^{9}$ The other countries are the following: Australia, Brunei Darussalam, Chile, New Zealand, Singapore, Taiwan, Uruguay and the special Chinese regions of Hong Kong and Macao.
} 
frequent meetings with her colleagues with portfolios relevant for the EU's external leverage such as trade, science, and education (Mogherini 2019). These coordination meetings also take place at the level of the civil servants. Under the coordination of the EEAS, DG NEAR, DG DEVCO and DG EAC meet frequently to update each other on the work done with a specific country in the field of education. Together, they also decide which countries will be a priority in the next calls for funding, benefiting those who are more relevant for the EU's external action in that year. ${ }^{10}$ For example, in 2017, the PI targeted "activities reinforcing the study, research, teaching and debate on European Union-related-issues among students and academics through Jean Monnet Actions in a selection of priority countries", among which stood the following strategic partners: China, India, Mexico, Russia, South Africa and the US. By then, the EU recognised that in view of "a more connected, complex and contested world (...) the way the EU engages with citizens in third countries needs to adapt"; and "Partnership Instrument supports the implementation of EU Foreign Policy objectives by strengthening the EU's ability to engage meaningfully with selected audiences in third countries (i.e. students/academics, multipliers/influencers, civil society and cultural operators/artists) in order to increase mutual understanding, improve the perception of the EU and of its policies and, ultimately, facilitate future cooperation" (European Commission 2017: 2).

The importance of the PI for the EU's soft power was reinforced by the findings of a 2015 study on the external perceptions of the EU and Europe. This study, funded by the European Commission, was conducted by an independent research team and targeted the ten strategic partners of the EU. Based on interviews with representatives of governments, academia, think tanks, the media, young people, and organisations connected to businesses and civil society, such study aimed ultimately at "facilitating a more meaningful and effective EU engagement globally" including better understanding how to engage locally more effectively and "rethinking of the EU narrative" (FPI 2015a: 4). The study drew important conclusions about how the strategic partners perceive the EU at different levels and various dimensions and have ultimately confirmed the need for the EU to invest in people-to-people contact. Generally, it concluded that the media mostly reports the most dramatic EU events,

${ }^{10}$ Interview with DG EAC official, Brussels, 05/11/2019. 
such as the sovereign debt crisis and Brexit; and that there is barely any media coverage about the Union's achievements. The most wellknown aspect about Europe is its culture and there is in general a good opinion about its leadership in world. Equally important, the study recommends better promotion of the Erasmus+ Programme as an opportunity for citizens of the EU's strategic partners to experience Europe and increase their general understanding of both the continent and Union. Hence, one of its major recommendations pointed out that "contact with Europe (living, visiting or having relatives in Europe) clearly supports more positive views on the EU; in the same vein, people who felt sufficiently informed about the EU tended to have more positive attitudes" (ibid.: 20). Given that the strategic reliance upon the Erasmus+ Programme as an element of soft power was just emerging at that time, the study also indicated that "educational programmes of the EU have the least visibility among the images connected with the EU", since only 9.5\% of survey respondents "have definitely heard about the Erasmus Programme" (ibid.: 4).

The evidence provided by the European Commission funded-study made a strong case for the EEAS to consolidate education as an element of the EU's soft power by using its PI mechanism. Concretely, the PI is used to enhance people-to-people contact and the partnership with civil society organisations on the ground, two concrete aims that resonate with the Global Strategy. Ultimately, all boils down to building trust and understanding by working directly with two main strands of targets: students and university staff, on the one hand and organisations and influencers close to them, on the other. ${ }^{11}$ To work on both strands, and following the recommendations of the study mentioned above, the synergetic work between the EEAS and DG EAC has already led to the opening of a new project named EU Alumni Engagement Initiative. This project was conceived to connect alumni of several EU programmes, ${ }^{12}$ when they return to their home country. The pilot phase of the project, which ran from 2018 to 2020 with a budget of 2 million euros, focused only on the ten EU SPs and Indonesia, which hosts the headquarters

${ }^{11}$ Interview with EEAS official, Brussels, 28/10/2019.

${ }^{12}$ Here we refer to Erasmus+, Jean Monnet, Schuman-Fulbright, Marie SkłodowskaCurie Actions, European Union Visitors Programme, Global Cultural Leadership Programme, EU-China interpreters programme, EU Voluntary Service, and EU Solidarity Corps. 
of ASEAN, an organisation that is building its own exchange programme with EU support. Through this project, the EEAS intends to partner with Erasmus+ Alumni organisations, such as the Erasmus Student Network and the Erasmus Mundus Alumni Association and EUDs to organise events across these eleven countries. Besides the physical connection, the project includes the creation of an online database through which the Erasmus Alumni will receive information directly from the EU and will be able to connect virtually with each other. This is expected to create new and more opportunities for networking and increase the EU's outreach capacity among a population that has become more fond of the Union thanks to the period it spent studying in Europe. ${ }^{13}$ This gained even more critical importance in view of impactful developments springing from the COVID-19 pandemic. In the next cycle of EU Programmes (2021-2027), the PI is likely to grow and to gather under its umbrella a "menu of programmes", 14 including Erasmus+ and its related initiatives, that the EUDs will be able to use to increase the EU's soft power in their countries.

\section{The Erasmus + Programme and Strategic Partnerships: The Cases of Brazil and Russia}

It is a relevant question to ask to what extent the EU's soft power strategy underpinning the Erasmus+ Programme has produced concrete effects in the framework of its developing relations with the strategic partners. Among these, Russia and Brazil stand out as two interesting study cases given some common traits they exhibit, despite various perceptible differences existing between them. While both countries belong to the BRICS group, their historical relationship with the EU, also conditioned by geographical factors, has been considerably different. The EU's SP with Russia began to be forged at the end of the 1990s in the ambit of the EU's Common Strategy on Russia, before the country was formally acknowledged a SP in the European Security Strategy of 2003. On the other hand, Brazil was the last country of the original BRIC group (i.e. without South Africa), with whom the EU established a SP in 2007. In

${ }^{13}$ Interview with EEAS official, Brussels, 28/10/2019.

${ }^{14}$ Interview with EEAS official, Brussels, 28/10/2019. 
the context of the Erasmus+ Programme, exchanges with South American countries have been mostly covered by DG DEVCO, particularly through its Development Cooperation Instrument. On the other hand, exchanges with Russia have been largely funded through the European Neighbourhood Instrument of DG NEAR. Additionally, both countries receive some support from the EEAS via the PI and local coordination by the respective EUDs. Since 2014, both countries have also been the target of a DG EAC-funded project entitled "Enhancing the Attractiveness of European Higher Education in the World" which has organised "Study in Europe" fairs in various locations to attract more Russian and Brazilian students to Europe. It also included the creation of a Brazilian network and a Russian network of "European Higher Education Experts", ten in each country, trained by the EU to support with the organisation of the local information fairs and better assist students interested in enrolling in European universities.

The perceptions of the two countries vis-à-vis the EU differ. In the light of the abovementioned study on the perception of the EU abroad, an average of $63.3 \%$ of the interviewees across the ten strategic partners agreed or strongly agreed with seeing the EU as an important partner for education exchanges. Nevertheless, while over $72.6 \%$ of Brazilians agreed or strongly agreed with this statement, only $53.7 \%$ of Russians conveyed the same opinion. Overall, more Brazilians (34.3\%) than Russians (23.5\%) thought they had seen, heard, or read about the Erasmus Programme (FPI 2015b: 118). Yet, as the following sections will show, many more Russians than Brazilians study in the EU. That said, promoting mutual collaboration in the domain of higher education constituted a common goal of both Brazil and Russia in the context of their strategic partnership with the EU.

\section{Brazil}

Brazilian interest in deepening its participation in the Erasmus Programme was conveyed in the EU-Brazil Joint Statement of July 2007 that initiated formally the bilateral privileged relationship. More concretely, this was made in connection to the (last) goal or milestone entitled "Bringing our people together" (Point 16). Here, one reads that both actors "agree to expand further EU-Brazil cooperation in higher education by intensifying university exchanges under Erasmus Mundus..." (Council of the European Union 2007). Interestingly, this 
is the first strategic partnership framework document to make an explicit reference to higher education as a platform for bilateral collaboration. Brazilian longstanding concerns with the matter of social inclusion may well help to explain this pioneering aspect since the joint statement further underlines that: "Both sides stress that quality education for all is an important task for social inclusion" (ibidem). This goal had been originally conveyed in the Commission's Communication to the Council and Parliament of May 2007 where it had announced the allocation of an additional 30.5 million euros for Erasmus Mundus scholarships for Brazilian students for the period 2007-2013 and had stressed the need for a "policy dialogue on education to exchange best practice" (European Commission 2007a: 14). Such ambition was inspired by the fact that at the time Brazilian students had already shown significant interest in the Erasmus Mundus programme, "making Brazil the leading country in the Programme", according to the Brazil Country Strategy Paper 2007-2013 (European Commission 2007b: 15). Youth exchanges, a sub-programme for the exchange of young people outside the formal education system were also mentioned as a form of collaboration in the Strategic Partnership.

Against the backdrop of the Erasmus+ Programme's evolution, the Brazilian interest would be consistently reaffirmed in all EU-Brazil joint statements; and the country's ambitions in the field of education would expand. The second joint statement issued in 2008 and the first Joint Action Plan approved in the same year for the period 2009-2011 mentioned, under the heading "promoting people-to-people contacts and cultural exchanges", collaboration in other fields besides higher education, namely vocational education and training. It also pointed to an increased collaboration between EU and Brazilian universities through programmes like Jean Monnet. The promotion of European and Brazilian universities in specialised fairs and the willingness showed by both parties to better engage minorities in the existing opportunities has showed the continued attention and salience ascribed to the field.

This was specially so since the creation in 2009 of a dialogue on education conceived to improve the collaboration mainly in the domain of higher education. Based on a routine of annual meetings that began in 2011 , this sectoral dialogue has further engaged higher education experts, academics, university staff and decision-makers. Policy development, efficiency of education systems, recognition of non-formal education and quality assurance have featured among the topics addressed under the 
umbrella of this dialogue. During this period, bilateral cooperation intensified with a meeting between the Brazilian Minister for education and the European Commissioner in charge of education held in 2011. The second Joint Action Plan, envisaged for the 2012-2014 period, laid the base for the organisation of a Brazil-EU Seminar on Academic Mobility, Internationalisation, and Innovation in Brasilia in 2013. The following year saw the organisation, in Brussels, of an EU-Brazil Rectors Forum on Internationalisation, Innovation and Entrepreneurship in Higher Education in the sequence of the seventh EU-Brazil Summit. By 2014, Brazilian representatives had also attended two Bologna Policy Forums, ${ }^{15}$ as observers.

The last EU-Brazil Summit was organised in 2014 and the optimistic tone that marked the ensuing political declarations did not bear fruit in the subsequent years that were marked by successive crises, both of internal and external nature, on the two sides of the Atlantic. Since then the EU-Brazil SP has been living in limbo when it comes to interactions at the summitry level (see Ferreira-Pereira, this volume). That being said, as a result of the creation of the PI, the progressive reinforcement of the EEAS and the wide network of EUDs around the world, the SP continued in operation on the ground, at more technical levels, away from the spotlight characteristic of the summitry organisation. Therefore, some sectoral dialogues, notably that related to education, remained alive and active between 2014 and 2020 despite the absence of EU-Brazil summits. Incidentally, it is worth noting that until 2014, the academic field received particular attention from President Dilma Rousseff, with the exchange of students and scholars experiencing a considerable expansion (Saraiva 2017: 13).

This discrete/quite "down to earth" life of the SP has been supported by the EU-Brazil Sector Dialogues Support Facility (SDSF), established in 2008, alongside the first Joint Action Plan, which has since then supported over 30 different sectoral dialogues. This is a structure run by the Management Secretariat of the Brazilian Ministry of Economy, the Brazilian Ministry of Foreign Affairs, and the EUD in Brazil, all under a PI-funded budget of four million euros for the period 2015-2020. Being considered since 2006, the early days of the SP planning and moulding,

15 The Bologna Policy Forum is an event gathering the EU, UNESCO, ministerial representatives, higher education experts and other stakeholders to discuss the development of the higher education sector. 
the SDSF supported, between 2008 and 2016, over 228 dialogue actions with 68 Institutional Partners (41 Brazilians and 27 Europeans) across the 30 dialogues. ${ }^{16}$ And despite the inertia plaguing the organisation of high-level bilateral summits since 2014, the SDSF continued to support the preparation of events and visits both in Brazil and in the EU.

After 2014 bilateral collaboration became particularly visible in the numbers of students, professors, and non-academic staff that spend a period abroad every year. Looking at the ICM type of exchange, which in this case is funded mostly by DG DEVCO, between 2015 (the first year of this type of exchange) and 2019 Brazil sent 1148 students and staff to the Erasmus+ Programme Countries that, in turn, sent 745 participants to Brazil. The difference in the numbers of students coming to and going from Europe is explained by the design of the Programme itself, which allocated more funding to bring non-Europeans into Erasmus+ Programme Countries. In total, Brazil got $22 \%$ of the budget reserved for the Latin American region during this period, followed by Chile with $13 \%$. In comparison, Mexico, the other SP in the region, got $11 \%$ of the budget. Considering that, as earlier mentioned, funding is distributed in accordance to the priorities of the EU's external action, such figures illustrate well the importance ascribed to Brazil (Fig. 4.1).

To these numbers, one can add the 538 students who, between 2014 and 2019, won a scholarship for an Erasmus Mundus Joint Master Degree. Also, in the same period, four Brazilian HEIs joined international Jean Monnet networks and 15 Jean Monnet projects were directly awarded to Brazilian HEIs increasing the opportunities to teach and learn about the EU in Brazilian universities (European Commission 2020a).

Finally, education has been a motor for the strengthening of EU-Brazil relations in multilateral fora, as reflected in the creation of a EU-LAC Common Area of Higher Education, a goal of the EU-CELAC (Community of Latin American and Caribbean States) Action Plan 2015 (EU-LAC Foundation 2020). In an attempt to replicate the successes of the European Higher Education Area, this initiative, according to Mariya Gabriel, European Commissioner for Innovation, Research, Culture, Education and Youth, aims at developing "quality assurance, accreditation and evaluation systems, which are the basis for academic mobility and mutual recognition of study periods and diplomas" (Gabriel 2020: parag 4).

\footnotetext{
${ }^{16}$ Retrieved from the website of the Sectoral Dialogues European Union Brazil (2020) "Background".
} 


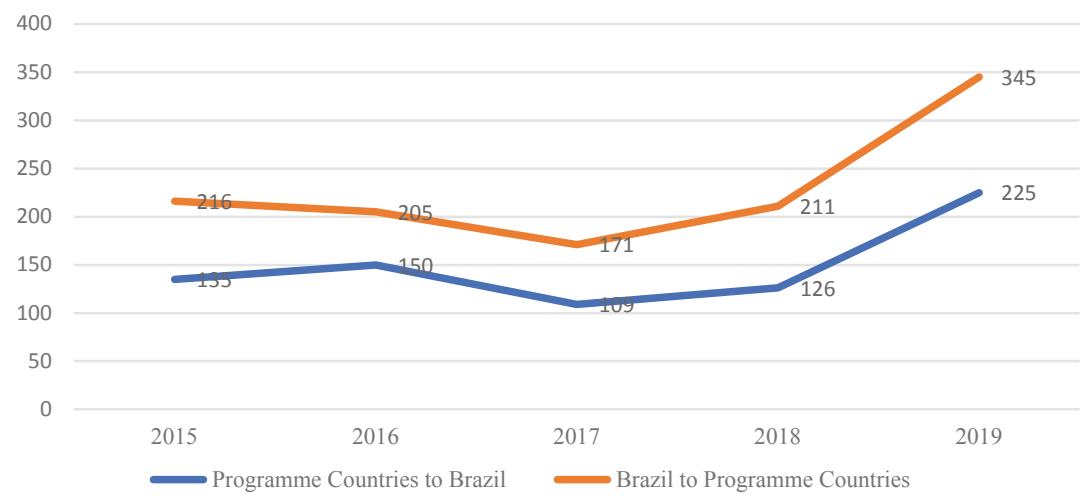

Fig. 4.1 Number of students and staff (academic and non-academic) participating in Erasmus+ exchanges between Erasmus+ Programme Countries and Brazil (2015-2019) (Source European Commission 2020a)

While using Erasmus+ as one of its mechanisms, it helps to increase the number of student exchanges between Latin America and the EU, further intensifying the use of education as a diplomatic tool. Through an EUCELAC strategic partnership strengthened over the years (Gabriel 2020), the EU creates more opportunities to engage with Mexico and Brazil, its two strategic partners in the block.

\section{Russia}

There is ample evidence that Russia's cooperation with the EU in the field of higher education is even deeper than that developed with South American partners, both in terms of historical trajectory and scope. This is so considering that Russia, as a participant in the former TEMPUS programme, has been developing exchanges with the EU for over 30 years. Moreover, this country joined the Bologna Process in 2003 and, consequently, became a member of the European Higher Education Area. Since then, the links between the two actors' higher education systems expanded. After the creation of the four EU-Russia Common Spaces in 2005, the two actors have further engaged themselves in a specialised education-related dialogue within the Common Space on Research, Education and Culture, which was designed "to reinforce people-to-people contacts" (European Commission 2005: parag 12). A 
major goal of this dialogue, which is closer to the heart of this discussion, was to "encourage integration and closer co-operation" (Council of the European Union 2005: 49) within the then emerging European Higher Education Area. Among the different actions envisaged to achieve this goal, the participation of Russia in the (then recently created) Erasmus Mundus Programme, as well as the intensification of youth exchanges outside of the formal education system were foreseen (Council of the European Union 2005).

As a result of the creation of Erasmus+ in 2014, the TEMPUS office was transformed into an Erasmus+ Office; at the same time as close ties with DG EAC and the EUD in Moscow were kept. The introduction of ICM in 2015, supported by the PI and the European Neighbourhood Instrument (funded by DG NEAR) offered a renewed and stronger setting for a formal dialogue with Russia on higher education. This particular aspect made exchanges between the EU and Russia in this field more natural and easier. Not surprisingly, 9\% of the Erasmus+ Programme 2014-2020 budget for the whole world of partner countries was earmarked for Russia alone. Due to its size and relevance, the country corresponds to an individual Erasmus+ region, with "Study in Europe" fairs being organised frequently in different national locations to promote more Russian students' mobility across Europe. Between 2015 and 2018, 11127 Russians, both university staff and students, spent a period in Europe and 8112 Europeans did the same in Russia. Interestingly, Russian students are not as interested in obtaining Erasmus Mundus Joint Master Degrees scholarships as their Brazilian counterparts-only 241 between 2014 and 2019, so less than half of Brazilian students. On the other hand, the interest in Jean Monnet activities was also quite high with 1079 applications from Russian HEIs between 2014 and 2019, representing $17.5 \%$ of the applications from the whole world. Of those, $130(8.7 \%$ of the total $)$ were selected for funding and eight Russian HEIs have joined international Jean Monnet networks during the same period (European Commission 2020b) (Fig. 4.2).

These numbers and figures alone stand in contrast with the fact that according to the study on external perceptions, mentioned earlier, Russia was the only strategic partner with an overall negative impression of the EU which was described as "hypocritical" and "arrogant", as voiced by both the Russian political elite and the media (FPI 2015a: 14). And more so with the circumstance that since 2015, in the sequence of a European Parliament vote, Russia ceased to be considered a strategic partner 


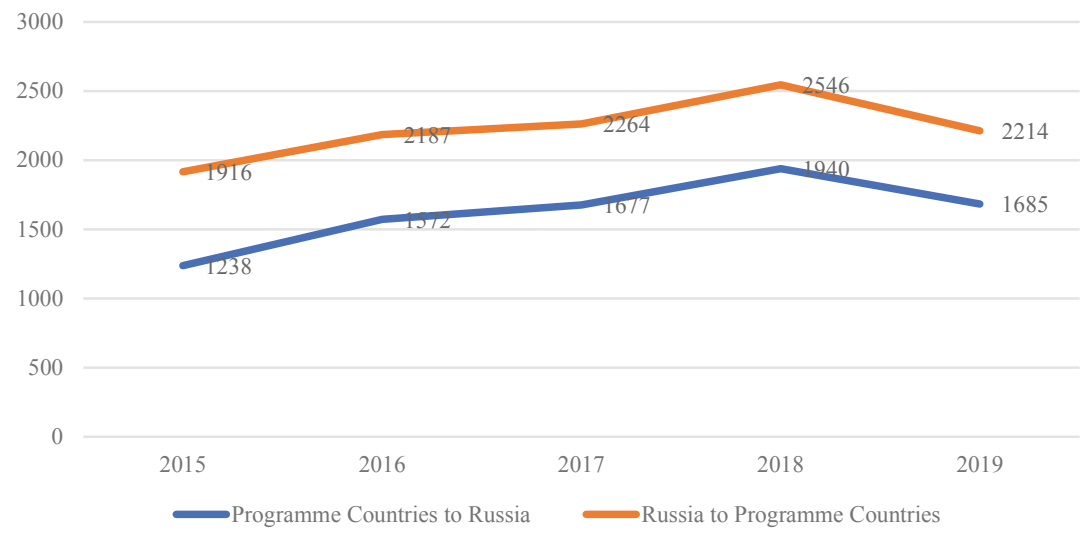

Fig. 4.2 Number of students and staff (academic and non-academic) participating in Erasmus+ exchanges between Erasmus+ Programme Countries and Russia (2015-2019) (Source European Commission 2020b)

of the Union (see Chapter 2 in this volume). For this reason, as underlined by the members of the European Parliament, the EU needed to "devise a soft-power contingency plan to counter Russia's aggressive and divisive policies" (European Parliament 2015: parag 1; emphasis added). In March 2016, the EU foreign ministers and the HRVP stipulated five guiding principles for EU-Russia relations among which stood out the "support for people-to-people contacts" (Council of the European Union 2016: 4), a goal that would then be enshrined in the Global Strategy launched in June 2016. When referring to EU relations with Russia, the Global Strategy proposed a "selective engagement" over matters of European interest which included "education, research" besides climate, the Arctic and maritime security. Moreover, it said that: "Engagement should also include deeper societal ties through facilitated travel for students..." (EEAS 2016b: 33).

In the period 2014-2017, funding allocation to EU-Russia collaboration was reduced in most domains, with the notable exception of areas such as education and public diplomacy (Valenza and Bossuyt 2019). Interestingly, the priority actions for the PI in 2018-2020 included Russia as a priority country and envisaged support for civil society cooperation through a direct grant to the EU-Russia Civil Society Forum, and the organisation of EU Film Festivals in the country. These initiatives are 
justified with the need to improve the EU's image in the eyes of the Russian public opinion. Such an image has been considerably affected by the EU sanctions since Russia felt directly affected by them although, according to the Commission, they "are designed to put pressure only on individuals and companies directly involved in the Ukraine crisis" (European Commission 2017: 11). Hence, through the PI and other instruments supporting education, the EU aims to find a balance between sanctioning the actions of Russia in Crimea and fostering a positive opinion about the EU among Russian public opinion. This is indeed a complicated task given the state control of Russian media and the fact that most EU outreach capacity is limited to Moscow and border regions (Valenza and Bossuyt 2019).

\section{CONCLUSION}

This chapter has examined how the Erasmus+ Programme, among other EU higher education programmes, has integrated the EU's soft power toolbox; and to what extent it has contributed to sustaining the bilateral dynamics of the EU's SPs, especially in the cases that the strategic rapport ended up "suspended" and even "frozen" at the highest political level. The cases of the SPs with Brazil and Russia featured as paradigmatic examples of this.

Despite the fact that exchange programmes such as Erasmus+ and its predecessors have long been used to generate "people-to-people" contacts, the introduction of this aim in the Global Strategy in 2016 has created conditions for their consolidation as soft power tools in the EU's foreign policy, namely in its diplomatic stance vis-à-vis its strategic partners. Thousands of students and university staff have benefited from these programmes since their inception over 30 years ago, creating links that eventually brought participants closer to each other in cultural, social and academic terms.

One can say that the trajectory of the Erasmus Programme has reflected the three logics of the EU's foreign policy (i.e. the internal logic, the external logic and the identity logic) alluded to in Chapter 2 of this volume. In its early stages, the programme was imagined to develop an eminently internal logic. In the 1990s, upon the impact of the fall of the Berlin Wall, there was a need to create novel tools that could bring all Europeans together, from East and West; and the Erasmus Programme paved the way for people/citizens from both sides to meet each other, 
thereby supporting a future EU enlargement to the East. Such need was felt not only by the European Commission, which worked towards increasing the citizenship dimension of the EU, but also within different member states, notably Germany, who were willing to build more solid bridges with the countries that belonged to the former Soviet bloc. As globalisation expanded, the EU needed to better prepare the future European elites for a more competitive job market against the backdrop of a more interconnected world. Following this external logic, the EU identified the opportunity structure to open the Erasmus programme to the world by creating its Mundus branch. But, the idea of including it deliberately in the EU's soft power toolbox was not there yet. ${ }^{17}$ The identity logic informed Erasmus as the world became more competitive and the values underpinning the EU's external action started to be increasingly challenged. As of 2014, with the creation of the ICM modality in Erasmus+ and through the funding of the PI, Erasmus became a dynamic tool to promote the EU's values and interests in the world, as the Global Strategy would acknowledge later.

Brazil and Russia are cases in point since from the outset their SPs with the EU included support for academic exchanges with the goal of increasing mutual trust and understanding. When these SPs came to a halt in 2014-2015, there were channels between universities and higher education experts that over the years had been put in place, relying since 2014 on the support of funding made available through the PI and the Erasmus+ Programme. This has allowed the SPs to be sustained at the "bottom" or more technical level, despite the continued inertia at the highest level. The case of the EU-Russia SP is particularly striking: while the country has ceased to be perceived as a strategic partner and the SP has been lying in shambles for five years, bilateral collaboration in the framework of the Erasmus+ Programme has grown fast, potentially sowing the seeds for a future re-set of EU-Russia relations at the highest political level. This has allowed one to conclude that the life of a given SP is not totally dependent upon or sustained by the intergovernmental dimension embodied in summitry. To be sure, there is life beyond the realm of bilateral summits, which has been generated mostly by peopleto-people connections based on exchanges of students and university staff,

${ }^{17}$ Interview with Viviane Reding, Brussels, 2019. 
(both academic and non-academic) between the EU and its strategic partners. Considering that the issue of "people-to-people contacts" is written into or assumed in all of the SPs, this calls into question academic enquiry that tends to give almost exclusive attention to what falls into the remits of inter-state politico-diplomatic elites interactions and activities.

As the number of students and staff exchanges continues to grow against the backdrop of the salience ascribed by the Global Strategy to "people-to-people contacts", it becomes relevant to re-evaluate the impact of the Erasmus+ Programme and its related programmes in the SPs' public perception of the EU. This is so considering that there is room for improvement regarding the familiarity of the Brazilian and Russian citizens with these programmes. The introduction of the EU Alumni Initiative can contribute to a better capitalisation of the EU investment in these students, by allowing Brussels to create a worldwide community of some of its stronger supporters. Incidentally, within the EU programming framework for the 2021-2027 period, most instruments funding the "international dimension" of the Erasmus+ Programme will be merged under a single Neighbourhood, Development and International Cooperation Instrument, which is expected to have a specific budget to support educational programmes. However, such actions will have little effect without vision and proportionate resources allocated to the international dimension of the Erasmus+ Programme. While some vision has been instilled in the Global Strategy, it remains to be seen how the EEAS will make use of the enormous potential of the EU's exchange programmes to further shape a differentiated global diplomacy.

The COVID-19 pandemic poses new challenges and opportunities for Erasmus+ in the EU's global diplomacy, encompassing relations with its strategic partners. In June 2020, the Council of the EU issued the resolution "Youth in External Action" (Council of the European Union 2020), highlighting how young people around the world are especially exposed to the economic recession provoked by the pandemic and how access to education, including through the Erasmus+ Programme is a part of the solution. In the final part of its resolution, the Council invited the Commission, in cooperation with the High Representative and the Member States, "to devise an action plan and to develop adequate toolkits to ensure that EU's external action contributes to the meaningful global engagement of youth at all levels in all regions" (ibidem: 7). Given the health authorities' recommendations for social distancing, such contribution from the Programme may well occur through new online platforms 
developed to promote "online exchanges". This is likely to support the expansion of the EU's digital soft power, thereby increasing exponentially its capacity to reach out to people.

Acknowledgments The authors acknowledge that this study was conducted at the Research Center in Political Science (UIDB/CPO/00758/2020), University of Minho/University of Évora, and was supported by the Portuguese Foundation for Science and Technology (FCT) and the Portuguese Ministry of Education and Science through national funds.

\section{REFERENCES}

Amirbek, A., \& Ydyrys, K. (2014). Education as a Soft Power Instrument of Foreign Policy. Procedia-Social and Behavioral Sciences, 143, 501-503.

Atkinson, C. (2010). Does Soft Power Matter? A Comparative Analysis of Student Exchange Programs 1980-2006. Foreign Policy Analysis, 6, 1-22.

Bislev, A. (2017). Student-to-Student Diplomacy: Chinese International Students as a Soft-Power Tool. Journal of Current Chinese Affairs, 46(2), 81-109.

Blanco, L. F. (2016). The Functions of 'Strategic Partnership' in European Union Foreign Policy Discourse. Cambridge Review of International Affairs, 29(1), 1-19.

Council of the European Union. (2005, May 10). 15th EU-Russia Summit. Road Map for The Common Economic Space-Building Blocks For Sustained Economic Growth Annex 1. Moscow.

Council of the European Union. (2007, July 4). EU-Brazil Summit Joint Statement. Lisbon.

Council of the European Union. (2016, March 14). Outcome of the Council Meeting. Brussels.

Council of the European Union. (2020, June 5). Youth in External Action. Brussels.

EU-LAC Foundation. (2020). Matrix of Objectives, Strategies and Initiatives for the Construction of the EU-LAC Common Area of Higher Education. EU-LAC Newsletter 05/2020.

European Commission. (2005). EU-Russia: The Four "Common Spaces". Brussels: European Commission.

European Commission. (2007a). Communication from the Commission to the European Parliament and the Council-Towards an EU-Brazil Strategic Partnership. Brussels: European Commission.

European Commission. (2007b). Brazil Country Strategy Paper 2007-2013. Brussels: European Commission. 
European Commission. (2008). Brazil-European Union Strategic Partnership Joint Action Plan. Brussels: European Commission.

European Commission. (2011). Brazil-European Union Strategic Partnership Joint Action Plan. Brussels: European Commission.

European Commission. (2014). The Erasmus Impact Study: Effects of Mobility on the Skills and Employability of Students and the Internationalisation of Higher Education Institutions. Luxembourg: Publications Office of the European Union.

European Commission. (2017). Annual Action Programme 2017 (Phase 1) for the Partnership Instrument for Cooperation with Third Countries. Annex 14. Brussels: European Commission.

European Commission. (2019). Erasmus+ Higher Education Impact Study. Luxembourg: Publications Office of the European Union.

European Commission. (2020a). Erasmus+ for Higher Education in Brazil. Brussels: European Commission.

European Commission. (2020b). Erasmus+ for Higher Education in Russia. Brussels: European Commission.

European Commission Service for Foreign Policy Instruments (FPI). (2015a). Analysis of the Perception of the EU and EU's Policies Abroad: Executive Summary. Brussels: FPI.

European Commission Service for Foreign Policy Instruments (FPI). (2015b). Analysis of the Perception of the EU and EU's Policies Abroad: Final Report Annexes. Brussels: FPI.

European External Action Service. (2016a, March 17). Mogherini Discusses EU Global Strategy Priorities with Erasmus Alumni. Brussels.

European External Action Service. (2016b). Shared Vision, Common Action: A Stronger Europe: A Global Strategy for the European Union's Foreign and Security Policy. Brussels: European Commission.

European Parliament. (2015). Russia Is No Longer a Strategic Partner of the EU, say MEPs. Brussels: European Parliament.

Ferreira-Pereira, L. C. (2012). The European Union as a 'Model Power': Spreading Peace, Democracy and Human Rights in the Wider World. In F. Bindi \& I. Angelescu (Eds.), The European Union Foreign Policy: Assessing Europe's Role in the World (pp. 293-305). Washington, DC: Brookings Institution Press.

Gabriel, M. (2020). Academic Cooperation with Latin America and the Caribbean. EU-LAC Newsletter 05/2020.

Hong, N. Y. (2014). EU-China Education Diplomacy: An Effective Soft Power Strategy? European Foreign Affairs Review, 19, 155-172.

Lima, A. F., Jr. (2007). The Role of International Educational Exchanges in Public Diplomacy. Place Branding and Public Diplomacy, 3(3), 234-251. 
Manners, I. (2002). Normative Power Europe: A Contradiction in Terms? Journal of Common Market Studies, 40(2), 235-258.

Mogherini, F. (2019, October 9). Legacy Speech at the conference "Walking the Strategic Talk: A Progressive EU Foreign Policy Agenda for the Future". Foundation for European Progressive Studies (FEPS), Brussels.

Moravcsik, A. (2017, April 13). Europe Is Still a Superpower and It's Going to Remain One for Decades to Come. Foreign Affairs.

Nye, J. (2004). Soft Power and Higher Education. Forum for the Future of Higher Education.

Official Journal of the European Union. (2014). Regulation (EU) No 234/2014 of the European Parliament and of the Council of 11 March 2014 Establishing a Partnership Instrument for Cooperation with Third Countries. Brussels: European Union.

Perilli, A. (2017). Erasmus Student or EU Ambassador? People-to-People Contact in the European Neighbourhood Policy: The Cases of Georgia, Ukraine and Tunisia. Bruges Political Research Papers, 59.

Polglase, G. (2013). Higher Education as Soft power in the Eastern Partnership: The Case of Belarus. Eastern Journal of European Studies, 4(2), 111-121.

Saraiva, M. G. (2017). The Brazil-European Union Strategic Partnership, from Lula to Dilma Rousseff: A Shift of Focus. Revista Brasileira de Politica Internacional, 60(1), e009.

Valenza, D., \& Bossuyt, F. (2019). A Two-Way Challenge: Enhancing EU Cultural Cooperation with Russia. CEPS Policy Brief 2019/02.

Wojciuk, A., Michałek, M., \& Stormowska, M. (2015). Education as a Source and Tool of Soft Power in International Relations. European Political Science, $14,298-317$. 


\section{The Transatlantic Partners: The United States and Canada}




\title{
The European Union and the United States: Competition, Convergence and Crisis in a Strategic Relationship
}

\author{
Michael Smith
}

\section{INTRODUCTION}

This chapter explores the often-contradictory elements embodied in the most significant of the EU's strategic relationships, that with the US, and asks whether the contradictions have now become so intense as to constitute a threat to the EU-US partnership. Historically, the partnership has been characterised by a mixture of competition, convergence and crisis: competition in the global political economy in particular, but also increasingly in areas of security and underlying values; convergence in the face of external threats, especially from the Soviet Union during the Cold War but also from a range of powers in the post-Cold War world, expressing not only common security interests but also similarities of economic organisation and underlying values; crisis brought about

M. Smith $(\bowtie)$

PAIS, University of Warwick, Coventry, UK

e-mail: M.H.Smith@warwick.ac.uk

(C) The Author(s), under exclusive license to Springer Nature

Switzerland AG 2021

L. Ferreira-Pereira et al. (eds.), The European Union's Strategic

Partnerships, The European Union in International Affairs, https://doi.org/10.1007/978-3-030-66061-1_5 
by the periodic fluctuations of US leadership and EU followership, by external change both in the political/security and in the political economy dimensions of transatlantic relations and world order, and by institutional and policy challenges rooted in domestic political change.

The distinctive character of the EU-US relationship lies partly in the fact that although it has always had a strategic component, it has never been declared as a formal 'strategic partnership' and embodied in the kinds of agreements around which other strategic partnerships have centred. During the 1960s, there were sustained efforts on the part of mainly American commentators to identify the components of an 'Atlantic Community' or 'Atlantic Partnership', but these were strongly contested, whilst during the 1970s and 1980s the nature of US leadership, the impact of change in the world economy and the later stages of the Cold War led to as many recriminations as statements of partnership (Grosser 1980; Smith 1984; Winand 1993; Tsoukalis 1986; Patel and Weisbrode 2013). During the past thirty years, there have been many agreements in specific areas of policy and declarations of common interest, but the extent and complexity of the relationship have meant that it has been resilient despite (or perhaps because of) the lack of a 'transatlantic treaty' between the EU and the US. That said, there are important agreements that have been central to the development of the relationship in the postCold War world: for example, the Transatlantic Declaration of 1990, the New Transatlantic Agenda and Action Plan of 1995, the mutual recognition agreements of the late 1990s and early 2000s, and the Economic Partnership agreements of the period after 2008. Behind much of this cooperation in political economy and 'soft' aspects of security, there has also stood the North Atlantic Treaty Organisation (NATO) - not an EUUS organisation, but one without which arguably the EU-US relationship could not have developed in the ways that it has (Sloan 2016; Howorth 2014; Rees 2009).

The current period in the EU-US relationship has posed challenges to the EU in all of its core areas. In terms of political economy, it has uncovered the tensions created by the shifting nature of power in the global arena and by the differing responses of Brussels and Washington in areas such as trade, finance, energy and the environment. In terms of security, it has generated controversy around not only the changing nature of security itself and the EU's capacity to respond to it, but also the changing approaches of both the EU and the US to the management of their security relationship. In the area of values, it has posed the 
challenge of potential and actual divergence between 'normative power Europe' and the increasingly nationalistic tone of US diplomacy under the Trump administration. Thus, it is appropriate to ask how the relationship has evolved in the post-Cold War period, in what ways it currently constitutes a 'strategic partnership', and how it might evolve in the foreseeable future.

The chapter addresses the following areas. First, it explores the ways in which the post-Cold War period gave rise not only to a new and creative period in the EU-US partnership (e.g., through the New Transatlantic Agenda and its related Action Plan and later through the Transatlantic Economic Partnership) but also to new areas of fluidity and tension in both transatlantic security relations and the management of the transatlantic political economy. This part of the chapter focuses on the tension between new institutional arrangements and the challenges of the global arena in a period of economic and security turbulence.

The second and most substantial part of the chapter focuses on the tensions and crises emerging from the growth of the EU as a foreign policy actor, the attempts of the US to restore global leadership in a changing security order, the failed attempts to negotiate a Transatlantic Trade and Investment Partnership and the growing perceptions of a crisis in the transatlantic relationship since 2016. The chapter thus explores the diplomatic challenges presented to the EU by the policies of the George W. Bush, Barack Obama and Donald Trump administrations since the early 2000s, and the ways in which these have led to changes in the EU-US relationship.

The third part of the chapter assesses the scope, scale and effectiveness of the EU's attempts to manage the fluctuations of transatlantic relations over the past decade, and especially since the advent of the Trump administration. This will entail an exploration of the EU's developing system of diplomatic management and of the ways in which the challenges posed by US foreign policy have been more or less effectively met. The chapter conclusions explore the ways in which the balance between competition, convergence and crisis has shifted in contemporary EU-US relations, and the extent to which the relationship can still be (or could ever have been) characterised as a 'strategic partnership' of the type studied in this volume. The argument thus returns to the key themes of the volume, dealing with the functional motivations, the policy focus, the institutional dimensions and the identity/role aspects of EU-US relations, and relates these 
to the complex system of competition, convergence and crisis that has characterised the relationship in the post-Cold War period.

\section{After the Cold War: Building}

\section{a Strategic Partnership?}

In the immediate aftermath of the fall of the Berlin Wall, there is no doubt that leaders in both the EU and the US saw the opportunity for new forms of partnership as a contribution to the consolidation of a new world order (Niblett and Wallace 2001; Keohane and Hoffmann 1993). The problem was that whilst they could agree on the need for transatlantic partnership, especially in the stabilisation and restructuring of Europe, their versions did not coincide. Whilst the Americans saw the EU as playing a key role in stabilising the continent through rapid and large-scale enlargement to include ex-Soviet bloc states, those in Brussels were also concerned with the stabilisation and development of the EU's internal order, as the basis for further expansion and integration. On the one hand, in the US view, the EU was to be an agent for the new US-led order; but on the other hand, for EU leaders, there was the possibility of playing a larger and more consequential role founded in the consolidation of the EU order (Smith 2007; Smith and Woolcock 1993; Niblett and Wallace 2001; Keohane and Hoffmann 1993). The wars in former Yugoslavia during the early and mid-1990s revealed the limitations of any EU role in 'hard security', but also the limitations of the US desire to engage in conflicts where there was not an immediate US national interest. These and other security challenges also revealed that for many (including a number of EU member states) the primary security organisation for Europeans and Americans was NATO (Sloan 2016: Chapter 6). As a result, the 1990s were characterised by attempts to find bridging mechanisms between an EU that was simultaneously enlarging and developing its security and defence identity and a NATO that was still dominated by the US but which itself was engaged in a major enlargement exercise and seeking out new roles.

This set of tensions did not preclude the development of key components in what might be called a strategic partnership between the EU and the US. In 1990, alongside other major end-of-Cold War agreements, the European Community (as it still was) and its member states signed the Transatlantic Declaration, which established a set of broad priorities and institutional arrangements for cooperation, both on economic 
issues and on broadly-defined security questions (remembering that at this stage, there was no CFSP, let alone CSDP) (Schwok 1991). In 1995, this was greatly expanded with the agreement of the New Transatlantic Agenda and an accompanying Transatlantic Action Plan-the latter covering 150 areas of potential joint action in political economy, security (other than military security) and what would today be called 'people to people contacts' (Peterson 1996; Featherstone and Ginsberg 1996; Pollack and Shaffer 2001). Alongside these agreements went the development of a series of transatlantic dialogues, the most significant of which was initially the Transatlantic Business Dialogue (Green Cowles 2001a, b), but which came to include legislative, environmental, employment and other networks. These dialogues could be seen as functionally equivalent in some ways to the sectoral and other dialogues that have come to characterise strategic partnerships between the EU and its other partners, as explored in other chapters of this volume. Between the late 1990s and the early years of the new century, these agreements and dialogues formed the framework for the EU-US relationship. Although plans for a Transatlantic Free Trade Area were proposed, they did not come to fruition-but a series of mutual recognition agreements (MRAs) did emerge, with varying degrees of effectiveness, to cover areas of EU-US trade and regulatory policy (Pollack and Shaffer 2001; Pollack 2005). Significantly, in these processes, the EU was the partner, rather than member states, although there were inevitable tensions between the two levels of European engagement. By 2007, there had also been agreed the beginnings of a Transatlantic Economic Partnership, with the establishment of mechanisms to ensure continued dialogue between the two sides of the Atlantic (McGuire and Smith 2008: Chapter 2).

These elements of what might be described as a strategic partnership were challenged by developments in the areas of security and global governance. As noted above, the tension between the EU and the US over the development of post-Cold War security structures was a continuing influence on any attempts by the Union to establish itself as a partner for the US in 'hard security'. This was crystallised in many ways by the US Secretary of State, Madeleine Albright, in 1999 when she pronounced what became known as the ' 3 Ds': no duplication of security efforts by the EU, no decoupling of Europe from the US and no discrimination in EU security policies between EU members and non-members (such as Turkey, a prominent member of NATO) (Howorth 2014; Sloan 2016: 
Chapter 6). The development of the CSDP around the turn of the millennium saw repeated underlining of the message that NATO should remain the primary transatlantic security institution, whilst efforts were made, for example, through the so-called Berlin Plus arrangements to ensure EU access to NATO assets if they needed them (Howorth 2014).

At the same time, in the broader domain of global governance, further tensions arose. Apart from the almost traditional disputes over trade policy within the World Trade Organization, allied to US apprehensions about the introduction of the Euro as a currency for many EU member states, the sharpest differences emerged over climate change and the agreement of the Kyoto Protocol on control of emissions, and then over policies to deal with war crimes and transnational terrorism (Smith 2005; Peterson and Pollack 2003). The EU was one of the most enthusiastic promoters of the Protocol, whilst the US eventually refused to ratify it, thereby throwing into question its implementation (which relied on its being ratified by a certain number of countries representing a certain proportion of carbon emissions). In similar fashion, the EU and its member states were strong supporters of the establishment of an International Criminal Court, whilst the US opposed it and refused to adhere to it. Policies to counter the threat of terrorism highlighted US dependence on the use of 'hard power' and the EU's necessary reliance on 'soft power' instruments, but it was clear that in these areas the EU had more leverage simply because of its well-developed mechanisms of policy and security coordination (Rees 2009). These brief examples provide a different perspective on any EU-US strategic partnership in the early years of the twenty-first century-they testify to continuing major differences not only over material interests but also over institutions and values, and they also cast doubt upon the capacity of the EU to be a strategic partner for the US in general (Smith 1998).

These differences over values arose in many ways from domestic politics. Within the US, although the Clinton administrations of 1993-2001 promoted the values of the 'Third Way' between naked capitalism and socialism, it was clear that the political centre of gravity was well to the right of that within the EU, where highly regulated social market economies were the norm and where globalisation was often seen as a threat to be defended against. Different EU member states had very different perceptions of the appropriate relationship to the US, and these intersected with the differences on issues such as global governance outlined above. Above all, different EU member states had markedly 
different attitudes to the leadership provided by the US in general and the ways in which this created risks and potential costs for them (Smith 1999). Such differences were to become especially pronounced in the period after 2003, to such an extent that they called into question any notion of a strategic partnership between the EU and the US.

\section{The Anatomy of a Transatlantic Crisis: 200I-2009}

During the George W. Bush administrations in the US (2001-2009), the tendencies outlined above came to dominate EU-US relations, to such an extent that the basic idea of transatlantic partnership was called into question. The Bush administrations were dominated by the search for a restoration of US primacy in the global arena, in the face of major challenges, and it might be argued that EU-US relations were collateral damage in this broader reassertion of US power (Smith 2009). As before, it can equally be argued that relations varied considerably between issue areas, and that the picture in political economy was very different from that in the high politics of security or in the ideological contest centred on values. From the point of view of this chapter, the key argument relates to the absence of any notion of a comprehensive strategic partnership between the EU and the US, and the implications of this absence.

The political economy of EU-US relations during the period 20012009 was conditioned sharply by the fact that the EU was in many respects an equal of the US, capable of carrying out trade and commercial policies in a strategic way and strengthened by the initiation of the Euro and Economic and Monetary Union (EMU). The competition in which the EU engaged with the US was carried out on several levels. First, within the global multilateral system, the EU was capable of withstanding US challenges and retaliating if necessary, in areas as diverse as the trade in bananas, steel and large commercial aircraft (McGuire and Smith 2008; Smith and Woolcock 1999). The EU could act strategically to protect the interests of its member states as a whole and could use multilateral institutions to defend itself and legitimise its actions. Second, the enlargement of the Union to Central and Eastern Europe between 2004 and 2007 provided both new challenges and new opportunities for Brussels, and further growth of scale in political economy at a time when the US was preoccupied with security concerns. Third, the EU could act within and shape the ways in which sanctions were imposed by the US on a variety of targets, including Iran and Afghanistan, linking commercial and security 
concerns in new arenas. Finally, the EU was able to use its resources in development policy to pursue democratisation and good governance in areas where the US was not fully engaged, such as the Middle East and North Africa, and to begin the construction of its network of strategic partnerships with emerging powers, especially China (see Chapter 9 in this volume; Renard and Biscop 2012). The strategic nature of these and other encounters between the EU and US in the global political economy is clear, but so is their competitive nature.

Considerations of political economy, however, were strongly conditioned by the emergence of a full-blown transatlantic crisis in security. The precipitating factors here were those concerned with the impact of transnational terrorism, most spectacularly through the attacks on New York and Washington on 1lth September 2001 ('9/11') and with the subsequent 'global war on terror' proclaimed by the Bush administration, which spilled over into more conventional interventions in Afghanistan (2001) and Iraq (2003). Despite initial solidarity between the EU, its member states and the US, and significant cooperation in areas such as police cooperation and the financial aspects of counter-terrorism, these interventions created a major rift not only between the EU and the US but also between EU member states, whose alignments for and against US policies led to an internal crisis in the EU's foreign and security policies (Lindstrom 2003; Lindstrom and Schmitt 2004; Pond 2004). In turn, these transmitted themselves into tensions within NATO and in global organisations such as the United Nations. US policies that made a distinction between 'old' and 'new' Europe, and which attempted to accentuate the divisions between the members of the Union, were a potent contribution to a full-blown transatlantic crisis, which was only gradually resolved (and then not completely) during the years 2005-2008 (Zaborowski 2006; Lundestad 2008). Any talk of the need for a transatlantic strategic partnership in security, in which the EU could be a key element, was significantly damaged by these events-but they did lead to further discussion of the need for effective EU external action in high politics, which in turn contributed to the negotiation and entry into force of the Lisbon Treaty (2009). Most notably, in 2003, the EU agreed its first European Security Strategy (European Council 2003), which presented a stark contrast with the US National Security Strategy; whereas the ESS emphasised the need for multilateral cooperation to deal with global threats, the US strategy rested upon the assumption that it was better to get retaliation in first if a threat was identified, and that material power including 
the use of force was not only acceptable but a preferred means of action (Dannreuther and Peterson 2003).

The issues arising between the EU and the US were not simply those of material interests, whether these were centred on commercial or on security concerns. The 'utopian radicalism' of the Bush administrations and the propensity to intervene were at odds with the EU's self-image of itself as a 'force for good' and a 'normative power'. In many ways, the US can also be seen as a normative power (Smith 2009, 2011a), but it was also clear that there was a deep normative gap between the 'sovereignist' and interventionist tendencies displayed in US foreign policy and the more civilian and 'soft power' centred positions adopted by the EU (Smith 2004). Not only this, but the divergences in approaches to global governance and regulation already pointed out were accentuated by the events of the early 2000s, in such a way that advances in transatlantic cooperation could be effectively ruled out. This, though, rather overstates the rift between the EU and the US. In commercial policy, there were the beginnings by 2007-2008 of deeper cooperation, through the Transatlantic Economic Partnership and its provisions for high-level consultations over potential disputes, whilst as already noted there were areas of cooperation in counter-terrorism policy that played to the strengths of the EU as a civilian security actor (Steffenson 2005; Rees 2006, 2009). Nonetheless, the continued tensions between EU member states over US interventions and the divide over new forms of global governance and regulation continued until the end of the Bush administrations. Notably, the divisions and sense of crisis did not substantially affect what might be described as the infrastructure of EU-US relations: the networks of private investment, production and exchange that have contributed to the development of the transatlantic economy and that in many ways are the key elements in the evolution of transatlantic partnerships. But such elements were in many ways at odds with the broader crisis at the governmental level that pervaded much of the period 2001-2009.

\section{A More Strategic Relationship? 2009-20i7}

Barack Obama was the President that (almost) all Europeans wanted after the crises and tensions of the Bush years, and many leaders of EU member states were only too eager to present themselves in Washington at the start of his first administration. The same goes for leaders of the EU institutions, and it might have been expected that a new drive for the 
establishment of some kind of formal 'strategic partnership' would be declared. But this did not happen, and for a variety of reasons. The first was that both the EU and the US were in the throes of dealing with the global financial crisis, which began as a problem in the US leveraged mortgage market and rapidly spread to Europe as well as to other parts of the world. The second was that the US administration set out not to conclude any kind of overarching partnership, but rather to persuade individual EU member states to play their roles as partners in security-and to wait for the implementation of the Lisbon Treaty before they would even consider anything more comprehensive and far-reaching. In many ways, this chimed with the position in the EU itself: the new external action provisions of the Treaty would not enter into full effect until the end of 2010, and the European External Action Service (EEAS), the new diplomatic service of the EU headed by the High Representative for Foreign Affairs and Security Policy who was also a Vice-President of the European Commission (HRVP), was not established even in skeleton form until the beginning of 2011 . Not unnaturally, there was a period of considerable introspection on both sides of the Atlantic-but from the point of view of this chapter, the key issue is whether as Obama's eight years in office unfolded, there was the prospect of anything more than pragmatic adjustment and adaptation.

In the economic sphere, and not just because of EU-US interaction, there was a search for something multilateral to help deal with the crisis and to reinvigorate the rules-based international system. The EU and the US were key players in the establishment and consolidation of the G-20, representing the world's largest economies, and in the halting progress towards some kind of agreement in the WTO's Doha Development Round of trade negotiations (Jokela 2011; Woolcock 2012). It can be argued that in both of these cases, there was more convergence than competition between the transatlantic partners; but it can also be argued that this convergence took place against a backdrop of major power-shifts in the global arena that vastly reduced its impact (Alcaro et al. 2016). As a result, whilst the EU and the US might wish to act strategically in the global political economy, it was becoming markedly less receptive to their initiatives. In the same vein, the major transatlantic trade policy initiative which led to intensive negotiations from 2013 onwards for a Transatlantic Trade and Investment Partnership represented perhaps the biggest single attempt since the Second World War to achieve shared transatlantic rules 
and institutions, and thus can be seen as key evidence for EU-US convergence; but at the same time, it aroused concerns everywhere else in the global political economy, and because of its potentially intrusive nature, it created major opposition within many EU member states (De Ville and Siles-Brugge 2016; Morin et al. 2015; Young 2016). In addition, the US was engaged simultaneously in attempting to conclude a Trans-Pacific Partnership, which in many observers' eyes was a higher priority than the TTIP and would take precedence over the EU-US negotiations. The growth of 'competitive interdependence' (Sbragia 2010; Damro 2014) also entangled both the EU and the US in negotiations with a range of partners aimed at producing bilateral or inter-regional free trade agreements (FTAs). This complex and interconnected context precluded any easy conclusion of an EU-US partnership agreement and indeed created a new set of tensions to be managed.

In the domain of security, both the EU and Obama's US were determined to retreat from the confrontations and interventions of the Bush years, but again events and broader structural trends militated against grand transatlantic agreements - and as noted above, the administration was also determined to persuade its allies to play their part in the management of existing interventions, especially those in Afghanistan and Iraq (Smith 2011b). Given the limitations of any potential EU contribution to these processes, it is not surprising that the major focus of attention was NATO and individual member states - these, after all, were the centres of 'hard power' and the basis for any material contributions. At a very early stage, the Americans had decided that there was little prospect of getting the EU to do anything, and so effectively the Union was marginalised. This did not prevent the development of EU military and civilian missions in zones of conflict-but it was explicit in these cases that they should be based on a UN mandate, rather than on any kind of contract with the US or any other individual state (Howorth 2014). One episode in which these tendencies did come together-but not altogether happily-was in the intervention by France and the UK in Libya, which was informed by the NATO perspective, with the US 'leading from behind' in an area where the EU had had a long-standing partnership agreement as part of the Barcelona Process (Koenig 2011; Renard 2011). In principle, the EU's prior engagement with the MENA (Middle East and North Africa) region as part of its 'southern neighbourhood' should have fitted it for a major role in the revolts that came to constitute the 'Arab Spring' from 2011 onwards, but as the process developed into one of hard power 
and violence the EU was effectively marginalised. Some of the same was true in the case of Ukraine after 2013, although the EU had considerably greater leverage through its Eastern Partnership programme and associated funding (MacFarlane and Menon 2014; Haukkala 2016).

In all of these cases, there was no suggestion of any broad EU-US collaboration; in fact, there were strong elements of competition in crisis management at various stages. In the broader world arena, the key US move was a 'pivot' to Asia and what has become known as the IndoPacific region, partly to counter Chinese influence-but here, the EU had almost nothing to say, beyond associating itself with various declarations from Washington (Christiansen et al. 2019: 129-133; Pennisi di Floristella 2019). One apparent exception to this pattern was in the negotiations over Iranian nuclear policies, where the EU through the HRVP provided a means of facilitating a complex and highly-charged diplomatic effort, and where the so-called EU-3 (France, Germany and the UK) provided a strong EU presence at the level of the interstate negotiations. There is debate about how far this EU presence contributed to the eventual agreement, and about its longer-term implications (see below) but there is no doubt that it represented a substantial achievement for the EU's new system of diplomacy (Sauer 2015; Geranmayeh 2017).

Security thus presented a complex picture in EU-US relations during the Obama years. Rather less complex, at least on the surface, was the relationship in terms of values and ideas. The Obama administration was in favour of multilateralism and the liberal international order, and in its 2010 Quadrennial Diplomacy and Development Review actually called for the development and deployment of its 'civilian power' in a wide range of areas (US Department of State 2010). At the same time, the EU's new system of diplomacy was actively directed towards the use of economic and administrative resources in pursuit of its normative goals, whether through trade agreements, development assistance or broader diplomatic initiatives (Smith et al. 2016). As a result, it might have been expected that there would be a good deal of convergence between the two partners-and indeed, the evidence outlined above seems to support this proposition. The problem is that this convergence at the level of Washington and Brussels was not replicated either in US domestic politics or in the internal politics of the EU and its member states. As a result, the absence of joint EU-US initiatives that were actually implemented is striking, in a period when in theory they were undoubtedly easier to launch. This was not simply a reflection of domestic constraints: 
the development of a multipolar world characterised by the emergence of new or resurgent 'powers', and the return of geopolitical calculations to the realm of everyday diplomacy, formed an unpromising backdrop to any major transatlantic initiatives. The securitisation of many areas in which the EU had long had an interest as a civilian or normative power, such as environment, energy, human rights and democracy promotion, also militated against any such attempts.

\section{CRISIS AND BREAKDOWN: 20I6-2020}

Whereas Obama had been the President virtually all Europeans had wanted, Donald Trump was the President virtually no European had expected, and one whose very essence appeared to centre on contestation and the fomenting of crisis. The combination in 'Trumpism' of nationalism, protectionism and 'domesticism' encapsulated in the proclamation that 'America First' would be the guiding principle of the administration's policies, created not only uncertainty about the commitment of the US to existing structures and policies in transatlantic relations, but also a linkage to the perceived surge of populism in Europe itself-a surge which raised questions about the legitimacy and effectiveness not only of national regimes in the EU but also of the European project more generally. The style of the President's approach to interactions with both allies and adversaries was frequently described as 'transactionalist', rejecting principles and existing affiliations in pursuit of 'the deal', and applying a strictly utilitarian calculus to the value of allies and partners (Smith 2021a, Forthcoming). Not for nothing was it questioned whether the President was capable of developing or applying a 'grand strategy' (Dombrowski and Reich 2017) beyond a simple search for short-term satisfaction and advantage.

Alongside the mercurial nature of the President's approach to foreign policy, a number of commentators also raised more fundamental questions about the US administration's commitment to the post-1945 'liberal order' (Ikenberry 2017, 2018; Stokes 2018; Peterson 2018), and by implication to any kind of strategic relationship (let alone a partnership) with the EU. Given that the European integration project from its inception has been integrally connected with this version of international rules, institutions and values, the challenge in transatlantic relations has always been there-but the challenge posed by the Trump administration was of a different order. Where its predecessors at least gave lip service to the idea 
of transatlantic order and to the notion of the EU being a key pillar of the liberal world order, the Trump administration initially had a severely transactional view of the world. It categorised the EU as a consistently under-performing ally and even-according to the President-a 'foe' in many areas of activity, and pressed it to deliver in practice the European support habitually promised in rhetoric. It also set out to undermine key pillars of the multilateral world order and global governance, with its attacks on the World Trade Organization, on the Paris Climate Accords and other organisations such as UNESCO (Smith 2021a). In a way, this was an extreme version of the established contrast between the EU as process-oriented and rules-focused and the US as results-oriented and 'sovereignist' in international dealings. But it was also accompanied by a tendency towards divide-and-rule tactics-tactics that were strengthened by the UK's Brexit defection. For the EU, this underlined the dilemmas of 'followership' in an age of increased economic and political-security risk. It also served to highlight the continuing contrast between the EUUS relationship in the global political economy and in the realm of hard security, and the difficulties of establishing any kind of understanding as the basis for a partnership.

This context of uncertainty and the forces tending to contestation of the transatlantic relationship within Washington were magnified by continuing policy uncertainty and instability within the EU. As already noted, the effects of the UK referendum on exiting the EU in 2016 reverberated within the Union and became linked with the impact of 'transnational nationalism' in leading member states, as well as in a number of Eastern European members (Smith 2018a, 2021b). The challenge to the established order was seen to diminish with the defeat of populist forces in the Netherlands and France, but was underlined by election results in Germany (with the rise of the AfD), Italy and Austria. Whilst responses to the Trump administration by Angela Merkel, Donald Tusk and others expressed, the view that it would be unwise to rely on Washington, and that the US should be seen as a source of challenge rather than a source of support, these views were themselves framed within a context of continuing uncertainty about the EU's role within Europe as well as in the framework of transatlantic relations (Smith $2018 \mathrm{a}, \mathrm{b}$ ). Whilst the EU's Global Strategy (EEAS 2016) called for the pursuit of 'strategic autonomy' as a key principle of external action (and such autonomy was bound to impact transatlantic relations), it was clear that among member states there was sometimes a more traditional and 
'sovereignist' approach to foreign policy more generally, and that this interacted with broader transatlantic and global trends to throw into question the nature of a 'strategic Europe' (Biscop 2019). Whatever the balance between these two elements, and their interaction with transatlantic tensions, there was little basis for any acts of strategic convergence between the two sides of the Atlantic.

From this brief sketch, it is clear that the Trump challenge led to extensive contestation and to a sense of crisis in EU-US relations. This was the case not only in respect of political economy and commercial competition, but also in terms of security and 'high politics', and in terms of the kinds of norms and values subscribed to by the putative partners. Whilst Washington (or rather, the Trump White House) challenged in such areas as the Iran nuclear agreements of 2015 and the Paris Climate Accordsboth of them areas that linked very strongly to the EU's self-perception of its international role and its approach to global governance-it also increasingly confronted the EU (not to mention the entire rules-based international order) in trade and investment, with the 'America First' policy extending to a growing range of commodities and national security criteria being applied both to these and to proposed investments in the US (Peterson 2018; Smith 2018a). Whilst it might be argued that all of this was really aimed at a non-European target (China), more important in some ways was the corrosive effect such actions might have on the broader liberal order, on which the EU depends so heavily. The net result was that by 2020 , the very idea of an EU-US strategic relationship, let alone a strategic partnership, was challenged; this was epitomised in late 2019 by the stance of the new President of the European Commission, Ursula von der Leyen, who called for a new focus on the EU as a 'power' with a focus on geopolitics rather than on norms and the rulesbased order (Rachman 2019). Whilst this might contribute to the idea of the EU as a more strategic actor, it also put the Union on course to collide more consistently with the US administration's external actions and preferences. The air of crisis persisted through 2020, with further tensions centred on the ways in which the Union and the US reacted to the crisis caused by COVID-19; internal tensions between EU member states about freedom of movement and the sharing of resources were linked to transatlantic differences about the necessity for international cooperation (prioritised by the EU, rejected by the US), whilst at the same time frictions continued over Iran and the US drive to re-impose 
an arms embargo, trade with China and policies towards Russia, among other areas.

\section{Conclusions: A Strategic Relationship, But Not a Strategic Partnership?}

The analysis in this chapter has focused quite strongly on 'history'-on processes of change and continuity in EU-US relations, in ways that might not be appropriate in the study of other strategic partnerships. One reason for that is clearly that EU-US relations have a long and complex 'back story': the US was present at or before the creation of the European project and has remained the most significant other for the EU in a wide range of policy domains. A second reason is that this history matters to the evolution of the EU-US strategic relationship, and to the ways in which successive transatlantic crises have been defined and (usually) managed. A third reason is that throughout its course, the EU-US relationship has been open to processes of change in the broader world arena-from the origins of the Cold War through to the impact of 'rising powers' and beyond. These processes of change have shaped and re-shaped the transatlantic relationship, and at the same time, they have influenced its salience and the extent of its dominance in the world order. The first area on which these conclusions will focus is that of the EU's place in this changing and complex system, and its capacity to assert itself in the management of transatlantic relations; the second area is framed by the key questions at the heart of this volume, relating to functions and motivations, policy focus, institutions, identity and roles. On the basis of these two linked areas, it should be possible to make some final judgements on the extent to which transatlantic relations form any kind of 'strategic partnership'.

There is no doubt that over the past two decades, the EU has equipped itself more appropriately to form and frame a 'strategic partnership' with the US. The growth of CFSP and CSDP, the external action provisions of the Lisbon Treaty and the terms of the ESS and now the Global Strategy have equipped the Union in principle to inject itself into new areas of potential transatlantic cooperation and thus to realise the internal logic' of institutional and policy development. At the same time, and in line with the 'external logic' of EU foreign policy, the emergence of new challenges and the fluctuations of US leadership have created openings through which the EU might assert itself and create a new balance in EU-US relations. But this has not happened-or at least, not in an 
organised and strategic way. One reason for this can be found in the internal tensions within the EU, both economic and political, which have underlined the difficulties of achieving strategic unity among 28 (now 27) member states and have opened the Union up to the potential for 'divide-and-rule' processes. When the EEAS was established, its officials were fond of referring to 'one message, many voices', but the reality has been more fragmented and variable than this implies. Whilst this is noticeable in other EU strategic partnerships, it is only the US that can reach the parts that no other strategic partner can reach, and nurture 'special relationships' with each of the twenty-eight. At the same time, the fact that the US has an impact in every area of EU external action has made the achievement of 'joined up policy-making' as advocated in the Global Strategy, and the expression of an 'identity logic' in external action much more challenging than in the case of other strategic partnerships. So, although the EU has become better-equipped in principle to establish a strategic partnership with the US, it has been much less able to do so in practice than might have been anticipated.

Does this mean that analysis should focus instead on the extent to which the EU might develop as a strategic rival to the US? After all, the erosion of trust and the growth of uncertainty in transatlantic relations, most notably but not only during the Trump administration after 2016, coupled with the cultivation of a wide range of alternative strategic partners for the Union, might provide evidence for this line of analysis. The evolution of a global opportunity structure that supports a new assertiveness by the EU outside the transatlantic area, and the sheer difficulty of constructing a comprehensive strategic partnership with Washington, might seem to support such an argument. But it is here that we must be aware of the limitations to the EU's collective capacity to act strategically on the global level and to achieve effective partnerships across a wide range of different interests and values. Not only this, but the opportunity structure that seemed open to EU initiatives in the late 1990s, for example, has since progressively become more closed with the resurgence of geopolitics and geo-economics-areas in which the EU has a chequered history (e.g. in the MENA region and Eastern Europe) over the past two decades.

One qualification to this analysis should be entered. A focus solely on the intergovernmental level when talking about EU-US relations and the potential for partnership or rivalry is misleading, since it ignores the major elements of transgovernmental and transnational linkages that 
support the relationship. These dimensions have been partly recognised in the development and implementation of transatlantic dialogues, but they are far more extensive in what might be termed the private governance of EU-US relations, with the engagement of large firms, networks of non-governmental organisations and professional bodies. There is a lot of evidence that EU-US relations constitute a 'networked partnership' in which governmental and non-governmental bodies interact and help to sustain the relationship. Whilst this might not be termed a 'strategic partnership' in the conventional (somewhat hierarchical) sense, there is strong evidence of the resilience of such a multidimensional infrastructure and of the importance of economic and social interactions in creating a sense of transatlantic community. Whether this kind of 'bottom-up' generation of partnership is capable of mitigating the fluctuations of partnership and rivalry at the inter-governmental level is an open question, even after around seventy years of deepening relations between the US and the European integration project.

This rather mixed and negative verdict can be clarified by reference to the four key questions around which this volume revolves. First, it is clear that questions of functional motivation in EU-US relations are complex and fluctuating, conditioned by the balance (and disparities) of power between the two putative partners, by the scope and multi-level character of linkages between them, and by the openness of the relationship to developments both in the broader global arena and in the internal politics of the two entities. Second, in terms of policy focus, there is clearly a depth and intensity in EU-US relations over a wide range of issues that are lacking in the case of other strategic partnerships fostered by the EU. It is not easy to see any parallels between this level and scope of integration and those achieved in other relationships. This adds to the resilience of the relationship, but at the same time it militates strongly against the idea of any comprehensive strategic partnership. It might be possible to imagine circumstances in which such a formal 'grand alliance' might be made, but it is very clear that those circumstances do not exist in the early 2020 s. The likelihood is that incremental agreements and joint working practices in an expanding range of policy areas will be the transatlantic reality for the foreseeable future.

In rather the same way, it is possible to point to large numbers of transatlantic institutions, but not to any formalised institutional framework for the EU-US relationship. Inevitably, these institutional arrangements are more highly developed in some areas than in others-economic 
and monetary policies being a key example of highly developed EUUS interactions not only at the transatlantic level but also within the institutions of multilateral management. In other areas, the presence of strong member state interests and a US preference to deal either bilaterally or through alternative institutions can make progress at the EU-US level difficult if not impossible-security and defence relations being an example, but with the qualification that in some areas such as cyber-security there is not only the incentive but also the capacity for development of joint working practices. A simple institutionalist model for the generation of EU-US strategic partnership is thus not easy to apply, but clearly has value in identifying areas with different densities and patterns of institutional development.

Many of the arguments made above can be related to issues of identity and role. As was pointed out by the Tindemans Report in the early 1970s, the first task of the EU as an international actor is to decide on a strategy and a role in relation to the US-and this has remained one of the key conundrums in EU external action. This chapter has provided ample evidence that the conundrum remains unsolved; in reality, the EU plays a number of roles in its relationship with the US, and at times those roles come into conflict with each other (Smith 2018b). Over an extended period of time, the Union has found itself acting as a proxy, a partner, a protagonist or a power in transatlantic relations, and elements of each of these roles are present in the current conjuncture. Whilst the image of the EU as a proxy (doing the US's work for it) has inevitably faded as the Union has developed its autonomy in external action, and it is not clear that the Union can yet act as a power taking on Washington in terms that might be appropriate to another major international 'pole', it seems that the EU's current role lies somewhere between the aspiration on the one hand to act as a strategic partner for the US and on the other hand to position itself as a protagonist and strategic rival. Each potential role is conditioned by the extent of internal cohesion or fragmentation within the EU, as well as the forces exerted by a changing world arena, and it is not clear whether or not the EU has established a stable role for itself in transatlantic relations, in the face of fluctuations in US policies as well as these domestic and external forces (Smith 2018a, b).

On the basis of the argument here, it is possible to conclude that there has not been and may never be a comprehensive EU-US strategic partnership in the formal sense. What there is, is a deep and enduring EU-US mutual entanglement at many levels and over a wide spectrum of policy 
domains, reflecting the simultaneous impacts of competition, convergence and crisis. This entanglement is resilient and can survive both internal and external shocks-but it can be undermined both in the short term and in the longer term by the effects of domestic change, institutional incapacity, external shocks and challenges. Even a more capable EU would not find it easy to resolve this conundrum in a comprehensive and 'strategic' manner; in its current state, it certainly cannot.

\section{REFERENCES}

Alcaro, R., Peterson, J., \& Greco, E. (Eds.). (2016). The West and the Global Power Shift: Transatlantic Relations and Global Governance. Basingstoke: Palgrave Macmillan.

Biscop, S. (2019). European Strategy in the 21st Century: New Future for Old Power. London: Routledge.

Christiansen, T., Kirchner, E., \& Wissenbach, U. (2019). The European Union and China. London: Red Globe Press.

Damro, C. (2014, October). Competitive Interdependence: Transatlantic Relations and Global Economic Governance (TRANSWORLD Paper No. 40). Edinburgh.

Dannreuther, R., \& Peterson, J. (Eds.). (2003). Security Strategy and Transatlantic Relations. London: Routledge.

De Ville, F., \& Siles-Brugge, G. (2016). TTIP: The Truth About the Transatlantic Trade and Investment Partnership. Cambridge: Polity.

Dombrowski, P., \& Reich, S. (2017, September). Does Donald Trump Have a Grand Strategy? International Affairs, 93(5), 1013-1038.

European Council. (2003). A Secure Europe in a Better World: European Security Strategy. Brussels: European Council.

European External Action Service. (2016, June). Shared Vision, Common Action: A Stronger Europe: A Global Strategy for the EU's Common Foreign and Security Policy. Brussels.

Featherstone, R., \& Ginsberg, R. (1996) The United States and the European Union in the 1990s: Partners in Tansition. London: Macmillan.

Geranmayeh, E. (2017). The Coming Clash; Why Iran Will Divide Europe from the United States (ECFR Policy Brief). London: European Council on Foreign Relations.

Green Cowles, M. (2001a). The Transatlantic Business Dialogue: Transforming the New Transatlantic Dialogue. In M. Pollack \& G. Shaffer (Eds.), Transatlantic Governance in the Global Economy (pp. 213-233). Lanham, MD: Rowman and Littlefield. 
Green Cowles, M. (2001b). The Transatlantic Business Dialogue: the Private Face of Transatlantic Relations. In E. Philippart \& P. Winand (Eds.), Ever Closer Partnership: Policy-Making in US-EU Relations (pp. 229-266). Brussels: Peter Lange/Inter-University Press.

Grosser, A. (1980). The Western Alliance: European-American Relations Since 1945. London: Continuum.

Haukkala, H. (2016). A Perfect Storm: Or What Went Wrong and What Went Right for the EU in Ukraine. Europe-Asia Studies, 68(4), 653-664.

Howorth, J. (2014). Security and Defence Policy in the European Union (2nd ed.). Basingstoke: Palgrave Macmillan.

Ikenberry, J. (2017). The Plot Against American Foreign Policy: Can the Liberal Order Survive? Foreign Affairs, 96(3), 2-9.

Ikenberry, G. J. (2018). The End of Liberal International Order? International Affairs, 94(1), 7-23.

Jokela, J. (2011). The G-20: A Pathway to Effective Multilateralism? (Chaillot Paper 125). Paris: European Union Institute for Security Studies.

Keohane, R., \& Hoffmann, S. (Eds.). (1993). After the Cold War: International Institutions and State Strategies in Europe, 1989-92. Cambridge, MA: Harvard University Press.

Koenig, N. (2011). The EU and the Libyan Crisis-In Quest of Coherence? The International Spectator, 46(4), 11-30.

Lindstrom, G. (2003). (Ed.). Shift or Rift? Assessing US-EU Relations After Iraq. Paris: European Union Institute for Security Studies.

Lindstrom, G., \& Schmitt, B. (Eds.). (2004). One Year On: Lessons from Iraq (Chaillot Paper, 68). Paris: European Union Institute for Security Studies.

Lundestad, G. (Ed.). (2008). Just Another Major Crisis? The United States and Europe Since. Oxford: Oxford University Press.

MacFarlane, N., \& Menon, A. (2014). The EU and Ukraine. Survival, 56(3), 95-101.

McGuire, S., \& Smith, M. (2008). The European Union and the United States: Competition and Convergence in the Global Arena. Basingstoke: Palgrave Macmillan.

Morin, J.-F., Novotná, T., Ponjaert, F., \& Telò, M. (Eds.). (2015). The Politics of Transatlantic Trade Negotiations: TTIP in a Globalized World. Farnham: Ashgate.

Niblett, R., \& Wallace, W. (Eds.). (2001). Rethinking European Order: West European Perspectives, 1989-1997. Basingstoke: Palgrave Macmillan.

Patel, K., \& Weisbrode, K. (Eds.). (2013). European Integration and the Atlantic Community in the 1980s. New York: Cambridge University Press.

Patrick, S. (2017). Trump and World Order: The Return of Self-Help. Foreign Affairs, 96(2), 52-57. 
Pennisi di Floristella, A. (2019). United States and European Union Evolving Approaches in Southeast Asia: Moving Closer to Convergence or Divergence? Journal of Current Southeast Asian Affairs, 38(2), 179-193.

Peterson, J. (1996). Europe and America in the 1990s: The Prospects for Partnership (2nd ed.). London: Routledge.

Peterson, J. (2018). Present at the Destruction? The Liberal Order in the Trump Era. The International Spectator, 53(1), 28-44.

Peterson, J., \& Pollack, M. (Eds.). (2003). Europe, America, Bush: Transatlantic Relations in the 21st Century. London: Routledge.

Pollack, M. (2005). The New Transatlantic Agenda at Ten: Reflections on an Experiment in International Governance. Journal of Common Market Studies, 43(5), 899-919.

Pollack, M., \& Shaffer, G. (Eds.). (2001). Transatlantic Governance in the Global Economy. Lanham, MD: Rowman and Littlefield.

Pond, E. (2004). Friendly Fire: The Near-Death of the Transatlantic Alliance. Washington, DC: Brookings Institution Press for the European Union Studies Association.

Rachman, G. (2019, 8 October). Europe Rightly Aspires to Be a Power Project. Financial Times.

Rees, W. (2006) Transatlantic Counter-Terrorism Cooperation: The New Imperative. London: Routledge.

Rees, W. (2009). The US-EU Security Relationship. Basingstoke: Palgrave.

Renard, T. (2011, April). Libya and the Post-American World: Implications for the EU (Security Policy Brief No. 20). Brussels: Egmont Institute.

Renard, T., \& Biscop, S. (Eds.). (2012). The European Union and Emerging Powers in the 21st Century: How Europe Can Shape a New Global Order. London: Routledge.

Sauer, T. (2015). The EU as a Coercive Diplomatic Actor? The EU-3 Initiative Towards Iran. In J. Koops \& G. Macaj (Eds.), The European Union as a Diplomatic Actor (pp. 103-119). Basingstoke: Palgrave Macmillan.

Sbragia, A. (2010). The EU, the US and Trade Policy: Competitive Interdependence in the Management of Globalization. Journal of European Public Policy, $17(3), 368-382$.

Schwok, R. (1991). U.S.-EC Relations in the Post-Cold War Era. Boulder, CO: Westview Press.

Sloan, S. (2016). Defense of the West: NATO, the European Union, and the Transatlantic Bargain. Manchester: Manchester University Press.

Smith, M. (1984). Western Europe and the United States: The Uncertain Alliance. London: Unwin Hyman.

Smith, M. (1998). Competitive Cooperation and EU-US Relations: Can the EU Be a Strategic Partner for the US in the Global Political Economy? Journal of European Public Policy, 5(4), 561-577. 
Smith, M. (1999). European Integration and American Power: Reflex, Resistance and Re-configuration. In D. Slater \& P. Taylor (Eds.), The American Century: Consensus and Coercion in the Projection of American Power (pp. 136-148) Oxford: Blackwell.

Smith, M. (2004). Between Two Worlds? The European Union, the United States and World Order. International Politics, 41(1), 96-117.

Smith, M. (2005). European Foreign Policy in Crisis? EU Responses to the George W. Bush Administration. European Political Science, 5(1), 41-51.

Smith, M. (2007). The European Union and International Order-European and Global Dimensions. European Foreign Affairs Review, 12(4), 437-456.

Smith, M. (2009). Perceptions, Misperceptions and Transatlantic Relations: Past, Present and Future. In N. Sola \& M. Smith (Eds.), Perceptions and Policy in Transatlantic Relations: Prospective Visions from the US and Europe (pp. 5976). London: Routledge.

Smith, M. (2011a). The European Union, the United States and Global Public Goods: Competing Models or Two Sides of the Same Coin?' In R. Whitman (Ed.), Normative Power Europe: Empirical and Theoretical Perspectives (pp. 127-140) Basingstoke: Palgrave Macmillan.

Smith, M. (2011b). European Responses to US Diplomacy: 'Special Relationships', Transatlantic Governance and World Order. The Hague Journal of Diplomacy, 6(3-4), 299-317.

Smith, M. (2018a). The European Union, the United States and the Crisis of Contemporary Multilateralism. Journal of European Integration, 40(5), 539553.

Smith, M. (2018b). The European Union in Transatlantic Relations: Four Roles in Search of an Actor. In R. Bengtsson \& M. Rosén Sundström (Eds.), The EU and the Emerging Global Order; Essays in Honour of Ole Elgström (pp. 127140) Lund Political Studies 194, Lund, Sweden: Lund University.

Smith, M. (2021a). European Union Diplomacy and the Trump Administration: Multilateral Diplomacy in a Transactional World? In R. Haar, T. Christiansen, S. Lange and S. Vanhoonacker (Eds.), The Making of European Security Policy: Between Institutional Dynamics and Global Challenges. London: Routledge.

Smith, M. (2021b). The European Union, Crisis Management and World Order. In M. Riddervold, M., J. Trondal, \& A. Newsome (Eds.), Handbook of EU Crises. Basingstoke: Palgrave Macmillan.

Smith, M., Keukeleire, S., \& Vanhoonacker, S. (Eds.). (2016). The Diplomatic System of the European Union: Evolution, Change and Challenges. London: Routledge.

Smith, M., \& Woolcock, S. (1993). The United States and the European Community in a Transformed World. London: Pinter for the Royal Institute of International Affairs. 
Smith, M., \& Woolcock, S. (1999). European Commercial Policy: A Leadership Role in the New Millennium? European Foreign Affairs Review, 4(4), 439462.

Steffenson, R. (2005). Managing EU-US Relations: Actors, Institutions and the New Transatlantic Agenda. Manchester: Manchester University Press.

Stokes, D. (2018, January). Trump, American Hegemony and the Future of the Liberal International Order. International Affairs, 94(1), 133-150.

Tsoukalis, L. (Ed.). (1986). Europe, America and the World Economy. Oxford: Blackwell.

US Department of State. (2010). Leading Through Civilian Power: The First Quadrennial Diplomacy and Development Review. Washington, DC: US Department of State/Agency for international Development.

Winand, P. (1993). Eisenhower, Kennedy and the United States of Europe. London: Macmillan.

Woolcock, S. (2012). European Union Economic Diplomacy: The Role of the EU in External Economic Relations. Farnham: Ashgate.

Young, A. (2016, March). 'Not Your Parents' Trade Politics: The TTIP Negotiations. Review of International Political Economy, online publication.

Youngs, R., \& Smith, M. (2018). The EU and the Global Order: Contingent Liberalism. The International Spectator, 53(1), 45-56.

Zaborowski, M. (Ed.). (2006). Friends Again? EU-US Relations After the Crisis. Paris: European Union Institute for Security Studies. 


\title{
The EU-Canada Strategic Partnership: Challenges and Opportunities
}

\author{
Amy Verdun
}

This chapter is an expanded version of a short journal article published in the Australia and New Zealand Journal of European Studies (February 2020). An earlier version of this chapter was presented at the International Workshop Jean Monnet Network on EU-Canada Relations: The EU and Canada in Dialogue 'New Opportunities for the EU-Canada Strategic Partnership', 8 November 2019, TU Darmstadt. The author thanks Natalia Chaban, Fengan Jiang (Richard), Michèle Knodt, Sharon Pardo, Laura Ferreira-Pereira, Godelieve Quisthoudt-Rowohl, Antoine Rayroux, Gordon S. Smith, and Michael Smith for comments on an earlier version of this chapter. The usual disclaimer applies.

\footnotetext{
A. Verdun (凶)

University of Victoria, Victoria, BC, Canada

e-mail: averdun@uvic.ca

(C) The Author(s), under exclusive license to Springer Nature

Switzerland AG 2021

L. Ferreira-Pereira et al. (eds.), The European Union's Strategic

Partnerships, The European Union in International Affairs, https://doi.org/10.1007/978-3-030-66061-1_6
} 


\section{INTRODUCTION}

The European Union $(\mathrm{EU})^{1}$ and Canada signed a strategic partnership agreement (SPA) on 30 October 2016. It provisionally entered into force on 1 April 2017 with the provisional application of the agreement on 21 September 2017 (European Union 2017). This chapter studies the origins of this agreement and examines how the EU-Canada relationship in this regard changed over time. It explores why an SPA was possible in 2016, but not before. To do so, I focus in particular on endogenous and exogenous factors (Hill 1993, 1998; Tsuruoka 2006). In this chapter, I divide up EU-Canada collaboration into four time periods: period one (from 1959 to 1976); period two (1977-1996); period three (1997-2008); period four (2009-2020).

The first Canadian agreement with the EU was a very important one. Signed in 1976, the 'Framework Agreement for Commercial and Economic Co-operation between the European Communities and Canada' was the first bilateral strategic partnership that the EU signed with an industrialised third country. For many years this agreement served as the basis for cooperation. Modest strengthening of the ties was achieved in 1990, 1995 and 1996 and also with the 2004 EU-Canada Partnership Agenda (DeBardeleben and Leblond 2010). However, a fully-fledged free trade agreement, let alone one in combination with a strategic partnership, remained elusive for some time, even though Canada was already mentioned in 2003 by the European Council in its then new European Security Strategy (ESS) as one of the strategic partners of the EU. ${ }^{2}$ Ultimately, however, the Comprehensive Economic and Trade Agreement (CETA) and the SPA were both signed on the same date. ${ }^{3}$ Although at the time of writing their full ratification is not yet

\footnotetext{
${ }^{1}$ For simplicity, I use 'European Union' or 'EU' to refer to the actual EU as well as to the earlier 'European Communities' or 'European Community'.

${ }^{2}$ Council of the European Union (2003) 'A Secure Europe in a better world'. Brussels 8 December, 15895/03, PESC 787. About Canada it literally mentions: 'In particular we should look to develop strategic partnerships, with Japan, China, Canada and India, as well as with all those who share our goals and values, and are prepared to act in their support.' For a discussion of the ESS see inter alia Bailes (2005).

${ }^{3}$ https://pm.gc.ca/en/news/statements/2016/10/30/eu-canada-summit-joint-dec laration. CETA is a large treaty. It contains 30 chapters, some protocols, annexes, reservations and counts a total of about 2250 pages (in the English language). It is also
} 
complete, the EU-Canada relationship has been further strengthened by having these agreements provisionally enter into force.

This chapter examines the following question: Why could this more institutionalised collaboration be signed in 2016, but not before? It seeks to address this question by assessing the path of the creation of the strategic partnership agreement. In particular, it asks, why has the deepening of the EU-Canada strategic partnership been a challenge to set up during the three decades after 1976 agreement, only to get an agreement four decades later, in 2016? To assess this process, the chapter seeks to understand the role of governance structures of both partners as well as the strategic opportunity that came out of the agreement.

The existing literature suggests that earlier cooperation in this domain failed for two reasons. First, in the earlier time period both Canada and the EU did not think that their partnership was a priority. Instead, Canada was mostly oriented towards the United States (US) and the same held for the EU. Neither saw a need to 'go around' the US in terms of developing relationships with each other that would not be reproduced by the other transatlantic partner. Most of the early period was characterised by the Cold War with both parties being in the North Atlantic Treaty Organization (NATO), which provided a strong security umbrella. Furthermore, internally the EU was institutionally not very strong and security as a policy area was not well developed at the EU-level. Each of the parties was also caught up with its own internal issues. On the Canadian side, the early years were coloured by issues such as the Quebec referendum, the creation of the North American Free Trade Agreement (NAFTA) but also the fisheries war (Crowley 2004). On the European side, during the first two decades internal European integration was more developed in the area of agriculture, commerce, and trade matters rather than on security and defence matters. Thus, in addition to not having a clear sense of its strategic goals, the EU did not yet speak with one voice on these more external political matters (Potter 1999; Long 2003; Barry 2004; Bernard-Meunier 2006; Croci and Verdun 2006; Haglund and Mérand 2010; Mérand and Vandemoortele 2011).

Second, there was also a lack of appreciation of the multilevel governance and federalist institutional structures on both sides (Benz 2010; Wood and Verdun 2010; Kukucha 2013: 529; Broschek and Goff

produced in the official languages of the EU which means that the total text is more than 50,000 pages. 
2020). The EU did not understand fully how decentralised the Canadian federation was; the Canadians, in turn, for many years lacked a solid understanding of the EU institutional set up. As a result, Canadian diplomats were more inclined to look to European member states separately and bilaterally, rather than deal with the EU as a collective. The present chapter seeks to re-assess these two insights from the literature in light of the recently signed CETA and SPA agreement with a view to obtaining a better insight as to why the agreements could be completed this time compared to the failed attempts (or weak arrangements) earlier. The eventual combination of the CETA and the SPA became the most comprehensive agreement between the EU and Canada to date, including many different dimensions (i.e., political, economic, strategic, security, judicial, environmental and social). In what follows we examine the extent to which the following factors played a role in the eventual signing of the agreements: an assessment of the costs and benefits of the type of relationship between Canada and the EU, the perceived role of the United States and the global arena, and the need mutually to understand the institutional structure of governance of both partners.

The remainder of the chapter is structured as follows. The next section looks at the literature of the Canada-EU relations with a particular focus on the Strategic Partnership Agreement. The third section provides an empirical case study and an analysis of the Strategic Partnership Agreement and the CETA. The fourth section concludes that the Canada-EU relationships have been coloured by a number of endogenous and exogenous factors, especially the development of domestic structures and political pressures but also the broader re-structuring of the global and transatlantic arenas. These factors help us to account not only for the content of the partnership, but also for the stages of negotiation that took place before it could finally be concluded, and they reflect both the 'internal' and the 'external' logics explored in Chapter 2 of this volume.

\section{What Is the Canada-EU Strategic Partnership Agreement? A Review of the Literature on the Canada-EU Relations}

In what follows I provide a brief review of the literature that discusses the strategic activities developed between Canada and the European Union. I have grouped these agreements into four time periods: period one (from 
1959 to 1976); period two (1977-1996); period three (1997-2008); period four (2009-present) (Table 6.1).

Table 6.1 Canada-EU agreements (1959-2016) (selection)

\begin{tabular}{|c|c|c|c|}
\hline Date & Name & Sectoral agreement & Framework agreement \\
\hline 1959 & $\begin{array}{l}\text { Agreement between the } \\
\text { Government of Canada and the } \\
\text { European Atomic Energy } \\
\text { Community (EURATOM) for } \\
\text { Cooperation in the Peaceful } \\
\text { Uses of Atomic Energy }\end{array}$ & $\times$ & \\
\hline 1976 & $\begin{array}{l}\text { Framework Agreement for } \\
\text { Commercial and Economic } \\
\text { Co-operation between the } \\
\text { European Communities and } \\
\text { Canada }\end{array}$ & & $\times$ \\
\hline 1990 & $\begin{array}{l}\text { 'Declaration on European } \\
\text { Community-Canada Relations' }\end{array}$ & & $\times$ \\
\hline 1991 & $\begin{array}{l}\text { Agreement on nuclear } \\
\text { co-operation (amendment of } \\
\text { the } 1959 \text { agreement) }\end{array}$ & $\times$ & \\
\hline 1995 & $\begin{array}{l}\text { 'EU-Canada Agreement on } \\
\text { Higher Education and Training } \\
\text { (renewed in 2000) }\end{array}$ & $\times$ & \\
\hline 1996 & $\begin{array}{l}\text { 'Joint Political Declaration on } \\
\text { EU-Canada Relations' }\end{array}$ & & $x$ \\
\hline 1996 & $\begin{array}{l}\text { 'Joint Canada-EU Action Plan } \\
\text { 1996' }\end{array}$ & & $x$ \\
\hline 1996 & $\begin{array}{l}\text { Agreement on Scientific and } \\
\text { Technical Cooperation }\end{array}$ & $x$ & \\
\hline 1996 & $\begin{array}{l}\text { Agreement for the conclusion } \\
\text { of negotiations between under } \\
\text { GATT Art XXIV: } 6\end{array}$ & $\times$ & \\
\hline 1997 & $\begin{array}{l}\text { Agreement on international } \\
\text { humane trapping standards } \\
\text { (with the Russian federation) }\end{array}$ & & \\
\hline 1998 & $\begin{array}{l}\text { Agreement on Customs } \\
\text { Cooperation and Mutual } \\
\text { Assistance in Customs Markets }\end{array}$ & $\times$ & \\
\hline 1998 & $\begin{array}{l}\text { Agreement on Sanitary } \\
\text { Measures to protect public and } \\
\text { animal health in respect of } \\
\text { trade in live animals and animal } \\
\text { products }\end{array}$ & $\times$ & \\
\hline
\end{tabular}


Table 6.1 (continued)

\begin{tabular}{|c|c|c|c|}
\hline Date & Name & Sectoral agreement & Framework agreement \\
\hline 1999 & $\begin{array}{l}\text { Agreement regarding the } \\
\text { Application of Competition } \\
\text { Laws }\end{array}$ & $\times$ & \\
\hline 2004 & $\begin{array}{l}\text { Agreement concerning trade } \\
\text { and commerce in alcoholic } \\
\text { beverages }\end{array}$ & $\times$ & \\
\hline 2004 & EU-Canada Partnership Agenda & & $x$ \\
\hline 2005 & $\begin{array}{l}\text { Agreement establishing a } \\
\text { framework for the participation } \\
\text { of Canada in the EU crisis } \\
\text { management operations }\end{array}$ & & $x$ \\
\hline 2006 & $\begin{array}{l}\text { Agreement between the } \\
\text { European Community and the } \\
\text { Government of Canada } \\
\text { establishing a framework for } \\
\text { cooperation in higher } \\
\text { education, training and youth }\end{array}$ & $x$ & \\
\hline 2007 & $\begin{array}{l}\text { Agreement between the } \\
\text { European Community and the } \\
\text { Government of Canada on the } \\
\text { conclusion of GATT Article } \\
\text { XXIV: } 6 \text { Negotiations }\end{array}$ & $\times$ & \\
\hline 2009 & $\begin{array}{l}\text { Agreement on Air Transport } \\
\text { between Canada and the } \\
\text { European Community and its } \\
\text { Member States }\left(^{*}\right)\end{array}$ & $\times$ & \\
\hline 2009 & $\begin{array}{l}\text { Agreement on civil aviation } \\
\text { safety between the European } \\
\text { Community and Canada }\end{array}$ & $\times$ & \\
\hline 2016 & $\begin{array}{l}\text { Strategic Partnership } \\
\text { Agreement (SPA) between the } \\
\text { European Union and its } \\
\text { Member States, of the one } \\
\text { part, and Canada, of the other } \\
\text { part }\end{array}$ & $\times$ & \\
\hline 2016 & $\begin{array}{l}\text { Comprehensive Economic and } \\
\text { Trade Agreement (CETA) } \\
\text { between Canada, of the one } \\
\text { part, and the European Union } \\
\text { and its Member States, of the } \\
\text { other part }\end{array}$ & $\times$ & \\
\hline
\end{tabular}

All agreements are between the Government of Canada and the European Communities unless specified otherwise

Sources Commission of the European Communities (2003: 16-17) and Mahant (1985), various other sources, and European Union External Action (Treaty Office Data Base): ec.europa.eu/trade/issues/ bilateral/countries/canada/index_en.htm (which lists 46 Canada-EU agreements); https://nuclearsa fety.gc.ca/eng/resources/international-cooperation/international-agreements.cfm\#Euratom, http://ec. europa.eu/world/agreements/searchByType.do?id=1 
The first period, between 1959 and 1976, starts with the agreement that was signed between the European Atomic Energy Community and Canada in 1959. Together with the one with the US (signed in 1958), it was the first such agreement and the period ends with the signing of the 1976 agreement (Mahant 1976). The early work focuses on the 1976 agreement (cf. Mahant 1981). It provided structure for dialogue. A Joint Cooperation Committee (JCC) was to meet annually 'to promote and keep under review the various commercial and economic cooperation activities'. In 1972, the Canadian government, led by Pierre Trudeau as prime minister, declared that it would seek to reduce Canadian reliance on the United States. ${ }^{4}$ Towards the end of this period scholars wrote about Canada's policy towards the rest of the world using the terminology of 'third option', meaning to steer away from an overly strong reliance on the US (Mace and Hervouet 1989; Muirhead 2004). This policy was developed in 1972 by Mitchell Sharp (secretary of state for external affairs) who rejected two other options (the first being the status quo, the second closer integration with the US) (Sharp 1972). The third option meant finding closer ties with other countries (the European Community or EC member states would be part of those partners to choose from). This Third Option strategy was taken seriously during 1972-1976 but petered out subsequently (Barry 2003: 3-6). ${ }^{5}$

The second time period, between 1977 and 1996, starts with the entry into force of the 1976 agreement, contains the 1990 agreement, 'The Declaration on Transatlantic Relations between the European Community and its Member States and Canada' and the 1995 sectoral agreement on 'EU-Canada Agreement on Higher Education and Training' as well as the 1996 'Joint Political Declaration on EU-Canada Relations'. Edelgard Mahant in an overview of the kind of collaboration that took place right after the signing of the 1976 agreement $^{6}$ till the

\footnotetext{
${ }^{4}$ To deal with its Balance of Payments issues, on 15 August 1971 the US ended convertibility of dollars into gold. At this time, it also raised $10 \%$ tariffs on goods coming into the US. Despite a request from the Canadian government, it did not give Canada an exemption. The Canadian government responded by considering its options (see also Croci and Tossutti 2007).

${ }^{5}$ The Third Option was formally dropped in 1980 (Mace and Hervouet 1989).

${ }^{6}$ Mahant (1985: 285) reports that the 'Semi-Annual' or 'High levels' meetings started to take place already before the 1976 namely, since the 1972 informal Canada-European Community Agreement although the meetings did not take place twice a year in every year (both in 1974 and 1977 only one such meeting took place).
} 
mid-1980s, provides a useful overview of what has happened in the first decade. She identified that most of the 'high level' meetings were in fact not at the highest level but rather at the level of the assistant deputy minister (Canada) and deputy director-general (Commission). Mahant characterised this level as "the meeting point between the political and the "official" levels... too low a level to deal with basic political issues but at too high a level to negotiate the details of the trade and scientific co-operation which are the day-to-day subjects of Canada-Community discussions' (Mahant 1985: 286). She also described the annual meetings of the parliamentary delegations of European and Canadian parliaments during this time and listed various subcommittees that have met during the period, such as the 'industrial co-operation subcommittee' and the 'preparatory and general co-operation subcommittee'. A highlight of this period was the signing of the 1990 political declaration. ${ }^{7}$ The interest in closer ties was triggered from both sides, and was in part in response to the changing geopolitical circumstances. On the European side, on 5 April 1990, Hans-Dietrich Genscher (German Foreign Minister at the time), at a presentation at the Canadian Parliament called for 'a new transatlantic architecture' (Potter 1999: 82). There was a brief consideration of a transatlantic trade agreement either focused on the North Atlantic in general or just on Canada-EC relations, but a working group exploring these issues did not generate any concrete proposals (Potter 1999: 89-90).

The remainder of the $1990 \mathrm{~s}$ did not generate major initiatives in bilateral cooperation. ${ }^{8}$ As the Cold War was coming to an end Charles Pentland identified the renewed process of European integration, (i.e. the

${ }^{7}$ In November 1990, a Canada-EC Joint Declaration was signed by Prime Minister Mulroney and Italian Prime Minister Giulio Andreotti as his country was holding rotating presidency of the EC at that time. The declaration states that it builds on the 'privileged relationship' created by the 1976 agreement and a 1988 arrangement for a 'political dialogue' (Pentland 1991: 139) and states a number of common values goals ranging from democracy, peace and prosperity, security, market economy, to closer economic, scientific and cultural cooperation. It also institutionalises some consultative mechanisms by spelling out 'regular meetings' of the leaders of both Canada and the EC, and biannual meetings of EC and Canadian officials at a host of levels from very high level to the level of representatives and the respective parliaments (see Pentland 1991: 139).

${ }^{8}$ The Canadian government also started a 'European Challenge' campaign (to inform Canadian business about the EU single market, established a 'Task Force on Europe 1992', and set up a 'European Trade Policy Strategy' in Brussels (see Hampson and Maule 1991: 17-18). 
aim to complete the Single Market and the EU's intention to create an Economic and Monetary Union), as 'the most far-reaching challenge to Canada arising from the post-war unification of western Europe' (Pentland 1991 also quoted by Hampson and Maule 1991: 17). At this time, no overarching agreement was signed. There were, however, numerous smaller, sectoral, agreements between Canada and the EU (see Table 6.1). Furthermore, cooperation took place within other international organisations, such as NATO and the Conference on Security and Cooperation in Europe (CSCE) (see also Hampson and Maule 1991: 18). ${ }^{9}$ In addition, Canada became a founding shareholder of the European Bank for Reconstruction and Development (EBRD). It also offered Hungary and Poland bilateral aid programs (Hampson and Maule 1991: 18). This piecemeal approach was the best that could be arranged during this time. These smaller steps should, however, not be underestimated. On the whole during this time Canada also maintained strong bilateral ties in particular with the United Kingdom (UK) although many observers were realising that the completion of the Single Market (1992 programme) was drawing the UK closer into the heart of the EU (Adams 1992).

The final part of this second period is characterised by fish-wars (Barry et al. 2014). At this time, Canada and the EU were having numerous issues around fishing in the North Atlantic (Barry 1998) with Canada eventually sending warships to try to address the issue of Portuguese and Spanish fishermen allegedly overfishing and violating international agreements on quantity and size of fish. The strategy chosen was confrontational but aimed at forcing the issue to the top of the agenda by using rogue strategies (Missios and Plourde 1996). Though it resolved the matter in Canada's favour, it costs the country considerably in terms of damage to diplomatic relations (Howe and Kerby 2009). ${ }^{10}$ Nevertheless, as mentioned above, the two sides did manage to sign the 1996 'Joint

\footnotetext{
${ }^{9}$ Evan Potter lists various other organisations in which Canada and the EU: '.. the Group of Seven (G-7), the Commonwealth, La Francophonie, the Northwest Atlantic Fisheries Organization (NAFO), the Organization of Economic Cooperation and Development, peacekeeping missions, development assistance, international financial institutions ...' (and this list is not even exhaustive as both parties also encountered one another in numerous other international missions where both parties had a role, such as peace keeping missions (Potter 1999: 8).

${ }^{10}$ Gordon S. Smith, who was involved in these fish-wars as deputy minister of Foreign Affairs, characterised Canada's stance as forceful. He said it was necessary to do something (personal interview 11 December 2019).
} 
Political Declaration on EU-Canada Relations' and in the same year both parties signed an Agreement for Scientific and Technical Cooperation ${ }^{11}$ which built on the 1976 cooperation agreement and the 1990 Declaration. Furthermore, both sides concluded the so-called Agreement for the conclusion of negotiations under General Agreement on Tariffs and Trade (GATT) Art XXIV:6 which offered concessions in terms of market access to Canada as a third country. Both sides also improved access in some areas of agriculture. $^{12}$

During the third period, between 1997 and 2008, Canada started to put the EU more centrally on the foreign policy agenda (Potter 1999: 1). ${ }^{13}$ Potter (1999: 3 ) argued that both sides had still focused considerably on bilateral relations with Canada continuing also to focus attention on individual larger member states, with the relationship with Germany increasing in importance whereas that with the UK gradually lost its relative importance (Potter 1999: 246). Furthermore, in terms of its agreements with the EU as a whole, rather than examining overarching agreements, Canada and the EU chose the bilateral agreement system whereby different sectoral issues were chosen as the way forward. Canada also cooperated together with a third party - the Russian Federation-to develop international humane trapping standards (in 1997). Two other agreements were signed in 1998, one in the area of Customs Cooperation and Mutual Assistance in Customs Markets and another Agreement on Sanitary Measures to protect public and animal health in respect of trade in live animals and animal products. A year later, in 1999, the two parties signed an Agreement regarding the Application of Competition Laws. At a Summit in Ottawa in December 2002 the EU and Canadian

11 'Agreement for Scientific and Technological Cooperation Between Canada and the European Community', E102117 - CTS 1996 No. 24 https://www.treaty-accord.gc.ca/ text-texte.aspx?id=102117.

${ }^{12}$ Agreement for the Conclusion of Negotiations Between Canada and the European Community Under Article XXIV:6, E100682 - CTS 1996 No. 43 (25 July 1996), https://www.treaty-accord.gc.ca/text-texte.aspx?id=100682.

${ }^{13}$ At this time, the desk officer in the Commission's Directorate I (DG External Relations) responsible for Canada was also responsible for the United States and Australia. Evan Potter (1999: 197) argued that Canada benefitted from being part of that officer's limited resources. Furthermore, during this time the bilateral relations between Canada and the United Kingdom saw a gradual move towards valuing the Canada-Germany relationship, in light of the ongoing enlargement in the EU (Potter 1999: 247). 
leaders stated that they were keen to explore a bilateral trade and investment enhancement agreement. In 2004, they signed another sectoral agreement that focused on single market issues, namely the Agreement concerning trade and commerce in alcoholic beverages.

This period was closed with an important step forward on various issues that were bundled together under the 2004 EU-Canada Partnership Agenda, that followed on the heels of the newly adopted ESS, by the European Council in Brussels in December 2003, that explicitly had named Canada as one of the countries with which it wanted to set up a Strategic Partnership (see Footnote 3 above). The leaders at the time, Canadian Prime Minister Paul Martin and Commission President Romano Prodi, decided in March 2004 to launch a so-called Trade and Investment Enhancement Agreement (TIEA). Negotiations between Canada and the Commission took place in December 2004. The goal was to see if regulatory barriers between Canada and the EU could be reduced (Hülsemeyer 2006: 382). In 2005, both parties signed the Agreement establishing a framework for the participation of Canada in EU crisis management operations. ${ }^{14}$ Although another round of TIEA negotiations took place in Brussels in May 2005, the two sides agreed to interrupt negotiations in 2006. ${ }^{15}$ All in all, there were many sectoral agreements but an overarching free trade agreement proved difficult (Hülsemeyer 2006; Mildner 2008). Various studies and reports have indicated that there were numerous obstacles at this stage to continued negotiations. These ranged from lack of mutual understanding about the institutional structures of each of the political systems, in particular the relationship between provinces and territories with the Canadian federal government concerning issues that provinces have jurisdiction over (Kukucha 2011: 131) and relatedly a perceived lack of appreciation by the EU of how Canada works (Rudd 2011: 53). Furthermore, both Canada and the EU were quite preoccupied with not alienating the US (Barry 2004: 38). In the EU context, the European Commission has responsibility to negotiate trade agreements and for a 'regular' free trade agreement the ratification

14 'Agreement between the European Union and Canada establishing a framework for the participation of Canada in the European Union crisis management operations', Official Journal of the EU L 315/21 1.12.2005 https://www.europarl.europa.eu/cmsdata/121 887/Agreement_participation_crisis_management_operations_EU-Canada_2005.pdf.

15 http://www.sice.oas.org/TPD/CAN_EU/CAN_EU_e.ASP; https://www.internati onal.gc.ca/trade-agreements-accords-commerciaux/agr-acc/eu-ue/tiea.aspx?lang=en. 
and implementation had been straightforward (i.e. before the onset of so-called second-generation FTAs). The Canadian Constitution stipulates that the federal government has competence to negotiate trade agreement but cannot force provinces and territories to implement them (Mestral and Fox-Decent 2008: 644). Because of this peculiarity, Grace Skogstad characterised trade negotiations in the Canadian context as 'a de facto shared jurisdiction' (Skogstad 2012 quoted in Paquin 2020: 35). Finally, the timing was an issue too. Both sides were keen to wait and see what would come out of the Doha Round (Mildner 2008: 654). Furthermore, in the EU context there was also some concern that the Canada-EU strategic partnership and trade agreement required an overhaul in structure, meaning that it had become preferable to focus on one or two major agreements rather than the many sectoral agreements. A larger agreement would make it easier to trade things off against one another. However, in the EU context the concern around the constitutional treaty process that was taking place in the mid-2000s, meant that there was some level of apprehension about ability to deal with such a potentially major trade and strategic agreement, and in that regard, what might be the best timing for these negotiations (Commission of the EC 2003). ${ }^{16}$

The fourth period, from 2009-2020, started off with another sectoral agreement, namely an EU-Canada 'Agreement on civil aviation safety between the European Community and Canada' (2009). Shortly after it became clear that the EU and Canada could collaborate on a free trade agreement and possibly a strategic partnership agreement if they embarked on the negotiations in a more bottom up fashion, in particular on the Canadian side (Dolata-Kreutzkamp 2010). Earlier attempts to negotiate a free trade agreement suffered on the Canadian side by having been conducted only at the federal level without including lower-level partners such as the provinces and territories (Paquin 2020). The European Commission was surprised that it was so difficult in Canada to have federal level bodies negotiate on behalf of the lower governance levels in Canada and thus insisted that provincial representatives be included on

${ }^{16}$ The Commission Communication on EU-Canada Relations of of 13 May 2003 states: 'Also, the picture is complicated by the ongoing Convention on the future of the EU, which is likely to change the landscape of the CFSP. It might be appropriate to wait for the results of the Convention and the IGC, as well as enlargement, before launching a procedure to bring the legal framework governing EU-Canada relations fully up to date' (Commission of the EC 2003: 13). 
the Canadian negotiating team (Paquin 2013: 545). During these negotiations, Canadian provinces and even territories obtained a much more prominent and substantial role in the negotiations (Fafard and Leblond 2013). Provinces also produced reports and provided statements of public support (Paquin 2020: 48). Approvals of the final agreement by Ontario and Quebec were explicitly included by the European Union (Hübner et al. 2017). The negotiations were very trying and it often seemed that they were close to being completed but a final text remained elusive (Hübner 2011; De Mestral, and Fox-Decent 2008).

Eventually the two sides pulled off a comprehensive economic trade agreement and the strategic partnership agreement and both were signed on the same date in 2016. The ratification of the agreement was, however, subsequently very tricky on the European Union side, for a number of reasons. First, the powers of the European Parliament to approve trade agreements had been enhanced by the Lisbon Treaty and due to an increased public interest in trade agreement the EP was taking this role much more seriously (Bierbrauer 2014; Kerremans et al. 2019). Furthermore, various subnational-level parliaments signalled being prepared to block the signing of the agreement, in particular the Walloon parliament resisted (Gotev 2016). Various Canadians and Quebeckers, including the Prime Minister, the Quebec premier, a few other Francophone Canadians, and other Canadian trade negotiators had been part of the process of seeking to convince the Francophone and Walloon members of parliament to approve the CETA agreement (Paquin 2020: 48; Bollen et al. 2020). Final ratifications of the SPA and CETA are still in process as this chapter goes to press.

\section{Evaluating the Strategic Partnership}

Mérand and Rayoux (2018: 189-194) identify three main debates within the EU about how the EU seeks to deal with its foreign relations visà-vis the rest of the world. These debates must be situated within the overall issues that the Common Foreign and Security Policy (CFSP) and Common Security and Defence Policy (CSDP) are faced with. In June 2016, the Council of foreign and defence ministers in their conclusions upped their level of ambition by launching a so-called EU Global 
Strategy, reinforced in November 2016. ${ }^{17}$ These important steps were taken just prior to the signing of the CETA and the Canada-EU SPA, even if those EU-Canada agreements had of course been negotiated during many years before they were finally signed. The three debates identified by Mérand and Rayoux (2018) shed light on how the EU-Canada agreements fit within the EU internal considerations. The first debate concerns the extent to which the large EU member states have more influence over EU foreign policy compared to the smaller ones. The second is whether all of the member states would participate in all EU actions. The EU consists of members with different interests, some are neutral or may have different relations with countries outside of the EU (due to their different historical past with countries external to the EU). The third is the extent to which the EU should remain focused mostly on 'soft power' or whether it needs to move towards becoming a stronger military actor. The negotiations between Canada and the EU covered all three of these debates.

Canadian foreign policy has traditionally been in line with its main allies (i.e. United States and the EU) and heavily oriented towards multilateralism. Over time it has become more assertive and started to consider to what extent Canadian Foreign Policy would be different from heavily relying on the United States. ${ }^{18}$ When in 2002 Robert Kagan famously argued that the transatlantic rift of the turn of the century could be seen as the Europeans being from Venus and the Americans from Mars, it hit a nerve in the Canadian context (Long 2003; see Kagan 2003). At the start of the negotiations that would lead to the SPA and CETA being signed in

17 'A Global Strategy for the EU's Foreign and Security Policy', June 2016 (https:// eeas.europa.eu/sites/eeas/files/eugs_review_web_0.pdf). This document (on page 37) explicitly mentions Canada and transatlantic trade agreements and the broader security agenda in the following way: "With the US, the EU will strive for a Transatlantic Trade and Investment Partnership (TTIP). Like the Comprehensive Economic and Trade Agreement (CETA) with Canada, TTIP demonstrates the transatlantic commitment to shared values and signals our willingness to pursue an ambitious rules-based trade agenda. On the broader security agenda, the US will continue to be our core partner. The EU will deepen cooperation with the US and Canada on crisis management, counter-terrorism, cyber, migration, energy and climate action". See also 'Implementation Plan on Security and Defence', November 2016 (this document does not mention Canada at all).

18 On Canada-US exceptionalism see Barry (1979). During the period under study the US also started to orient itself a bit more on the newly emerging powers in the world, such as Brazil, China, India, and so on. On the EU-US strategic partnership see Michael Smith (this volume). 
2016, the EU had become a much more important potential partner to Canada than before (Haglund and Mérand 2010). Both parties had also learnt about the importance of appreciating the difficulties of negotiating with loosely federated systems (Benz 2010). In the run-up to the negotiations, Canadian elites considered numerous international threats to need attention.

In a paper analysing the threat perceptions of Canadian political, bureaucratic and academic security elites as compared with those articulated by the Canadian government, a survey conducted with bureaucrats and foreign policy experts found that the EU was perceived to be important to solve the most salient foreign policy issues of the day but not absolutely crucial (Tossutti et al. 2007). Experts also still look more towards the US for support than across the Atlantic.

The negotiations for the Strategic Partnership started only in September 2011 at the same time as those for the CETA. Here the premise was that the $1976 \mathrm{EU}$-Canada framework agreement had become ineffective due to the many changes in the bilateral relations that had emerged since its signing in the mid-1970s. Also the entry into force of the Lisbon Treaty enabled the EU to be more effective, institutionally, in dealing with foreign relations (with the European External Action Service having been created) and was overall more ambitious in the area of security and defence due to the reinforcement of the CSDP. European Commission President José Manuel Barroso and Canadian Prime Minister Stephen Harper announced in spring 2014 that an agreement in principle had been reached, which they had made in the margins of a summit that took place in The Hague (Gardner 2014). Three years later, in September 2014, various media signalled once again that the EU and Canada were closer to reaching an agreement (Gardner 2014). Both CETA and the SPA between Canada and the EU were formally adopted by the European Commission in April 2015, signed by the EU and Canada leaders at the EU-Canada summit on 30 October 2016, provisionally entered into force on 1 April 2017 with the provisional application of the agreement on 21 September 2017. Some of the issues on which progress had been made on the partnership agenda of 2004 were incorporated into this SPA. ${ }^{19}$ An innovation was made here to avoid a deadlock: knowing that

19 http://eeas.europa.eu/archives/docs/canada/docs/partnership_agenda_en.pdf. There were numerous issues that overlapped between the SPA agreement and the 7-paged general document called "EU-Canada Partnership Agenda" concluded to at 
ratification could be an obstacle, namely to have some parts of the SPA enter into effect even before full ratification had been included.

In terms of the substance, the SPA deals with issues related to values and reinforces an interest in bilateral cooperation, in particular in policy areas where strategic cooperation would be beneficial to both parties such as agriculture, arctic politics, environment, fisheries, internetsecurity, judicial, maritime issues, political, research and development, security, social, taxation, combatting terrorism, and of course on global economic issues (although most of the economic issues which deal with bilateral matters are dealt with comprehensively in the CETA agreement). In these areas, the two sides commit to enhance the dialogue and where appropriate cooperate. The important issues with regard to values are cooperation on matters such as human rights, democracy, the rule of law, peace and security, and global governance. One of the ways, mentioned in the agreement, to ensure collaboration is to work together in various multilateral forums. The text literally states: 'The Parties share a commitment to multilateralism and efforts to improve the effectiveness of regional and international fora and organisations such as the United Nations and its specialised organisations and agencies, the Organisation for Economic Co-operation and Development (OECD), NATO, OSCE and other multilateral fora' (SPA, article $8(1)$ ). Other forms of cooperation through such multilateral organisations include the International Monetary Fund (IMF), World Bank, and the various G-7 or G-20 fora. In addition, another way to enhance consultation would be through summits where leaders meet (on an annual basis) and have high-level meetings such as those at the level of foreign ministers. Furthermore, consultation would be developed at the various ministerial levels depending on the policy area of 'mutual interest' (SPA article 27(lc)). In addition, Joint Ministerial Committees would be established to replace the existing 'transatlantic dialogue' (SPA article $27(2 \mathrm{~b})$ ), and a Joint Cooperation Committee was established.

the EU-Canada Summit in Ottawa on 18 March 2004. It featured broad headers (with various subheaders) such as (A) Advancing International Security and Effective Multilateralism; (B) Advancing Global Economic Prosperity; (C) Advancing Cooperation on Issues of Justice and Home Affairs; (D) Cooperating on Global and Regional Challenges, and (E) Fostering People to People Links. Many of the themes mentioned in the 2004 document in one form or other reappear in the 2016 EU-Canada SPA. 
When analysing this SPA, we find a few things that are noteworthy. ${ }^{20}$ First is that it covers a very wide range of issues. The SPA brings together so many different issues that were previously either explicitly mentioned in bilateral agreements or were considered to be of mutual interest but less well articulated in formal agreements. Second, the wording of the SPA signals a need to collaborate as much as possible in as many areas as possible, and using as much as possible the various multilateral forums in addition to having annual meetings. ${ }^{21}$

In earlier attempts to complete such an agreement in the area of free trade the multilevel governance nature of the EU and of Canada was something that both parties found hard to understand (Croci and Tossutti 2009; Benz 2010). Furthermore, the SPA only emerged when both Canada and the EU realised that they needed to diversify away from a predominant orientation towards the United States (Croci and Verdun 2004). Both sides had at different times been more focused on keeping the US on side than appreciating the benefits that the 'other transatlantic' partner could give (DeBardeleben and LeBlond 2010). Over the first half of the 2010s the US was increasingly orienting itself towards Asia and neither Canada nor the EU were given the feeling by US diplomats that they were very 'special'. At this time, the EU was becoming more aware of its need to have its own external relations and a more autonomous security and defence pillar. With the EU expanding into countries (through enlargement but also developing a European Neighbourhood Policy) it became more clear to the Europeans that they shared much more with Canada than they did with these other countries that they were pulling closer (Pentland 2009). Finally, the realisation dawned on both sides that the collaboration would benefit from being, on the one hand a free trade agreement, on the other hand more 'strategic'. To keep the negotiations doable, and also given how the EU is structured in terms of competences for foreign policy versus trade issues, having these agreements discussed at two separate tables increased the chance of success in either agreement. Thus, the two elements were separated. Dividing up these issues in this way was something the EU had started to do, notably in its relations

\footnotetext{
${ }^{20}$ It is worth noting, however, that the SPAs that the EU has signed with other countries, such as Brazil and China, in recent years, also cover a broad range of issues.

${ }^{21}$ Again, this is largely true for SPAs with other countries; for a discussion of the SPAs that the EU has signed with these other countries, see Cottey on the EU-China SPA (this volume) and Ferreira-Pereira on the EU-Brazil SPA (also in this volume).
} 
with other strategic partners starting off with the new generation FTA bilateral agreements between the EU on the one hand and respectively other countries such as South Korea and Japan on the other (AtanassovaCornelis and Hellendorff, this volume). ${ }^{22}$ Having these separate issues covered between the two sides was also of interest also to Canada. In fact, by separating out these issues the SPA agreement was able to be more declaratory rather than overly legal. It also meant that the trade agreement could remain separate. Having the SPA meant updating the 1976 agreement so as to cover a much broader range of issues.

One of the final considerations for the Canada-EU agreements is whether the provisions will be ratified. When negotiations were taking place right after the immediate start of the negotiations, the Canadian provinces were closely involved, because they had been insufficiently involved in earlier rounds of negotiations. Canadian provinces have not had this privileged position in negotiating subsequent trade agreements, however (such as the subsequent renegotiation of the North American Free Trade Agreement or NAFTA). However, whilst starting the negotiations it was unclear whether the final agreement would have to be ratified by governments at all levels. In the EU, trade agreements are the responsibility of supranational bodies. However, a mixed-agreement does require ratification by lower levels. At a late stage, the EU decided that in order for them to enter into force in their entirety, the ratification process had to be completed by obtaining approval from all levels (a decision suggested by Commission President Juncker and taken over by the Council). In practice, this process required that the European Parliament needed to give its consent (which it did on 15 February 2017), as did the parliaments of all EU member states and regional parliaments and upper houses). As we have seen above, there have been strong voices of opposition in several lower-level parliaments (such as the Walloon parliament ${ }^{23}$ ) but also in Germany and most recently in the Netherlands to the

${ }^{22}$ More generally, the EU was starting to examine different strategic partnerships with major new powers around the globe such as Brazil, India, China and South Africa (Knodt et al. 2015).

${ }^{23}$ The situation in Belgium is that in total seven parliaments need to sign and then to ratify for the treaty to pass: the two chambers of the bicameral parliament of Belgium, the five regional parliaments and two language community parliaments. The Walloon parliament upset the process by voting against it in mid-October 2016. After hefty negotiations, the Walloons approved it two weeks later. Ratification is another step that has at the time of writing not yet been completed neither in Belgium nor in the EU at large. In May 
SPA and the CETA. In Germany in October 2015 more than 250,000 people protested the agreement-the largest number of demonstrators in the past two decades (Miéral 2017). In the Netherlands in February 2020 the Dutch second chamber of parliament only passed the CETA and SPA agreement by three votes, but given the political composition of the upper house, it was possible that it could fail in a vote there (Reuters 2020). If it failed there, the Netherlands would be the first member state parliament to reject a Free Trade Agreement. Those opposing it in the Netherlands included farmers and labour groups, supported by various opposition parties (Financial Times, 18 February 2020). In an interview conducted by the author with a member of the Dutch parliament who opposes CETA, the concerns focus in particular on the Investment Court System (ICS). Those who oppose CETA worry that companies would put legal challenges to national governments. They are also concerned that CETA would lead to lower environmental and labour standards. ${ }^{24}$ In the Canadian context, the federal parliament has full authority to negotiate, sign and ratify international trade agreement. It does not, however, have the power to impose treaties on provinces. Thus, earning the approval by Canadian provinces has been achieved by involving provinces directly in the negotiations. Canada has fully ratified the agreement, and at the time of writing, 13 of the current $27 \mathrm{EU}$ member states have ratified the agreements. ${ }^{25}$

The Canada-EU strategic partnership and the CETA agreement reflect the considerations mentioned in the introduction of this book (FerreiraPereira and Smith 2021) pertaining to the three different 'logics' of strategic partnerships. We observe patterns that we can trace back to the internal logics of strategic partnership due to a desire within the EU to develop relationships with countries such as Canada as a preferred partnership. This occurs in particular after the September 11 attacks (Croci and

2020 in total 14 member states have given the Council notification of ratification, with Luxembourg having completed the parliamentary approval process in May 2020 and will give notification shortly.

${ }^{24}$ Interview with the author with a member of the Dutch senate, video-phonecall, 17 June 2020.

${ }^{25}$ European ratification is kept up to date on this website: https://www.consilium. europa.eu/en/documents-publications/treaties-agreements/agreement/? id=2016017. In addition, the United Kingdom had also already ratified the agreement on 8 November 2018-well before leaving the EU. 
Verdun 2007) and with reference to the ESS. There are also elements of the external logic of strategic partnership that play a role here: the external environment changes dramatically in the 2000s and into the early 2010 s. From the perspective of the EU partnership with Canada is seen as a smaller version of might one day be a partnership with the US. Finally, the identity logic plays a role here too-Canada is seen as a country that in many ways shares similar values. Both parties (i.e. both Canada and the EU) realise that there are many overlaps in terms of values in the two polities. What is however a bit of a challenge here is that the external environment has been changing in the past years. The winds of change are blowing; there is less support for trade agreements and there is more criticism towards the substance of the agreements. Therefore the ratification of the CETA is at the time of writing unclear.

\section{CONCLUSION}

Having reviewed the four periods of EU-Canada cooperation, this chapter is now in a position to provide an answer to the core question that is addressed here: Why was it possible to sign an SPA, in 2016 but not before? In answering this question, the chapter looked at why the deepening of the EU-Canada strategic partnership was difficult to achieve in the first three decades after having established the early institutional structure provided by the 1976 agreement. In providing an answer to the overarching question raised here, the chapter took stock of the various agreements that have been made in the period since the 1950s. It looked among other things at the role of the kinds of agreements that have been signed.

The literature reviewed suggested that, among other things, earlier cooperation in this domain after 1976 mostly consisted of sectoral agreements in part because Canada and the EU had not yet identified the Canada-EU partnership as important to the international well-being of either side, whether this was economic, security, or otherwise. Each of them relied on Cold War legacies with the US being the dominant partner in the transatlantic alliance and neither of them considering the need for an institutionalised bilateral agreement separate from the United States as absolutely crucial. Clearly, during the first and second time periods (i.e. respectively 1959-1976 and 1977-1996), the international context was still characterised as bipolar with the Soviet Union and its partners versus the US and the western partners with all of them collaborating on security 
matters through NATO. Even as the Cold War had ended, Canada and the EU were still not seeing each other as significant others; instead the US was seen as the major partner to work with. Furthermore, the institutional structure of the EU was still less developed compared to what it became with the entry into force of the Maastricht Treaty (November 1993) and later the Lisbon Treaty (December 2009). The EU was a unitary actor only in the area of commercial relations, not in the area of foreign and security relations but both treaties contributed to a further institutional development of the EU as a foreign and security policy actor. Indeed, even to this day the EU is only as strong in foreign relations as the agreement that can be mustered among the member states.

The 2007 Lisbon Treaty that entered into force in December 2009 provided the EU with a more bureaucratic and institutional apparatus to make it easier to work on what the EU is about in terms of foreign relations. Thus, the reason that the strategic partnership and the CETA could be signed in 2016 has both an endogenous and an exogenous component. Endogenous in that both Canada and the EU were realising that they were internally needing to diversify and become less reliant on the US. In the case of the EU, the institutional structure of the EU had changed with the Lisbon Treaty. In Canada, its experience with the failed trade agreement with the EU in the 2000s had brought about a realisation that any agreement like this needed stronger buy-in from lower-level governments. A key exogenous factor was a move of the US away, gradually, from being a reliable transatlantic partner that was keen on multilateralism with a strong allegiance to Canada and the EU, towards an orientation increasingly more towards the rising powers of the rest of the world. Neither Canada nor the EU were getting strong signals from the US that they were an 'important' or 'preferred' partner. Thus, it became easier to do a bilateral deal together. Furthermore, each of these polities needed the experience of the prior decades to learn that the other side was governed institutionally in a loosely federal way. Each of them had veto players among them that needed to be catered to, and thus any negotiation between them needed to be undertaken very carefully with full attention to the many voices around the table. Because of these factors, neither side was keen to work on a comprehensive agreement prior to the fourth period. In fact during the third period there could have been a deeper free trade agreement but it did not materialise, in part because on the Canadian side the federal level was unable to commit the lower levels 
to a joint agreement and the EU was concerned the time was not right to create an overarching agreement.

Thus the SPA, together with the CETA that was signed at the same time and covered other ground, became the most comprehensive set of agreements that the EU had signed with another major advanced economy. It includes various dimensions: agriculture, arctic politics, environmental, fisheries, Internet-security, judicial, maritime issues, political, research and development, security, social, taxation, combatting terrorism, and of course global economic issues. As the world moves towards more nationalistic tendencies, the CETA and SPA if ratified may stand out as a much more valuable and important agreement, seeing that it was negotiated during a time that was more favourable to these kinds of agreements. The CETA has been mentioned as a possible model for the UK that has left the EU, for instance, whilst the US is less oriented towards trade agreements or multilateralism.

For Canada and the EU to come to these important agreements, they first had to understand each other's internal institutional structures a bit better. They also needed to appreciate the global pressures that each were facing. The EU has a tendency of specialising its foreign agreements and borrowing from some agreements with some countries as a template for their agreements with others. Both parties had a major focus on the US. For decades this preoccupation made it difficult for either party to embark on a major Canada-EU deal. However, the twenty-first century changed this orientation. Furthermore, the Canada-EU SPA/CETA agreements were negotiated at a time when there was permissive consensus for such an advanced agreement. At this time, there was less citizen discontent in Western societies (Schirm 2020). By the tail end of the negotiations, but even the time of signing and ratification, citizens and non-governmental associations increasingly queried its components, such as the implicit powers provided to multinationals and as well as whether sufficient social and environmental safeguards were in place. The election of Donald Trump to the US presidency and the process of Brexit have led to a profound change the international global order and a sense of the future of multilateralism. The Canadians and the EU level are very keen to secure the Canada-EU agreements.

As we look towards the next period, we still need to await a few developments: first whether all EU member states and lower-level regional governments and upperhouse in the EU member states will in fact ratify the CETA and SPA agreements; second what the Agreement will lead to 
in practice. Furthermore, as the COVID-19 crisis unfolds it is as of yet unclear to what extent the parties will remain oriented towards multilateralism and globalisation or retreat towards more localism and nationalism, thereby become more inward looking. Only time will tell whether the framework offered will provide the collaboration that those who drafted the agreement had in mind.

\section{REFERENCES}

Adams, D. K. (1992). Overview. In D. K. Adams (Ed.), Britain and Canada in the 1990s. Proceedings of a UK/Canada Colloquium. Leeds Castle, Kent, England. The Institute for Research on Public Policy. Aldershot: Dartmouth Publishing.

Bailes, A. J. K. (2005, February). The European Security Strategy: An Evolutionary History. Stockholm, Sweden: Stockholm International Peace Research Institute.

Barry, D. (1979). The Politics of "Exceptionalism": Canada and the United States as a Distinctive International Relationship. Dalhousie Review 60 (Spring).

Barry, D. (1998). The Canada-European Union Turbot War. Internal Politics and Transatlantic Bargaining. International Journal, 53(2), 253-284.

Barry, D. (2003). Managing Canada-U.S. Relations in the Post-9/11 Era. Do We Need a Big Idea? Policy Paper on the Americas (Vol. XIV, Study 11), Center for 1996 Joint Political Declaration on EU-Canada Relations.

Barry, D. (2004). Towards a Canada-EU Partnership? In P. Crowley (Ed.), Crossing the Atlantic: Comparing the European Union and Canada (pp. 3560). Aldershot: Ashgate Publishing.

Barry, D., Appelbaum, B., \& Wiseman, E. (2014). Fishing for A Solution: Canada's Fisheries Relations with the European Union, 1970-2013. Calgary: Calgary University Press.

Benz, A. (2010). Multilevel Parliaments in Canada and Europe. International Journal, 66(1), 109-126.

Bernard-Meunier, Marie. (2006). Did You Say Europe? How Canada Ignores Europe and Why That Is Wrong. In A. Cooper \& D. Rowlands (Eds.), Canada Among Nations. Montreal: McGill University Press.

Bierbrauer, E. (2014). Negotiations on the EU-Canada Comprehensive Economic and Trade Agreement (CETA) Concluded. Study for the European Parliament, Directorate-General for External Policies Policy Department, DG EXPO/B/PolDep/Note/2014_106 October 2014 PE 536.410.

Bollen, Y., De Ville, F., \& Gheyle, N. (2020). From Nada to Namur; SubFederal Parliaments' Involvement in European Trade Politics, and the Case 
of Belgium. In J. Broschek \& P. Goff (Eds.), The Multilevel Politics of Trade (pp. 256-279). Toronto: University of Toronto Press.

Broschek, J., \& Goff, P. (2020). Introduction: The Evolution of Multilevel Trade Politics. In J. Broschek \& P. Goff (Eds.), The Multilevel Politics of Trade (pp. 3-33). Toronto: University of Toronto Press.

Commission of the European Communities. (2003, May 5). Communication from the Commission on EU-Canada Relations. COM (2003) 266 final.

Croci, O., \& Tossutti, L. (2007). That Elusive Object of Desire: Canadian Perceptions of the European Union. European Foreign Affairs Review, 12(4), 287-310.

Croci, O., \& Tossutti, L. (2009). Canada and the EU: A Story of Unrequited Attraction. In F. Laursen (Ed.), The EU in the Global Political Economy. Brussels: PEI Peter Lang.

Croci, O., \& Verdun, A. (2004). Searching for a Counterweight-Canada and the European Union. Jean Monnet/Robert Schuman Paper Series, 4(12), 1-11. https://eucenter.as.miami.edu/_assets/pdf/crociverdunfinal. pdf. Accessed 19 January 2020.

Croci, O., \& Verdun, A. (2006, June 12). Security Challenges in the 21st Century: EU, USA, and Canadian Approaches. Policy workshop, The Transatlantic Security Triangle: Where Does Canada Fit? Ottawa. https://carleton.ca/can adaeurope/wp-content/uploads/Croci-Verdun19-June2006.pdf. Accessed 19 January 2020.

Croci, O., \& Verdun, A. (2007). Canada: Taking Security Seriously After 11 September? In E. Kirchner \& J. Sperling (Eds.), Global Security Governance: Competing Perceptions of Security in the 21st Century (pp. 137-160). London: Routledge.

Crowley, P. (Ed.). (2004). Crossing the Atlantic: Comparative EU-Canadian Studies. London: Ashgate.

De Mestral, A., \& Fox-Decent, E. (2008). Rethinking the Relationship Between International and Domestic Law. McGill Law Journal, 53(4), 576-648.

DeBardeleben, J., \& Leblond, P. (2010). The Other Transatlantic Relationship: Canada, the EU, and 21st-century Challenges. International Journal, 66(1), $1-7$.

Dolata-Kreutzkamp, P. (2010). Drifting Apart? Canada, the European Union and the North Atlantic. Zeitschrift Für Kanada-Studien, 30(2), 28-44.

European Union. (2017, April 1). 'EU-Canada Strategic Partnership Agreement' Factsheets. Brussels, Unique ID: 161029_11.

Fafard, P., \& Leblond, P. (2013). Closing the Deal: What Role for the Provinces in the Final Stages of the CETA Negotiations? International Journal, 68(4), $553-559$. 
Ferreira-Pereira, L. C., \& Smith, M. (2021). Introducing the EU's Strategic Partnership. In L. C. Ferreira-Pereira \& M. Smith (Eds.), The European Union's Strategic Partnerships. Cham: Palgrave-Macmillan.

Financial Times. (2020, February 18). A Dutch Trade Rebellion, by Mehreen Khan.

Gardner, A. (2014, September 11). EU and Canada Move Closer to Strategic Partnership Agreement. Politico.

Gotev, G. (2016, October 31). CETA: Controversy Over EU Pressure on Wallonia. Euractiv. https://www.euractiv.com/section/trade-society/news/ controversy-over-eu-pressure-on-wallonia-over-ceta/.

Government of Canada and European Commission. (2008). Assessing the Costs and Benefits of a Closer EU-Canada Economic Partnership. A Joint Study by the European Commission and the Government of Canada.

Haglund, D. G., \& Mérand, F. (2010). Transatlantic Relations in the New Strategic Landscape: Implications for Canada. International Journal, 66(1), 23-38.

Hampson, F., \& Maule, C. (Eds.). (1991). Canada Among Nations 1990-1992. Ottawa: Carleton University Press.

Hill, C. (1993). The Capability-Expectations Gap, or Conceptualizing Europe's International Role. Journal of Common Market Studies, 31(3), 305-328.

Hill, C. (1998). Closing the Capabilities-Expectations Gap? In J. Peterson \& H. Sjursen (Eds.), A Common Foreign Policy for Europe? (pp. 18-38). London: Routledge.

Howe, B., \& Kerby, M. (2009). The Canada-EU Turbot War of 1995 and the Cybernetic Model of Decision-Making. The Round Table, 98(401), 161-179. https://doi.org/10.1080/00358530902757883.

Hübner, K. (Ed.). (2011). Europe, Canada and the Comprehensive Economic and Trade Agreement. London: Routledge.

Hübner, K., Deman, A.-S., \& Balik, T. (2017). EU and Trade Policy-Making: The Contentious Case of CETA. Journal of European Integration, 39(7), 843-857. https://doi.org/10.1080/07036337.2017.1371708.

Hülsemeyer, A. (2006). The Political Economy of Canada's Relations with the European Union. In P. James, N. Michaud, \& M. O'Reilly (Eds.), Handbook of Canadian Foreign Policy (pp. 337-364). Lanham: Lexington.

Kagan, Robert. (2003). Of Paradise and Power: America and Europe in the New World Order. New York: Alfred A. Knopf.

Kerremans, B., Adriaensen, J., Colli, F., \& Coremans, E. (2019). Parliamentary Scrutiny of Trade Policies Across the Western World. EP/EXPO/B/INTA/2018/07, Study prepared for the Policy Department, DG External Policies, European Parliament. https://www.europarl. europa.eu/RegData/etudes/STUD/2019/603477/EXPO_STU(2019)603 477_EN.pdf. 
Knodt, M., Piefer, N., \& Müller, F. (Eds.). (2015). Challenges of European External Energy Governance with Emerging Powers. Farnham: Ashgate.

Kukucha, C. J. (2011). Provincial Pitfalls: Canadian Provinces and the CanadaEU Trade Negoations. In K. Hübner (Ed.), Europe, Canada and the Comprehensive Economic and Trade Agreement (pp. 130-150). London and New York: Routledge.

Kukucha, C. J. (2013). Canadian Sub-Federal Governments and CETA: Overarching Themes and Future Trends. International Journal, 68(4), 528-535.

Long, D. (2003). Transatlantic Relations and Canadian Foreign Policy. International Journal, 58(4), 591-614.

Mace, G., \& Hervouet, G. (1989). Canada's Third Option: A Complete Failure? Canadian Public Policy, 15(4), 387-404.

Mahant, E. E. (1976). Canada and the European Community: The New Policy. International Affairs, 52(4), 551-564.

Mahant, E. (1981). Canada and the European Community: The First Twenty Years. Journal of European Integration, 4(3), 263-279.

Mahant, E. (1985). Institutional Aspects of Canada-European Community Relations. Canadian Yearbook of International Law, 23, 285-296.

Mérand, F., \& Rayoux, A. (2018). Foreign, Security and Defence Policies. In E. Brunet-Jailly, A. Hurrelmann, \& A. Verdun (Eds.), European Union Governance and Policy-Making: A Canadian Perspective (pp. 176-195). Toronto: University of Toronto Press.

Mérand, F., \& Vandemoortele, A. (2011). Europe's Place in Canadian Strategic Culture (1949-2009). International Journal, 66(2), 419-438.

Miéral, J. (2017). The CETA, the German Federal Constitutional Court and the Distribution of Competences Between the EU and Its Member States. https://rsiblog.blogactiv.eu/2017/11/07/the-ceta-the-german-federal-con stitutional-court-and-the-distribution-of-competences-between-the-eu-andits-member-states/\#_ftnref4.

Mildner, S.-A. (2008). Junior Partner Canada: Transatlantic Trade Relations Under Germany's EU Presidency. International Journal, 63(3) (Summer), 646-663.

Missios, P., \& Plourde, C. (1996). The Canada-European Union Turbot War: A Brief Game Theoretic Analysis. Canadian Public Policy, 22(2), 144-150.

Muirhead, B. (2004). From Special Relationship to Third Option: Canada, the US and the Nixon Shock. American Review of Canadian Studies, 34(3), 439462 .

Paquin, S. (2013). Federalism and the Governance of International Trade Negotiations in Canada: Comparing CUSFTA with CETA. International Journal, $68(4), 545-552$. 
Paquin, S. (2020). Federalism and Trade Negotiations in Canada: CUSFTA, CETA and TPP compared. In J. Broschek \& P. Goff (Eds.), The Multilevel Politics of Trade (pp. 35-54). Toronto: University of Toronto Press.

Pentland, C. (1991). Europe 1992 and the Canadian Response. In F. Hampson \& C. Maule (Eds.), Canada Among Nations 1990-1992 (pp. 125-144). Ottawa: Carleton University Press.

Pentland, C. (2009). Enlargement: Expanding the Realm of European Governance. In I. Tömmel \& A. Verdun (Eds.), Innovative Governance in the European Union: The Politics of Multilevel Policymaking (pp. 179-196). Boulder: Lynne Rienner.

Potter, E. (1999). Transatlantic Partners: Canadian Approaches to the European Union. Montreal and Kingston: McGill-Queen's University Press.

Rayroux, A. (2019). The EU's Reputation in Canada: Still a Shallow Strategic Partnership? In N. Chaban \& M. Holland (Eds.), Shaping the EU Global Strategy: Partners and Perceptions (pp. 55-75). Basingstoke: Palgrave Macmillan.

Reuters. (2020, February 18). EU-Canada Free Trade Deal Clears Hurdle in Dutch Parliament. https://www.reuters.com/article/eu-canada-nether lands/eu-canada-free-trade-deal-clears-hurdle-in-dutch-parliament-idUSA5 N28R00I.

Rudd, D. (2011). The Future of Trans-Atlantic Relations: A View from Canada. In A. Dorman \& J. Kaufman (Eds.), The Future of Transatlantic Relations: Perceptions, Policy and Practice (pp. 56-77). Stanford: Stanford University Press.

Schirm, S. (2020). Parallel Orders? Emerging Powers, Western Discontent, and the Future of Global Economic Governance. In M. Rewizorski, K. Jędrzejowska, \& A. Wróbel (Eds.), The Future of Global Economic Governance: Challenges and Prospects in the Age of Uncertainty (pp. 15-28). Cham, Switzerland: Springer.

Sharp, M. (1972). Canada-U.S. Relations: Option for the Future (special issue). International Perspectives, 32(2), 1-21.

Skogstad, G. (2012). International Trade Policy and the Evolution of Canadian Federalism. In H. Bakvis \& G. Skogstad (Eds.), Canadian Federalism (3rd ed.). Don Mills, ON: Oxford University Press.

Tossutti, L., Croci, O., \& Verdun, A. (2007). National Threat Perception: Survey Results from Canada. In E. Kirchner \& J. Sperling (Eds.), Global Threat Perception: Elite Survey Results from Canada, China, the European Union, France, Germany, Italy, Japan, Russia, the United Kingdom and the United States (GARNET Working Papers No. 18/07).

Tsuruoka, M. (2006). "Expectations Deficit" in EU-Japan Relations: Why the Relationship Cannot Flourish. Current Politics and Economics of Asia, 17(1), 107-126. 
Wood, D., \& Verdun, A. (2010). Canada-European Union Relations: A Review of the Literature from 1982 to 2010. International Journal, 66(1) (Winter), $9-21$. 
Strategic Partnerships with the BRICS 


\title{
European Union-Brazil Relations: A Strategic Partnership in Suspended Animation
}

\author{
Laura C. Ferreira-Pereira
}

\section{INTRODUCTION}

The Strategic Partnership (SP) between the European Union and Brazil signed in July 2007 was forged at an auspicious juncture (Ferreira-Pereira 2016; Gratius 2016; Saraiva 2017; Blanco and Luciano 2018) that would reveal itself transitory and virtually unrepeatable in virtue of a succession of crises that started to unfold shortly afterwards on both sides of the Atlantic. At the time, both actors were engaged in the process of redefining their international personae and postures towards the consolidation of their status and reputation as ascending global powers-a sort of rising stars. The EU emerged as an aspiring foreign and security actor committed to the promotion of 'effective multilateralism' in the global arena (Council of the EU 2003). It was enthused by the prospect of a new Treaty (i.e. the Treaty of Lisbon) that would finally put an end to a

L. C. Ferreira-Pereira $(\varangle)$

Department of Political Science and Research Center in Political Science (CICP-UMinho), University of Minho, Braga, Portugal e-mail: lpereira@eeg.uminho.pt

(C) The Author(s), under exclusive license to Springer Nature

Switzerland AG 2021

L. Ferreira-Pereira et al. (eds.), The European Union's Strategic

Partnerships, The European Union in International Affairs, https://doi.org/10.1007/978-3-030-66061-1_7 
tortuous constitutional crisis and by the conclusion of its historic Central and Eastern enlargement that brought 12 new members into the European fold. In its turn, Brazil stood out as an emerging ambitious political and economic power driven by its willingness to change the rules of the game in international politics and economics, and to make the principal multilateral fora more inclusive and democratic, thereby mirroring the power shift that had taken place in the global arena since the beginning of the 2000s. Such common 'rising star' experience was mirrored in the sizeable political ambition underpinning the Lisbon Joint Statement that inaugurated the SP in 2007 as well as the ensuing bilateral high-level dialogue and jointly coordinated political agenda focused on a vast gamut of policy areas of particular relevance to both actors.

However, after a few years of promising achievements covering the period between 2008 and 2014 (Ferreira-Pereira 2016), the SP entered into a kind of suspended animation. From 2015 until 2019, there was no annual summit and the implementation of the third joint plan was postponed sine die. A multilevel crisis, which crystallised on both sides of the Atlantic after 2008 only to get particularly acute as of 2014, has plagued EU-Brazil cooperation with a state of inertia, whose disappearance is hard to predict at the time of writing. On the one hand, the EU has witnessed the deterioration of its security environment after the Russian annexation of Crimea in 2014 and has been under stress with the migration and refugee crises while facing increased contestation fostered by radical parties with an anti-EU agenda. Moreover, since 2016, it has been enmeshed in the Brexit imbroglio bringing with it systemic instability and uncertainty (which extended throughout 2020 in the aftermath of the withdrawal of the UK on 31st January of that year), and has had to cope with the Donald Trump administration's neglect regarding the European integration process. Understandably, the Global Strategy for the European Union Foreign and Security Policy launched in the same year has aptly depicted the EU as living 'in times of existential crisis' and 'under threat' (EEAS 2016: 13). On the other hand, Brazil experienced the worsening of an endemic politico-institutional, economic and social crisis leading up to the impeachment of Dilma Rousseff in August 2016 and eventually to the emergence of a far-right leadership in the wake of the presidential elections of 2018 . Besides resulting in considerable reputational losses for Brazil's status and image in its region and the world, both processes have deepened polarisation in national politics and society. 
The most recent relevant literature on the EU-Brazil SP emphasises its deterioration and current stagnation (Gratius 2018; Blanco and Luciano 2018; Wisniewski and Dahab 2017). Such a negative evolution partly reflects the 2008 economic crisis and its diverse internal repercussions on both sides that have affected the EU's and Brazil's predisposition to invest in closer relations (Gratius 2016; Saraiva 2017; Neves 2018). It also reflects upon future challenges and paths for cooperation between the two actors in the economic, security/military and climate change spheres (Ayuso and Gratius 2018; Poli 2018; Neves 2018). In addition, the origins of the SP have been revisited to scrutinise further the main factors that enabled its successful conclusion in 2007 (Santander 2016; Meissner 2018; Müller 2018). Some studies address the bilateral SP and related topics largely from the perspective of Brazil (Gratius 2018; Saraiva 2018; Guimarães and Piefer 2016), while most of them overlook the hardening of the EU's multilevel crisis path derived from the combination of challenges mentioned above.

This chapter traces and critically assesses the EU's and Brazil's crisis experiences that have thrown the SP into a state of suspended animation, and its particular implications in the context of the EU's endeavours to build a stronger international presence in a post-Brexit globalised world. Although the analysis will be undertaken from the perspective of the actor 'EU', rather than from that of the partner 'Brazil', a key contribution of the argument is its focus on the impact of political change within one of the EU's key strategic partners on the capacity or inclination of the EU to further the partnership. For analytical purposes, the temporal focus considered to be most relevant to this chapter corresponds to the years between 2015 and 2020, since the post-2014 period is illustrative of the cooperative inertia in relations between the EU and Brazil at the highest political level. The present study argues that the EU-Brazil SP has been captured by and enmeshed in a multilevel crisis mindset that pushes both actors apart, and, for that reason, it has become a hostage to fortune, rather than reflecting a deliberate politico-strategic mindset focused on seizing opportunities to revamp the bilateral engagement. Hence, the EU-Brazil SP came to be characterised largely by number of missed opportunities that are examined in the final section. The chapter concludes that, ironically enough, the state of limbo characterising EUBrazil relations in recent years is at odds with the EU's need to reinforce its strategic partnership policy to cope with an increasingly complex and contested world, as acknowledged in the Global Strategy. 


\section{The Short History of the EU-Brazil Strategic Partnership: Key Motivations, Major Themes, Policy Areas and the Institutional Dimension}

When compared with other strategic relationships cultivated by the EU, whose deepest roots either precede the Cold War period or were consolidated during this period, like those with the US and Canada (see Smith; Verdun in this volume), the bilateral partnership with Brazil embodies a relatively short story. Historically, the 'Framework Agreement for Cooperation between the Economic European Community and the Federative Republic of Brazil' signed between the two parties in September 1980 (known as the 1982 agreement for the date it entered into force) and the 'Framework Agreement for Cooperation between the European Economic Community and Brazil' of June 1992 formed the foundational framework for EU-Brazil relations. Yet, such relations were characterised by a minimalist cooperation throughout most of the 1990s and 2000s (Ferreira-Pereira 2016). The establishment of the EU-Mercosur Cooperation Framework Agreement in 1995 demonstrated the EU's preference for interregionalism, rather than bilateralism, in its approach to South America. This strategy with a view to strengthening regional integration modelled on the European integration venture (Santander 2016) would linger for more than a decade. As a result of this, both the scope and the weight of the EU-Brazil relationship remained limited (Lessa 2010; Lazarou and Edler 2012). On the other hand, the process of selfreinvention undergone by the EU in the first decade and a half or so after the end of the Cold War, encompassing simultaneous processes of deepening (i.e. successive Treaty revisions) and enlargement to Northern and Eastern Europe, also took its toll on the relations between Brussels and Brasília. Therefore, little further progress in the EU-Brazil partnership was made between 1992 and 2007 (Ferreira-Pereira 2016).

A more institutionally structured and integrative bilateral rapport only emerged in the context of the formal SP signed during the first EU-Brazil Summit held in Lisbon, in July 2007. Considering the significant role that Portugal had played hitherto in the development of the relationship and the agenda set-up for the Portuguese Presidency of the Council of the EU (August-December 2007), it was no coincidence that this milestone was reached when Portugal was at the helm of the EU Council (FerreiraPereira 2008). Equally important, the achievement of the Portuguese aims greatly benefited from the Barroso-led Commission's advocacy of a 
strategic partnership in two key documents that initiated the SP, notably the Brazil Country Strategy Paper 2007-2013 and the Communication from the Commission to the European Parliament and the CouncilTowards an EU-Brazil Strategic Partnership, both of which appeared in May 2007. Besides acknowledging Brazil as a rising power, a pivotal player in global governance fora such as the UN and the World Trade Organisation (WTO) and 'a vital ally for the EU' in tackling issues of global concern like climate change, these documents of reference clearly singled out its status as regional leader vis-à-vis other Latin American states. The Commission's Communication literally stated: 'The time has come to look at Brazil as a strategic partner...A quasi-continent in its own right, Brazil's demographic weight and economic development make it a natural leader in South America and a key player in Latin America' (European Commission 2007). In these terms, Brazil was recognised by the EU as its main strategic counterpart in South America and included in its selective network of SPs in the realm of the Common Foreign and Security Policy (CFSP).

The motivations for the establishment of a SP were thus mixed on the part of each actor, but they had in common three interlinked aspects related to the redefinition of the EU's and Brazil's international personae and roles. This had a bearing not only on the self-perception of each actor's role in the international arena, but also on their mutual perceptions (i.e. perceptions of each other). From the perspective of the EU and Brazil, the institutionalisation of a SP would enable them to leverage a range of global interests and preferences. And, in so doing, it would reinforce the external recognition of their developing global status. Overall, the SP was considered a mutually reinforcing vehicle for the amplification of their profiles and roles in the global governance architecture(s), with all the reputational gains this entailed (Ferreira-Pereira 2016). Interestingly, the redefinition of the EU's and Brazil's foreign policy profiles as international political and security actors, besides exhibiting similar traits and ambitions (ibid.), was more or less temporally contiguous. On both sides of the Atlantic, it began to take shape as of 2003 only to become more pronounced during the second half of the 2000s, against the backdrop of the repercussions of the post-9/11 US drift towards unilateralism and the failure of multilateral trade negotiations, notably of a global agreement at WTO's Doha Round and the EU-Mercosur association agreement. 
In Brazil, the move towards a globalist foreign policy coincided with the Presidency of Luís Inácio Lula da Silva (2003-2010) and his determination to ensure that the acknowledgement of Brazil's international citizenship became reflected in the upgrade of the country's stance in major global governance structures, but also in the globalisation of the country's economy (Cervo 2010). There was also the ambition to promote the assertion of 'Power Brazil' ('Brasil Potência') that would enable the country to speak on equal terms with other powers in international politics, economy and trade, and which encompassed the selfendowed right to engage in proposals, agreements and negotiations with game-changing effects. The so-called Lula Moment ('Momento Lula') corresponded to an exceptionally non-conformist, counter-hegemonic, pro-active and resourceful phase of presidential diplomacy, which saw the emergence of a Brazilian self-image marked by self-esteem and selfassurance, both regionally and on the international stage. Symptomatic of this was the leadership of the UN-sanctioned peacekeeping mission in Haiti (MINUSTAH), the mediator role in the Iran nuclear crisis, but even more so the bid for a permanent seat on the UN Security Council (Lessa 2010; Cervo 2010; Christensen 2013; Steiner et al. 2014).

Curiously enough, the 'Lula Moment' gained momentum after a phase in which the leadership status of Brazil was challenged by its neighbours. This deprived the country of both individual and collective Mercosur backing for its bids for international posts in major organisations, including the UN Security Council (Malamud 2011). Nonetheless, at the regional level, the SP with the EU represented a sort of diplomatic vindication of Brazil's leadership status. In the midst of the numerous regional integration-based organisations and initiatives (the so-called 'spaghetti bowl') that had traditionally hindered the emergence of a single voice in South America and its extra-regional recognition, the country stood out - if not as the uncontested interlocutor-as the leading power of the region. It was in this context that Brazil came to prioritise a united South America as a strategic platform for its domestic affluence and insertion in global governance structures (Cervo 2010; Christensen 2013); and to take the lead in efforts to propel regional integration, namely in the domain of security and defence, conducive to the creation of the Union of South American Nations (UNASUR) and the South American Defense Council (SADC) in 2008 and 2009, respectively. At the same time, Brazil looked assertively for opportunities to secure a leading place in the Global South as part of a foreign policy strategy, which pursued 
'autonomy through diversification' of external ties with non-traditional more peripheral partners (e.g. China, Middle East and Africa) (Vigevani and Cepaluni 2007: 283), and sponsored a global power diffusion agenda (Christensen 2013), deemed instrumental to 'democratise globalisation' (Cervo 2010: 9).

Within the EU, the process of redefinition of its international profile was inaugurated with two novel developments in 2003, namely the operationalisation of the European Security and Defence Policy (ESDP), through the launching of the first autonomous military and civilian crisis management operations in different regions of the world, and the approval of the European Security Strategy (ESS). While enshrining, for the first time ever, a common European threat assessment, the latter explicitly signalled the EU's ambition to 'make an impact on a global scale' in order 'to contribute to an effective multilateral system leading to a fairer, safer and more united world' (ESS 2003). In view of Brazil's proclivity to play a vocal role in the reform of the key international economic organisations and multilateral negotiations, as exhibited in the Brazilian-led collapse of the WTO's Doha Round (Cervo 2010; Saraiva 2018), the establishment of a SP presented itself as a valuable instrument for the EU to pursue multilateral solutions to contemporary challenges such as the fight against terrorism, transnational crime, human trafficking, proliferation of weapons of mass destruction and the achievement of the Millennium Development Goals. On the other hand, the EU feared that its traditionally distinctive role in South America, cemented by deeprooted historical and cultural ties, might be overshadowed or overtaken by the increasing Chinese economic presence in South America and, particularly, Brazil with whom China had signed a strategic alliance and trade agreements in 2004 (Meissner 2018: 61; Santander 2016: 187). Similar reasoning may be applied to the US that at the time featured as an additional source of competition in trade, investment and business spheres, despite the collapse of negotiations aimed at the creation of a Free Trade Area of the Americas (FTAA). Therefore, efforts to maintain the prevalence of its role in South America and counterbalance Chinese and American presence in the region (Meissner 2018: 62) pushed the EU towards including Brazil in its exclusive circle of strategic partners.

One of the acknowledged key underpinnings of the EU-Brazil SP has been the cultural, normative and political-institutional affinities manifested in the adherence of the two actors to the Western community of 
values (e.g. democracy, rule of law, human rights and peaceful settlement of disputes) and common participation in Western-inspired relevant international regimes (e.g. Treaty on Non-Proliferation of Nuclear Weapons) and institutions (Valladão 2008; Steiner et al. 2014; Stuenkel 2011; Müller 2018). Also, the two actors have shared an unswerving commitment to multilateralism. Not unnaturally, the framework document formalising the SP underlined themes such as the centrality of multilateralism, the defence of democracy and human rights, the promotion of sustainable development and the fight against poverty, besides cooperation in environmental and energy policy-related issues and tackling global security challenges (e.g. disarmament, non-proliferation, arms control and transnational crime) (Council of the EU 2007). At the same time, the need to overcome the fatigue with and failure of negotiations of a EUMercosur association agreement was among the principal factors that accounted for the signing of the EU-Brazil SP (Lessa 2010; Gratius 2016; Santander 2016). The advancement of the Mercosur agenda towards the success of the EU-Mercosur negotiations was a key theme of the SP. The role of Brazil was of central importance to the achievement of that outcome, which was deemed crucial for regional power balance, notably the relations with its strategic neighbour and partner, Argentina (Gratius 2018; Ferreira-Pereira 2016; Wisniewski and Dahab 2017). Viewed from this angle, it has been noted that Brazil has used the SP with the EU 'as an instrument for its regional policy' and as a means of prioritising the interregional (i.e. EU-Mercosur) agenda (Lazarou and Edler 2012: $41-42)$.

The above-mentioned matters constituted the principal, albeit not exclusive, policy focus of the EU-Brazil SP. Yet, as the politico-diplomatic partnership dynamics became more institutionalised with the organisation of high-level summits and regular ministerial meetings, the array of thematic domains of cooperation became wider and denser. Areas such as science and technology, education, intellectual property, space policy and tourism became the subject of sectorial dialogues established within the framework of the SP which eventually would operate not only on a bilateral basis, but would also gain an interregional and international focus. These sector-specific (ministerial) dialogues were set up and developed more or less dynamically under the aegis of the joint plans that were conceived by both actors to 'serve as the framework for practical action in their Strategic Partnership' and to enable them 'to start new regular 
bilateral dialogues as well as deepen existing partnership in areas that are of mutual strategic importance' (Council of the EU 2008a).

In the institutional context, besides the intergovernmental apparatus encompassing the annual summitry routine and specific sector-oriented ministerial dialogues, the business sector and civil society became associated with the EU-Brazil SP functional structure; a Business Summit and a Civil Society Roundtable were usually scheduled for the same week as the EU-Brazil Summits (Blanco and Luciano 2018: 463). It is also worth noting that in 2014, seven years after the Commission played a key role in the launching of the EU-Brazil SP, the European Parliament started to get engaged in the development of the bilateral relationship through the creation of a special parliamentary delegation to Brazil under the leadership of Portuguese MEPs. In spite of its still incipient work, this fledgling parliamentary group has provided an additional platform for political communication, events organisation and other activities directed at improving bilateral relations (Ibidem).

The joint action plans have been central for the continued institutionalisation of the SP since they have called for a joint reflection on modes to advance the bilateral relationship by means of identifying new areas of mutual concern and developing a strategic agenda of activities of common interest. The first Brazil-EU Joint Action Plan covering the period between 2009 and 2011 was enacted at the 2nd EU-Brazil Summit, held in Rio de Janeiro, in December 2008 (Council of the EU 2008a); and the second Joint Action Plan, due to be implemented between 2012 and 2014, was signed on the occasion of the 5th EUBrazil Summit, in October 2011, against the backdrop of the Eurozone crisis. Although no Summit had been held in 2012, when the 6th EUBrazil Summit took place in Brasília, in January 2013, European and Brazilian representatives showed overall 'satisfaction with the development of the bilateral Sectoral Dialogues, which involve initiatives in some 30 different areas' (Council of the EU 2013). Such groundwork created favourable conditions to establish in the course of 2013 a High-Level Dialogue on International Peace and Security as a new forum for debate and cooperation on matters related to security, peace-building, crime and human rights; and a new sectorial dialogue on drug matters (Council of the EU 2014). The third EU-Brazil Joint Action Plan, which was envisaged to serve as a roadmap for the 2015-2017 period, was agreed during the 7th EU-Brazil Summit held on 24 February 2014. This highlevel meeting signalled some evolution in the SP's agenda given the 
attention devoted to global governance-related matters and joint action on transnational security challenges. However, the third action plan has never been implemented, and with the passing of time, it has become an anachronism.

That being said, it is evident that under the umbrella of the 2007 SP the EU-Brazil relationship saw positive changes. This new bilateral format produced a more institutionalised and comprehensive framework that transcended the economic and trade spheres. A degree of convergence of viewpoints developed regarding the defence of respect for human rights and multilateralism, the conclusion of the Doha Round and the promotion of environmental consciousness through the RIO+20 Conference (Ferreira-Pereira 2015).

The 7th EU-Brazil Summit closed a cycle of regular annual highlevel summits which represented the 'core business' or the basis of the political dialogue developed within the institutionalised EU-Brazil relationship, and which were the main stimulus for the negotiation and approval of novel agreements and initiatives. This implicit dependence of the advancement of the SP's agenda upon the organisation of regular high-level meetings, alongside the absence of the trade 'card' (dealt with separately in the framework of the EU-Mercosur trade negotiations) or incentive that has bolstered other strategic partnerships such as the one with Mexico (see Dominguez, this volume) can be identified as two main handicaps of the EU-Brazil SP and, therefore, as major factors behind the current deadlock (Blanco and Luciano 2018). However, this only partly explains the impasse.

The EU-Brazil SP was clearly challenged by various fluctuations in the realm of international security and global governance that by exposing fault lines in the shared normative agenda further eroded the bilateral relationship. But perhaps more importantly, it was intrinsically affected by the multilevel crisis experiences on both sides of the Atlantic that will be discussed in the following section. By questioning the significance and credibility of the developing global role that both the EU and Brazil were carving out for themselves, such traumatic experiences ultimately reverberated upon the EU-Brazil SP while entailing changes in how the partners saw each other's role in the global arena. 


\section{Crises as the Order of the Day: The European Union and Brazil Under STRESS}

As noted in Chapter 2 by Ferreira-Pereira and Smith, the EU has suffered from a series of linked crises over the period since 2008, which among other effects have shaped its capacity to pursue ambitious initiatives in external action. The global economic and financial crisis created problems of both economic and political capacity, and accentuated divisions between those member states and regions that were robust and resilient, and those that were fragile and challenged. This set of tensions was underlined by crises in the realm of migration, and by the accompanying rise in populist political groupings, which challenged the kind of social solidarity that might have underpinned major integration initiatives. At the same time, the external challenge posed by Russian policies first towards Georgia and then towards Ukraine, and the resurgence of geopolitics within the global arena more generally, created both an incentive to pursue new strategic partnerships and a set of severe limitations on what might be achieved through such arrangements. Finally, from 2016 onwards, the rise of the Trump administration in the US, along with the process of Brexit in the UK, created new disruptions in transatlantic relations and more generally in the global arena, as rivalries not only between the US and China, but also between Washington and Brussels and London and Brussels became a central preoccupation of EU policymakers.

The endogenous and exogenous crisis conditions outlined above called for continuous intra-EU crisis management efforts. They forced both European leaders and institutions to adopt a more inward-looking posture, which further contributed to the EU's 'neglect' of Brazil (Gratius 2016; Guimarães and Piefer 2016). On the other hand, the difficulties encountered by the EU in tackling its successive crises had a major bearing on the EU-Brazil SP. They underlined the Brazilian perception, also imparted in the media, of the EU as a power in decline (Guimarães and Piefer 2016) that did not 'walk the talk', given its limitations regarding the promotion of economic growth, security and solidarity in the face of adversity. Qualms about eventual spillback in the European integration process against the backdrop of Brexit and the rise of nationalism, bringing with it the erosion of the quality of democracy in relevant EU member states, have affected the EU's image as well as the attraction of its own brand of interregionalism in Brazil (Gratius 2016: 77). And a 
more realist-driven approach to interregionalism endorsed by the Global Strategy has further corroborated this (Gratius 2018: 7-8). Furthermore, the European positions adopted during the crises in Libya (i.e. military intervention) and Syria (i.e. unilateral sanctions against Assad's regime)—criticised by Brazilian authorities - have validated not only the perception of the EU as a post-/neo-colonial power, but also the normative mismatch between the two actors' understandings of sovereignty, the non-intervention principle and the concept of 'responsibility to protect', as well as more general approaches to conflict resolution and international security dialogue (Guimarães and Piefer 2016; Neves 2018). All this, combined with the Brazilian 'media fascination' with the EU's internal problems (e.g. Eurozone and migration crises, and Brexit), double standard practices and inconsistencies (Sandrin and Hoffmann 2019: 39), has undermined the EU's relevance as a strategic partner in the political elites' eyes. It is not surprising, therefore, that these multiple challenges shaped the EU's ability to focus on the EU-Brazil partnership and its credentials as a strategic partner; what is more surprising is the extent to which they were paralleled in the case of Brazil by a series of domestic and external crises that intersected with the EU's preoccupations, which have thrown the strategic partnership into a state of limbo.

Although the economic and financial recession of 2008 hit Brazil a few years later than Europe, it has taken its toll upon Brasília's interest and capacity to sustain the country's strategic partnership with the EU (Saraiva 2017; Gratius 2016; Wisniewski and Dahab 2017; Neves 2018; Blanco and Luciano 2018). On the other side of the Atlantic, the negative effects of this crisis begun to be felt in 2012 (Saraiva 2017: 295) - just one year after Dilma Rousseff replaced her mentor, Lula da Silva, as President of Brazil. This led the country's authorities to focus on internal 'bread and butter' issues, to the detriment of foreign affairs. Against the backdrop of the economic crisis and the new president's putative lack of interest regarding the foreign policy agenda (Ferreira-Pereira 2016), the 2012 EU-Brazil summit did not take place. This was the first sign of the limited importance of the SP in the external agenda of President Rousseff (Wisniewski and Dahab 2017)—a tendency that would persist until the end of her mandate despite some advances made as a result of the EU-Brazil Summits held in 2013 and 2014. More broadly, there was a retreat on the part of Brazil from key international issues and debates which eroded the credibility of the Foreign Ministry (Barbosa 2016) and 
which meant that the country abstained from major international initiatives such as the Trans-Pacific Partnership, while at the same time, the influence of China in Latin America more generally and in Brazil itself grew significantly (Saraiva 2018: 9; Santander 2016: 187-188).

As a result, Brazil lost steam in terms of global power projection and (pro)activism while being perceived as adopting a paradoxical foreign policy line: one that sanctioned the promotion of human rights while blocking UN legitimacy to intervene to protect populations in peril/in danger (Lazarou and Edler 2012: 46). Hence, the attraction factor that had underpinned the European interest in establishing and then sustaining a SP has somewhat faded away. The only highlight worth noting links to the 'contesting entrepreneur' role that the Brazilian diplomats played in the short-lived proposal of the concept of 'Responsibility while Protecting' put forward at the UN Security Council in 2011 in the aftermath of the Libyan conflict (Kotyashko et al. 2018). The profound political, economic and social turmoil that intensified towards the end of Dilma Rousseff's first mandate (2011-2014), accompanied continuously by numerous corruption scandals involving high-profile politicians, public companies (e.g. Petrobras) and private enterprises (e.g. Odebrecht) unveiled mainly by the Lava Jato Operation launched in 2014, became a 'horror movie with no end' (Financial Times 2015). This downward spiral had a major impact on Brazil's standing in international relations and had an immediate bearing on the SP with the EU. No EUBrazil summit was organised in 2015, when the recession in the national economy showed all its darkest colours. It was the end of the Brazilian 'magic spell' (Ibidem).

In the meantime, the evolution of the SP itself generated tensions and frustration on the part of Brazilian foreign policymakers. A source of particular disillusionment was the reform of US-led multilateral institutions (e.g. the UN, WTO, IMF and World Bank) openly advocated by Brazil in the name of 'reciprocal multilateralism' (Cervo 2010: 11-12) under both the Lula da Silva and Dilma Rousseff Presidencies. This did not gather the support that Brazil hoped for, either in the EU, or in some of its key member states individually considered. The most paradigmatic example links to the lack of concrete support for the expansion of the UN Security Council, although this issue had been mentioned in some joint statements resulting from the EU-Brazil Summits (Saraiva 2018: 5). As a result, Brasília realised that it could not rely on the EU to back up its advocacy of a reformist multilateralism inspired by a non-hegemonic 
perspective of an international order that should be intrinsically multipolar and more symmetrically globalised. Rather, the EU was more prone to endorse the American-hegemonic status quo within the multilateral system, in order to safeguard Europe's prominence in international fora as well as the maintenance of privileged relations with the US that were considered critical for European security. This could also be seen in the EU's backing of the US military interventionism, which clashed with the sovereignty-orientated stance of Brazilian foreign policy informed by its cornerstone principle of non-intervention. Moreover, despite the existence of common values, a number of divergences emerged over issues related to climate change and the agreement of the Kyoto Protocol on control of emissions, human rights and policies to deal with war crimes and transnational terrorism (Saraiva 2018; Wisniewski and Dahab 2017).

The contentious and emotionally charged impeachment of Dilma Rousseff put an end to the Workers' Party era (2003-2016) and foreign policy line. Her successor Michel Temer, who took office in August 2016 , introduced a foreign policy course correction. This translated into a rupture with a more ideological orientation and revisionist path-which had led Brasília be a vocal promoter of the 'Global South' and align with the BRICS - and the return to the country's traditional Western alignment. Such foreign policy reorientation did not entail the reset or the revival of the EU-Brazil SP that had been anticipated in a positive note issued by the Itamaraty Brazilian Ministry of Foreign Affairs one day after the British referendum. Here, the government had described its relationship with the EU as 'robust' and pointed to a 'forthcoming Brazil-EU Summit to be held in Brazil' (Brazilian Ministry of Foreign Affairs 2016). Eventually, this high-level meeting failed to be organised in July 2017 for the celebration of the 10th anniversary of the SP. By then, there was only a press release issued by the Foreign Ministry conveying that Brazil was 'convinced that the Brazil-European Union Strategic Partnership will continue to increase in the coming years, with renewed and growing real benefits for our societies' (Brazilian Ministry of Foreign Affairs 2017). The bilateral political dialogue at the summit level remained absent until the end of Temer's Presidency (December 2018), despite the advocacy of improved economic relations with the EU-which remained a major trade partner and source of foreign investment in Brazil-made by the two Foreign Ministers, José Serra and Aloysio Nunes Ferreira, throughout this transitional political period (Gratius 2018). 
In addition to political turmoil in Brazil, the country's engagement in other partnerships, notably in the context of coalitions of like-minded emerging states in such fora as BRICS, IBSA and BASIC, has relegated the relationship with the EU to a more secondary place (Saraiva 2017: 281; Ferreira-Pereira 2016). These alternative partnerships added to those that Brazil cultivated with some important individual EU member states and consolidated in parallel to other interregional partnerships, in which Brazil played a prominent role, namely those centred on EUMercosur and EU-Community of Latin American and Caribbean States (CELAC). The continual political instability causing successive changes in the Planalto (Presidential) Palace and the Foreign Ministry made it even more complicated for Brazil to resume and renew a more meaningful collaboration with the EU. Consequently, Brussels did not know what to expect from the Brazilian authorities (Blanco and Luciano 2018: 470). In addition, Brazil's 'realist' preference for intergovernmental cooperation has not enabled national political and diplomatic elites to take full advantage of the consolidation of the European External Action Service (EEAS) and the opening of an EU delegation in Brasília. Given the continued dearth of multilateral high-level dialogue, nonetheless, some observers have highlighted the delegation's active role in the promotion of bilateral dialogues focused on issues of a more technical nature, such as technical and scientific exchanges, among others mostly linked to Brazilian domestic affairs (Saraiva 2017: 274; 2018: 2 and 16).

The beginning of Jair Bolsonaro's presidential mandate in January 2019 brought about additional difficulties in the suspended high-level EU-Brazil relationship. European uncertainties and apprehensions were raised by a foreign policy agenda which emphasised very close relations with the Trump administration while de-emphasising and ultimately questioning the country's commitment to the protection and strengthening of multilateral arrangements (e.g. Paris Agreement on climate change), global public goods (e.g. Amazon rainforest) and even of democratic values. To this should be added the perspective of a free trade agreement with the US tabled by the US Secretary of Commerce, Wilbur Ross, during his visit to Brazil in Summer 2019. Such a proposal-which, not coincidentally, was put forward after the conclusion of the EUMercosur Agreement - came with a calculated string attached: a strategic plan within which Brazil stood out as a major non-NATO ally, linked to that of a strategic alliance for the whole continent implying the expansion 
of NATO to the South Atlantic, as an attempt to defend US strategic and defence interests in the face of growing Chinese clout in South America.

\section{5-2020: Five Years, Five Missed Opportunities for Revamping Bilateral CoOperation}

As the previous sections have demonstrated, the European and Brazilian multiple crisis experiences and their diverse implications have thrown the EU-Brazil SP into a state of suspended animation. However, at the same time, they have generated a variegated number of incentives to explore untapped opportunities that could have favoured the revamp of the SP. For the purpose of this chapter, it is relevant to underline five of these incentives in the 2015-2020 period.

Firstly, under Michel Temer's Presidency, the abandonment of an ideologically-oriented foreign policy that during the Workers' Party era (2003-2016) had been at the origins of a set of tensions between the EU and Brazil on international security-related issues, could have been seized to break stagnation and find new avenues for political consensus across the Atlantic (Gratius 2016). However, Brazil continued to be much (over)taken by the need to address the politico-institutional and economic crisis in the midst of a profoundly polarised society. Against this backdrop, the celebration of the 10th anniversary of the SP in 2017 can be considered an outstanding missed opportunity to resume the EU-Brazil political dialogue at the summit level.

Secondly, although the European and Brazilian assessments of threats have been generally different, Brazil's permanent sense of insecurity (Neves 2018) and the EU's perception of being 'under threat', as imparted in the 2016 Global Strategy, could have engendered an axis of security cooperation substantiated in new bilateral schemes to tackle common transnational threats, such as organised crime and drug and human trafficking. This could have been extended to cybersecurity in the context of the successful experience with a Rousseff-Merkel proposal ${ }^{1}$ on

${ }^{1}$ In December 2013, the UN General Assembly has adopted a resolution proposed by Brazil and Germany, which aimed at protecting privacy rights to internet users. This came about after allegations of US snooping leaked to media organisations by US intelligence fugitive Edward Snowden. One of the leaks claimed that the NSA had been spying Angela Merkel's mobile phone for years; another that NSA had hacked the computer network of Brazil's state-run oil company Petrobras to collect data on emails and telephone calls. 
online privacy tabled at the $\mathrm{UN}$ in response to the revelations of espionage by the CIA (ibid.) and the Cambridge Analytica scandal related to the manipulation of 'Leave' votes in the Brexit referendum.

Thirdly, the development of an unprecedented common focus on the promotion of regional security integration designed to secure autonomy vis-à-vis the US could have created an opportunity to reinforce bilateral security relations. While the EU has deepened its security and defence dimension by means of the implementation of the CSDP provisions enshrined in the Lisbon Treaty, Brazil, as noted earlier, has asserted itself the driving force and paymaster behind the regional approach to defence, structured originally around the UNASUR and the SADC (Neves 2018). The establishment of the Centre for Strategic Defence Studies (CSDS) and the South American Defense School (SADS) in 2011 and 2015, respectively, as the first offspring of this novel confidence-building initiative designed to keep the US away from the region, reinforced hopes about the future consolidation of a de facto South American security and defence community—one that largely emulated the emerging EU intergovernmental security and defence pillar. Nevertheless, Brazil's politico-diplomatic and economic disinvestment in the sustainability of UNASUR, including SADC, after the end of the Workers' Party administrations, has resulted in a rapid erosion of the regional security integration acquis. Although making a causal connection between the EU-Brazil SP deadlock and the recent inactivity of UNASUR would be utterly simplistic, it is plausible to question whether the UNASUR would have seen its current moribund condition if the EU-Brazil SP agenda had progressed tangibly in the last five years. This is so since one of the SP's milestones was 'enhancing Latin America's stability', which encompasses the promotion of regional cooperation and cohesion-something that also matched the EU's traditional role as a staunch defender of integration in this region.

Fourthly, especially after the launching of the Belt and Road Initiative (BRI) by Xi Jinping in 2013, the challenge posed to both the EU and Brazil by the inescapably mounting Chinese (geo)economic influence and (geo)political leverage in their respective regions (Müller et al. 2017; Blanco and Luciano 2018) could have moved the two actors to adopt a joined-up approach embedding a soft balancing strategy under

Cf 'The UN General Assembly adopts anti-spy resolution', available at https://www.bbc. com/news/world-latin-america-25441408, accessed 20 February 2020. 
the umbrella of a politically reinvigorated SP. Incidentally, the Central and Eastern European countries have been highly receptive to BRIrelated initiatives, inside and outside the sub-regional $17+1$ cooperative forum, to bolster their economic development, thereby catching up with the EU's Western member states; and 14 countries, including Britain, France and Germany, have joined the China-proposed Asian Infrastructure Investment Bank in the face of Washington opposition. Yet, there has been widespread criticism and worries among European policy elites about the negative implications of Chinese financial investments, economic competition, monetary links and Europe-focused foreign policy ambitions for the EU's internal unity and external political clout (Pepermans 2018; Minghao 2016; Casarini 2016). At the same time, one has witnessed China's fast-evolving economic penetration in Latin America that, as Kaplan underscored, 'developed into the second largest destination for China's overseas investment' which made the region a special extension of the BRI (Kaplan 2018: 5). In this region, as in Brazil, the Chinese investors and companies have found a wide-open environment and supportive governments seeking infrastructure development and growth opportunities, besides the lure resulting from their enhanced connection(s) to China and its BRI global project (Klinger and Narins 2018). As a result, China became the principal trade partner for Brazil, and Brazil one of the main debtors to China in the region (Kaplan 2018: 9).

Finally, there was a missed opportunity, particularly on the part of the EU, to encourage the revitalisation of the SP with Brazil in the context of its Global Strategy. While the new strategic document places the EU's partnerships at the epicentre of the organisation's global outlook (see Chapter 2 by Ferreira-Pereira and Smith in this volume) and espouses the reform of the UN Security Council and international financial institutions-issues that have ranked high in twenty-first-century Brazilian foreign policy-it bypasses an individual reference to Brazil. Latin America only receives a passing reference in one paragraph which shows the somewhat peripheral position of the region in the strategic document, while raising doubts about whether Brazilian perceptions were ever taken into consideration in the making of the Global Strategy (Sandrin and Hoffmann 2019). This modest reference is made in the following terms: ' ...the Union will expand cooperation and build stronger partnerships with Latin America and the Caribbean, grounded on shared 
values and interests...' (EEAS 2016: 37). As such, Brazil seemed to have evolved into a sort of blind spot in the CFSP priorities.

This cannot plausibly be considered fortuitous considering the precedent represented by the 2008 Report on the Implementation of the European Security Strategy, in which there was an explicit reference to Brazil as a strategic partner (Council of the EU 2008b). Moreover, given the existence of explicit references to other BRICs (e.g. China and India) and to Japan as strategic partners, an individual mention of Brazil could have reasonably been expected. The centrality that the new strategic document continued to ascribe to the fight against transnational terrorism-something which stood in contrast to the passive Brazilian posture in relation to an international threat that has never been a top foreign policy priority (Ferreira-Pereira and Villa 2016; Gratius 2016; Poli 2018) - may help to explain why the Global Strategy did not single out Brazil as the EU's strategic partner in South America. In the three annual reports on the Global Strategy issued in 2017, 2018 and 2019, the omission of Brazil as a strategic partner could have been remedied. But this was not the case.

Despite the missed opportunities mentioned above, it should be recognised that the state of suspended animation of the EU-Brazil SP did not undermine the pursuit of one of its original major goals: 'advancing the Mercosur agenda' towards the conclusion of the negotiations for an EUMercosur free trade agreement. This objective was finally achieved in July 2019, and this development can be linked to the familiarity with and insight into the European 'modus operandi' based on multiple channels of communications that the Brazilian authorities have gained in several years of active interactions with the EU institutional structures. Incidentally, the two actors have reaffirmed their commitment to the EU-Mercosur Association Agreement during the 6th Meeting of the High Level Political Dialogue held in Brasília on 19 November 2019. This exchange of views, which have taken into account the priorities of Jair Bolsonaro-led government and the perspectives related to the new European Commission, has brought about a glimpse of hope given the Brazilian proposal to host the 8th EU-Brazil Summit in the first semester of $2020 .^{2}$

${ }^{2}$ See 'The EU and Brazil held their $6^{\text {th }}$ High Level Political Dialogue', available at https://eeas.europa.eu/headquarters/headquarters-homepage/70850/node/708 50_tk, accessed 4 March 2020. 
Be that as it may, the state of limbo characterising EU-Brazil relations since 2015 has been at odds with the EU's self-diagnosed need to invest in its partnerships in order 'to be a responsible global stakeholder'; its purpose to work with 'strategic partners in Asia, Africa and the Americas' to address global governance issues and common challenges; and its ambition to 'deliver effective global governance' based on a 'networked web of players' (EEAS 2016: 8 and 43). The same can be said, if one considers the more realist and interest-driven approach of the Global Strategy that further favours the prominence of bilateral schemes and patterns underlying strategic partnerships (Gratius 2018). Such inconsistency may well become even more conspicuous in the light of the efforts undertaken by Ursula von der Leyen-led self-designated 'Geopolitical Commission' to 'invest in alliances and coalitions' in order to advance European values and interests (European Commission 2020).

\section{CONCLUSION}

As this chapter has demonstrated, the EU-Brazil SP remains on hold after a promising period of less than a decade. During this period, both actors have pursued the institutionalisation of an innovative relational dynamic founded on political coordination mechanisms and sectoral/thematic agendas. A summitry routine and joint plans have fostered political dialogue across a wide range of areas, growing mutual knowledge resulting from socialisation processes and collective decision-making. From the European perspective, this reflected mostly the intersection of underlying external and identity logics shaping the EU-Brazil SP (see Chapter 2 in this volume). The EU saw in Brazil's rise in world economics and politics an international opportunity to enlarge its strategic partnership diplomacy, thereby enhancing its developing identity as a distinctive political and security actor in global arena.

Yet, since 2015, internal pressures and external opportunities have changed for the EU, but also Brazil. Each of the parties has become immersed in its own multilevel crisis experiences. On the EU's side, the 2008 economic crisis and its ensuing more or less associated crises exposed both endogenous and exogenous failures of integration and its impacts. As for Brazil, the internal economic, politico-institutional and social turmoil, which the country experienced particularly during Dilma Rousseff's second mandate, including her impeachment process, 
has confirmed its decline as an emerging power, resulting in influence and reputational losses in the regional and international arenas.

While the succession of crises in Europe has generated in Brasília the realisation that the EU no longer had the monopoly of the 'great and good', the endemic Brazilian crisis has dampened the perception of Brazil as a privileged political and economic interlocutor for the achievement of EU's international goals and priorities in the eyes of European foreign policy makers. In the context of a SP surrounded by multifaceted crisis, there was no initiative on the part of each partner to organise a summit and resume political dialogue at the highest level. The 10th anniversary passed almost unnoticed and the SP became characterised by a relational torpor, unmet expectations and missed opportunities for bilateral cooperation, rather than by reinvigorating political impulses and creative initiatives. Along these lines, considering the 'images' dimension of the strategic partnership diplomacy alluded to in Chapter 2 of this volume, the largely managerial image of the EU-Brazil SP became more reactive, with this reactive tendency becoming crystallised in the state of suspended animation plaguing Euro-Brazilian relations since 2015. All this boiled down to a paradox given that paralleling the enduring impasse in the EU-Brazil SP there has been an appreciable expansion of the EU's aspiration for international status through building 'partnerships at the frontiers of global affairs', as conveyed in its 2016 Global Strategy (43) and its follow-up reports.

The foreign policy strategy under President Jair Bolsonaro, notably its strong alignment to the bellicose Trump administration, has the potential to impose limits to Brazil's long-cherished autonomist tradition, thereby undercutting future efforts towards the regeneration of the EU-Brazil SP. Yet, the post-Brexit European and international juncture pervaded by 'predictable unpredictability' and the development of Chinese influence in Brazil into partnerships in various domains may push the EU to invest in cooperative engagements in order to reignite the bilateral cooperation with its Brazilian counterparts. That being said, the outbreak of the COVID-19 pandemics on both sides of Atlantic, with dramatic consequences being severely felt in Brazil, may well continue to reinforce the current impasse, while undermining the prospects for the future 8th EU-Brazil Summit. Nevertheless, the coming years will show if and how the EU and Brazil managed to turn the COVID-19 global crisis into an opportunity to revamp a fully working bilateral partnership and reach a strengthened strategic cooperation. 
Acknowledgments The author acknowledges that this study was conducted at the Research Center in Political Science (UIDB/CPO/00758/2020), University of Minho/University of Évora, and was supported by the Portuguese Foundation for Science and Technology and the Portuguese Ministry of Education and Science through national funds.

\section{REFERENCES}

Ayuso, A., \& Gratius, S. (2018). The Economic Agenda between Brazil and the EU: Prospects for a Bilateral and Global Upgrading. IAI Papers, 18(6), 1-30. Barbosa, R. (2016, September 13). Balanço da política externa do governo Dilma. O Estado de São Paulo.

Blanco, L. F., \& Luciano, B. T. (2018). Understanding EU's Strategic Partnerships in Latin America: A Comparative Assessment of EU-Brazil and EU-Mexico Relations. Journal of Contemporary European Studies, 26(4), $1-14$.

Brazilian Foreign Ministry. (2016). Press Note 228 'Referendo sobre a permanência do Reino Unido na União Europeia’.

Brazilian Foreign Ministry. (2017). Brazilian-EU Joint Statement-Ten Years of the Strategic Partnership.

Casarini, N. (2016). When All Roads Lead to Beijing: Assessing China's New Silk Road and Its Implications for Europe. The International Spectator, 51(4), 95-108.

Cervo, A. (2010). Brazil's Rise on the International Scene: Brazil and the World. Revista Brasileira de Política Internacional, Special Issue, 53, 7-32.

Christensen, S. F. (2013). Brazil's Foreign Policy Priorities. Third World Quarterly, 34(2), 271-286.

Council of the European Union. (2003). A Secure Europe in a Better World: European Security Strategy. Brussels.

Council of the European Union. (2007, July 4). I Brazil-European Union Summit Joint Statement. Lisbon.

Council of the European Union. (2008a, December 22). II Brazil-European Union Summit (Joint Statement and Joint Action Plan). Rio de Janeiro.

Council of the European Union. (2008b). Report on the Implementation of the European Security. Brussels.

Council of the European Union. (2013, January 24). VI Brazil-European Union Summit Joint Statement. Brasilia.

Council of the European Union. (2014, February 24). VII Brazil-European Union Summit Joint Statement. Brussels. 
European Commission. (2007, May 5). Communication from the Commission to the European Parliament and the Council-Towards an EU-Brazil Strategic Partnership. Brussels.

European Commission. (2020, January 29). Commission Work Programme 2020: A Union That Strives for More. Brussels.

European External Action Service. (2016). Shared Vision, Common Action: A Stronger Europe. A Global Strategy for the European Union. Brussels: European Commission.

Ferreira-Pereira, L. C. (2008). Portugal and the 2007 EU Presidency: A Case of Constructive Bridge-Building. Journal of Common Market Studies, 46(1), 61-70.

Ferreira-Pereira, L. C. (2015). EU-Brazil Relations as a Developing Field of Study: State of the Art and Perspectives on Future Research. In K. E. Jorgensen, Å. K. Aarstad, E. Drieskens, K. Laatikainen, \& B. Tonra (Eds.), SAGE Handbook of European Foreign Policy (Vol. 2, pp. 646-658). London: Sage.

Ferreira-Pereira, L. C. (2016). The European Union's Partnership Policy Towards Brazil: More Than Meets the Eye. Special Issue-The Strategic Partnerships of the European Union: Conceptual Insights, Cases and Lessons. Cambridge Review of International Affairs, 29(1), 55-77.

Ferreira-Pereira, L. C., Villa, R. (2016, September 1). Brazil and the European Union in Global Security: Are They Joining Forces in the Fight Against Terrorism? Paper presented at the X Congress of the Brazilian Association of Political Science. Belo Horizonte.

Financial Times. (2015, July 22). Recession and Graft: The Growing Rot in Brazil.

Gratius, S. (2016). From Soft to Hard Power? Security and Geo-Economics in Brazil-EU Relations. In J. Woischnik (Ed.), Might and Right in World Politics (pp. 71-79). XIII Forte de Copacabana Conference. Rio de Janeiro: Konrad Adenauer Stiftung.

Gratius, S. (2018, April 5). Brazil and the EU: From Liberal Interregionalism to Realist Bilateralism. Revista Brasileira de Politica Internacional, 61(1), e003. Epub. https://doi.org/10.1590/0034-7329201800103.

Guimarães, C., \& Piefer, N. (2016). Brazil: (Future) Green Energy Power and Strategic Partner for the EU? Comparative European Politics, 15(1), 23-44.

Kaplan, S. B. (2018). The Rise of Patient Capital: The Political Economy of Chinese Global Finance. Institute for International Economic Policy, WP-2.

Klinger, M., \& Narins, T. (2018). New Geographies of China and Latin America Relations: Introduction to the Special Issue. Journal of Latin American Geography, 17(2), 6-22.

Kotyashko A., Ferreira-Pereira, L. C., \& Vieira, A. (2018). Normative Resistance to Responsibility to Protect in Times of Emerging Multipolarity: The Cases of 
Brazil and Russia. Special Issue-International Security and Defence: Taking Stock of Brazil's Changes. Revista Brasileira de Politica Internacional, 61(1).

Lazarou, E., \& Edler, D. (2012). EU-Brazil Relations in a Time of Crisis: An Assessment of the 5th EU-Brazil Summit. Political Perspectives, 6(2), 30-57.

Lessa, A. C. (2010). Brazil's Strategic Partnerships: An Assessment of the Lula Era (2003-2010). Revista Brasileira de Politica Internacional, 53(special edition), 115-131.

Malamud, A. (2011). A Leader Without Followers? The Growing Divergence Between the Regional and Global Performance of Brazilian Foreign Policy. Latin American Politics and Society, 53(3), 1-24.

Meissner, K. L. (2018). Resorting to Bilateralism: The EU, MERCOSUR, and the Strategic Partnership with Brazil. Journal of European Integration, 40(1), $51-66$.

Minghao, Z. (2016). The Belt and Road Initiative and Its Implications for ChinaEurope Relations. The International Spectator, 51(4), 109-118.

Müller, G., Wouters, J., Defraigne, J.-C., Santander, S., \& Raube, K. (2017). The EU-Latin American Strategic Partnership: State of Play and Ways Forward. Brussels: European Parliament, Directorate General for External Policies of the Union.

Müller, N. M. (2018). The Strategic Partnership Between Brazil and the EU Motives and Consequences. In G. Gardini et al. (Eds.), Interregionalism and the Americas (pp. 55-72). London: Lexington Books.

Neves, L. P. (2018). Roadblocks and Avenues for Brazil-Europe Cooperation: Exploring a Wider Security Agenda. IAI Papers, 18(6), 1-13.

Pepermans, A. (2018). China's $16+1$ and Belt and Road Initiative in Central and Eastern Europe: Economic and Political Influence at a Cheap Price. Journal of Contemporary Central and Eastern Europe, 26(2-3), 181-203.

Poli, E. (2018). European External Actions in a Multilateral Arena: An Analysis of EU Relations with Brazil. IAI Papers, 18(13), 1-13.

Sandrin, P., \& Hoffmann, A. R. (2019). The EU Seen from Brazil: Images and Perceptions. In N. Chaban \& M. Holland (Eds.), Shaping the EU Global Strategy: Partners and Perceptions (pp. 27-54). London: Palgrave Macmillan. Santander, S. (2016). Brazil-EU Relations: Strategic Partner or Competitors? In M. Smith, S. Keukeleire, \& S. Vanhoonacker (Eds.), The Diplomatic System of the European Union: Evolution, Change and Challenges (pp. 181-196). London: Routledge.

Saraiva, M. G. (2017). The Brazil-European Union Strategic Partnership, from Lula to Dilma Rousseff: A Shift of Focus. Revista Brasileira de Politica Internacional, 60(1), e009. 
Saraiva, M. G. (2018). As Relações com a União Europeia (2008-2015). In W. A. Desiderá Neto et al. (orgs), Politica Externa Brasileira em Debate: Dimensões e Estratégias de Inserção Internacional no Pós-crise de 2008 (pp. 273-300). Brasilia: Ipea, Funag.

Steiner, A., Medeiros, M., \& Lima, R. (2014). From Tegucigalpa to Teheran, Brazil's Diplomacy as an emerging country. Revista Brasileira de Politica Internacional, 57(1), 40-58.

Stuenkel, O. (2011). Identity and the Concept of the West: The Case of Brazil and India. Revista Brasileira de Politica Internacional, 54(1), 178-195.

Valladão, A. (2008). L'UE et le Brésil: un partenariat naturel. In Partnership for Effective Multilateralism: EU Relations with Brazil, China, India and Russia (pp. 33-48). Chaillot Paper 109, Paris: EU Institute for Security Studies.

Vigevani, T., \& Cepaluni, G. (2007). A Política Externa de Lula da Silva: Estratégia de Autonomia pela Diversificação. Contexto International, 29(2), 273-335.

Wisniewski, B., \& Dahab, S. (2017). The European Union Strategic Partnership Agreement with Brazil-Ten Years of Action in Place and Future Perspectives. Studia Europejskie, 4, 55-71. 


\title{
The End of Ambiguity: Excavating the Remains of the EU-Russia 'Strategic Partnership'
}

\author{
Hiski Haukkala
}

The road to hell is paved with good intentions

A proverb

A Tree Is Known by Its Fruit

Luke 6:43-45

H. Haukkala $(\varangle)$

Tampere University, Tampere, Finland

e-mail: hiski.haukkala@tuni.fi

(C) The Author(s), under exclusive license to Springer Nature

Switzerland AG 2021

L. Ferreira-Pereira et al. (eds.), The European Union's Strategic

Partnerships, The European Union in International Affairs, https://doi.org/10.1007/978-3-030-66061-1_8 


\section{INTRODUCTION}

One of the many things buried under the rubble of the Ukraine conflict in 2014 was the so-called EU-Russia strategic partnership (SP). ${ }^{1}$ The EURussia SP was the first of its kind in the EU's external relations with non-western partners and it is the oldest but also unarguably the most difficult strategic partnership it has sought to promote. The roots of the SP with Russia go back to the early 1990s when the EU was actively developing both its international actorness and relations with the rest of the world. But it has never been officially codified as such by the parties and there has been no 'agreement of strategic partnership' nor necessarily even a declaration that would have unambiguously testified to that effect. Instead, the legal basis of relations has remained the Partnership and Cooperation Agreement (PCA) that entered into force in 1997. The Agreement is laden with references to 'partnership' and 'cooperation' but it omits the word and the perspective of a 'strategic partnership' entirely. ${ }^{2}$

Yet the strategic nature of relations between the EU and Russia has not been in doubt. The EU's Common Strategy on Russia (CSR) from 1999, the first of its kind in a troika of common strategies adopted by the EU around the turn of the millennium (the other two were adopted on Ukraine in 1999 and the Mediterranean in 2000), underlined Russia's importance as a strategic partner to the EU (European Council 1999). The document also outlined two main strategic goals for the Union in its relations with Russia:

1. a stable, open and pluralistic democracy in Russia, governed by the rule of law and underpinning a prosperous market economy benefiting alike all the people of Russia and of the European Union;

${ }^{1}$ This chapter draws from over 20 years of my own research and policy-making experience on the topic. The chapter has also benefited from a confidential group discussion between the author and three former EU officials with over 30 years of combined experience of working on EU-Russia relations. The three-hour discussion took place on 27 August 2019. I want to thank the three anonymous officials for their generosity both in terms of time and the frankness of views expressed. I also want to thank the editors of this book for helpful comments as well as Pekka Isotalus for help in writing this article.

${ }^{2}$ Words 'strategy' or 'strategies' are mentioned five times in passing, referring to the EU's and Russia's development strategies, not to the strategic nature of their relationship. The text of the PCA is available at https://eur-lex.europa.eu/legal-content/EN/TXT/? uri=celex:21997A1128(01), accessed 6 September 2020. 
2. maintaining European stability, promoting global security and responding to the common challenges of the continent through intensified cooperation with Russia (ibid.).

Already ten years after this declaration of intent it seemed safe to conclude that the EU had not, in fact, been able to secure its first strategic goal vis-à-vis Russia (Haukkala 2009: 1757). Instead of pursuing the value-laden liberal path promoted by the EU, Russia, especially under President Vladimir Putin, charted a course that stressed a strong and centralised 'vertical of power' domestically coupled with increasingly hard-nosed interest-based interaction internationally. Taken together, these two strands have resulted in what has been dubbed 'Putin's Russia' (Shevtsova 2005). Moreover, the developments during the last decade have shown how the aspirations concerning the second strategic objective have proven to be equally elusive. The war in Georgia in 2008 was already a sign of things to come but the real rupture in European stability and security came in the form of the Ukraine conflict that erupted in 20132014. All in all, the current outcome of some quarter of a century of relations between the EU and Russia has been far from a success with the relations largely frozen and to a degree even in crisis over the conflict (Casier and DeBardeleben 2018). Instead of deeper engagement and cooperation the two 'strategic partners' have been drifting away from each other both economically and politically. In the process, wider European security and stability have been seriously jeopardised.

This is not the occasion to discuss the evolution or the many policyareas of EU-Russia relations in detail (for works to that effect, see Forsberg and Haukkala 2016; Maass 2016). Instead, this chapter develops an overarching analytical narrative that examines and discusses the genesis and the practice of the strategic partnership between the EU and Russia over the 15 years it was in place (1999-2014) on a more general level. ${ }^{3}$ It will do so by, firstly, analysing the EU's initial objectives and comparing them with those put forward by Russia while analysing the key milestones in the relationship with a view of teasing out the gradual increase in tensions between the partners. This is followed by sections that delve

\footnotetext{
${ }^{3}$ For all intents and purposes Russia's annexation of Crimea in March 2014 resulted in the cessation of the EU-Russia strategic partnership. Yet a degree of EU-Russia relations have continued to this day, warranting discussion in this article.
} 
into how the internal dynamics and third parties have affected the relations. Finally, the chapter will conclude by drawing these strands together by looking at the outcomes of the EU's SP with Russia in light of the Ukraine conflict with a view of probing the current and future potential of relations. The section will also ponder possible lessons learned: What, if anything, the EU, or Russia for that matter, could or perhaps should have done differently, and are there perhaps something to be learned that would enable re-building bridges with Russia and/or avoid similarly catastrophic outcomes with the EU's other partnerships?

\section{From an Unambiguous Starting Point TO 'The Proliferation of the FuzzY'}

The Introduction to this volume noted how the EU's SPs in general have been characterised by a certain level of ambiguity (see also Ferreira-Pereira and Vieira 2016). To be sure, ambiguity is rife in human interaction. Communication even within single languages that benefit from high degrees of cultural affinity are not immune to this problem. Some argue that ambiguity does not result only in harmful distortion in meaning but it is also in fact an essential element that facilitates effective communication (Wasow et al. 2005). A particular form of ambiguity is constructive ambiguity that is often seen as the way forward in international politics. Stanley Hoffmann (1995: 131) has argued that the use of constructive ambiguity has become a norm in European integration in particular whereby the 'European project' has been able to progress in leaps and bounds without any formal agreement or necessarily even consensus about an eventual finalité politique. Indeed, Henry Kissinger, the grand master of constructive ambiguity in international politics, has defined the term as 'the deliberate use of ambiguous language in a sensitive issue in order to advance some political purpose' (Jegen and Mérand 2014: 182).

There is no denying that ambiguity has its positive political uses. But sometimes ambiguity can be a source of frictions as well as mounting and serious political tensions and problems, even conflicts. This is so in particular when ambiguity masks or is intentionally used to mask several and potentially severe differences in the way political issues and relationships are understood on a very basic level. The main argument of this chapter is that when it comes to relations between the EU and Russia, the notion of a 'strategic partnership' has not only proven to be an ambiguous concept but it has proven to be one in the most negative of senses: utterly 
misleading and in the final analysis politically corrosive, even destructive to the future of relations between the two 'strategic partners' precisely because it was used to mask the underlying and continuously mounting differences and even disagreements between the two while legitimising the continuation down a path that would eventually result in a wholesale collapse of relations in $2014 .^{4}$

The irony in relations for the last two decades has been that while the official talk of partnership and cooperation persisted, the actual interaction between the two pointed towards and resulted in lack of genuine progress in substantive issues that fuelled mutual disappointment and disillusionment. Ultimately, the relationship did collapse under the strain of mounting tensions that repeated attempts at papering over the differences through a process what Michael Emerson (2005) has called 'the proliferation of the fuzzy' could not conceal. The conflict in Ukraine was the perfect storm (Haukkala 2016) that resulted in a rupture in the most spectacular fashion with long-standing effects on not only the EU-Russia SP but overall European security and stability.

The paradox underlying this observation, however, is that despite all this ambiguity the relationship was initially based on ostensibly the most unambiguous of foundations: the Partnership and Cooperation Agreement that laid out a dense, highly institutionalised and legally binding framework for relations. It is worth remembering in this context, and contrary to what President Putin has come to assert, that the institutionalised framework of relations was not an imposition by the West on a 'weak' Russia but the end result of a process of very hard bargaining on the part of Russia where Moscow was a demandeur in terms of more ambitious forms political partnership and economic association, even integration (for a detailed analysis of the process, see Haukkala 2010: Ch. 5). Moreover, the fact that the PCA also inserted the notion of conditionality into the relations by making the continuation and further development of relations between the EU and Russia dependent on the observance of 'European values' was a logical consequence of the Russian insistence on

\footnotetext{
${ }^{4}$ Anecdotal evidence of the existence and even tacit acknowledgement of this at least on the EU's side is the adoption of an internal Commission working document called 'Key outstanding issues' in the EU's relations with Russia. The practice was begun in 2004 and by January 2014 the document had become 47 pages long. The document is no longer updated due to the existence of what could be called the outstanding issue: the Ukraine conflict. Source: Confidential discussion with former EU officials 2019.
} 
an ambitious relationship that included the perspective of eventual free trade area (ibid.).

The full explanation of the Russian conduct during the early years of relations is beyond the aims of this chapter. Most probably, considerations of status were primary (see Larson and Shevchenko 2019). Indeed, an analysis of the negotiation process indicated that for Russia it was important to be seen as being on par with the former Soviet satellites of Central and Eastern Europe that already had been granted with politically ambitious and broad-based Europe Agreements with the EU (Haukkala 2010: Ch. 5). The eventual implementation of agreed deliverables was hardly an issue at the time. Yet in the process the agreed objectives in EU-Russia relations had become anything but ambiguous. On the contrary, the aim, now jointly agreed, was to support the gradual transition of Russia towards Western/European liberal modes of governance with a view of integrating Russia into a wider economic area built around 'European' norms and values. The EU, in particular the Commission, as a thoroughly legalistic actor can hardly be blamed for having acted accordingly.

It is important to note how the EU's relations with Russia ended up being part and parcel of the overall external approach the Union was developing. The Europe Agreements, that would eventually result in accession for the Central and Eastern Europeans, were based on clear benchmarks and continued monitoring of progress, an approach the EU transferred into its European Neighbourhood Policy (ENP) as well (Smith 1999; Haukkala 2008). Yet this approach proved ill-suited for dealing with an actor like Russia that instead of painstaking implementation of technical norms prefers politically grand lines and declarations. Here the essential tension and even incompatibility between the EU and Russia comes to the sharpest of reliefs: For the EU, foremost as an economic entity, there is only so much it can achieve with declarations alone. Implementation not aspirations carry the day in Brussels. This basic tension was evident in the EU-Russia summits that were organised twice a year between 1998 and 2014 where the EU was prodding Russia to implement the PCA with Moscow preferring declarations of intent instead (Schmidt-Felzmann 2016: 6).

Therefore, the 'original sin' in relations was that despite this apparent contractual commonality, the EU and Russia did not in fact enjoy a shared understanding concerning what the actual implementation of the vision outlined in the PCA would eventually entail. This is not unusual in international politics (Jönsson 1990). Yet in the case of the EU-Russia SP 
this basic propensity was compounded by the fact that not only the two departed from entirely different points of origin but they also practically for the whole duration of their relationship were both essentially moving targets. The EU was busy devising its own political union combined with single currency and a growing appetite for a more ambitious international role and actorness. It was also engaged in a near-constant enlargement that would not only change its own body politic particularly through the Eastern 'Big Bang' enlargement but that would also bring the EU and Russia into an increasingly intimate geopolitical connection that would result in the emergence of the so-called common neighbourhood between the two.

The crucial role that Ukraine would play in the EU's relations with Russia was acknowledged early on. For example, already in 1999 the first High Representative Javier Solana noted that what 'the EU does in Ukraine will have an immense impact on Russia' (Solana 1999). But although Solana's conclusion was sound, the underlying analysis was not: for long the EU perceived Ukraine as a source of potential leverage, or at least dynamism for both good and for ill when it came to transforming Russia. It was not foreseen that Ukraine would become a geopolitical object of contention and the catalyst for the eventual collapse of relations with Russia. Indeed, most of the problems and tensions discussed in this chapter could most probably have been managed by the parties had it not been for the emergence of increasingly competitive elements over the so-called common neighbourhood during the 2000s that locked the relationship on an increasingly conflictual mode (DeBardeleben 2018; Haukkala 2016).

\section{The Internal EU and Russian Logics and Dynamics}

The internal logics and dynamics both within the EU and Russia are an important part of the story (see Chapter 2 of this volume). When it comes to the EU, Putnam's (1988) two-level game is in fact a three-level game: the international, the intra-institutional in 'Brussels' and the intergovernmental between the member states. Bureaucratic infighting was not invented in Brussels but it has perhaps been perfected there: stories about the level of turf wars, competition and even sabotage between the Council and the Commission are old hat (Cameron 1998). The emergence of the European External Action Service (EEAS) has ameliorated some of these tensions: the bulk of the EU's 'external relations' are now under one roof 
and the divide between the Council and the Commission is even officially bridged in the person of the High Representative that is also doublehatted as the Vice-President of the Commission. Yet the all-encompassing nature of EU's external relations entails that a significant bulk of relations still reside within the exclusive purview of the Commission and some of the tensions still persist (Henökl 2015).

Nor does the EEAS, or the HR/VP for that matter, manage to fully iron out the differences between the member states. Indeed, the role of the member states has been crucial in the development of EU-Russia relations. This is so for the most obvious of reasons: despite the hustle and bustle of common Russia policy in Brussels, none of the member states have forfeited their own national interests and perspectives on the country (for a discussion, see David et al. 2013). Yet it would be erroneous to characterise the situation in zero-sum terms, a favourite Russian past time. The EU's current approach could be summed up with the words unity but diversity. During the Ukraine conflict the member states have managed to agree on a set of unprecedentedly hard restrictive measures while adopting a set of five principles for the conduct of relations between the EU and Russia. ${ }^{5}$ At the same time, this consensus remains thin in a sense that beyond these two items there is little agreement within the Council on how to take relations with Russia forward and in what manner. This lack of consensus was reflected in the French President Macron's initiatives in 2019 that sought to engage Russia while making its dissatisfaction with the certain policy paralysis on the EU level no secret (Macron 2019).

Macron's initiative alludes to a wider role the member state level has played in EU-Russia relations. At times they have acted as a safety valve creating opportunities for the lessening of tensions with Russia but they have also undermined the strategic quality and reach of the EU in its relationship with the country. Perhaps most ominously the good cop-bad cop routine the majority of member states have played-pursuing a positive agenda bilaterally with Russia while shifting the problematic issues on the EU level and often blaming 'Brussels' for them-has vindicated the

\footnotetext{
${ }^{5}$ In March 2016 EU foreign ministers and the HR Federica Mogherini agreed on five guiding principles for EU-Russia relations: (i) full implementation of the Minsk agreements; (ii) closer ties with Russia's former Soviet neighbours; (iii) strengthening EU resilience to Russian threats; (iv) selective engagement with Russia on certain issues such as counter-terrorism; and ( $v$ ) support for people-to-people contacts. See https://www.europarl.europa.eu/thinktank/en/document.html?reference= EPRS_BRI(2018)614698, accessed 19 December 2019.
} 
Russian suspicion that all the talk about common values and institutions are a sham and double standards while the 'real' issues of significance are dealt with on the bilateral level. Giving ample evidence of this tendency to the Russians has been a self-inflicted wound by the Europeans. That said, it is also testimony of the essential inability to agree on Russia within the EU beyond the current approach.

Russia, for its part, was going through its own internal changes while trying to figure out and eventually re-calibrate its own understanding of national security and international politics for itself. Here Russia has traversed a full circle, moving from a self-standing great power that the USSR was to an aspiring member of the community of civilised states during the early Yeltsin era and back again under Putin. Domestically, it became early on evident that Russia was not in a transition towards the Western/European liberal model but that it was experiencing a transformation that would result in a new and more self-confident but not necessarily hostile or antagonistic Russia.

Yet this on-going and far-reaching change in the internal make-up of both partners was not reflected in the foundations of their relationship. On the contrary, the foundational logic was reaffirmed repeatedly by the EU in particular and any Russian attempts to amend the basis of relationship were received with scepticism as attempts at 'watering down' relations and jeopardising the EU's preferred modus operandi in (international) relations. For example, the ultimately unsuccessful negotiations for the new basic agreement that began in 2008 that would have replaced the PCA were plagued by this tension from the beginning. In a similar manner, the negotiations for the so-called Four Common Spaces (2001$2005)^{6}$ witnessed the Russian attempts, and some success, in diluting or at least muddying the waters when it came to the question of normative convergence (Haukkala 2010: Ch. 8).

As time passed on the EU's normative approach turned into an insistence. In a speech at the State Duma in Moscow in June 2008, the Commissioner for External Relations and Neighbourhood Policy Benita Ferrero-Waldner framed the issue in terms of commitments both the EU and Russia had adopted (Ferrero-Waldner 2008). Yet at the same time

\footnotetext{
${ }^{6}$ The Four Common Spaces were: Common Economic Space; Common Space of Freedom, Security and Justice; Common Space of Co-operation in the Field of External Security; and Common Space on Research, Education and Culture. See https://ec.europa. eu/commission/presscorner/detail/en/MEMO_05_103, accessed 18 December 2019.
} 
the actual track-record of relations had already shown that the EU proved unable and at times even unwilling to fully, or at least successfully insist that Russia did live by with its commitments. Indeed, the uneven application of conditionality watered down the EU's credibility in the eyes of Russia and resulted in further ambiguity in the relationship. The wars in Chechnya (1994-1996 and again 1999-2009) showed to Russia that the Europeans always had also other considerations than purely normative when engaging Moscow.

To make a long story short, Chechnya introduced the EU to a set of difficult trade-offs in its relationship with Russia: whether preserving the territorial integrity and the promise of a political partnership with Moscow or human rights and 'European values' were in the ultimate interest of the EU in its relations with the country (Forsberg and Herd 2005; see also Haukkala 2010: Ch. 7). It might have been a flawed dichotomy but it proved politically effective and one that resulted in the EU opting for the former to the detriment of latter. As is always the case in politics, something was gained while something was forfeited. The EU secured an opportunity to engage the new energetic President Putin at the outset of his tenure that has proven to be much longer than anybody, including probably Putin himself, ever expected. At the same time the EU's credibility as a genuinely value-driven actor received a serious dent in Moscow, and a pattern where Russia has been repeatedly getting literally away with murder was set in motion.

Another issue where conditionality proved difficult was the question of wider normative convergence underlying the creation of the possible free trade area between the EU and Russia. In this field it was Russia's own sovereignty that proved to be the key resource in resisting the EU's essentially 'post-sovereign' approach (Haukkala 2010): Russia did not have to implement anything it did not want in terms of normative convergence with the EU. At first the Russian approach was that of inertia and passive resistance, simply failing to implement what had been mutually agreed. Over time, Russia adopted a more assertive stance, first starting to question the feasibility and legitimacy of European norms and values as the only source of 'best practices' worthy of emulation and then beginning to insist that instead of unipolar EU hegemony, the Greater Europe should be constructed along more bipolar lines with Russia as an acknowledged power centre in its own right (Haukkala 2016).

All of these issues and tensions cumulated over time. Yet it should have been evident to both parties that the SP would not be smooth 
sailing. The essential incommensurability of the starting points was already visible in the strategy documents the two adopted for each other. The EU Common Strategy on Russia from 1999 framed the relationship in terms of value-driven integration. By contrast, the Russian Mid-Term EU Strategy adopted a year later spoke clearly about interest-based cooperation and transactional interaction instead (for an analysis of the documents, see Haukkala 2010: Ch. 6). Yet this basic incompatibility went politically unnoticed and unheeded. For example, the EU officials did not pay any attention to the Russian document at the time (confidential discussion with former EU officials 2019). There was simply no time and perhaps even less interest for this. Whether the same applies in the Russian case is more difficult to assert. Instead of addressing the differences in the very basic approaches concerning the foundations of their relationship-whatever that would have entailed politically at the time-they were papered over with the hectic proliferation of fresh concepts, instruments and initiatives that were supposed to keep the relationship going. Here the EU went along with what is an age-old Russian tradition, in fact: engaging in simulacra meant to erect the appearance of progress without necessarily generating any real forward momentum (Malia 1999). ${ }^{7}$

Indeed, the 2000s were a period of hectic activity between the EU and Russia with a host of ambiguous concepts or institutions adopted in the process. These ranged from institutional innovations, such as establishing the Permanent Partnership Council (PPC) in 2003 to broad-based policy platforms, such as the so-called Four Common Spaces (2005) or the Partnership for Modernisation (P4M 2010). One should not, however, ridicule or even belittle these attempts. In varying degrees, they were genuine attempts at generating progress in a relationship that was increasingly mired in problems and characterised by mutual recrimination

${ }^{7}$ The notion of a Potemkin village is of course well known. But a more apt characterisation could be this old Soviet joke: Vladimir Lenin, Joseph Stalin, Nikita Khrushchev and Leonid Brezhnev are all travelling together in a railway carriage. Unexpectedly, the train stops. Lenin suggests: 'Perhaps we should announce a subbotnik, so that workers and peasants will fix the problem'. Stalin puts his head out of the window and shouts, 'If the train does not start moving, the driver will be shot!' But the train doesn't start moving. Khrushchev then shouts, 'Let's take the rails from behind the train and use them to lay the tracks in front'. But still the train doesn't move. Then Brezhnev says, 'Comrades, Comrades, let's draw the curtains, let the workers gently rock the carriage from the outside, and pretend we're moving!' 
and disillusionment. This increasingly negative outcome, and our acute post hoc awareness of the fact, should not detract from the many positives and even successes in relations that included, among other things, expanding trade and other economic relations, developing successful and even ambitious forms of regional co-operation in the form of Northern Dimension, and facilitating a veritable explosion in people-to-people contacts, including Russia's accession into the so-called Bologna Process in 1999 that has facilitated co-operation in the field of higher education (see also Chapter 4, this volume). All of these accomplishments have persisted even in the face of openly adversarial relations augured by the Ukraine conflict.

Having established this, it is nevertheless apparent that these positives were not enough to prevent the political relationship from capsizing. But they do provide the relationship with ballast of sorts that should provide it with a modicum of stability going forward. Indeed, it is erroneous to think, all the talk about 'hybrid war' or 'regime change' notwithstanding, that all interdependence is problematic or negative for either party (Haukkala 2018). On the contrary, some of it at least is positive and it would be dangerous to assume that releasing the ties that bind economically but also elsewhere would somehow increase stability and/or potential for cooperation between the EU and Russia.

Moreover, the very fact that both partners did engage in the process until the bitter end is testimony to the inherent value and importance both attached to their relationship. Interestingly, this basic acknowledgement has withstood the complete rupture in relations over the conflict in Ukraine. For example, in November 2019 President Putin noted-probably with some schadenfreude-how Russia was interested in the EU 'to keep going... Incidentally, we are interested in this. We in Russia want to deal with a predictable and understandable partner' (Putin 2019). In a similar manner Macron's (2019) calls for re-engaging Russia already mentioned above reflect the same underlying realisation: the EU and Russia are destined to co-exist and potentially stand to lose out tremendously for failing to take their relations towards a more normal footing. Interestingly, Foreign Minister Sergey Lavrov echoed this sentiment in a newspaper article timed to commemorate the 30th anniversary of the signing of the Trade and Cooperation Agreement between the USSR and the EC in December 1989 (Lavrov 2019). Whether these signals indicate a promise of a new opening in relations is too early to assess. Experience cautions against excessive optimism, however. 


\section{The EU-Russia Strategic Partnership in a Triangular Setting}

A related question that needs to be addressed is the role of third parties in the evolution of the EU-Russia SP-the second logic in the parlance of Chapter 2. To begin with, it simply makes no sense to analyse the issue in isolation of the role the United States has played in European security and politics-yet almost the totality of extant literature on EU-Russia relations has done precisely that (the exception to the rule is Birchfield and Young 2018). For the EU, the relations and the role the United States has played in Europe have been indispensable (McGuire and Smith 2008, see also Smith's chapter in this volume). The objectives of the nascent 'European foreign policy' and those of the United States in the 1990s were largely compatible with and even complementary to each other. Therefore, the EU's Eastern enlargement was clearly in the US interests while the expansion of NATO was seen as the key in stabilising Central and Eastern Europe with a view to paving the way for the eventual and in many respects much more demanding EU accession (Baun 2004). At the same time, the fact that these two organisations did seem to move and enlarge in lock-step created the expectation, perhaps even fear, in Moscow that this would be the case also in future. Whether this perception was justified is a moot point as it seems evident that Russia has taken it as a starting point in its own foreign and security policy, becoming increasingly wary about the Western penetration of its 'near abroad' in the process (see, e.g., Meister 2013). This concern received its starkest manifestation in the Ukraine conflict.

One way to characterise the role the United States and the EU have played in Europe during the post-Cold War era is to think of two concentric hegemonies where the United States through its primacy has set the global parameters and guaranteed security in Europe through the expansion of NATO, while the EU has assumed the responsibility for stabilising the continent through the enlargement of its institutions and/or projection of its policies through modes of 'external governance' (Lavenex 2004 ) in directions where a rapid and full immersion into the EU was not an option (Haukkala 2008). Indeed, it was the spectre of the perpetual motion engine of dual enlargements of the EU and NATO that resulted in the eventual breakdown of relations with Russia over Ukraine. Even though NATO's and the EU's dual movement was more reactions and responses to events and demands beyond their control or initial appetite 
rather than preconceived programmes to order or subjugate Eastern Europe ruthlessly to their will (for discussions, see Asmus 2002; Smith 1999; Hill 2018), the fact remains that Russia chose to frame the issue increasingly in this manner and responded accordingly.

But the Russians had also a wider complaint concerning the role the transatlantic community had played in international relations. In particular, the wars in Kosovo (1999) and in Iraq (2003) and their diplomatic aftermaths drove home in Moscow at least two lessons that made a lasting impact on its subsequent relations with the EU as well (Averre 2009). The first lesson was that the United States, and to a lesser degree also the EU member states, were prepared to use military intervention to effect regime change as they saw fit. The second lesson was that unilateral military intervention can take place without an explicit mandate from the UN Security Council and against the voiced objection of the Russian Federation in particular. This is a pattern Russia has continuously detected in other colour revolutions in the post-Soviet space, including recently in Middle East and North Africa. Taken together, the Kosovo and Iraq affairs had the wider implication of distancing Russia from the West paving the way for the galvanisation of a much more hard-nosed realist foreign policy consensus during the Putin era (Trenin 2007).

Similarly, the growing role of China must be noted (see also Cottey's chapter in this volume). Although clearly not present at the creation in the early 1990s, during the 2000s Beijing has forcefully inserted itself into the equation. When it comes to China, it has played the US role but in reverse. First of all, it has played a structural role moulding the wider global landscape within which the EU-Russia SP has evolved. In effect, Beijing has sought and managed to hollow out the space for the EU's preferred value-centric mode of operation while shifting the centre of gravity in global politics distinctly and irrevocably away from Europe (Christiansen and Maher 2017). The EU and its normative approach have become marginalised in the process. More recently, China has acted as a cover and back up for Russia as it has helped Moscow to face the sanctions imposed by the West and has given political support (Wang 2015). By doing so China has reduced the perceived sense of isolation and the consequent effectiveness of the EU policy vis-à-vis Russia.

In addition, the version of multilateralism promoted by China differs from that preferred by the EU. Whereas the EU speaks about rules- and right-based, essentially norm- and value-driven 'effective multilateralism' (Council of the EU 2019), China underlines the essentially multi-polar 
nature of multilateralism founded on full recognition of sovereignty and reciprocity as the key principles (Scott 2013). The Chinese reading in effect aligns itself with the Russian vision concerning multilateralism (Casier 2018) and by doing so inadvertently strengthens Moscow's hand vis-à-vis Brussels. This is another factor that has already affected the relations between the EU and Russia and it is one that will continue to do more so in future.

\section{Conclusions}

The analytical narrative in this chapter leads to the grimmest of conclusions: the pretence of a strategic partnership between the EU and Russia is over. To use the notion of 'images' from Chapter 2, the relationship between the two has evolved from strategy via management to reaction. This applies not only to the EU but to Russia as well. In the process the political component of relations has atrophied and currently the 'strategic partnership' drifts rudderless at the mercy of events. At the time of the writing the acute political crisis in Belarus combined with the shock generated by the poisoning of the Russian opposition leader Alexei Navalny with the use of Novichok type nerve agent, effectively a chemical weapon, seem poised to thrust the EU and Russia on yet another bout of deepening hostility, mistrust and even conflict.

Over time the two pushed ambiguity in their relationship to and beyond its political limits. Currently constructive ambiguity has been replaced with constrictive clarity. This need not come as a surprise. Already Stanley Hoffmann argued that even constructive ambiguity is prone to setbacks that often come in the form of what he called 'the terrible clarifier'; a person or an issue that 'calls for a lifting of ambiguities, at which point deadlock is more likely than resolution' (Hoffmann 1995: 131). In the case of the EU-Russia SP the terrible clarifier was both a person and an issue: the person was 'Putin' (in parentheses because we are talking about a system and the evolution of a vast nation and not just one person, however significant he might have been), the advent of which augured in the period of increasing divergence between the EU and Russia chronicled in this chapter.

The final clarifying issue was the Ukraine conflict. Without the events in 2013-2014 the EU-Russia SP need not have collapsed in a rupture of such severity that was eventually witnessed. In a word, in and over Ukraine the EU's normative integrationist approach ran headlong against 
Russia's more traditional geopolitical approach. The question that needs to be asked-but cannot be answered with full certainty yet-is whose approach is more fitting with the spirit of the age. The fact that Ukraine persists on its road towards the EU would seem to testify that the EU's approach still holds sway-even if Europeans themselves are at times showing signs of losing faith, as exemplified by the Brexit, for example. But equally, the growing talk about the return of a great power competition and multipolar world order hint that geopolitics is far from losing its relevance. On the contrary, there has been a pendulum swing back towards geopolitics over the past decade or more, creating challenges for the EU and narrowing down the external opportunity structure for EU external action. ${ }^{8}$ It goes without saying that the future of EU-Russia relations will crucially be affected by the wider global context in which the relationship will play out and the ways how it either reinforces or manages to contradict some of the wider global trends.

In a word, all the three logics spelled out in Chapter 2 have been present and responsible for generating the current situation. Internally, the EU has become more unwieldy and in fact less coherent and able to agree on its Russia policy. The diverging interests, interpretations and even actions within the member states during the 2000s contributed to the current situation. More importantly, however, the external logic has been the key in framing the issues and eventual EU responses. Here Russia's own evolution and choices have been primary but also the changing face of US power and role in Europe as well as the rise of China have affected the process. Consequently, the logic of identity has become increasingly challenged and constrained for the EU. As a thoroughly value-laden entity it cannot escape the imperatives generated by this logic in its external relations that obviously include its relations with Russia as well. But at the same it is hard to avoid the impression that the EU is currently entirely unable to impose its vision of acceptable international behaviour and conduct on others and seems increasingly insecure and even at a loss how to go about it.

Currently relations between the EU and Russia are at an impasse. Both sides are waiting but it is not entirely clear for what (David and Romanova 2019: 128). Not only is the political relationship mired in a deep-seated crisis but increasingly also the economic component, the glue that was

\footnotetext{
${ }^{8}$ I want to thank Michael Smith for capturing the crux of the issue so well with these words.
} 
supposed to ensure positive mutual interdependence between the partners, is called into question. On top of this, we are witnessing the collapse of key instruments of arms control in Europe and indeed wider strategic stability in the world. Europe is a much more unstable, competitive and even conflictual space than was ever envisaged at the beginning of the 1990s. It is fair to say that only rarely has the EU failed so miserably as it has in its attempts at forging a strategic partnership with Russia.

But the same applies to Russia's attempts at developing a working relationship with the EU. Both are culpable for mismanaging the relationship. Neither side advocated the outcome, yet sometimes interaction generates undesired outcomes despite the best of mutual intentions (or perhaps to a degree precisely because of them; see Casier 2016). Therefore, laying blame is politically a useless exercise. This is especially so when thinking about a potential way forward.

There is no going back to the status quo ante. A new modus vivendi is required. Relations between individuals often require making amends but the same need not apply in international politics. But restraint is called for, as is mutual acknowledgement that the current situation is not sustainable. To a degree this realisation seems to be emerging, as exemplified by the admissions on both sides that they do in fact need each other. But concrete ideas how to move forward are still few and far between. Both agree that there is no going back to business as usual but neither has any idea what mutually acceptable business could look like.

An additional problem is that neither partner has remained in a standstill during the period of contestation. Five years is a long time in international politics, as it is in domestic politics as well. What began as a tactical pivot of necessity to Asia for Russia has gained a momentum of its own. A new generation of Russian experts and policy-makers is already coming into place with less attachment to Europe, both to its values and practices (Liik 2019). On the European side, too, changes are taking place; both in the EU and in the member states alike.

But the way forward cannot and indeed should not be a return to ambiguity. The main underlying problem in the EU-Russia SP was that it was never a fully equal partnership between two 'strategic partners' but one that was in effect aimed at integrating one partner into an order generated by the other. This basic asymmetry became the key source of tensions and was also a factor that sets the relationship apart from other SPs analysed in this book that have not included this objective/pretence. Probably a way forward will have to entail the acknowledgement that the 
EU's relations with Russia will have to be on par with its other strategic partners: more equal and interest-driven, more transactional. Aspiring to restore normal relations too soon again would be ill-advised. Both the EU and Russia should build concrete co-operation with the view of securing the continued relevance of their relationship before seeking 'resets' or other forms of more ambitious political engagements.

To move beyond this baseline some issues will need to be settled. The Ukraine conflict is the obvious one that should not be allowed to leave to fester indefinitely. It is also to be hoped that the situation in Belarus does not spiral out of control resulting in another conflict in the geographical heart of Europe. Here ambiguity might be of some help, in fact, as the sides will most probably have to avoid clarity in terms of revisiting some of the key principles of European security architecture. Here the EU's own credibility and security hangs in the balance. Having staked its own credibility on the line in defending these principles, it cannot be seen as folding under Russian pressure. At the same time the EU needs to tread carefully in the region.

In a sense the EU has lost both its policy on and strategic partnership with Russia. They have been replaced with a sanction line where increasingly the main objective is not effecting meaningful change on Russia but simply preserving the EU's own unity instead. For the moment, these are mainly rear-guard activities aimed at preserving the bare minimum of the EU's actorness and its preferred vision of international relations in the world. But as long as the wider aspirations and the necessary cohesiveness persists, the EU has a chance to restore its relationship with Russia and its role in the world. If the EU's failed attempts at constructive ambiguity with Russia have helped to reach some clarity concerning the essential trade-offs for the EU, then the experience of the past quarter of century of a 'strategic partnership' between the two need not have been in vain, after all.

\section{REFERENCES}

Asmus, R. D. (2002). Opening NATO's Door: How the Alliance Remade Itself for a New Era. New York: Columbia University Press.

Averre, D. (2009). From Pristina to Tskhinvali: The Legacy of Operation Allied Force in Russia's Relations with the West. International Affairs, 85(3), 575591. 
Baun, M. (2004). The Implications of EU Enlargement for the United States. Perspectives, 21(Winter 2003/04), 27-38.

Birchfield, V. L., \& Young, A. R. (Eds.). (2018). Triangular Diplomacy among the United States, the European Union and the Russian Federation: Responses to the Crisis in Ukraine. London: Palgrave Macmillan.

Cameron, F. (1998). Building a Common Foreign Policy: Do Institutions Matter? In J. Peterson \& H. Sjursen (Eds.), A Common Foreign Policy for Europe? Competing Visions of the CFSP (pp. 59-76). London and New York: Routledge.

Casier, T. (2016). From Logic of Competition to Conflict: Understanding the Dynamics of EU-Russia Relations. Contemporary Politics, 22(3), 376-394.

Casier, T. (2018). The EU and Russia in a Multilateral Setting. In T. Casier \& J. DeBardeleben (Eds.), EU-Russia Relations in Crisis: Understanding Diverging Perceptions (pp. 201-218). London and New York: Routledge.

Casier, T., \& DeBardeleben, J. (Eds.). (2018). EU-Russia Relations in Crisis: Understanding Diverging Perceptions. London and New York: Routledge.

Christiansen, T., \& Maher, R. (2017). The rise of China-Challenges and Opportunities for the European Union. Asia Europe Journal, 15(2), 121-131.

Council of the EU (2019, June 17) Strengthening Multilateralism: Council Adopts Conclusions. Press Release. Available at https://www.consilium.eur opa.eu/en/press/press-releases/2019/06/17/effective-multilateralism-cou ncil-adopts-conclusions/\#. Accessed 6 September 2020.

David, M., Gover, J., \& Haukkala, H. (Eds.). (2013). National Perspectives on Russia: European Foreign Policy in the Making? London and New York: Routledge.

David, M., \& Romanova, T. (2019). The EU in Russia's House of Mirrors. Journal of Common Market Studies, 57(Annual Review), 128-140.

DeBardeleben, J. (2018). Alternative Paradigms for EU-Russia Neighbourhood Relations. In T. Casier \& J. DeBardeleben (Eds.), EU-Russia Relations in Crisis. Understanding Diverging Perceptions (pp. 115-136). London and New York: Routledge.

Emerson, M. (2005, May). EU-Russia Four Common Spaces and the Proliferation of the Fuzzy. CEPS Policy Brief 71. Available at https://www.ceps.eu/ ceps-publications/eu-russia-four-common-spaces-and-proliferation-fuzzy/. Accessed 6 September 2020.

European Council. (1999, June 3-4). Common Strategy of the European Union on Russia. European Council, Cologne. Available at https://op.europa. $\mathrm{eu} / \mathrm{en} /$ publication-detail/-/publication/38943c06-7e5d-4ca3-acc3-c5154b d9c04e. Accessed 6 September 2020.

Ferreira-Pereira, L. C., \& Vieira, A. V. G. (2016). Introduction: The European Union's Strategic Partnerships: Conceptual Approaches, Debates and Experiences. Cambridge Review of International Affairs, 29(1), 3-17. 
Ferrero-Waldner, B. (2008, June 4). Russia and the EU's Need for Each Other. A speech at the European Club, State Duma, Moscow. Available at https://ec.europa.eu/commission/presscorner/detail/en/SPEECH_ 08_300. Accessed 6 September 2020.

Forsberg, T., \& Haukkala, H. (2016). The European Union and Russia. London: Palgrave Macmillan.

Forsberg, T., \& Herd, G. (2005). The EU, Human Rights, and the RussoChechen Conflict. Political Science Quarterly, 120(3), 455-478.

Haukkala, H. (2008). The European Union as a Regional Normative Hegemon: The Case of European Neighbourhood Policy. Europe-Asia Studies, 60(9), $1601-1622$.

Haukkala, H. (2009). Lost in Translation? Why the EU has Failed to Influence Russia's Development. Europe-Asia Studies, 61(10), 1757-1775.

Haukkala, H. (2010). The EU-Russia Strategic Partnership: The Limits of PostSovereignty in International Relations. London and New York: Routledge.

Haukkala, H. (2016). The Perfect Storm: Or What Went Wrong and What Went Right for the EU in Ukraine. Europe-Asia Studies, 68(4), 653-664.

Haukkala, H. (2018). Negative Mutual Interdependence? The Clashing Perceptions of EU-Russia Economic Relations. In T. Casier \& J. DeBardeleben (Eds.), EU-Russia Relations in Crisis. Understanding Diverging Perceptions (pp. 53-71). London and New York: Routledge.

Henökl, T. E. (2015). How Do EU Foreign-Policy Makers Decide? Institutional Orientations within the European Union External Action Service. West European Politics, 38(3), 679-708.

Hill, W. H. (2018). No Place for Russia. European Security Institutions Since 1989. New York: Columbia University Press.

Hoffmann, S. (1995). The European Sisyphus. Essays on Europe 1964-1994. Boulder: Westview Press.

Jegen, M., \& Mérand, F. (2014). Constructive Ambiguity: Comparing the EU's Energy and Defence Policies. West European Politics, 37(1), 182-203.

Jönsson, C. (1990). Communication in International Bargaining. London: Pinter.

Larson, D. W., \& Shevchenko, A. (2019). Quest for Status: Chinese and Russian Foreign Policy. New Haven and London: Yale University Press.

Lavenex, S. (2004). EU External Governance in "Wider Europe". Journal of European Public Policy, 11(4), 680-700.

Lavrov, S. (2019, December 18). Russia-EU: Thirty Years of Relations. Rossiyskaya Gazeta. Available at https://www.mid.ru/en/foreign_policy/ news/-/asset_publisher/cKNonkJE02Bw/content/id/3960550/pop_up?_ 101_INSTANCE_cKNonkJE02Bw_viewMode=print\&_101_INSTANCE_ cKNonkJE02Bw_qrIndex=0. Accessed 6 September 2020. 
Liik, K. (2019, November). The Last of the Offended: Russia's First Post-Putin Diplomats. ECFR Policy Brief. Available at https://www.ecfr.eu/publicati ons/summary/the_last_of_the_offended_russias_first_post_putin_diplomats. Accessed 6 September 2020.

Maass, A.-S. (2016). EU-Russia Relations (1999-2015): From Courtship to Confrontation. London and New York: Routledge.

Macron, E. (2019, August 27). Ambassadors' Conference, A Speech by M. Emmanuel Macron, President of the Republic. Paris. Available at https://lv. ambafrance.org/Ambassadors-conference-Speech-by-M-Emmanuel-MacronPresident-of-the-Republic. Accessed 6 September 2020.

Malia, M. (1999). Russia Under Western Eyes: From the Bronze Horseman to the Lenin Mausoleum. Cambridge, MA. and London: Belknap Press.

McGuire, S., \& Smith, M. (2008). The European Union and the United States: Competition and Convergence in the Global Arena. Basingstoke: Palgrave Macmillan.

Meister, S. (Ed.). (2013). Economization versus Power Ambitions: Rethinking Russia's Policy towards Post-Soviet States. Berlin: Nomos.

Putin, V. (2019, November 20) Remarks at Russia Calling! Investment Forum. Moscow. Available at http://en.kremlin.ru/events/president/news/62073. Accessed 6 September 2020.

Putnam, R. D. (1988). Diplomacy and Domestic Politics: The Logic of TwoLevel Games. International Organization, 42(3), 427-460.

Schmidt-Felzmann, A. (2016). The Breakdown of the EU's Strategic Partnership with Russia: From Strategic Patience Towards a Strategic Failure. Cambridge Review of International Affairs, 29(1), 99-127.

Scott, D. A. (2013). Multipolarity, Multilateralism and Beyond...? EU-China Understandings of the International System. International Relations, 27(1), $30-51$.

Shevtsova, L. (2005). Putin's Russia (Rev and expanded ed.). Washington, DC: Carnegie Endowment for International Peace.

Smith, K. E. (1999). The Making of EU Foreign Policy: The Case of Eastern Europe. Basingstoke: Macmillan.

Solana, J. (1999, October 13). The EU-Russia Strategic Partnership, a speech by the High Representative designate of the European Union for Common Foreign and Security Policy, Stockholm.

Trenin, D. (2007). Russia Redefines Itself and Its Relations with the West. The Washington Quarterly, 30(2), 95-105.

Wang, W. (2015). Impact of Western Sanctions on Russia in the Ukraine Crisis. Journal of Politics and Law, 8(2), 1-6.

Wasow, T., Perfors, A., \& Beaver, D. (2005). The Puzzle of Ambiguity. In C. O. Orgun \& P. Sells (Eds.), Morphology and the Web of Grammar: Essays in Memory of Steven G. LaPointe (pp. 265-282). Stanford, CA: CSLI Publications. 


\title{
The European Union and India: A Reluctant Partnership Between Aspiring Global Powers
}

\author{
Emilian Kavalski
}

\section{INTRODUCTION}

In an interview in December 2019, Ugo Astuto, the European Union (EU) ambassador to India, declared his expectation that the controversial Citizenship Amendment Bill (CAB) will stand up to 'the high standards of the Indian constitution' (The Wire 2019). In the context of widespread protests against the discriminatory nature of the bill, pro-government media quickly picked up Astuto's statement and proclaimed it as a clear indication of Brussels' support for the CAB. It is noteworthy that most Indian pundits chose to overlook that the bulk of the interview was on the status of the EU-India Free Trade Agreement (FTA), which has remained stalled almost since negotiations began in 2007 (Khorana and Garcia 2013). Such use of the EU as a legitimating force in ongoing domestic

E. Kavalski $(\bowtie)$

Jagiellonian University in Krakow, Krakow, Poland

e-mail: emilian.kavalski@gmail.com

University of Nottingham Ningbo, Ningbo, China

(C) The Author(s), under exclusive license to Springer Nature

Switzerland AG 2021

L. Ferreira-Pereira et al. (eds.), The European Union's Strategic

Partnerships, The European Union in International Affairs, https://doi.org/10.1007/978-3-030-66061-1_9 
political debates is neither new, nor specific to India. In fact, it has been touted as a crucial aspect of the so-called Europeanizing effects of the EU in global life. Yet, it seems that in India, such localization of the Brusselsbased bloc has been championed by political formations purposefully disregarding the very foundations of the EU's alleged normative power. Even prior to the $\mathrm{CAB}$ controversy, the Indian government appeared unusually keen to deploy the EU as a trump card against its domestic opponents. In the wake of the equally divisive scrapping of Article 370 from the Indian constitution in August 2019, which used to grant a special status to the contested region of Jammu and Kashmir, the office of the Indian Prime Minister organized a 'private tour' of 24 MEPs to the region. In a time when Indian parliamentarians were banned from travelling to Jammu and Kashmir and political representatives from the region were either thrown in jail or put under house arrest, the Prime Minister's Office hand-picked MEPs from primarily right wing and socially conservative groupings in the European parliament and took them on a carefully orchestrated tour of the restive province (Choudhury and Dhawan 2019). The intent was two-fold: firstly, 'to shape the European narrative' on the issue; and, secondly, to demonstrate to the Indian electorate the EU's support for the measure (Sharma and Sethi 2019).

These incidents offer a good indication of the character of the EU-India Strategic Partnership-a lacklustre arrangement between two partners who have both very different aspirations on the world stage and understanding of each other. In their public pronouncements, the $\mathrm{EU}$ and India present themselves as two of the key actors shaping the complex dynamics of international affairs in the twenty-first century. Yet, they do not share a common vision of what the patterns of world affairs should look like nor how they should be practised. This produces a rather peculiar strategic partnership between the EU and India-one that is neither very strategic, nor really a partnership. On the one hand, both the EU and India assert that as the largest democracies in the world they share common values and normative outlook, which in the words of the former Indian PM Manmohan Singh makes them 'natural partners' (Jain 2011: 27; Kavalski 2014: 321). The implication is that these birds of a democratic feather should have no problem flocking together around a common strategic vision. On the other hand, the EU and India remain rather aloof to one another while showering their affections on other international partners-China, for the EU, and the United States, for India. In this respect, both Brussels and New Delhi oftentimes not 
only neglect each other's interests but appear to actively challenge one another. In fact, Dr. Murli Manohar Joshi, at the time the Chair of the powerful Public Accounts Committee, went as far as openly declaring that closer trade and economic ties with the EU 'will seriously jeopardize the interests of the Indian people' (Sengupta 2013; Khorana and Asthana 2014).

Thus, while formally labelled as 'strategic', the partnership is more often than not described as 'lukewarm', and 'reluctant', and characterized by 'mutual neglect' (Kavalski 2018b). This study traces the evolution of the bilateral relationship since the end of the Cold War to 2020. The attention is on outlining the cornerstones of the interactions between the EU and India. Unlike most analyses, this examination does not blame the United Kingdom (UK) for the current fraught state of the strategic partnership between the EU and India-for the former, the UK has been a difficult member departing from the Brussels-based bloc in 2020 and for the latter, London represents the colonial metropole that still very much frames Indian perspectives on Europe (Kavalski 2017). Instead, this chapter draws attention to the importance of 1999 as a critical juncture, urging both Brussels and New Delhi to significantly alter their outlook on global life and each other. Consequently, despite the ongoing emphasis on shared objectives and common challenges, the 1999 juncture does not seem to have produced a coincidence of interests between the EU and India and has led them to espouse divergent visions for the twenty-first century.

The suggestion is that such divergence reflects underlying contradictions both in the motivations and the international identities of the EU and India that make their presumed strategic partnership anything but strategic. As the following sections will demonstrate, the bilateral relationship is a story of two actors aspiring to global prominence, who-to their own frustration-find themselves consigned and constrained to play a leading role only in their respective neighbourhoods. In fact, the bilateral interactions appear only to reinforce this marginalization in global affairs as neither of the strategic partners considers the other significant enough to deepen the relationship (Kavalski 2008b, 2010a; Khandekar 2011). While this observation has been noted by other commentators (Czechowska 2019; Jain and Sachdeva 2019; Kumar 2016; Pandey 2018), the qualitative distinction here is the contention that such a situation seems to further scupper the prospect for closer relations between the $\mathrm{EU}$ and India despite all the 'strategic' rhetoric of their interactions. The 
study concludes with a brief assessment and future trajectories of the EUIndia SP in the context of the EU's SP diplomacy. It will demonstrate that the next stages of the EU-India SP will very much depend on the contingent interactions between the three logics of the EU SPs outlined in Chapter 2.

\section{Process Tracing the EU-India Strategic Partnership}

In theory, Strategic Partnerships (SP) are treated as equalizing arrangements of asymmetrical bilateral relations - that is, an actor with presumed greater international standing grants a privileged position to a counterpart, who is (usually) of a lower status in global life (Kavalski 2019). In such a setting, SPs are also disciplining arrangements in that the weaker party has both to acknowledge the leadership position of the stronger actor and to be willing to emulate aspects of the behaviour of that actor (if not adopt it wholesale). For instance, the EU has used the SPs to assert itself as a viable economic and political model, offering a meaningful (and, hopefully, preferred) alternative that can be emulated by others. The equalizing nature of SPs is closely connected to such willingness of the weaker party to simultaneously recognize and follow the lead of the stronger party in the relationship (Blanco 2016; Kavalski 2006). As such, the policy convergence underpinning SPs tends to be the product of strategic calculation on behalf of both actors: on the one hand, they involve the ability of weaker parties to demonstrate that they are deserving of such trust; on the other hand, they revolve around the capacity of the stronger actor to maintain its appeal. The gains for the weaker actor are multiple: they obtain exclusive access to and are recognized as peers by the stronger actor; at the same time, their status in global life also improves as a result of such a privileged relationship (Kavalski 2016). In the meantime, the stronger actor secures a reliable long-term partner in a pivotal strategic locale of the world.

Of course, the reality of SPs is far messier than such analytical assumptions would suggest. For instance, the SPs of the EU with countries as diverse as the United States, China and Russia reflect a far fuzzier relationship (Kavalski 2010b). As such cases illustrate, SPs provide entrepreneurial arrangements for both Brussels and its partners to diminish (if not fully neutralize) the asymmetries of specific bilateral relationships (Blanco 
2016: 44). At the same time, these SPs reveal a paradoxical 'asymmetric (inter)dependence', which makes Brussels highly contingent on (if not vulnerable to) its partners' whims, while the latter incur little cost for their non-compliance with the EU (Hughes 2007). Furthermore, it seems that the Eurozone debt crisis has significantly dented the economic power and influence of the EU-probably, the most important leverage in its relations with 'out-of-Europe' partners such as India. In particular, it has shifted the 'external perception of Europe from a zone of wealth and stability to a continent in crisis looking for handouts from abroad' (von Muenchow-Pohl 2012). In the case of India, for instance, the debt crisis has urged many to question the legitimacy of Brussels' drive to 'Europeanize' world affairs. In particular, it has exposed the poor economic governance and weak collective response of the EU-trends that have come to undermine the very core of the European integration project as well as the EU's international standing. In fact, the European sovereign debt crisis turned the tables of the SP when New Delhi pledged to contribute $\$ 10$ billion to the IMF's rescue fund for the crisis-hit Eurozone (Narendranath 2012).

In this respect, SPs can be treated as a complex, volatile and ongoing diplomatic dance in which both parties constantly assess, affirm and adapt their relationship to the contingencies of local, regional and global affairs. The key feature of such arrangements is their flexibility-in other words, both parties to an SP need to agree to disagree. Trust, thereby, becomes a crucial feature of such dynamics. On the one hand, partners need to be willing to manage 'unavoidable conflicts so that they can continue to work together on areas of vital interest' (Goldstein 2005: 135; Kavalski 2007a: 441 ). On the other hand, as a goal-oriented and process-driven diplomatic tool of 'cooperation for the sake of cooperation' (Strüver 2017: 33-37), SPs facilitate 'hedging against all eventualities, while allowing for the common pursuit of mutual interests' (Nadkarni 2010: 46). At the same time, it should not be forgotten that SPs do not operate in a vacuum, but reflect the broader spectrum of relations in which each of the parties is enmeshed. Hence, in contrast to alliances and security pacts, SPs promote close cooperation without forcing any of the partners to choose a side in any current or prospective conflict that each one of them might be involved (Kavalski 2020b).

As already mentioned, the EU-India SP is no stranger to the contingent movements of this complex diplomatic dance and reflects the vagaries of their privileged, yet asymmetrical and fluid bilateral relations. 
At the same time, it adds its own wrinkles to the consideration of both SPs, in general, and the SPs of the EU, in particular. To begin with, depending on the sources, there is a controversy as to who is the initiating party. According to European sources, the EU-India SP was instigated by Brussels and is discussed in the context of the evolving diplomatic toolkit of the EU's external affairs. Indian sources however tend to treat this as an Indian enterprise reflecting the growing global stature of New Delhi (Jain and Pandey 2019; Kavalski 2011a). As such the EU-India SP is part and parcel of India's aspiration to overcome the constraints of its South Asian context and become a fully fledged global power. Yet, as the relationship develops, it seems that one feature becomes dominantboth partners to the SP are growing increasingly inflexible towards one another; a feature which even the rhetorical façade of both the EU and Indian policy pronouncements finds difficult to conceal.

\section{The 'Lost' Decade of The ig9os}

The relationship between the EU and India reflects the complex historical contexts of the connections between Europe and South Asia. For instance, the European Commission routinely acknowledges that during the 1960s India was one of the first countries to set up relations with the nascent European Community (Cameron et al. 2005: 6). Yet, New Delhi is quick to remind that the interactions could have been closer and more meaningful had India not been struck out from the 1975 Lomé Convention due to French apprehensiveness (Allen 2013: 580; Kavalski 2011b: 208). Such developments appeared to confirm Indian perceptions that the European Community was 'a self-centred inward-looking economic giant' (Swaminathan 1973: 30) uninterested in the pursuit of 'a new postcolonial, horizontal, multilateral relationship' (Singh 1976: 444-445). In a sign of changing attitudes as well as an attempt to redress such misgivings, the then European Community signed in 1981 an Agreement for Commercial and Economic Cooperation with India. The focus was both on lifting obstacles to trade and 'the creation of new trading opportunities through commercial and economic cooperation' (Boselli 1981: 25). The Agreement provided the key framework for the bilateral interactions well into the 1990s and at the same time has set the tone for the economic focus of the relationship pretty much to the present day.

The key document for the post-Cold War relationship was the socalled third-generation 1994 Cooperation Agreement on Partnership and 
Development. It largely reiterated the economic nature of the relationship by granting a most-favoured nation treatment, while outlining a range of issues and areas for future cooperation (Kavalski 2009). The preamble insisted that the main aim of the Cooperation Agreement is 'to enhance commercial and economic contacts between India and the EU [by] creating favourable conditions for a substantial development and diversification of trade and industry within the framework of a more dynamic relationship which will further their development needs, investment flows, commercial and economic cooperation' (European Commission 1994: 24). In fact the centrality of economic interests was intimated by Article 4, which spells out the three main areas of the EU-India interactions: (i) 'improving the economic environment in India by facilitating access to Community know-how and technology'; (ii) 'facilitating contracts between economic operators and other measures designed to promote commercial exchanges and investments'; and (iii) 'reinforcing mutual understanding of their respective economic, social and cultural environment as a basis for effective cooperation' (European Commission 1994: 26). Within these three areas, the 1994 Cooperation Agreement outlined a set of seventeen targets stretching from 'improvement in the economic environment and the business climate' to 'cooperation in the fields of information and culture' (European Commission 1994: 26). In this respect, the EU and India established ten 'means' for achieving these objectives ranging from the 'exchange of information and ideas', 'provision of technical assistance and training programmes' to the 'establishment of links between research and training centres, specialised agencies and business organisations' (European Commission 1994: 27).

However, despite all the rhetoric of 'a closer and upgraded relationship', it was apparent to both sides that the Cooperation Agreement offered little in terms of deliverables. In fact, the 1994 Cooperation Agreement made explicit the noncommittal nature of the EU-India relationship by insisting that rather than formalized and regular interactions, the EU and India should 'hold friendly ad hoc consultations' whenever they can (European Commission 1994: 30). Thus, despite the publication of the first 'strategy paper' on India in 1996 (European Commission 1996), which provided an extensive list of areas in which the EU and India could work closely together, for most of the 1990s both Brussels and New Delhi led parallel existences owing to their distinct adaptations to the post-Cold War international system. The EU interpreted the fall 
of the Berlin Wall as a unique opportunity for expanding its role on the continent. For India, the end of the Cold War posed major challenges reflecting 'the loss of familiar foreign policy contours', which allowed New Delhi to play an 'exaggerated role' on the international stage by 'moralizing about the inequalities of bipolarity' (Kavalski 2010a: 29). As a result, despite its alleged broader scope, the 1994 Cooperation Agreement remained rather fuzzy about the framework of the bilateral relationship beyond reiterating the potential for economic exchanges.

\section{The 1999 Transformation: A Coincidental Juncture}

The claim here is that 1999 marked just such a coincidence in the postCold War trajectories of the EU and India which had a lasting bearing both on their external outlooks and their bilateral relations. For both Brussels and New Delhi, the juncture was marked by brief wars-the one in Kosovo for the EU and the Kargil War for India. At the same time, the 1999 juncture was made possible by nearly a decade-long foreign policy experimentation and adaptation. The claim here is that their post1999 foreign policy stance indicates a distinct interpretation of Brussels' and New Delhi's role in global life and the character of the international system. At the same time, it is this shift (and, especially, the different lessons that the EU and India seem to have drawn during the first post-Cold War decade) that belies the fault lines plaguing the bilateral relationship (Pan and Kavalski 2018).

For the EU, the operational significance of 1999 is procedurally indicated by its response to the Kosovo crisis. It was then that the EU collectively seemed to furnish a rhetorical and policy platform for addressing the challenge of relevance that it was facing by the end of the decade. Brussels did this by investing in the sui generis nature of its political formation through the articulation of a responsibility for maintaining European security through the enlargement project. In the wake of the Kosovo conflict, the EU (i) launched its European Security and Defence Policy (ESDP), (ii) appointed its first High Representative for Common Foreign and Security Policy (CFSP), (iii) delineated the extent of its outreach leavened by its decision to open enlargement negotiations with all candidate-countries and initiated accession procedures with the states of the Western Balkans, (iv) recognized Turkey's prospective status as a candidate country, and (iv) consigned the rest of the continent to 
the outskirts of a 'Wider Europe', conveniently reframed as the 'European Neighbourhood' (Kavalski 2008a). The post-1999 European order seemed to suggest that for the EU the broader lesson from the experience of the 1990s was that its purpose in international life is to 'Europeanize' world affairs by promoting transparent forms of governance, viable market mechanisms and strong civil societies. Consequently, the term 'normative power' has become a convenient label for the external agency of Brussels (Kavalski 2013; Kumar 2012).

For India, the short and decisive 1999 Kargil War with Pakistan seems to have validated the country's new-found confidence in the wake of its 1998 nuclear tests. The five nuclear devices detonated by India in May 1998 set off a barrage of international criticism. In a stark contrast, India was markedly unfazed by the international censure. By flaunting its capacity for 'pre-emptive response', New Delhi emphasized that India should 'be taken seriously as a player who could inflict unacceptable military and diplomatic costs' (Kapur 2006: 169; Hess 2013: 200). Thus, in a poignant break with its post-Independence foreign policy tradition, New Delhi made the strategic choice 'to rely more on power politics and less on morality and unilateral restraint in the pursuit of Indian interests' (Kapur 2006: 23). The assertion was that 'a country with non-violent values has little chance to enter the major-power system' (Nayar and Paul 2003: 105). Consequently, the post-1999 stance of India has strived to put behind the perceived 'softness' and 'pseudo-secularism' of the almost half-a-century-old foreign policy of non-alignment, which 'twisted India's strategic culture into all kinds of absurdities' and ultimately led to 'enfeebling a once fierce nation' (Chaulia 2002: 220; Kavalski 2015b: 433). This re-formulation of India's external outlook has also morphed into a powerful ideology for the consolidation of a conflict-ridden domestic political stage (whose most recent iterations are the $\mathrm{CAB}$ and the revoking of Article 370).

In this setting, while the experience of the first post-Cold War decade urged both Brussels and New Delhi to radically reconsider their external outlook during 1999, this shift led neither to a coincidence of views, nor to closer bilateral relations between the them. Such trend seems to detract from the experience of some of the other SPs of the EU-in particular, the one with Brazil (see Chapter 5). Yet, as Dave Allen (2013: 576) had presciently observed, 'whilst the EU has sought to make the most of its post-Westphalian characteristics, India and almost all the other established or emerging powers remain firmly Westphalian in their nature and 
outlook'. Many have noted that India cannot afford to be a 'pacifist and postmodern island [when it is] surrounded by a hard Westphalian world' (Telo 2008: 124). Thus, India's 'jettisoning of moralpolitik in favour of realpolitik' (Jain 2005: 2) in the wake of the 1998 nuclear tests has provoked 'disdain in India for the EU' (Jaffrelot 2006: 5). A good indication of the normative divergence between the two strategic partners is demonstrated by their voting patterns at the UN General Assembly (UNGA). Since 1999 there has been a nearly 60\% margin of difference in their voting patterns, which grows to over $75 \%$ when the resolutions involved human rights issues (Keukeleire and Hooijmaaijers 2013: 120; Kavalski 2020a). In fact, the bilateral human rights dialogue between the EU and India has not been held since the election of PM Modi and, for the time being at least, it seems unlikely that the two partners will be resuming it any time soon. This divergence in foreign policy outlooks underpins the contradictions in the international interactions between India and the EU since 1999, on the one hand, and their SP, on the other.

\section{Post-1999 Relations: Struggling to Define the Strategic Partnership}

It must be acknowledged that there was nothing inevitable about the strategic decision taken by the EU and India during 1999. In fact, the start of the new millennium seemed to offer some propitious signs for the bilateral relationship (European Commission 2001, 2002). To begin with, since 2000 the EU and India have been holding regular high-level summits, with the intention to facilitate the development of a shared strategic vision. Such aspirations appeared reinforced by the 2003 European Security Strategy (ESS) which clearly stated that the EU's 'history, geography and cultural ties give us links with every part of the world... These relationships are an important asset to build on. In particular, we should look to develop strategic partnerships with Japan, China, Canada and India as well as with all those who share our goals and values, and are prepared to act in their support' (European Council 2003: 14; Cho and Kavalski 2015: 441). Reinforcing this objective, Chris Patten, the then External Relations Commissioner of the EU, proclaimed that the regular summit-meetings have opened 'a new chapter in the EU-India relationship' premised on the appreciation that 'just as we are changing fast, India herself is evolving' and have provided the foundations for 'a coalition of interest in addressing global challenges' (Patten 2004). 
It was therefore encouraging that in 2004, the EU followed on its commitments and established a SP with India. A senior European diplomat has suggested that the SP confirms 'that India is gaining in real importance for the EU. Before we looked more to China, and saw India rather as a leader of the developing world. Now it is an equal partner' (cited in Bava 2008: 248). In this respect, the SP has been promoted as 'the starting point of a collective reflection on upgrading EU-India relations' (European Commission 2004: 11). What is interesting about this 'collective reflection' is Brussels' recognition that 'the institutional architecture of EU-India relations defined by the 1994 Cooperation Agreement and the 2000 Lisbon Summit has created a complex structure of meetings at different levels in virtually all areas of interest and cooperation. It is now time to streamline and increase its effectiveness' (European Commission 2004: 10). In this respect, the 2004 SP identified five areas for the interactions between Brussels and New Delhi: (i) cooperation at international fora-on multilateralism, human trafficking and migration, conflict prevention and post-conflict reconstruction, non-proliferation of weapons of mass destructions, promotion of democracy and protection of human rights; (ii) economic cooperation-joint sectoral dialogues on regulatory and industrial policies; (iii) development cooperation; (iv) intellectual, scientific and cultural cooperation; and (v) cooperation on the improvement of the institutional collaboration between India and the EU (European Commission 2004: 3-10). The implicit agenda of this 'streamlining' was 'to facilitate bridge-building' between Brussels and New Delhi by providing a framework for 'continuous dialogue... especially, on implementation of [our] international obligations and commitments, and the strengthening of global governance' (European Commission 2004: 4).

However, just as with the 1994 Cooperation Agreement, the 2004 SP reiterated the noncommittal nature of EU-Indian interactions. It plainly stated that it is underwritten by the intention 'to produce non-binding guidelines for a further deepening of EU-India relations' (European Commission 2004, 11. Emphasis added). Such replication of 'ad hoc' procedures seemed to confirm the absence of strategic agreement-both in Brussels and in New Delhi-on the long-term vision for their relations. At the same time, despite its rationalizing drive, the SP did not produce 'a concrete list of mutually-beneficial priorities for day-to-day cooperation' (Khandekar 2011: 3; Cho and Kavalski 2018: 61). In fact, ever since its inception, one of the key challenges for the EU-India SP has been the inability to find a manageable set of issues on which the two partners 
can demonstrate shared strategic concerns and vision. Instead, the EUIndia summits continue to be dominated by an inventory-like catalogue of issues that provide an 'exhaustive laundry list' with 'no deliverables', 'no goals', 'no timelines', and which merely confirm New Delhi's perception that Brussels is 'a non-credible political actor' (Schöttli 2014: 128).

At the same time, despite its aspiration for enhanced EU agency in global affairs, the European Security Strategy made it (bluntly) explicit that India (and most other areas of the world, for that matter) fell outside of its immediate security purview. As the policy document proclaimed, 'even in an era of globalization, geography is still important. It is in the European interest that countries on our borders are well governed' (European Council 2003: 11). In this way, the EU seemed to have voluntarily constrained itself to 'external' action within the confines of the European continent and its immediate environs. Such developments both confirmed the framework of the post-1999 European order and reflected the historical evolution of Brussels' global outreach. The development of the EU's foreign and security policy has become closely intertwined with the Europeanization of candidate states. Owing to the dominant focus on enlargement, the EU's external action has traditionally been treated largely as coterminous with the transformative potential underwriting the dynamics of accession-driven conditionality (Kavalski 2007b). This is not least, because the EU has had very little reasons to develop such capacities while the Central and East European enlargement was still ongoing for the better part of the 2000s.

Thereby, it was only with the start of the 2010s- that is, in the wake of the so-called 2007 'big bang' enlargement to the EU and the subsequent Eurozone debt crisis - that the relevance of the EU's ability to alter the practices of states (outside of the purview and the prospect of membership) has been given serious consideration (Cho and Kavalski 2019). It seems, however, that the bulk of popular and policy attention has been captured by the development of the European Neighborhood Policy (ENP), which has been further exacerbated by the crisis in Ukraine and the deterioration in relations with Russia as a result of the annexation of Crimea. In this respect, the development of EU's agency in 'out-ofEurope' areas-such as India-is still fairly nascent. Thus, as Michael Smith $(2009,603)$ has discerned,

...the status of the EU as a continental model of economic and social organization might be seen as giving a strong basis for the development 
of European foreign policy, but in many ways the strengths that give the EU a major role in the European order do not export easily; they are less immediately appropriate to a fluid and often chaotic world, and this means that the attempt to project 'Europe' into the global arena brings with it new risks and potential costs.

The Lisbon Treaty was expected to address the insularity inherent in the EU's external outreach. It established a President of the European Council and elevated the status of the High Representative of the Union for Foreign Affairs and Security Policy (HR) to a Vice-President of the European Commission to be supported by the newly minted diplomatic corps of the European External Action Service (EEAS). These were all steps intended to strengthen the visibility and coherence of the EU's international outreach. As Herman Van Rompuy acknowledged in 2010, 'until now, we had strategic partners, now we also need a strategy' (Van Rompuy 2010). Such statements tend to corroborate the assertion that the strategic partnerships of the EU had no clear vision for their implementation. However, the suggested strategic reflection implicit in Van Rompuy's acknowledgement is yet to occur. The key impetus of the Lisbon Treaty was to strengthen the EU's role in the international arena. However, as Dave Allen (2013) had suggested, the result was the very opposite. There was growing institutional infighting between the newly established President of the Council and the HR (often siding with one another) and the European Commission, the European Parliament, the European Council, and the Member States. This wrangling was made conspicuous by the sluggish development of the EEAS (Allen 2013: 585).

It was therefore not surprising that in the early 2000s the EU 'hardly figures on the Indian "radar screen" (Jaffrelot 2006: 2). The United States and China were usually considered to be the key actors on New Delhi's foreign policy horizon. Such attitude reflected a growing realization that India does not really need the EU (Schmidt 2013: 11). On the one hand, India found Washington an increasingly receptive partner, who-unlike the EU-seemed to share New Delhi's strategic concerns about the (perceived and real) security threats posed by both Pakistan and China (Kavalski 2010c). The shared language of 'hard power' capabilities fostered a perception among many that India was 'becoming Asia's America' (Lak 2008: 277; Kavalski 2018a: 91). On the other hand, despite the strategic anxiety that China seemed to provoke among Indian policymakers ever since the 1962 war, many commentators appeared envious of 
Beijing's ability to 'establish quickly an international reputation for being able to look after itself [and, thus] become a "great power", whereas India's potential remains unrealized' (Kavalski 2012a: 81). In fact, prominent Indian policy-makers and commentators have noted that Beijing posed a major structural impediment for closer relations between Brussels and New Delhi. For instance, Shashi Tharoor, then Minister of State for External Affairs, insisted that 'despite its human rights rhetoric, the EU has long favoured China over India: for every euro that the EU invests in India, it invests $€ 20$ in China' (Tharoor 2011).

The 2016 EU Global Strategy (EUGS) did little to alleviate such concerns. It insisted on 'scaling up' its strategic ambitions in Asia by developing a 'more politically rounded approach' that makes 'greater practical contribution to Asian security' (EEAS 2016: 37-38). Envisioned as a more 'realistic' approach to a volatile and dynamic world, the EUGS promoted 'strategic autonomy' and 'principled pragmatism' as the cornerstones of EU's outreach (EEAS 2016). Just as with the SP, Indian commentators were quick to point out that both these principles were pioneered by Indian foreign policy (Jain and Pandey 2019; Horesh and Kavalski 2014). Thus, some welcomed this move 'as a long-overdue shift towards realism in Brussels' (Mohan 2017), others saw this as a feeble 'plea for credibility' in EU's foreign policy (Kumar 2016: 32). Still others noted that the EU missed yet another opportunity to learn from Indian experience in the development of its strategic vision. These commentators were quick to point out that India is mentioned only twice in the EUGS, which for them was yet another indication of the 'bureaucratic mistrust and political neglect' that defines the EU-India SP (Jain and Pandey 2019: 120-122).

Taking account of these sentiments, at the end of 2018 the European Commission issued a new India Strategy Paper, titled Elements for an EU Strategy on India (European Commission 2018). The paper stressed that the EU-India SP plays a key role in developing a 'balanced EU policy towards Asia as a whole'. At the same time, the new strategy paper outlined a list of 66 'proposed actions' across areas as diverse as sustainable modernization, multilateral cooperation, trade and investment, strengthening the rules-based global order, security and defence cooperation, and clean energy transition. The intent was to refocus the SP around areas of mutual interests and a 'flexible and result-oriented approach' (European Commission 2018: 15). Yet, the 
intervening months did not seem to suggest any significant improvement in the relations between the two strategic partners; in fact, it appeared that the EU and India were drifting further apart. Indian foreign policy-makers continued to be confused about the simultaneous initiatives unveiled under the auspices of the EU's bilateral (SP) diplomacy and its inter-regional diplomacy (as pointed out earlier in Allen 2013: 577). As a result, a number of Indian commentators observed that New Delhi has found itself increasingly in positions where it has 'to counter the agendasetting capabilities of the EU' (Jain and Sachdeva 2019: 311). Such stance became even more pronounced since the victory of the Bharatiya Janata Party (BJP) in the 2014 general elections. For Prime Minister Narendra Modi relations with India's Asian counterparts (especially, Japan, China, and Singapore) tend to take priority over relations with the EU (Traub 2014). In particular, India has invested significant strategic capital in the construction of an 'Indo-Pacific' geopolitical zone where it plays a leading role (alongside Japan, Australia, and the United States).

Not surprisingly, therefore, many in India see the SP as a 'loveless arranged marriage' with the EU (Khandekar 2011; Hess 2013; Zolkos and Kavalski 2007). In such a relationship, Brussels plays the part of the ageing partner unable to show empathy to the concerns (nor cater to the needs) of its younger spouse, while insisting on lecturing New Delhi on how it should behave itself on the international stage and what are its appropriate domestic practices. Reflecting on this development, the then European Commission President Jean-Claude Juncker acknowledged that the stalled FTA agreement with India would be concluded 'only once the circumstances are right' (Juncker 2017; Kavalski 2015a; Walton and Kavalski 2017). This statement offers a good indication of the current status of the SP-it not only is not right, but it is nowhere near it. The SP lacks both shared strategy and common vision, and oftentimes can hardly be described as a partnership.

\section{CONCLUSION}

It is difficult to fit the EU-India SP in the continuum provided by the EUs different SPs. As some have noted, the SPs can be distinguished between the 'partnerships of necessity', such as those with China and (formerly) Russia, and 'partnerships of choice' owing to perceived norm convergence, such as those with Canada and Japan (Vivet and de Lalande 2014: 
4). It appears that the EU-India SP is closer to the 'partnerships of necessity' both as a result of the country's rising status and as a counterbalance to China; in other words, the EU-India SP is very strongly motivated by the external logic outlined in Chapter 2 as the EU sought to upgrade the existing infrastructure of dialogues and policy engagements with New Delhi. However, at the very same time, Brussels justified the EU-India SP as a 'partnership of choice', owing to India's democratic credentialsthat is, the SP was framed through the identity logic of the EU SPs. In that way, the EU-India SP backstopped Brussels' international identity of 'EUropean exceptionalism' on the world stage (see Chapter 2).

On the other hand, the EU-India SP seems to offer ample evidence that Brussels selects its SPs 'more by accident than by strategic reflection' (Renard 2012: 6). While there are plenty of historic, economic and political rationales backstopping the EU-India SP, there is nothing particularly compelling about India's selection for such a privileged relationship. Thus, especially in the context of their distinct foreign policy interpretation of the 1999 juncture, it seems that the EU and India find themselves in an accidental partnership, which they are discovering to be increasingly unpalatable and frustrating. Yet, it is the events of 1999 that appear to have provided a set of internal pressures leading towards the development of a more structured EU approach to key international partners (see Chapter 2). As such, the internal logic of the EU SPs has prodded Brussels to opt for a high-level policy device such as the SP to reflect the distinct internal forces within the EU.

It is therefore the contingent interactions between the internal, external and identity logics of the EU SPs that backstop the emergence of the EU-India SP. As the SP has developed it appears that there is little beyond commercial interests that brings the two strategic partners together (Kavalski 2016). New Delhi has grown increasingly doubtful that Brussels understands India's security considerations, let alone that it is able (and willing) to offer any meaningful assistance to alleviate them. Thus, while the EU continues to insist on the global relevance of its normative power, India's assertive foreign policy is framed by the emphasis on hard power capabilities. It is expected that such ideational discrepancy would continue to hinder the interactions between Brussels and New Delhi. As one observer noted, 'despite shared values, the lack of shared interests on a number of issues will continue to limit cooperation' (Jain 2011: 230). Thus, perhaps paradoxically, India (together with its other democratic counterpart Australia) appears to show one of the 
most consistent resistance to the EU's outreach in Asia, as a whole, and the Indo-Pacific region, in particular (Murray 2016; Benvenuti 2018). In this respect, while the external agency of both the EU and India has been framed by idiosyncratic constructions of proximity, the prospective pattern of relations between them would continue to be dependent upon the discursive articulations of geographic and normative contiguity.

In particular, the SP reveals that the EU still remains a 'bit player'-an actor with a very limited impact and leverage in Asian affairs (MacFarlene 2004: 14; Zolkos and Kavalski 2008: 47). In other words, the EU-India SP offers a good illustration of the reactive image of Brussels' strategic outreach-that is, it disputes the very the notion of an organized or systematic EU partnership diplomacy (see Chapter 2). In this respect, the SP between Brussels and New Delhi confirms that in 'out-of-Europe' areas the EU is profoundly challenged by the lack of (voluntary) acquiescence with its rules and norms (Kavalski 2018c). What Brussels finds particularly testing is the need to work for the recognition of its legitimacy as a normative power. Such context appears to challenge the EU's resilience and its diplomatic ability to adapt and iron out some of the elements that stand in the way of 'a comprehensive, differentiated, and purposeful approach to what is a complex and messy area' (see Chapter 2).

Thus, the EU is yet to fully comprehend that its capacity to define what is 'normal' in international life depends on the recognition of its external agency by target states. Such 'target acquisition' requires both strategic flexibility and adaptive, yet explicit setting of goals and priorities through means that are gradual, continuous and incremental. In other words, the EU's legitimacy as a normative power derives from and is embedded in the practices through which it projects a social purpose in global life. So far, it does not seem likely that India will be able to articulate any time soon a meaningful social purpose for its foreign policy within the confines set up by the 'European model' of international affairs (Kavalski 2012b). If anything, New Delhi's increasingly geopolitical foreign policy vision appears to clash with the very tenets of the identity logic backstopping Brussels' partnership diplomacy. Therefore, for the foreseeable future the EU-India SP is likely to continue to gather dust on the foreign policy shelves in both Brussels and New Delhi as one that is neither strategic, nor much of a partnership either. 


\section{BIBLIOGRAPHY}

Allen, D. (2013). The EU and India: Strategic Partners, but No Strategic Partnership. In T. Christiansen, E. Kirchner, \& P. Murray (Eds.), Palgrave Handbook of EU-Asia Relations (pp. 571-586). Basingstoke: Palgrave.

Bava, U. (2008). India-EU Relations. In R. Balme \& B. Bridges (Eds.), EuropeAsia Relations (pp. 233-256). Basingstoke: Palgrave.

Benventi, A. (2018). Australia's Relations with the European Community: An Elusive Partership. Australian Journal of International Affairs, 72(3), 194207.

Blanco, L. (2016). The Function of Strategic Partnerships in EU Foreign Policy. Cambridge Review of International Affairs, 29(1), 36-54.

Boselli, L. (1981). EEC Contribution to Development in South Asia. India and the European Community, 6(3), 18-27.

Cameron, F., Berkofsky, A., Bhandari, M., \& Halley, D. (2005). The EU-India Relations. Brussels: European Policy Centre.

Chaulia, S. S. (2002). BJP, India's Foreign Policy, and the "Realist Alternative". International Politics, 39(2), 215-234.

Cho, Y. C., \& Kavalski, E. (2015). Governing Uncertainty. Comparative Sociology, 14(3), 429-444.

Cho, Y. C., \& Kavalski, E. (2018). European Union in Central Eurasia. Asia Europe Journal, 16(1), 51-63.

Cho, Y. C., \& Kavalski, E. (2019). Worlding the Study of Normative Power. Uluslararası İlişhiler Dergisi, 15(57), 49-65.

Choudhury, A., \& Dhawan, P. (2019, November 5). Why the European Parliament Group's Visit to Kashmir Backfired. The Diplomat.

Czechowska, L. (2019). A marriage of Convenience? The EU-India Reluctant Strategic Partnership. In L. Czechowska \& J. Piechowak-Lmaprska (Eds.), States, International Organizations, and Strategic Partnerships (pp. 258-280). Cheltenham: Edward Elgar.

European Commission. (1994, August 27). Cooperation Agreement Between the European Community and the Republic of India. Official Journal of the European Communities L223, 24-34.

European Commission. (1996). EU-India Enhanced Partnership. $\operatorname{COM}(96) 275$ final.

European Commission. (2001). Europe and Asia: A Strategic Framework for Enhanced Partnerships. Brussels: COM(2001)469final.

European Commission. (2002). Towards a New Asia Strategy. Brussels: $\operatorname{COM}(2002) 314 f i n a l$.

European Commission. (2004). EU-India Strategic Partnership. Brussels: $\operatorname{COM}(2004) 430 f i n a l$.

European Commission. (2018). Elements for an EU Strategy on India. Brussels: JOIN(2018)28final. 
European Council. (2003). European Security Strategy. Brussels: EUISS.

European External Action Service. (2016). Shared Vision. Common Action: A Stronger Europe. Brussels.

Goldsten, A. (2005). Rising to the Challenge. Stanford: Stanford University Press. Hess, N. (2013). The Strategic Partnership Between the EU and India. FPRC Journal, 1(1), 185-202.

Horesh, N., \& Kavalski, E. (2014). Asian Thought. Basingstoke: Palgrave.

Hughes, J. (2007). EU Relations with Russia. In N. Cassarini \& C. Musu (Eds.), European Foreign Policy (pp. 76-94). Basingstoke: Palgrave.

Jaffrelot, C. (2006, March 6). India and the European Union. CERI-Focus.

Jain, R. (2005). India, the European Union and Asian Regionalism. EUSAAP Conference, Tokyo. http://wwwsoc.nii.ac.jp/eusa-japan/download/ eusa_ap/paper_RajendraJain.pdf. Accessed on 25 December 2019.

Jain, R. (2011). India's Relations with the European Union. In D. Scott (Ed)., Handbook of India's International Relations (pp. 223-232). London: Routledge.

Jain, R., \& Pandey, S. (2019). The EU Global Strategy and EU-India Relations. In N. Chaban \& M. Holland (Eds.), Shaping the EU Global Strategy (pp. 101-126). Basingstoke: Palgrave.

Jain, R., \& Sachdeva, G. (2019). India-EU Strategic Partnership. Asia Europe Journal, 17(2), 309-325.

Juncker, J.-C. (2017). President Juncker at the EU-India Summit. https://ec. europa.eu/commission/news/president-juncker-eu-india-summit-2017-oct06_en. Accessed on 18 January 2020.

Kapur, A. (2006). India. London: Routledge.

Kavalski, E. (2006). From the Western Balkans to the Greater Balkans Area. Mediterranean Quarterly, 17(3), 86-100.

Kavalski, E. (2007a). The Fifth Debate and the Emergence of Complex International Relations Theory. Cambridge Review of International Affairs, 20(3), $435-454$.

Kavalski, E. (2007b). Partnership or Rivalry between the EU, India and China. European Law Journal, 13(6), 839-856.

Kavalski, E. (2008a). Extending the European Security Community. London: I.B.Tauris.

Kavalski, E. (2008b). Venus and the Porcupine: Assessing the European UnionIndia Strategic Relationship. South Asian Survey, 15(1), 63-81.

Kavalski, E. (2009). Timescapes of Security. World Futures, 65(7), 527-551.

Kavalski, E. (2010a). India and Central Asia. London: I.B.Tauris.

Kavalski, E. (2010b). The Peacock and the Bear in the Heartland. Indian Journal of Asian Affairs, 23(1/2), 1-20.

Kavalski, E. (2010c). An Elephant in a China Shop. In M. Laruelle (Ed.), China and India in Central Asia (pp. 41-60). Basingstoke: Palgrave. 
Kavalski, E. (2011a). Coming to Terms with the Complexity of External Agency. Journal of Eurasian Studies, 2(1), 21-29.

Kavalski, E. (2011b). Looking North. In D. Scott (Ed.), Handbook of India's International Relations (pp. 201-210). London: Routledge.

Kavalski, E. (2012a). Central Asia and the Rise of Normative Powers. New York: Bloomsbury.

Kavalski, E. (2012b). Pax Indica or Brand India. Harvard Asia Quarterly, 14(2), 46-51.

Kavalski, E. (2013). The Struggle for Recognition of Normative Powers. Cooperation and Conflict, 48(2), 247-267.

Kavalski, E. (2014). The Shadows of Normative Power. Pacific Focus, 29(3), 303-328.

Kavalski, E. (2015a). World Politics at the Edge of Chaos. Albany, NY: State University of New York Press.

Kavalski, E. (2015b). India's Bifurcated Look to Central Eurasia. In D. Malone \& C. Raja Mohan (Eds.), The Oxford Handbook of Indian Foreign Policy (pp. 424-436). Oxford: Oxford University Press.

Kavalski, E. (2015c). The European Union and India. In P. Winand (Ed.), The External Relations of the European Union (pp. 151-166). Bern: Peter Lang.

Kavalski, E. (2016). The EU-India Strategic Partnership. Cambridge Review of International Affairs, 29(1), 192-208.

Kavalski, E. (2017). Recognizing Normative State Action. Political Studies Review, 15(2), 231-242.

Kavalski, E. (2018a). Guanxi of Relational International Theory. London: Routledge.

Kavalski, E. (2018b). India: Breaking Out of the Middle Power Straitjacket. In T. Struye de Swielande, D. Vandamme, D. Walton, \& T. Wilkins (Eds.), Rethinking Middle Power in the Indo-Pacific (pp. 162-173). London: Routledge.

Kavalski, E. (2018c). Community of Values or Community of Practice. East Asian Community Review, 1(1/2), 5-17.

Kavalski, E. (2019). The Puzzle of India's Relations with "Central Eurasia”. Asian Security, 15(3), 304-322.

Kavalski, E. (2020a). Unexpected Consequences. International Studies, 57(1), $1-19$.

Kavalski, E. (2020b). Inside/Outside and Around. Global Society, 34(4), 467486.

Keukeleire, S., \& Hooijmaaijers, B. (2013). EU-India Relations and Multilateral Governance. FPC Journal, 13(1), 118-122.

Khandekar, G. (2011). The EU and India (p. 90). No: FRIDE Policy Brief.

Khandekar, G. (2014, June 11). Modi and the EU. FRIDE Blog. 
Khorana, S., \& Asthana, A. (2014). EU FTA negotiations with India. Asia Europe Journal, 12(1), 1-13.

Khorana, S., \& Garcia, M. (2013). EU-India Trade Negotiations. JCMS: Journal of Common Market Studies, 51(4), 684-700.

Kumar, R. (2016). EUGS After Brexit: An Indian View. International Spectator, $51(3), 32-33$.

Kumar, V. (2012, April 24). The EU Keen to Strengthen Relations with India. The Hindu.

Lak, D. (2008). The Future of a New Superpower. New York: Viking.

MacFarlane, S. N. (2004). Caucasus and Central Asia. GCSP Occasional Paper Series 37.

Mohan, C. R. (2017). Letter from New Delhi. http://carnegieeurope.eu/strate giceurope/68593. Accessed on 18 January 2020.

Murray, P. (2016). EU-Australia Relations. Cambridge Review of International Affairs, 29(1), 171-191.

Nadkarni, V. (2010). Strategic Partnerships in Asia. London: Routledge.

Narendranath, K. G. (2012, June 20). India Pledges \$10billion. Indian Express.

Nayar, B., \& Paul, T. V. (2003). India in the World Order. Cambridge: Cambridge University Press.

Pan, C., \& Kavalski, E. (2018). Theorizing in and Beyond International Relations. International Relations of the Asia-Pacific, 18(3), 232-241.

Pandey, S. (2018). India and the European Union. New Delhi: KW Publishers.

Patten, C. (2004, February 17). The EU and India. The Hindu.

Renard, T. (2012). The EU Strategic Partnerships Review. ESPO Policy Brief Brussels: ESPO.

Schmidt, J. D. (2013). India and the European Union. FPRC Journal, 13(1), $1-20$.

Schöttli, J. (2014). India-EU Strategic Relations. In S. Wolf (Ed.), The Merits of Regional Cooperation (pp. 119-130). Berlin: Springer.

Sengupta, R. (2013, May 13). Political Opposition to EU-India FTA. Third World Network.

Sharma, S., \& Sethi, A. (2019, October 20). Kashmir: "Private" Visit of European MPs. HuffPost.

Singh, D. (1976). India and the European Community. Studia Diplomatica, 29(3), 443-456.

Smith, M. (2009). Between "Soft Power" and a Hard Place: European Union Foreign and Security Policy Between the Islamic World and the United States. International Politics, 46(5), 596-615.

Strüver, G. (2017). China's Partnership Diplomacy. Chinese Journal of International Politics, 10(1), 31-65.

Swaminathan, T. (1973). An Indian Looks at the European Community. Politique Etrangere, 26(1), 29-38. 
Telò, M. (2008). The EU and India. In S. A. Wülbers (Ed.), EU-India Relations (pp. 105-126). New Delhi: Academic Foundation.

Tharoor, S. (2011, November 15). New India, Old Europe. Project Syndicate.

The Wire. (2019, December 10). EU to India: Hope CAP is in Line with Indian Constitution.

Traub, J. (2014, May 23). Faster, Stronger, Worse. Foreign Policy.

Van Rompuy, H. (2010, September 14). We Have Strategic Partners, Now We Need a Strategy (PCE 186/10). Brussels.

Vivet, E., \& de Lalande, V. (2014). EU Strategic Partnerships (IRENE Working Paper 4).

von Muenchow-Pohl, B. (2012, August 23). India and Europe in a Multipolar World. Carnegie Endowment for International Peace. http://carnegieendo wment.org/2012/05/10/india-and-europe-in-multipolar-world/apo6?rel oadFlag=1. Accessed 17 January 2020.

Walton, D., \& Kavalski, E. (2017). Power Transition in Asia. London: Routledge.

Zolkos, M., \& Kavalski, E. (2007). The Hoax of War. Journal of Contemporary European Studies, 15(3), 377-393.

Zolkos, M., \& Kavalski, E. (2008). Defunct Federalisms. London: Routledge. 


\title{
The European Union and China: Partnership in Changing Times
}

\author{
Andrew Cottey
}

\section{INTRODUCTION}

The European Union's strategic partnership with China is one of the longest-standing and most institutionalised of the EU's strategic partnerships, having been established in the 1990s and consolidated in the 2000s. The emergence of the EU-China strategic partnership was striking given that the EU (a post-sovereign collective of liberal democracies) and the People's Republic of China (a Communist developing state with a strong attachment to state sovereignty) might not be viewed as natural or likely partners.

This chapter explores the EU-China strategic partnership, focusing on the time period from the end of the Cold War (1989-1990) to 2020. The chapter argues that the EU-China strategic partnership emerged and deepened (even flourished) in a particular set of circumstances defined

\footnotetext{
A. Cottey $(\bowtie)$

Department of Government and Politics, University College Cork, Cork, Ireland e-mail: A.Cottey@ucc.ie

(C) The Author(s), under exclusive license to Springer Nature Switzerland AG 2021

L. Ferreira-Pereira et al. (eds.), The European Union's Strategic

Partnerships, The European Union in International Affairs, https://doi.org/10.1007/978-3-030-66061-1_10
} 
by: the end of the Cold War and the apparent triumph of a liberal international order; China's continuing reform and 'opening up', which (at least to many Western eyes) suggested that China might join the liberal order (or, at least, could live peaceably alongside it); and the pursuit by the West (led by the US, but also including the EU, Japan and other Western states) of partnership and cooperation with the major non-Western powers (China and Russia). Today, these circumstances have changed radically and consequently the EU-China relationship faces more difficult times. The liberal international order is challenged as never before and China's increasing assertiveness is a significant part of this challenge. China has now reached a decisive phase in its development, both domestically and as a global power, and both of these developments raise troubling questions for the EU-China relationship. Great power relations are returning to more traditional patterns of conflict, competition and power balancing, raising difficult questions about where and how the EU and the EU-China relationship fit into this pattern.

The first section of this chapter traces the evolution of the EUChina relationship from quiet beginnings in the 1970s and 1980s to the development of a much more extensive economic, political and arguably strategic relationship in the 1990s and 2000s. The second section explores the way in which the return of great power geopolitical competition since the 2010s has complicated the EU-China relationship. The third section explores how China's increasing foreign policy assertiveness has resulted in a quiet re-calibration of EU policy away from one of 'China first' in the 1990s and 2000s to one of developing strengthened ties with other Asian partners (arguably to counter-balance Chinese power). The fourth section explores EU and Chinese policies towards and mutual engagement on global issues, such as trade, climate change and peacekeeping, noting a mixed pattern of policy convergence in some areas and divergence in others. The conclusion argues that the EU-China strategic partnership can be understood through a social constructivist lens, with the partnership helping to project and reinforce both parties construction of new foreign policy identities for themselves and the two together constructing a rhetoric of 'comprehensive strategic partnership'. The conclusion also discusses how the three logics of EU strategic partnerships identified in the introduction to this book-internal EU, external international environment and role/identity - can clearly be seen in the EU-China case. The chapter ends by concluding that the much changed global context 
is likely to make the maintenance of the EU-China strategic partnership significantly more challenging.

\section{The European UNion AND China: From Non-RELATIONSHIP to 'Comprehensive Strategic Partnership'}

The collective EU (or as it then was European Economic Community (EEC)) relationship with China can be traced back to the 1970s. Formal diplomatic relations were established between the EEC and the People's Republic of China in 1975 and in 1978 the two parties signed a Trade Agreement, committing them to support mutual trade. In 1985 the Trade Agreement was replaced by a Trade and Economic Cooperation Agreement, which expanded the range of economic areas in which there was an in principle commitment to cooperate. This period also saw the first official interactions between EU institutions-the Commission, the Parliament and the Council-and their Chinese counterparts (Snyder 2008: 42-120, Kapur 1990: 122-123, 149-151 and 170-174). In practice, however, the relationship was a rather limited one. Trade between Europe and China was relatively small in scale. In the context of the Cold War, Europe and China's relationships with the United States (US) and the Soviet Union were far more important than those with one another.

China's dramatic economic growth and emergence as a major global economic power in the 1980s and especially the 1990s provided the context for the emergence of a new and more important relationship between the EU and China. Trade between the two grew rapidly, with Europe becoming a major destination for Chinese exports, European exports to China growing significantly and European companies investing in China (in particular via the production of components and to some extent finished goods in China). By the 1990s and 2000s the EUChina economic relationship was broadly comparable in size to the US-EU economic relationship. For both the EU and China, the other became their second main economic interlocutor alongside the US. In this context, it was always likely that Brussels and Beijing would want to build-up politico-diplomatic relations in order to manage and shape their new economic relationship.

Broader political factors, however, also contributed to the development of the EU-China relationship. China's economic rise coincided 
with the establishment of the EU's Common Foreign and Security Policy (CFSP) in the 1990s: engaging the emerging superpower in the east was an obvious priority for an EU seeking to establish itself as an international actor. China's economic rise would inevitably have political and geostrategic implications, reinforcing the logic, from a European perspective, of engaging China. From the international economic institutions to economic development in Africa to climate change and much else, China was becoming a major player. If the EU wished to shape policy in such areas, it needed to recognise China's growing role. China also sought recognition of its newfound power and status and developing a relationship with one of the developed world's two big power centres helped to fulfil this goal. Additionally, there were hopes in Beijing that the EU might help China to balance against US power and American hegemonism.

The development of the EU-China politico-diplomatic relationship was to some extent driven by the EU. In a series of official policy papers on China, published in the 1990s and 2000s, the EU made the case for a policy of engaging China and advanced proposals for the development of bilateral EU-China institutions and specific areas in which the two might cooperate (European Commission 1995, 1998, 2003, 2006). A first EU-China summit was held in 1998 and summits have been held most years since then. A wide range of bilateral institutional ties were put in place between EU institutions and their Chinese counterparts and various sectoral dialogues and cooperation activities and initiatives were established. The relationship began to be described by the EU and China as a 'strategic partnership' in the late 1990s and early 2000s, with the language upgraded to that of 'comprehensive strategic partnership' from 2003 (European Union 2003). In 2013 the two adopted an EU-China 2020 Strategic Agenda for Cooperation, which detailed the areas in which they intended to develop cooperation, encompassing peace and security, economics, sustainable development and people-to-people exchanges (European Union 2013). As a consequence, over the past twenty-five years the EU and China have established a very extensive 'dialogue architecture', with a wide variety of meetings, dialogues and exchanges under three broad headings of political dialogue, economic and sectoral dialogue and people-to-people dialogue (European Union 2015). The EU-China strategic partnership now includes more than sixty different sectoral dialogues (European External Action Service 2019b). In terms 
of EU foreign policy, this institutionalised politico-diplomatic relationship parallels the EU's relationship with the US and is significantly more extensive than those with any of the Union's other strategic partners.

If one simply accepted at face value the diplomatic language of joint statements from annual EU-China summits, one could be forgiven for thinking that all is rosy in the EU-China garden and that Brussels and Beijing do, indeed, share a deep partnership across many areas. If one looks below the surface, however, the relationship is more complicated and problematic than the rhetoric of 'comprehensive strategic partnership' might suggest. First, there remain significant differences and disagreements between the EU and China. On economic policy and trade the EU has a large trade deficit with China - $€ 185$ billion in 2018 (European Commission Directorate-General for Trade 2019: 2) —and the EU has long-standing concerns about access to the Chinese market, protection for European investors and what it views as market-distorting Chinese government subsidies to Chinese producers. On human rights, notwithstanding the existence of a bilateral human rights dialogue since 1995, the EU has long-standing concerns about the human rights record of the Chinese regime, while China opposes what it views as European interference in its internal affairs (Kinzelbach 2015). As is explored further below, there are also significant differences over some geostrategic and security issues.

Second, although the EU-China partnership is now quite deeply institutionalised-with various bilateral institutions established and operating for twenty years or more - the substance and impact of that institutionalisation can be questioned. It is far from clear that the many EU-China sectoral dialogues really involve substantive cooperation or result in changes in either the EU's or China's positions or policies. At some points, further, EU-China summits have been cancelled or have been unable to adopt agreed statements: in 2008 China cancelled the EUChina summit in protest at then French President Nicolas Sarkozy's plans to meet with Tibetan spiritual leader the Dalai Lama ${ }^{1}$; in 2016 and 2017 differences over China's disputes with its neighbours in the South China Sea meant there were no joint statements from the EU-China summits (EURACTIV 2016; VN Express 2017).

\footnotetext{
${ }^{1}$ The summit would have been held in France because France at that point held the six-monthly rotating Presidency of the EU Council.
} 
Some attempts to institutionally strengthen the EU-China relationship, further, have been unsuccessful. In 2006 the EU and China agreed to negotiate a Partnership and Cooperation Agreement (PCA) to replace the outdated 1985 Trade and Economic Cooperation Agreement as the legal and institutional basis for their relationship, but differences prevented the conclusion of an agreement and the idea has been quietly shelved (Men and Balducci 2010). In 2012 the EU and China agreed to include a Comprehensive Agreement on Investment (CAI, initially referred to as a Bilateral Investment Treaty [BIT]) to update and replace member states existing BITs with China. The proposed CAI impacts sensitive economic issues (European Parliament 2019). A CAI was concluded in late 2020, but the agreement was controversial and it was unclear whether it would be ratified by the European Parliament. A balanced assessment of the EU-China relationship as of the late 2010s would suggest that the EU and China have made significant progress in establishing an institutionalised bilateral politico-diplomatic relationship, that the two partners share certain common interests and perspectives (in particular, in terms of maintaining a broadly multilateral international order), but that the rhetoric of 'comprehensive strategic partnership' belies enduring differences between the two (Christiansen et al. 2019).

\section{The EU, China And the Return of Great Power Geopolitics}

To some extent both the EU and China have treated their bilateral relationship as if it were free-standing, independent of wider great power relations, geopolitics and the global balance of power. In reality, however, no relationship involving two major actors is, or can be, separate from larger geopolitical questions. The wider context for the development of the EU-China relationship in the 1990s and 2000s was the end of the Cold War, the apparent triumph of liberalism and consolidation of a liberal international order, and a period in which both China and Russia were reforming their economies and at least in part democratising (certainly in Russia's case and potentially in China's case). Great power relations appeared to be moving in a more peaceful and cooperative direction, with observers suggesting the emergence of a new great power concert. In this context, the EU's policy towards China was one of engagement, designed to support reform within China and integrate China into the liberal international order. This aligned with the policies of 
the US, Japan, Australia and Southeast Asian states, who were also trying to engage China along similar lines (Shinn 1996).

The EU and the US, furthermore, were also pursuing a parallel strategy of engagement with Russia (on the EU's efforts to engage Russia see Hiski Haukkala's chapter in this volume). This larger context allowed the EU-China relationship to remain relatively free from potential complications arising from great power relations and power balancing: the US, the EU and other Western powers were united in pursuing policies of engagement towards China and Russia; China and Russia were in large part willing to reciprocate Western engagement; and considerations of classical balance of power politics (which great powers might be aligned with one another against other great powers) moved to the background. However, more traditional balance of power considerations were never entirely absent, as illustrated by the issue of possible European arms sales to China. The EU and the US imposed arms embargoes on China in response to the 1989 Tiananmen Square massacre. In 2003-2004 China tried to persuade the EU to lift its embargo. A lifting of the EU embargo could hypothetically have resulted in future conflict scenarios, over Taiwan, for example, in which the US might face a China armed with European weapon systems. The US strongly pressed its European allies on the issue and succeeded in persuading them not to lift the arms embargo-which remained in place as of 2020 (Casarini 2007).

By the late 2000s and 2010s the global context of the EU-China relationship had changed significantly. Material power had shifted towards the non-Western world, with the continued economic growth of China, but also of other large developing countries. Hopes for political reform in China had dissipated, while Russia had returned to authoritarianism under President Vladimir Putin, leading Western observers to describe the two as resurgent authoritarian great powers (Gat 2007; Brands 2018). Both China and Russia increased their defence spending significantly in the 2000s and 2010s, modernising their militaries. In various contexts, both China and Russia were both more willing and more able to challenge the West and Western influence. In the Syria war, from 2015 Russia deployed air forces in support of the Assad regime, tipping the balance in the conflict against the regime's opponents. Both Russia and China also backed the Assad regime in the United Nations Security Council, using their veto to oppose potential resolutions criticising the Assad regime or authorising the use of force against the regime. In Africa and Latin America, China and latterly Russia began to expand their economic and 
political influence. Russia's 2014 intervention in eastern Ukraine and its annexation of Crimea was a major turning point in Russo-Western relations, with the US and the EU imposing economic sanctions on Russia and NATO putting in place new plans to defend its Central and Eastern European members (on the evolution of EU policy towards Russia since 2014 see Hiski Haukkala's chapter in this volume).

Although there was no comparable single turning point in the US (and wider Western) relationship with China, Beijing's policy in the South China Sea, where in 2009 it announced a territorial claim encompassing most of the sea, followed up with naval activities and military installation building designed to support that claim, had an important impact on other states' perceptions of China. In the 2010s, the Obama administration implemented a so-called pivot to Asia, designed to strengthen US political, economic and military engagement with Asia: although the administration argued that it was not seeking to contain China, it was clear that the policy was largely driven by the perceived need to counter China's rising power (Shambaugh 2013). The Trump administration's formal National Security Strategy document, adopted in December 2017, bluntly stated that 'China and Russia challenge American power, influence, and interests, attempting to erode American security and prosperity', arguing that previous policies of engagement had failed and must be replaced with policies recognising the reality of great power competition with China and Russia (United States 2017: 2-3). The Trump administration's introduction of extensive tariffs on Chinese imports deepened the growing tensions in Sino-American relations.

By the late 2010s, observers were describing both the US-China relationship and the West-Russia relationship as 'new Cold Wars' (Legvold 2016; Rennie 2019). Although the parallels with the original US-Soviet Cold War could be questioned, that great power relations had entered a more conflictual era was beyond doubt. If the liberal international order faced external challenges from authoritarian powers, it also faced a major internal challenge in the form of populism within Western democracies. The United Kingdom's June 2016 Brexit referendum vote, the election of Donald J. Trump as US President in November 2016 and the rise of populist parties in many European countries reflected a questioning of the domestic political consensus which had underpinned a liberal international order in the West since 1945.

The changed global context raised important questions for the EU's China policy and EU-China relations. If the EU's China policy had been 
underpinned by a logic of engagement, by the 2010s the limits of such engagement had become clear, in terms of both encouraging reform within China and persuading China to modify its foreign policy. In 2016 and 2019 the EU adopted new China policy papers, significantly different in tone from its earlier China policy papers (European Commission and High Representative of the Union for Foreign Affairs and Security Policy 2016, 2019). The 2019 paper stated that 'China is, simultaneously, in different policy areas, a cooperation partner with whom the EU has closely aligned objectives, a negotiating partner with whom the EU needs to find a balance of interests, an economic competitor in the pursuit of technological leadership, and a systemic rival promoting alternative models of governance' (European Commission and High Representative of the Union for Foreign Affairs and Security Policy 2019: 1). Although the two papers advocated a policy of continued engagement with China, they argued that the EU's relationship with China must be based on more reciprocity, especially in the economic sphere. How far China would be willing to address European concerns about issues such as market access and protection of intellectual property rights remained to be seen.

The growing strategic competition between the US and China also raised questions about where the EU places itself vis-à-vis the world's two leading powers and the implications for the EU-China strategic partnership, as well as for the long-standing transatlantic alliance. One scenario might involve the EU aligning largely with the US, likely triggering a downturn or a rupture in the EU-China relationship. An alternative scenario might see the EU aligning more closely with China, triggering a downturn or a rupture in the transatlantic alliance. More likely, probably, the EU may seek to maintain its relationships with both the US and China and avoid a dichotomous choice between the two.

In the late 2010s, three particular issues brought the EU's dilemma to the fore: trade, climate change and the Iran nuclear deal (the 2015 agreement concluded between Iran and the six major powers to prevent Iran from developing nuclear weapons). In all three areas, the Trump administration's opposition to multilateralism united the EU and China in support of multilateral approaches to these issues. The Trump administration imposed trade tariffs on both the EU and China, announced its intention to withdraw from the 2015 Paris climate change agreement and withdrew from the Iran nuclear deal and began to pursue a policy of ' $m a x-$ imum pressure' against Iran. At their 2018 summit, the EU and China issued a strong statement of support for multilateralism, in particular in 
relation to trade and climate change (European Union 2018). The EU (and Germany, France and the United Kingdom-the three European signatories of the agreement with Iran) also joined with China and Russia in maintaining support for the Iran nuclear deal, despite US pressure to join it in abandoning the agreement. Some observers argued that if the US retained its unilateralist approach it was likely to push the EU and China closer to one another (Patrick and Feng 2018).

On balance, however, there are strong arguments to suggest that Europe and the EU will retain closer, stronger relations with the US, than they will with China. The US and European countries share a long history of partnership stretching back to the Second World War and earlier; NATO provides a key institutional link with the US and remains central to European security; and as democracies the US and European states have core systemic values in common. In contrast, China remains an authoritarian communist state and the rhetoric of EU-China strategic partnership hides important differences across a range of international issues. By the late 2010s, the intensification of authoritarian measures under President Xi Jinping, the worsening human rights situation in Xinjiang (where an estimated one million or more people from the Uighur minority are believed to be detained in prison camps, according to many reputable Western sources) and prolonged mass protests in Hong Kong in 2019 and 2020 and the imposition of a new Chinese national security law on Hong Kong in 2020 all suggested that the future of the EU-China relationship was unlikely to be entirely smooth. A US withdrawal from NATO or a more general US retreat from multilateralism (including institutions such as the WTO) might be game changers that would more fundamentally re-set the balance of the US-European-China triangle. Even if the US withdrew from NATO and retreated into unilateralism or isolationism more generally, however, this would not necessarily result in a European turn towards China: the EU might equally likely find itself facing troubled relations with both the US and China rather than aligned more closely with China than with the US.

An additional factor relevant to the EU-China relationship is the EU's relationship with Russia. Through the 1990s and 2000s, the EU treated its relationships with China and Russia as parallel but largely separate policies. By the 2010s, however, China's Belt-and-Road initiative-involving significant Chinese investment in European states and in transport and trade infrastructure linking Europe and China (including via Russia)—was having an increasing impact on the geopolitics of the Eurasian landmass. 
Increasingly close political, economic and military cooperation between China and Russia reinforced a sense of the Eurasian continent being remade, with Europe reacting to others' initiatives rather than shaping the process (Economist 2019). Against this background, some observers interpreted arguments by French President Emmanuelle Macron that the EU need to re-engage with Russia and find a way to draw Russia fully into the European order as partly driven by the desire to establish Russia as a buffer against China (Gressel et al. 2019; Nixey 2019). Given that China was likely to be the dominant partner in the Sino-Russian alliance, Russia might also view an improved relationship with the EU as useful in countering Chinese power (Economist 2019). While one could hypothetically see the appeal for both Brussels and Moscow of a strengthened EU-Russia relationship in balancing against China, the obstacles to such an EU-Russia rapprochement remained substantial, including continued differences over the Ukraine conflict (and the former Soviet space more generally) and the renewed military confrontation between Russia and NATO since 2014.

\section{The EU, China and Asia: Beyond 'China First'}

Through the 1990s and 2000s, the EU pursued its strategic partnership with China largely separately from any wider EU Asian policy and avoided its relationship with Beijing becoming entangled with larger Asian geopolitics. De facto the EU pursued a 'China first' policy: bilateral relations with China were developed ahead of those with other Asian states; the expansion of institutionalised EU-China ties outpaced similar ties with the EU's other Asian partners. China's increasing assertiveness within Asia and other Asian states' growing concerns about the implications of China's rise, however, have triggered a quiet re-calibration of EU policy. This policy shift was alluded to in the EU's 2016 Global Strategy document, which stated that the Union would 'deepen and scale up our security role in Asia'. According to the EU Global Strategy, in parallel with its partnership with China, the EU would 'deepen its economic diplomacy in the region', working towards free trade agreements with Japan, India and ASEAN agreement, and 'develop a more politically rounded approach to Asia', expanding partnerships, including on security, with Japan, South Korea, Indonesia and others (European Union 2016: 40-41). 
Since the mid-2010s the EU has significantly ramped up its political and economic relations with other Asian states, especially Japan, India and Australia, as well as with ASEAN and its members. In 2015 EU member states agreed a new policy for enhanced cooperation with ASEAN (European Commission and High Representative of the Union for Foreign Affairs and Security Policy 2015). The EU has also concluded Partnership and Cooperation Agreements (PCAs-general frameworks for political and sectoral cooperation) with Indonesia (in 2009), Vietnam (2012), the Philippines (2012), Singapore (2013), Thailand (2013, although suspended by the EU until democracy is restored in Thailand following a military takeover in 2014) and Malaysia (2015) and is negotiating a PCA with Brunei. The EU concluded Free Trade Agreements (FTAs) with Singapore (2013) and Vietnam (2015) and is negotiating FTAs with Indonesia, Malaysia, the Philippines and Thailand. Efforts to strengthen ties with Japan lead to the signing of an Economic Partnership Agreement (EPA, a free trade agreement) and Strategic Partnership Agreement (SPA) in July 2018. The SPA commits the EU and Japan to dialogue and cooperation on a wide range of foreign and security policy areas (European Union/Government of Japan 2018). The EU also sought to enhance relations with India, with annual EU-India summits restarted in 2016 after a four-year gap, resulting in the adoption of an EU-India Agenda for Action 2020 (Mohan 2018; see also Kavalski, this volume). In 2018 the EU adopted a new strategy on India, which called for the strengthening and institutionalisation of relations across the spectrum and the possible negotiation of an SPA similar to that with Japan (European Commission and High Representative of the Union for Foreign Affairs and Security Policy 2018). With Australia, the EU concluded a 2017 Framework Agreement as a long-term basis for enhanced dialogue and cooperation (including a regular dialogue on foreign and security policy issues) and is negotiating an FTA (Selivanov and Casarini 2018).

Although EU policy documents and statements on relations with other Asian states do not mention China, China's rising power is the elephant in the room which explains the EU's efforts to strengthen ties with other Asian states. The EU's 2018 strategy paper on India states that 'a strong partnership with India is key for a balanced EU policy towards Asia as a whole' (European Commission and High Representative of the Union for Foreign Affairs and Security Policy 2018: 1). Likewise, the EU's 2015 policy paper on relations with ASEAN states: 
The EU has a strategic interest in strengthening its relationship with the Association of South-East Asian Nations (ASEAN). A strong, cohesive and self-confident ASEAN proceeding with its own integration is good for regional stability, prosperity and security and creates new opportunities for cooperation on regional and global challenges... A united and selfconfident ASEAN is key to ensure that regional challenges are addressed in a rules-based manner. (European Commission and High Representative of the Union for Foreign Affairs and Security Policy 2015: 1)

Similarly, the joint statement from the 2017 EU-Japan summit declared: '(W)e remain united by our common values of democracy and the rule of law and by our determination to promote together an open and fair global economy that benefits everyone. These are the foundations of our political and economic Strategic Partnership for peace, prosperity and a rules-based international order' (European Union/Japan 2017).

Although the EU is very far from pursuing a Cold War-style policy of seeking to contain China, it nonetheless appears that it is, albeit quietly, bolstering its relations with other Asian states in order to counter China's growing power and assertiveness. Over time, the result is likely to be a more balanced EU Asia policy compared to the de facto 'China first' policy of the 1990s and 2000s. In some areas, further, the EU has been more openly willing to criticise China. On the South China Sea disputes, since the mid-2010s the EU has pursued an approach which has effectively criticised China, calling for restraint by all parties and efforts to resolve the disputes in multilateral frameworks such as the UN Convention on the Law of Sea (UNCLOS), which China opposes (Cottey 2019; European External Action Service 2019a). Some EU member states, such as Greece and Hungary, have been wary of antagonising China over the South China Sea (in part because they benefit from Chinese investment in their countries) and the issue has been divisive within the EU (Fallon 2016; Hungarian Ministry of Foreign Affairs and Trade 2016). As noted, above differences between the EU and the China over the South China Sea were a factor behind the failure to agree joint statements at the 2016 and 2017 EU-China summits.

The EU-China relationship is thus now one of a set of bilateral relations with other Asian states, as well as increased EU multilateral engagement with Asia (in particular ASEAN), in a way which was not the case a decade ago. The EU's new engagement in Asia could be viewed as 
challenging by China and may generate tensions in the EU-China relationship (as over the South China Sea). To date, this quiet re-calibration of EU Asia policy has not fundamentally disrupted the EU-China relationship, but it remains to be seen how this dynamic will play out in the longer term.

\section{Global Challenges: Sino-European CONVERGENCE Or Divergence?}

Both the EU and China view themselves as global players, with the right to input into how global challenges are addressed and particular contributions and strengths to bring to the table. The global presence and activism of the two powers, however, raise questions over how far their approaches converge or diverge and the extent to which they are likely to be able to collaborate in addressing global challenges. Since China's era of reform began in the late 1970s it has gone from being an isolationist critic of existing international institutions to an increasingly active participant in most of these institutions and, now, to a degree at least, re-shaping their policies and practices. During the same period, the EU has developed its CFSP, with a strong emphasis on multilateralism and international norms and institutions as the centrepiece of EU foreign policy. At the 2019 EU-China summit, the two parties reaffirmed 'their commitment to multilateralism, and respect for international law and for fundamental norms governing international relations, with the United Nations (UN) at its core' and 'to uphold the UN Charter and international law, and all three pillars of the UN system, namely peace and security, development and human rights' (European Union-China 2019: para. 1). While both the EU and China may be viewed as committed to multilateralism, there are important differences in their approaches. The EU's approach is arguably an in principle commitment to multilateralism, including a willingness to accept constraints on state sovereignty, underpinned by the fact that the EU is itself a multilateral institution in which its member states pool and accept constraints on state sovereignty. In contrast, China's approach to multilateralism is heavily embedded in state sovereignty, with China reluctant, both in principle and in practice, to accept constraints on state sovereignty (most obviously in relation to human rights but also in other areas such as trade).

Some analysts argue that China's approach to multilateralism is essentially instrumental: China is willing to work with and through multilateral 
institutions when they serve its interests, but will bypass or oppose multilateral institutions if they do not align with Chinese interests ( $\mathrm{He}$ and Feng 2015; Kolmas 2016). Maull (2019) argues that this is an international version of the distinction between the 'rule of law' principle underpinning Western democracies and the 'rule by law' concept emphasised by the Chinese Communist Party, with latter rooted in power rather than norms and institutions. An additional distinction is that while both the EU and China claim to support multilateralism, China also strongly emphasises multipolarity, which implies in particular the emergence of other power centres (such as China and Russia) to counter US hegemony in the international system (Womack 2004). Multilateralism and multipolarity are not necessarily incompatible, but China's emphasis on multipolarity as a means of countering US hegemony clearly differs from Europe's long-standing alliance with the US (notwithstanding periodic European reactions against perceived American hubris).

An examination of various major global policy issues reveals a mixed pattern of convergence and divergence in European and Chinese approaches. In the area of trade, since China's economic reforms and opening up to the world from the late 1970s, both China and the EU have been supporters of broadly free trade and multilateral institutions to underpin the international trade system-symbolised above all by China's accession to the WTO in 2001 and the EU's support for that accession. Nonetheless, the EU has on-going concerns about access to the Chinese market and government-supported subsidies to Chinese industries, while China continues to seek Market Economy Status (MES) within the WTO, which the EU opposes in light of its concerns (Christiansen et al. 2019: 95-98). On climate change, over a twenty-year period the EU and China's positions have converged. The EU has led global calls for action on climate change, but has shifted from arguing for 'hard' legally binding greenhouse gas (GHG) emission targets (an approach opposed by China) to supporting 'soft' targets in the context of an overall global agreement-the latter approach embodied in the 2015 Paris climate change agreement. China has shifted from arguing that the developing states such as itself should be largely excluded from GHG emission reduction targets to recognition of the necessity of action by all states. Consequently, the EU and China have found common cause in defending the Paris agreement in the face of the Trump administration's decision to withdraw from the agreement. The two partners have also developed bilateral cooperation on climate change, with the EU, 
in particular, provide financial and technical support for climate action projects in China (Torney 2015). Ironically, however, both the EU and China may now face the gap between their shared rhetorical commitment to addressing climate change and their ability to achieve the scale of GHG emission reductions necessary to avert worst case climate change scenarios.

Issues of peacekeeping and intervention also illustrate a mixed picture of convergence and divergence in European and Chinese approaches. On peacekeeping and intervention, European states have long been significant contributors to a variety of operations, in some cases United Nations peacekeeping operations, since the 1990s and 2000s NATO's intervention in former Yugoslavia, Afghanistan and Libya and more recently the US-led coalition operation against Islamic State in Syria. Since the early 2000s, further, in the context of its Common Security and Defence Policy (CSDP), the EU has undertaken 35 peace support operations (as of 2020), in particular in the Balkans and Africa (although most of these have been small in scale and many civilian rather than military) (European External Action Service 2020). Since the 1980s, China has gone from being strongly sceptical of military intervention (including peacekeeping) to being a leading contributor to UN peacekeeping (both in terms of troop contributors and the UN peacekeeping budget). In this context, China and European states have found themselves working alongside one another in some peacekeeping operations (such as in Mali), as well as in counter-piracy operations in the Gulf of Aden (Duggan 2017). While there are elements of convergence in European and Chinese approaches to peacekeeping and intervention, however, there remain important differences. China's approach remains strongly rooted in state sovereignty, requiring the support of the governments of the countries involved, whereas the European and EU approach reflects a logic of liberal peacebuilding, implying intervention in defence of a larger liberal project and a post-sovereigntist approach to intervention (Richmond et al. 2011). The differences in European and Chinese approaches could be seen clearly in the Syria war: European states and the EU have been strongly critical of the Assad regime, while also, in the case of a number of European states, joining the US-led intervention against Islamic State; China has been a backer of the Assad regime (albeit less prominently than Russia and Iran), including being willing to use its veto in the UN Security Council to oppose measures against the Assad regime (Calabrese 2019). 
The experience of the last twenty to thirty years suggests that EU and Chinese approaches to global challenges and global governance are likely to remain characterised by a mixed pattern of convergence and divergence. Trade and climate change may continue to provide important areas of commonality between the EU and China. The underlying systemic difference between a Europe of democracies and communist-ruled China, however, are likely to impose substantial constraints on the extent to which the two will truly be partners in addressing global challenges.

\section{Conclusion}

Since the 1990s the EU and China have invested significantly in their bilateral relationship, establishing a quite highly institutionalised relationship and to some extent substantive cooperation with one another. Social constructivist theoretical approaches to international relations and foreign policy, with their emphasis on identities, norms and the processes through which these are produced and re-produced, can help us to understand this (Hopf 1998; Katzenstein 1996). From this perspective, both the EU and China have been engaged, since the 1990s, in processes of constructing new foreign policy identities for themselves: for the EU, of itself an international actor based on the CFSP and with a particular emphasis on supporting international norms and institutions; for China, of itself as a re-emerging great power and a central actor in world politics. For both the EU and China the establishment of their strategic partnership helped to legitimate and reinforce the identity projects at the heart of their respective foreign policies. In this sense, the EU-China strategic partnership was a mutual recognition pact: each recognised the status of the other and their strategic partnership reinforced their status. Together, further, the EU and China constructed a vocabulary of 'comprehensive strategic partnership': rhetorically at least the partnership was real, substantive and important. As this chapter has suggested, however, the substance was sometimes, arguably even often, less than the rhetoric.

This chapter has argued that the (social) construction of the EU-China strategic partnership in the 1990s and 2000s took place in a context which was amenable to such a partnership: the end of the Cold War seemed to herald the emergence of a liberal international order and a period of great power cooperation; China was reforming (even, potentially, democratising); and the US and the EU were pursuing policies of engagement towards China and Russia, which both countries welcomed. As 
this chapter has explored, since the 2010s these dynamics have changed and they create a significantly more challenging environment for EUChina relations. The liberal international order is under serious stress from without and within, great power relations have become more confrontational (with both the US-China and West-Russia relationships sometimes now described as Cold Wars) and China has experienced an authoritarian re-assertion under President Xi. The EU and China arguably still share significant common interests, in areas such as trade, climate change and nuclear non-proliferation, but differences between them have grown since the 1990s and 2000s. Growing tensions between the US and China may face European states and the EU with choices as to how closely they align with Washington or Beijing, although they will surely seek to avoid a dichotomous choice if at all possible.

The EU-China case also sheds light on the three logics of strategic partnerships identified in the introduction to this volume. First, in terms of the internal logic of the EU, the EU-China strategic partnership reflects the long-term evolution of EU foreign policy. The EU-China relationship in the 1970s and 1980s was initially a limited economic relationship, conducted on the European side primarily by the European Commission, at a point when EU foreign policy was largely economic and trade policy. From the 1990s, with the development and institutionalisation of the Common Foreign and Security Policy, the EU-China relationship gained a substantial political dimension, with member states and the European External Action Service (EEAS) playing a greater role alongside the Commission. The heavy institutionalisation of the EU-China relationship noted in this chapter is also arguably a reflection of an internal EU logic: as organisation with institutions at its core, it is hardly surprising that the EU seeks to project this institutionalism outwards in its relationships with other actors, including strategic partners. Second, in terms of the external logic of the international environment, this chapter has argued that the 1990s and 2000s constituted an environment that was conducive to the development of the EU-China strategic partnership, underpinned by the apparent triumph of the liberal international order and the idea of engaging China. In contrast, challenges to the liberal international order in the 2010s-including China's shift towards greater authoritarianism internally and greater assertiveness internationally-have created a much more problematic context for the EU-China strategic partnership. These dynamics seem likely to continue in the 2020s. Third, in line with the social constructivist logic suggested above, the EU-China 
strategic partnership has had an important identity/role dimension for the EU, supporting the Union's projection of an identity or role as a significant global actor-and, as noted, performing a similar mirror image function for China. In the 1990s and 2000s, these three logics largely aligned, helping to underpin the development of the EU-China strategic partnership. Since the 2010s, the external environment has become less conducive to that partnership and the EU and China's identity projects have drifted apart.

Through the 2010s and into the COVID-19 crisis which began in 2020, the increasingly authoritarian character of the Chinese regime domestically and China's growing assertiveness internationally triggered a significant shift in European attitudes to China. Observers suggested that there was a new European consensus around the problematic nature of China as a partner and the need for Europe to pursue a more robust policy towards China (Oertel 2020). As of 2020, whether and how European states and the EU might translate this apparent consensus into substantively different policies towards China remained to be seen. At minimum, the EU-China strategic partnership is likely to remain a more challenging one than was the case in the 1990s and 2000s. In extremis, an escalation of US-China tensions or a major crisis (over, say, Taiwan or the South China Sea) could fracture the EU-China partnership entirely.

\section{REFERENCES}

Brands, H. (2018). Democracy vs Authoritarianism: How Ideology Shapes GreatPower Conflict. Survival, 60(5), 61-114.

Calabrese, J. (2019, July 9). China and Syria: In War and Reconstruction. Washington, DC: Middle East Institute. Available at https://www.mei.edu/public ations/china-and-syria-war-and-reconstruction.

Casarini, N. (2007). The International Politics of the Chinese Arms Embargo Issue. The International Spectator, 42(3), 371-389.

Christiansen, T., Kirchner, E., \& Wissenbach, U. (2019). The European Union and China. Basingstoke: Red Globe Press.

Cottey, A. (2019). Europe and China' Sea Disputes: Between Normative Politics, Power Balancing and Acquiescence. European Security, 28(3), 473-492.

Duggan, N. (2017). The People's Republic of China and European Union Security Cooperation in Africa: Sino-EU Security Cooperation in Mali and the Gulf of Aden. International Journal of China Studies, 8(1), 1-23.

Economist. (2019, July 25). The Junior Partner: How Vladimir Putin's Embrace of China Weakens Russia'. The Economist. Available at: https://www.econom 
ist.com/briefing/2019/07/25/how-vladimir-putins-embrace-of-china-wea kens-russia.

EURACTIV. (2016, July 13). South China Sea Ruling Looms Large Over EUChina Summit. EURACTIV. Available from: https://www.euractiv.com/sec tion/trade-society/news/china-sea-ruling-looms-large-over-eu-china-summit.

European Commission. (1995). Communication of the Commission: A Long Term Policy for China-Europe Relations, COM (1995) 279/Final. Brussels: European Commission. Available at http://eeas.europa.eu/archives/docs/china/ docs/com95_279_en.pdf.

European Commission. (1998). Communication from the Commission: Building a Comprehensive Partnership with China, COM (1998) 181 Final. Brussels: European Commission. Available at http://eur-lex.europa.eu/LexUriServ/ LexUriServ.do? uri=COM:1998:0181:FIN:EN:PDF.

European Commission. (2003). Commission Policy Paper for Transmission to the Council and the European Parliament: A Maturing Partnership-Shared Interests and Challenges in EU-China Relations, COM (2003) 533 Final. Brussels: European Commission. Available at http://trade.ec.europa.eu/doc lib/docs/2005/september/tradoc_124565.pdf.

European Commission. (2006). Communication from the Commission to the Council and the European Parliament: EU-China: Closer Partners, Growing Responsibilities, COM (2006) 631 Final. Brussels: European Commission. http://trade.ec.europa.eu/doclib/docs/2006/october/tradoc_130875.pdf.

European Commission Directorate-General for Trade. (2019). European Union: Trade in Goods with China. Available at https://webgate.ec.europa.eu/isdb_r esults/factsheets/country/details_china_en.pdf.

European Commission and High Representative of the Union for Foreign Affairs and Security Policy. (2015, May 18). Joint Communication to The European Parliament and The Council: The EU and ASEAN: A Partnership with a Strategic Purpose, JOIN (2015) 22 Final. Brussels: European Union. Available at https://op.europa.eu/en/publication-detail/-/publication/aba f503d-fd58-11e4-a4c8-0laa75ed7lal/language-en.

European Commission and High Representative of the Union for Foreign Affairs and Security Policy. (2016). Joint Communication to the European Parliament and the Council: Elements for a New EU Strategy on China, JOIN (2016) 30 Final. Brussels: European Commission and High Representative of the Union for Foreign Affairs and Security Policy. Available at https:// eeas.europa.eu/sites/eeas/files/joint_communication_to_the_european_par liament_and_the_council_-_elements_for_a_new_eu_strategy_on_china.pdf.

European Commission and High Representative of the Union for Foreign Affairs and Security Policy. (2018). Joint Communication to the European Parliament and The Council: Elements for an EU Strategy on India, JOIN (2018) 2. Brussels: European Union. Available at https://cdn5-eeas.fpfis. 
tech.ec.europa.eu/cdn/farfuture/MJxuGXIelnF8rvfq4cRLxzClmUacEWgvf outl3dMi4o/mtime:1542708985/sites/eeas/files/jc_elements_for_an_eu_ strategy_on_india_-_final_adopted.pdf.

European Commission and High Representative of the Union for Foreign Affairs and Security Policy. (2019). Joint Communication to the European Parliament, the European Council and the Council: EU-China-A Strategic Outlook, Strasbourg, 12 March 2019 JOIN (2019) 5 Final. Brussels: European Commission and High Representative of the Union for Foreign Affairs and Security Policy. Available at https://ec.europa.eu/commission/sites/beta-political/files/com munication-eu-china-a-strategic-outlook.pdf.

European External Action Service. (2019a, August 28). Statement by the Spokesperson on Recent Developments in the South China Sea. Brussels: European External Action Service. Available at https://eeas.europa.eu/hea dquarters/headquarters-homepage/66749/statement-spokesperson-recentdevelopments-south-china-sea_en.

European External Action Service. (2019b, October 18). EU-China Relations Factsheet. Brussels: European External Action Service. Available at https://eeas.europa.eu/topics/external-investment-plan/34728/eu-chinarelations-factsheet_en.

European External Action Service. (2020). Military and Civilian Missions and Operations. Brussels: European External Action Service. Available at https://eeas.europa.eu/topics/military-and-civilian-missions-and-ope rations $/ 430 /$ military-and-civilian-missions-and-operations_en.

European Parliament. (2019). EU-China Comprehensive Agreement on Investment. Brussels: European Parliament. Available at https://www.europarl.eur opa.eu/legislative-train/theme-a-balanced-and-progressive-trade-policy-toharness-globalisation/file-eu-china-investment-agreement.

European Union. (2003, October 30). Joint Press Statement, Sixth China-EU Summit, Beijing, 13424/03, Presse 298. Available at http://www.consilium. europa.eu/ueDocs/cms_Data/docs/pressData/en/er/77802.pdf.

European Union. (2013). EU-China 2020 Strategic Agenda for Cooperation. Available at https://eeas.europa.eu/sites/eeas/files/20131123.pdf.

European Union. (2015). EU-China Dialogue Architecture. Available at https:// eeas.europa.eu/sites/eeas/files/2015_november_eu-china_dialogue_architect ure.jpg.

European Union. (2016). European Union, Shared Vision, Common Action: A Stronger Europe. A Global Strategy for the European Union's Foreign and Security Policy. Brussels: European Union. Available at https://europa.eu/global strategy/sites/globalstrategy/files/regions/files/eugs_review_web_0.pdf.

European Union. (2018, July 17). Joint Statement of the 20th EU-China Summit. Brussels: European Union. Available at https://eeas.europa.eu/del 
egations/china_en/48424/Joint\%20statement\%20of\%20the $\% 2020$ th\%20EUChina\%20Summit.

European Union-China. (2019, April 9). EU-China Summit Joint Statement. Brussels. Available at https://www.consilium.europa.eu/media/39020/euc hina-joint-statement-9april2019.pdf.

European Union/Japan. (2017, July 6). Statement following the 24th EU-Japan Summit. Brussels. Available at https://www.consilium.europa.eu/en/press/ press-releases /2017/07/06/eu-japan-summit-statement.

European Union/Government of Japan. (2018, July 17). Strategic Partnership Agreement Between The European Union and Its Member States, of the One Part, and Japan, of the Other Part. Available at https://www.mofa.go.jp/ files/000381942.pdf.

Fallon, T. (2016, October 13). The EU, the South China Sea and China's Successful Wedge Strategy. Asia Maritime Transparency Initiative. Available at https://amti.csis.org/eu-south-china-sea-chinas-successful-wedge-strategy.

Gat, A. (2007). The Return of Authoritarian Great Powers. Foreign Affairs, 86(4), 59-69.

Gressel, G., Liik, K., Shapiro, J., \& Varma. T. (2019, September 25). Emmanuel Macron's Very Big Idea on Russia. European Council on Foreign Relations. Available at https://www.ecfr.eu/article/commentary_emmanuel_macr ons_very_big_idea_on_russia.

He, K., \& Feng, H. (2015). Transcending Rationalism and Constructivism: Chinese leaders' Operational Codes, Socialization Processes, and Multilateralism After the Cold War. European Political Science Review, 7(3), $401-426$.

Hopf, T. (1998). The Promise of Constructivism in International Relations Theory. International Security, 23(1), 171-200.

Hungarian Ministry of Foreign Affairs and Trade. (2016, July 16). Statement on the Situation in the South China Sea. Budapest: Hungarian Ministry of Foreign Affairs and Trade. Available at http://www.kormany.hu/en/min istry-of-foreign-affairs-and-trade/news/statement-on-the-situation-in-thesouth-china-sea.

Kapur, H. (1990). Distant Neighbours: China and Europe. London and New York: Pinter Publishers.

Katzenstein, P. J. (Ed.). (1996). The Culture of National Security: Norms and Identity in World Politics. New York: Columbia University Press.

Kinzelbach, K. (2015). The EU's Human Rights Dialogue with China: Quiet Diplomacy and Its Limits. London: Routledge.

Kolmas, M. (2016). China's Approach to Regional Cooperation. China Report, $52(3), 192-210$.

Legvold, R. (2016). Return to Cold War. Cambridge: Polity. 
Maull, H. W. (2019, October 4). China's Alternative Multilateralism, MERICS Mercator Institute for Chinese Studies. Available at https://www.merics.org/ en/blog/chinas-alternative-multilateralism.

Men, J., \& Balducci, G. (Eds.). (2010). Prospects and Challenges for EU-China Relations in the 21st Century: The Partnership and Cooperation Agreement. Brussels: Peter Lang.

Mohan, G. (2018). Politics Over Trade: A Revival of the EU-India Partnership. Berlin: Global Public Policy Institute (GPPi). Available at https://www.gppi. net $/ 2018 / 08 / 27 /$ politics-over-trade-a-revival-of-the-eu-india-partnership.

Nixey, J. (2019, September 5). On Russia, Macron Is Mistaken, Chatham House website. Available at https://www.chathamhouse.org/expert/comment/ russia-macron-mistaken?gclid=EAIaIQobChMIpLW025fv5QIVWeDtCh3Jc gGMEAAYASAAEgK8wvD_BwE.

Oertel, J. (2020). The New China Consensus: How Europe Is Growing Wary of Beijing. Berlin: European Council on Foreign Relations. Available at https://www.ecfr.eu/publications/summary/the_new_china_consen sus_how_europe_is_growing_wary_of_beijing.

Patrick, S. M., \& Feng, A. (2018, July 20). Trading Places: How the EU-China Summit Underlined U.S. Isolationism in Trade Under Trump, Council on Foreign Relations blog. Available at https://www.cfr.org/blog/trading-pla ces-how-eu-china-summit-underlined-us-isolationism-trade-under-trump.

Rennie, D. (2019, May 16). China and America: A New Kind of Cold War, The Economist.

Richmond, O., Björkdahl, A., \& Kappler, S. (2011). The Emerging EU Peacebuilding Framework: Confirming or Transcending Liberal Peacebuilding? Cambridge Review of International Affairs, 24(3), 449-469.

Selivanov, M., \& Casarini, N. (2018). Australia and the EU in the Indo-Pacific: Is Cooperation Towards a Rules-Based Order Possible? Rome: Istituto Affari Internazionali. Available at http://www.iai.it/sites/default/files/iaicoml819. pdf.

Shambaugh, D. (2013). Assessing the US "pivot" to Asia. Strategic Studies Quarterly, 7(2), 10-19.

Shinn, J. (Ed.). (1996). Weaving the Net: Conditional Engagement with China. New York: Council on Foreign Relations.

Snyder, F. (2008). The European Union and China, 1949-2008: Basic Documents and Commentary. Oxford and Portland, OR: Hart Publishing.

Torney, D. (2015). European Climate Leadership in Question: Policies Toward China and India. Cambridge, MA: MIT Press.

United States. (2017). National Security Strategy of the United States of America. Washington, DC: The White House. Available at https://www.whitehouse. gov/wp-content/uploads/2017/12/NSS-Final-12-18-2017-0905.pdf. 


\section{A. COTTEY}

VN Express. (2017, June 2). EU to Raise South China Sea Issues Again After Last Year's Tense Discussion, VN Express International. Available at https://e.vnexpress.net/news/news/eu-to-raise-south-china-seaissues-again-after-last-year-s-tense-discussion-3593784.html.

Womack, B. (2004). Asymmetry Theory and China's Concept of Multipolarity. Journal of Contemporary China, 13(39), 351-366. 


\title{
The European Union-South Africa Strategic Partnership: Aligning Interests in a Multi-Layered Environment
}

\author{
Talitha Bertelsmann-Scott
}

\section{INTRODUCTION}

The EU-South Africa Strategic Partnership is distinctive, both because it constitutes the only bilateral SP pursued by the EU in Africa and because it is a relationship between the EU and what it sees in part as a major developing (as opposed to emerging) country. From the early 1990s, in the wake of the end of apartheid and the emergence of a new South Africa, the relationship has been through a number of fluctuations, with periods of significant development interrupted by periods of stagnation and apparent erosion. In important respects, these fluctuations reflect the shifting balance between the internal politics both of the EU and of South Africa, the tension between South Africa as a bilateral partner and a regional power, and the impact of broader global challenges. These

T. Bertelsmann-Scott $(\bowtie)$

Cape Town, South Africa

(C) The Author(s), under exclusive license to Springer Nature

Switzerland AG 2021

L. Ferreira-Pereira et al. (eds.), The European Union's Strategic

Partnerships, The European Union in International Affairs, https://doi.org/10.1007/978-3-030-66061-1_11 
elements form central parts of a multi-layered policy formation and negotiation environment, creating a series of tensions and potentially disabling linkages. As such, they provide a distinctive insight into the three logicsinternal, external and identity-identified as underlying the EU's SPs more generally, and add a powerful regional dimension to the analysis.

In this chapter, the focus is on this set of fluctuating forces, and on the ways in which they have played out in EU-South Africa relations. How does the shifting balance of forces in a multi-level context help us to account for the fluctuations in the scope, scale and impact of the partnership? This question links with the key volume themes relating to the functions and motivations, the policy focus, the institutionalisation

Table 11.1 Timeline of EU-South and Southern African negotiations and Summits

\begin{tabular}{|c|c|c|}
\hline Year & $\begin{array}{l}S A-E U \text { TDCA negotiations/EU-SADC } \\
\text { EPA negotiations }\end{array}$ & SA-EU Strategic Partnership Summits \\
\hline 1994 & TDCA negotiations initiated & \\
\hline 2000 & $\begin{array}{l}\text { TDCA enters into force with South } \\
\text { Africa having a longer timeframe } \\
\text { within which to reduce its tariffs to } \\
\text { EU imports }\end{array}$ & \\
\hline 2002 & EU-ACP EPA negotiations launched & \\
\hline 2005 & $\begin{array}{l}\text { Five-year review of TDCA and launch } \\
\text { of the EU-SADC EPA negotiations. } \\
\text { South Africa forms part of the talks as } \\
\text { an observer }\end{array}$ & \\
\hline 2006 & $\begin{array}{l}\text { The SADC EPA group put forward } \\
\text { their framework for the negotiations } \\
\text { and suggest that South Africa should } \\
\text { participate in the negotiations and also } \\
\text { that South Africa's tariff commitments } \\
\text { under the TDCA be used as the basis } \\
\text { for SACU-EU tariff negotiations, } \\
\text { subject to the condition that all BLNS' } \\
\text { sensitivities are fully accommodated }\end{array}$ & $\begin{array}{l}\text { The SA-EU Strategic Partnership is } \\
\text { established. The TDCA provided the } \\
\text { legal basis for relations between SA } \\
\text { and the EU. Furthermore, common } \\
\text { interests provide a natural foundation } \\
\text { for a strategic partnership that } \\
\text { significantly enhances existing } \\
\text { cooperation by moving from mere } \\
\text { political dialogue to active political } \\
\text { cooperation on issues of mutual } \\
\text { interest, at bilateral, regional, } \\
\text { continental or global level. (Council } \\
\text { of the European Union) Inaugural } \\
\text { Summit held in Bordeaux, France }\end{array}$ \\
\hline
\end{tabular}


Table 11.1 (continued)

\begin{tabular}{l} 
Year $\begin{array}{l}\text { SA-EU TDCA negotiations/EU-SADC } \\
\text { EPA negotiations }\end{array}$ SA-EU Strategic Partnership Summits \\
\hline 2007 EU accepts SADC's negotiating \\
framework. WTO waiver Of Lomé \\
preferences set to expire at end of \\
2007 placing enormous pressure on \\
the negotiations. In April 2007, the \\
EU offers DFQF access to all ACP \\
countries that are negotiating EPAs, \\
except for South Africa, on the basis \\
that an IEPA is signed. \\
On 23 November 2007, Botswana, \\
Lesotho, Mozambique and Swaziland \\
initialled the IEPA with an intention \\
to secure their DFQF access after 31 \\
December 2007. \\
Namibia initialled in December 2007 \\
when assurances were received that \\
contentious issues would be ironed out \\
after the expiry of the WTO waiver. \\
South Africa continues to implement \\
the TDCA \\
Parties try and address the most \\
contentious issues that remained \\
unresolved at the signing of the IEPA. \\
These included market access, rules of \\
origin, MFN clause, export taxes and \\
agricultural safeguard measures
\end{tabular}

(continued)

and the impact of strategic partnerships, and relates them to a distinctive set of contexts. The chapter deals first of all with the changing context for the strategic partnership, and with the nature of the 'triangle of forces' (domestic, regional and global) outlined above. It then moves on to examine South Africa's credentials as a strategic partner for the EU, before exploring the ways in which regional forces have helped to shape EU-Southern African relationships-especially the nature of relationships within the Southern African Development Community, which is in itself engaged in a partnership with the EU, and other regional organisations. The chapter then looks at the period of stagnation in EU-South African relations before evaluating the ways in which this reflected the interaction 
Table 11.1 (continued)

\begin{tabular}{|c|c|}
\hline Year & $\begin{array}{l}\text { SA-EU TDCA negotiations/EU-SADC } \\
\text { EPA negotiations }\end{array}$ \\
\hline 2009 & $\begin{array}{l}\text { Botswana, Lesotho, Swaziland and } \\
\text { Mozambique sign an IEPA, whilst } \\
\text { Namibia and South Africa still remain } \\
\text { outside of this arrangement as their } \\
\text { key concerns were not sufficiently } \\
\text { addressed. These concerns included } \\
\text { fears of a negative development impact } \\
\text { on the region, threats to regional } \\
\text { integration and an erosion of South } \\
\text { Africa's policy space. During this } \\
\text { period and following Angola remains } \\
\text { satisfied with having 'Everything But } \\
\text { Arms' access and does not actively } \\
\text { participate in the negotiations }\end{array}$ \\
\hline
\end{tabular}

2010
SA-EU Strategic Partnership Summits

Second SA-EU Strategic Partnership Summit held in Kleinman, South Africa in September 2009. Topics for discussion included science and technology and the impact of the global financial crisis on Africa. Here the two parties agreed to work together within the $\mathrm{G} 20$ process. The parties also agreed to push for a completion of the Doha Development Agenda at the WTO. Other discussion areas included climate change. The communique speaks of a frank discussion on the SADC-EU EPA negotiations.

Third SA-EU Strategic Partnership Summit held in September in Brussels, Belgium. Similar areas were discussed as in 2009 , with stronger cooperation emerging in science and technology, migration and customs. Recognition of the TDCA Dialogue Facility that would support the dialogues under the Strategic Partnership. The new MDGs were discussed and South Africa's role as a donor and development partner in Africa within this context. The SADC-EU EPA is again discussed, and these discussions are labelled as 'frank'. Hopes were high that the negotiations could be completed by year-end

(continued)

of domestic, regional and global forces and reflecting on the key themes in the volume as a whole.

\section{Contexts}

The roots of the European Union (EU)-South Africa bilateral relationship can be traced to pre-colonial times, when the first Europeans settled 
Table 11.1 (continued)

$\begin{array}{ll}\text { Year } & \text { SA-EU TDCA negotiations/EU-SADC SA-EU Strategic Partnership Summits } \\ & \text { EPA negotiations }\end{array}$
South Africa. The Summit reviewed the implementation of the Joint Action Plan and commended progress in the areas of health and human rights. It also commended South Africa for the strong implementation of EU ODA and its relationship with the European Investment Bank. Cooperation on migration and asylum seekers was discussed. The SADC-EU EPA is again mentioned and both parties urged to finalise the agreement Fifth EU-South Africa Strategic Partnership Summit held in Brussels-cracks appear around mutuality of agenda items. The communique focused on peace and security as a starting point, rather than to refer to progress made under the Joint Action Plan. SADC-EU EPA negotiators are urged to expedite their work. However, the paragraph reads less optimistically than in preceding years

2013 South Africa allows Bilateral Sixth EU-South Africa Strategic Investment Treaties with individual European Union member states to laps and open spats between chief negotiators places a strain on the SA-EU relationship. South Africa increasingly focuses foreign relationship on the BRIC nations that the EU sees as a threat to its long-standing primacy in South Africa as its largest trade and ODA partner Partnership Summit held in Pretoria, South Africa. There was a focus on job creation in both South Africa and the EU, with a special emphasis on Youth Employment. There was extensive focus on the peace and security agenda. Again, the chief negotiators are urged to clear the final hurdles towards signing the SADC-EU EPA 
Table 11.1 (continued)

\begin{tabular}{|c|c|c|}
\hline Year & $\begin{array}{l}\text { SA-EU TDCA negotiations/EU-SADC } \\
\text { EPA negotiations }\end{array}$ & SA-EU Strategic Partnership Summits \\
\hline 2014 & $\begin{array}{l}\text { The Chief Negotiators finally signed } \\
\text { the SADC-EU EPA. Services and } \\
\text { investment negotiations were set to } \\
\text { continue post-signature }\end{array}$ & No Summit takes place \\
\hline 2015 & $\begin{array}{l}\text { Legal scrubbing of text finalised } \\
\text { towards the end of } 2015\end{array}$ & No Summit takes place \\
\hline 2016 & $\begin{array}{l}\text { SADC-EU EPA singed in Kasane, } \\
\text { Botswana on } 10 \text { June } 2016 \text {. (Angola } \\
\text { still remains outside of the agreement. } \\
\text { Finally, it only includes the SACU } \\
\text { countries and Mozambique.) }\end{array}$ & No Summit takes place \\
\hline 2017 & & No Summit takes place \\
\hline 2018 & & $\begin{array}{l}\text { Seventh EU-SA Summit takes place in } \\
\text { Brussels. This comes after Cyril } \\
\text { Ramaphosa becomes president in } \\
\text { South Africa and has set attracting } \\
\text { foreign direct investment as a key } \\
\text { priority. This Summit also takes place } \\
\text { against the backdrop of the initiation } \\
\text { of the post-Cotonou negotiations }\end{array}$ \\
\hline
\end{tabular}

on South African soil in 1652. The relationship has evolved over many decades into a seemingly important political and economic relationship, which, on the surface, has deepened since South Africa's transition to democracy in 1994. Arguably at that time the relationship was at a high point: the two parties concluded a trade deal, deepened investment ties and shared a vision of regional integration in Southern Africa. It was not surprising that a Strategic Partnership (SP) was concluded in 2006, making South Africa the only African country to have an SP with the EU.

South Africa remains the EU's largest trading partner in Africa, and over recent years the export mix from South Africa to the EU has become more diverse, to now also include manufactured products and not only primary commodities. The EU is also South Africa's largest development partner with $70 \%$ of all of South Africa's official development assistance (ODA) coming from the EU. This should, however, be seen against the backdrop of multiple donors having left South Africa since its economic status changed to that of a middle-income country. Whereas South Africa 
was always seen as the economic powerhouse of Africa, the donor community recognised that apartheid had inflicted many ills on the majority of the population and that ODA could go a long way towards eliminating inequality and poverty. However, after twenty years of democracy the donor community increasingly saw that ODA formed only a tiny portion of South Africa's overall budget and started to disengage or change to programmes that would focus on trade and economic linkages (Masters 2014a: 57).

Masters (2014b: 5) further argues that the SA-EU Strategic Partnership and the Joint Action Plan is unique amongst the Strategic Partnerships in that it continues to treat the SA-EU relationship primarily as a donor-aid recipient relationship, referring most often to how the EU can assist South Africa in its development. The Joint Country Strategy Paper 2007-2013 confirmed this argument as its focus remained on developing South Africa; the role South Africa plays in the region and on the African continent was merely given as context and not as a strategic objective (Council of the European Union 2007). Whereas a number of dialogues have taken place in a variety of areas, the principal focus in the SA-EU relationship has been on trade within the context of the Trade Development and Cooperation Agreement and the Economic Partnership Agreement. It is within this context also that the relationship has strengthened and weakened over the years.

The EU was the first actor to approach democratic South Africa under the leadership of President Nelson Mandela for a comprehensive trade and development agreement. The relationship strengthened during the initial years of the negotiations but the protracted nature of reaching agreement soon showed that seeing South Africa as a development partner on the one hand and yet expecting a free trade agreement equal to those the EU has with other developed nations would always be complicated. This complication is amplified when South Africa is seen in its geographical location, surrounded by least developed and developing economies that have had pre-existing trade arrangements with South Africa. This underlines the presence of a 'triangle of forces'-domestic, regional and global-that can be traced through much of the EU's engagement with South Africa, and which has links analytically with the three logics explored in Chapter 2 of this volume. The EU anticipated that South Africa would play a dominant and leading role in Southern Africa in all fields but did not grasp the nuanced approach Pretoria had to take-on 
the one hand it wanted to use its economic strength to uplift its neighbours and yet as the new democracy in the region it could not assume a leadership role in a political reality within which struggle history and hierarchy still dominated.

A marked waning of affections between the EU and South Africa took place after 2006 that transcended the disengagement of other bilateral donors, and the relationship reached a low point between 2013 and 2018 . If the Mandela administration's foreign policy (1995-1999) was aimed at reengaging international partners across the globe after apartheid, the Mbeki years (1999-2008) saw South Africa's foreign policy take on an African focus with his firm belief in the African Renaissance. President Zuma (2009-2016) was particularly interested in strengthening South Africa's relationship with the East and joined the BRICS alliance in 2010, a year after he becomes president. The Zuma Presidency also soon became known for corrupt practices and the country entered a period of economic decline. This fluctuation in South African policy coincided with the EU struggling to define its role on the global stage and with several developments in the EU's internal challenges: in 2016 the UK indicated its intent to leave the Union, and at the same time several member states suffered from low economic growth, high immigration and austerity measures being implemented by national governments.

As a result, the two parties did not host a SP Summit for over four years-between 2014 and 2018. The appetite for engagement waned as both parties had domestic and global issues of concern that could not necessarily be addressed within the SA-EU relationship. However, after Cyril Ramaphosa took over from Jacob Zuma as president of South Africa in 2018 a brake was put on the corrupt and disengaged civil service and President Ramaphosa reengaged old partners in Europe and elsewhere in an attempt to attract foreign investors and development partners back to the country. The Ramaphosa administration recognised that the EU must play an important investment and partnership role in South Africa in order for the country to overcome economic decline. Meanwhile, the turbulence caused by Brexit in 2018-2019 has thrown up questions about the roles of both the EU and the UK: whilst the Union could be seen as gaining strength due to its solidarity in the face of British demands, there have been continuing economic and political challenges emerging from the linkages between economic performance, political populism and the need to deal with instability in the wider Europe. These have been accompanied by turbulence in the wider global arena, particularly in relation to 
US policies and US-China tensions (see chapters by Smith and Cottey in this volume).

It would be simplistic, therefore, to assume that all challenges facing South Africa and the EU have dissipated, but within the context of the SA-EU SP both parties might emerge stronger and more willing to engage and support one another post deep decline and disengagement. The chapter, however, is unable to delve into the exact nature of the current state of the European Union or to discuss the progress made against corruption in South Africa whilst many state-owned entities are in steep decline and the economy is heading for a recession. The chapter will focus on the nature of the relationship between South Africa and the EU since the inception of the SP in 2006 to date and track the years of optimism and decline. The chapter argues that the reasons for disengagement between the two parties were two-fold and that they were rooted in the contending forces that were identified in this section and the Introduction. Thus, both parties were going through a period of domestic crisis that in South Africa meant an ever closer relationship with the BRIC nations at the cost of its relationships with its traditional partners in Europe and North America; and the SA-EU relationship soured over South Africa's participation in the Economic Partnership Agreement (EPA) negotiations alongside its regional partners in the Southern African Development Community (SADC).

The second part of the chapter presents an analysis of the creation of the SA-EU SP, and especially the ways in which EU policy-makers saw South Africa as a link between regional concerns and broader global issues. It then further explores the end of the Lomé Convention and the objective set by the EU in the Cotonou framework to conclude regional trade agreements with African regional economic communities. South Africa has always stood out as an anomaly amongst its regional partners having a far more sophisticated economy that could compete on equal footing with the EU and hence special arrangements have always been in place to mitigate for this fact. However, having different sets of trade agreements for the members of the Southern African Customs Union (SACU) makes agreements technically impossible to implement and the SADC Economic Partnership Agreement (EPA) was an attempt to find a solution that could accommodate both the strength of the South African economy and the needs of the other members of SACU (Eswatini, Botswana, Lesotho and Namibia). The chapter then looks at the conclusion of the SADC EPA and the impact the negotiations had on 
the SA-EU relationship as expressed in the SP. ${ }^{1}$ The chapter's conclusion is that perhaps the lesson for any relationship between parties of different levels of economic strength, regional integration and geographical realities is that it will strengthen in times of mutual need and decline in times where national and regional realities have to take priority. As such, it confirms the impact of the 'triangle of forces' identified above and provides an important additional dimension to our understanding of the logics underlying strategic partnerships more generally.

\section{South Africa as a Strategic Partner}

Alongside its BRIC partners, South Africa became a Strategic Partner of the EU in 2006 the first and to date the only partner in Africa. Key underlying principles in the SP from the outset included a recognition of South Africa's progressive constitution, which lay the foundation for the SP, but these were expanded to include other shared key values such as the promotion of peace and security, human rights, democracy, the rule of law and sustainable development across both regions. Although there should arguably be many areas that South Africa and the EU could collaborate on within the domestic South African agenda as well as the international agenda within the G20 and other fora, the Strategic Partnership has not yet been used to leverage these potentials. The SP did establish an overarching framework within which all areas of cooperation between the two parties could be addressed and South Africa named this the Mgobagoba Dialogue-indicating that the relationship between South Africa and the EU had now gone beyond just trade issues to include Policy Dialogues, Sectoral Cooperation, Development Cooperation and Political Dialogue. Institutionally the SP is supported by the Joint Cooperation Council, the Ministerial Political Dialogue and the Summits at Heads of State or Government level.

The SA-EU Strategic Partnership and its Action Plan had at its core the objective to strengthen institutions as they relate to peace and security and development. During the 1990s there was a strong correlation between South Africa and the EU on many common values and beliefs. Existing

\footnotetext{
${ }^{1}$ For a detailed timeline of these negotiations at the EU-South Africa and the regional level, see Table 11.1 at the end of this chapter.
} 
areas of cooperation included development cooperation, trade and investment, economic cooperation and science and technology. The Mgobagoba Dialogue or Action Plan envisaged that new areas of cooperation would be developed in areas of environmental cooperation and climate change, sharing of experiences on EU Regional Policy, Information and Communication Technology, employment and social affairs, combating crime, macro-economic dialogue, education and training, cultural cooperation and sport and recreation. The EU's official statements supported this wide-ranging interpretation of the SP:

Both partners support the struggle against poverty and underdevelopment, racism and xenophobia, as well as the promotion of equal distribution of power, influence an opportunity in the global political and economic systems. South Africa and the EU strongly believe in the primacy of liberty, peace and security, equality, democracy, human rights, good governance, tolerance and respect for the rule of law, and are committed to advancing these values in Africa and globally. Both partners believe in rulesbased multilateralism, the primacy of the UN in global security matters, sustainable development, the basic economic principles of a social market economy, free and fair trade and an equitable international economic order. South Africa and the EU further share a concern for the environment in general, and climate change in particular. Both partners recognise the fundamental role of science and technology innovation for development and are committed to closer cooperation in this regard. (European Union 2007)

Tangible benefits that have accrued for South Africa since the establishment of the SP included the establishment of the Infrastructure Investment Programme for South Africa (worth Euro 1 Million) that is being used to unlock infrastructure backlogs, not only in South Africa but also within the region. A key objective for all of the EU's SPs is to focus on how the strategic partners can unlock or promote greater regional integration and as noted above the EU had identified South Africa as a leading actor within Southern Africa on regional integration issues. However, South Africa's role within the region is often misunderstoodincluding by EU policy-makers. Whereas it is the largest economic actor and has great interest in opening the markets of its neighbours, this role is often not welcomed by other Southern African states. South Africa has to walk a fine line between being seen as the big brother dictating policy to 
other states and acting exclusively in its own interest without the consideration of its regional partners. The sensitivity of South Africa's role in SADC and SACU was underestimated by both the EU and South Africa in 1995 when negotiations started towards a free trade agreement-the Trade, Development and Cooperation Agreement - that largely ignored the interests and rights of the member states of primarily SACU but also SADC. When South Africa later tried to rectify the mistakes made, within the context of the Economic Partnership Agreement negotiations, it would lead to a decline in the hitherto strong relationship it had with the EU. In terms of the argument at the centre of this chapter, this reflected the tension between regional partnerships in southern Africa and the more global objectives of the EU, and linked closely with domestic changes both within the EU and South Africa.

\section{The Regional Dimension}

As noted above, the difficulties in the South Africa-EU relationship have their origins in the SA-EU Trade Development and Cooperation Agreement (TDCA). During the years of the TDCA negotiations (1994-2004), South Africa maintained the position that it could ill afford to be an island of prosperity in a sea of poverty. All foreign policy decision and directions taken in Pretoria thus had to take due cognisance of their effects on the rest of Southern Africa. Under the first democratic presidency of Nelson Mandela, there was also a desire to extend the model of democracy followed in South Africa to other international organisations, key amongst which was the Southern African Customs Union (SACU). SACU was established in 1910 at the same time that the Union of South Africa came into being. The organisation was an instrument devised by the British colonial administration to allow Botswana, Lesotho and Swaziland to remain independent from South Africa, not to be subsumed into the Union of South Africa, but still enjoying the economic benefits of South Africa's mineral wealth. (Namibia joined SACU in 1990 as an independent member state. Up to this point it had been under South African administration.) From 1910 to 2002, South Africa dominated SACU and acted without any substantial consultation or policy sanction from the BLNS (Botswana, Lesotho, Namibia and Swaziland) countries. A new, more democratic agreement in 2002 changed this situation, and allowed for consensus decision-making and the express objective 
of unified negotiating positions for all future trade negotiations (Gibb 2006).

However, the SA-EU TDCA negotiations were well underway before the democratisation of SACU and in essence South Africa was negotiating on behalf of SACU. As a member of a customs union South Africa could not negotiate a free trade area with a third party without impacting dramatically on the other member states of the customs union. Tariff offers made by South Africa, would automatically become tariffs that all of SACU would have to implement, keeping in mind that the vast majority of produce that enters the SACU area enters via South Africa. The loss of tariff revenue would have a direct and immediate impact on the fiscal purse of the BLNS countries. It is, therefore, staggering that South Africa did not include the BLNS in the TDCA via some mechanism or that the European Union also never paused to give due consideration to the problems the TDCA negotiations would ultimately cause in the region. The focus clearly was more on South Africa's access to the European market without much initial focus on how South Africa was expected to reciprocate. These did, however, become key stumbling blocks ahead of the finalisation of the agreement. South Africa was granted a longer implementation period, but essentially a dramatic tariff reduction did occur with subsequent negative impact on the collective SACU revenue pool. According to a complex distribution mechanism, this pool is distributed amongst the BLNS countries, with South Africa essentially not taking its fair share. If one were to consider the SACU tariff pool distribution to the BLNS as ODA, South Africa becomes a significant donor.

At the time of the TDCA negotiations, the BLNS countries had a very liberal and generous arrangement for access to the European market, under the Lomé Convention. As members of the Africa, Caribbean and Pacific (ACP) group of countries, almost all of them former colonies of the EU member states, the BLNS enjoyed tariff free access for $99 \%$ of industrial goods and a large percentage of commodities and primary goods. South Africa only became a partial member of the grouping in 1997 and it enjoyed all the political aspects of the accession, but was never given the same preferential trade access to the EU. The BLNS countries had a positive trade balance with the EU-a seven-fold higher export than import ratio (Meyn 2004: 3).

This special market access arrangement was ruled World Trade Organisation (WTO) incompatible as benefits extended to the ACP were not extended to all WTO countries, nor to all least developed countries 
(LDC). As a result, the Lomé convention was replaced with the Cotonou Agreement in 2000, which was intended to run until 2020. It is a very comprehensive agreement that covers all aspects of the ACP-EU relationship, including political dialogue on peace and security as well as migration. Under the trade envelope it was agreed that the provisions of the Lomé Convention would give way to negotiated reciprocal trade agreements.

As a long-standing proponent and promoter of regional integration, the EU expressed its ambition that the trade arrangement that would follow Lomé, should ideally be regional in nature in order to allow for the strengthening of regional integration efforts within the ACP grouping. The planned new agreements were named the Economic Partnership Agreements (EPA). It became clear that the ACP were not going to be able to negotiate a successor to Lomé as a grouping, but would have to split into smaller regional blocks. In Southern Africa this caused great difficulty in deciding on the negotiating configurations given the overlap in membership that exists between SACU, SADC, the Common Market for Eastern and Southern Africa (COMESA) and the East African Community (EAC). As already noted, it also set up a complicated set of negotiations which challenged the relative roles of South Africa and other regional actors.

The five-year review of the TDCA coincided with the launch of the EU-SADC EPA negotiations. Initially it was not foreseen that South Africa would form part of these negotiations as it was not a member of the Cotonou trade provisions. South Africa initially participated as an observer but then asked to be included in the talks. 'SA decided to join the SADC EPA Group negotiations in an attempt to, inter alia, lessen further fragmentation in SADC and harmonise the trade relations between SACU and the EU especially in relation to the common external tariff of SACU. South Africa also wanted to align the TDCA with the EU-SADC EPA and improve on its preferential agricultural market access into the EU' (DTI 2016: 6).

Therefore, in 2006, the framework for the EU-SADC EPA negotiations included South Africa and started from the understanding that the TDCA would form the basis of the negotiations. It took the European Union more than a year to agree to South Africa's inclusion, which placed enormous pressure on the negotiations once they resumed, as the WTO deadline for the end of the Lomé preferences was given as December 2007: 'Due to pressure to conclude market access negotiations before 
the expiry of the WTO waiver for Cotonou on 31 December 2007, the EU and the SADC EPA group decided to negotiate in two phases. Phase I was to agree on an interim EPA (IEPA) covering trade in goods whilst Phase II was envisaged to negotiate a full EPA covering also the socalled new generation issues such as trade in services, intellectual property rights, competition, government procurement, and trade and sustainable development' (DTI 2016: 6). In April 2007, the EU offered duty-free quota free (DFQF) access on all products except for rice and sugar, originating from ACP countries negotiating EPAs. South Africa would not have access to this provision. The DFQF access was scheduled to enter into force immediately after entry into force of the IEPA, which was envisaged to happen on 1 January 2008. (ICTSD 2007: 1)

However, signing up to the IEPA in and of itself became contentious as the overlapping of existing arrangements, such as Everything but Arms (EBA) and the TDCA, placed less pressure on South Africa, Angola, Mozambique and Lesotho to sign, whereas Botswana, Swaziland and Namibia urgently needed to have some form of agreement in place to ensure their continued access to the EU market. Again, if not all of SACU were going to sign up to the IEPA, it would threaten the integrity of the customs union as the five member states would be governed by three separate agreements in their trade with the EU, which to date remained SACU's largest trading partner. Interim measures to differentiate would have to be introduced at all ports of entry and careful inspection of shipments would have to be introduced at border-crossings. Instead of promoting regional integration, the EPAs were now seriously threatening the collapse of the world's oldest customs union and would cause irreparable damage to Southern Africa's integration agenda-an outcome clearly at odds with the aims of the EU-South Africa SP.

In sum, South Africa's participation in the EU-SADC EPA had become inevitable and was perceived as a good opportunity to address the mistakes made during the TDCA negotiations - not only from the perspective of South Africa negotiating on its own but also in terms of having given away too much access for little return in agricultural coverage of the agreement. However, it did not count in the BLNS's favour. Instead of being treated as a group of LDC and developing countries, they were instead caught in the crossfire between the EU and South Africa. The negotiations became very difficult as both these parties refused to back down on a number of issues and it would eventually take personality changes within the negotiating teams to open up the deadlocks and 
progress towards reaching a mutually beneficially EU-SADC EPA. Instead of the SA-EU Strategic Partnership serving as a guiding light and positive influence on the EPA negotiations, the difficulties within the EPA talks had a negative impact on the SP.

The finalisation of the SADC-EU EPA (2016) finally brought some stability and commonality to SACU in that all of its member states now have the same trade agreement with the European Union. South Africa ultimately benefitted from participating in the negotiations. The inclusion of South Africa in these negotiations was an important acknowledgement that Southern Africa's economic well-being and future development are intrinsically linked to South Africa. Although the negotiations took many years of hard talks and threats of collapse and walk-outs, SACU with Mozambique now has an agreement that allows for the region to grow its exports to the important market of the European Union, without facing too many risks that the most vulnerable amongst them, namely Lesotho and Mozambique, would be exposed to uncompetitive practices. For South Africa and the EU there could now be a period of consolidation of the Strategic Partnership without the negativity of the trade negotiations spilling over to other fields. At the same time, however, a range of domestic factors was at work and had led to a stagnation of the SP itself. This is an important element in an explanation of the fluctuating fate of the SP and is the concern of the next section.

\section{The Strategic Partnership in the Doldrums}

Writing in 2012 on the outcomes of the fifth EU-South Africa Summit, one commentator already hinted at the difficult road ahead for the relationship, whilst also underlining its multi-level nature:

The Brussels summit, while deepening the partnership, was held in a somewhat volatile environment. It represented a reality-check for both parties' ambitions. The EU's model has lost some of its credibility. South Africa is both a donor and, to a lesser extent, an aid recipient. Its partnership with the EU is still a mix of jointly designed development focused efforts and peer-to-peer cooperation. This duality seems to be here to last. [...] Finally, given Pretoria's preeminent role in Africa, the young EU-South Africa strategic partnership has a very strong African regional dimension. Pilot measures and successful models of cooperation experimented in the framework of the partnership could well serve other countries in Africa as well as other regional powers, making of this relationship a sort of 
laboratory to engage other pivotal actors in a globalised world. (Helly: 6)

During the 2012 and 2013 Summits, it became increasingly clear that the European Union itself was experiencing difficulties with its integration agenda. The EU economies still struggled to strengthen after the 2008 financial crisis with growth levels stagnating and unemployment rising. The common currency, the Euro, came under threat from defaulting member states, including Italy and Greece. The height of this crisis was in 2011, but the shockwaves of its impact started to bring about a deeper resentment towards the EU from countries hit hardest by austerity measures and bailouts. In addition, the first glimpses of the pending migration crisis were on the horizon, with a steady stream of refugees arriving in Europe. The flow escalated in 2015 when thousands of refugees attempted to enter the EU from war-torn countries, many arriving by boat. Thousands more perished at sea and the world stood horrified when images of drowned children made headlines around the world. These early problems have developed into a much larger and more multi-dimensional crisis in Europe with the United Kingdom (UK) having notified the EU of its intention to leave the union after a national referendum that was won by the Brexit camp. The Brexit crisis gripped Europe during 2018 and 2019, but was linked to a broader crisis of authority in many member states. Populism increased in many member states with calls for closures of EU borders to more migrants and even calls for the reintroduction of internal EU borders in order to control the movement of refugees that enter via one port but aim to reach the richer countries of Germany and Sweden. At the same time, the escalation of the US-China trade war, which spilt over into transatlantic relations, created a new sense of crisis at the heart of the EU's commercial existence (see Chapter 5 in this volume). In terms of the argument in this chapter, such developments posed challenges at all levels of the EU-South Africa partnership.

In South Africa, Jacob Zuma took over the presidency in 2009, marking the start of a steady but yet dramatic decline for the country. Growth rates could not keep up with population growth and young job seekers were poorly equipped by the country's education system to find employment in a shrinking economy. Sectors that traditionally absorbed labour, like the mining industry, were in steady decline and no new areas showed promising signs of growth. Against this backdrop corruption 
emerged and has found foothold in many part and levels of government with municipal governments badly affected. By 2014 suspicions rose that corruption and state capture were present within the highest levels of government with Jacob Zuma himself being accused of letting outsiders influence his decision-making. It was inevitable that after yet another cabinet reshuffle that saw the trusted and respected Pravin Gordhan being removed as Finance Minister in 2017, South Africa was downgraded to junk status by some of the leading global rating agencies. This crisis culminated in an early exit for Jacob Zuma from the presidency with his deputy taking over the reigns. President Ramaphosa took office aiming to project an image of cleaning up the mess left by State Capture but the damage done will take many years to rectify.

Under President Zuma, South Africa's foreign policy and trade and investment policy had undergone a shift away from traditional partners in Europe and in the United States to seek out like-minded countries in the South. Foremost amongst these is the BRICS alliance that South Africa joined in December 2010. Although punching above its weight within a grouping that consists of economic giants like China and India, South Africa's participation within the grouping has given it a strong foothold in Africa and has allowed South Africa to strengthen trade and investment ties with the new partners. The BRICS have launched their own development bank that aims to disburse funding for sustainable infrastructure projects in member states at a much faster pace than traditional multilateral development banks. The first seven projects have already been initiated. A next objective is to establish a BRICS rating agency that could serve as a counter-weight to the significant power that traditional rating agencies yield over developing countries. In addition to seeking closer ties with the BRICS partners, South Africa also made the decision to let its bilateral investment treaties (BITs) with individual EU members lapse. This was the cause of great concern to the EU states, and they warned South Africa that this could lead to de-investment and decrease the appetite for new investments into South Africa. South Africa viewed this step as critical as it feared being challenged on domestic legislation that is discriminatory in nature but aims at addressing the injustices of apartheid by giving preference to companies that are black-owned (Soko and Qobo 2017).

The net result of these trends was a challenge to key assumptions of the EU-South Africa partnership. At the domestic level, a crisis of legitimacy and political authority in the EU was paralleled by turbulence in South 
African politics. At the same time, the interaction between the EU and the wider southern African region was questioned by the emergence of new aid and investment patterns both in the Union and in South Africa, whilst at the global level there were shifts of power and attention that affected both of the partners in different ways. Whilst it might be argued that the Ramaphosa government stood for a more substantive partnership with the EU, this was overlaid with developments at the level of the BRICS grouping and in South Africa's regional role, to create a new and demanding diplomatic landscape.

\section{CONCLUSION}

Amongst the EU's roster of strategic partnerships, that with South Africa is unique in that it does not speak to the general objectives of the Strategic Partnership approach as many of the others might. In terms of the partnership's overall texture, it appears that the two parties have not as yet been able to transcend the past relationship of donor-recipient and where this has been pursued in the area of trade and regional integration the Strategic Partnership has been unable to give broader context or leadership to the SA-EU relationship. In fact, the SP suffered due to intense trade negotiations that were complex given South Africa's unique geographical position. The EU would have liked to use South Africa's influence to encourage other countries to sign up to the EPAs and to use the process to strengthen regional integration. However, as argued above, the reality of South Africa's economic strength and strong European interest-both offensive and defensive-made it near impossible to reach agreement. With the SADC EPA now being implemented and with a new president at the helm in South Africa the EU and South Africa can look forward to new levels of engagement within the SP. Hopefully the parties can now develop mechanisms of support in times of crisis and take the EU-SA Strategic Partnership to a level of global import.

The level of regional diplomacy and negotiation is thus critical to an understanding of the ways in which the EU-South Africa SP has developed, and to an evaluation of its fluctuations over the period since 1994 . As we have seen, however, this level has to be analysed in the context of two other key levels of EU-South Africa engagement. The first is that of domestic politics and economics, and this chapter has traced the ways in which the changing balance of domestic forces has affected both of the partners. The second is that of the global arena, and the chapter 
has assessed the ways in which shifts of power and attention at this level have helped to shape the EU-South Africa partnership. It is clear that the management of this multi-level context, with its attendant linkages and tensions, has been at the heart of the EU's approach to South Africa, but it is also clear that the EU has had to adapt its approach to significant developments in South Africa's approach to its global and regional role.

Whilst this might be true of all SPs in different ways, it has a sharp and continuing impact in EU-South African relations; in terms of the initial question posed in this chapter, it is clear that the scope, scale and impact of the EU-South Africa SP have strongly reflected the ability and inclination of the partners to manage multi-level diplomacy in pursuit of agreed objectives. In terms of the overall themes at the centre of this volume, it is clear that the EU-South Africa SP has reflected a tangled set of motivations on both sides, which have been underlined by the institutional complexities of regional integration and negotiation processes, and by challenges to the regional and global roles of both parties. These judgements link strongly with the three logics identified in Chapter 2-internal, external and identity - and demonstrate the ways in which regional as opposed to bilateral relationships can constitute an important intervening variable in the evolution of SPs. Given the uncertainties of a post-COVID world, and the continuing processes of change in southern Africa, this condition is likely to persist if not to strengthen in the foreseeable future.

\section{REFERENCES}

Bertelsmann-Scott, T. (2013). South Africa and the EU-Where Lies the Strategic Partnership? In A. Adebajo \& K. Whiteman (Eds.), The EU and Africa: From Eurafrique to Afro-Europa. South Africa: Wits University Press. Bridges, ICTSD. (2007, April 18). EU Proposed Duty- and Quota-Free Access for ACP Countries in EPA Talks, $11(13)$.

Council of the European Union. (2007, May 15). The South Africa-European Union Strategic Partnership Joint Action Plan. 9650/07 Presse.

Department of Trade and Industry, South Africa. (2016, June 20). Briefing to the Parliamentary Committee on the Evolution of EU-ACP Relations and the Economic Partnership (EPA) Negotiations.

Gibb, R. (2006). The New Southern African Customs Union Agreement: Dependence with Democracy. Journal of Southern African Studies, 32(3) (September), 583-603.

Helly, D. (2012) The EU-South Africa Strategic Partnership: Changing Gear? ESP Policy Brief 7, October. 
Masters, L. (2014a). The EU and South Africa; Towards a New Partnership for Development. In C. Castillejo (Ed.), New Donors, New Partners? EU Strategic Partnerships and Development (pp. 53-62). Brussels: European Strategic Partnership Observatory (ESPO).

Masters, L. (2014b). The EU and South Africa: Towards a New Partnership for Development. Policy Brief 11. Brussels: European Strategic Partnership Observatory (ESPO).

Meyn, M. (2004, January 22-23). The EU-South Africa FTA and Its Effect on EPA Negotiations: An Examination of Some Options, Opportunities and Challenges Facing the BLNS Countries. Conference Paper prepared for the European Community Studies Association in Southern Africa: The Relationship Between Africa and the European Union, University of Western Cape.

Soko, M., \& Qobo, M. (2017). Economic, Trade and Development Relations Between South Africa and the European Union: The End of a Strategic Partnership? A South African Perspective. South African Journal of International Affairs, 24(2), 137-157. 


\section{Reaching Out for Strategic Partnerships Beyond the BRICS}




\section{The EU and Mexico: The Strategic Partnership in the Context of the Global Agreement}

Roberto Dominguez

\section{INTRODUCTION}

Despite asymmetries, geographical distance, and a low level of interdependence, the EU-Mexico relationship has been resilient in adapting to the challenges posed by regional and global transformations since the mid-1990s. Even before the design and implementation of EU Strategic Partnerships (SPs), Mexico and the EU had already concluded the Economic Partnership, Political Coordination and Cooperation Agreement (or Global Agreement-GA) in 1997 to address trade deviations produced by the North American Free Trade Agreement (NAFTA) and to increase strategic coordination in the context of the uncertainties of the end of the Cold War. When the EU's SPs were implemented in the 2000s, the EU-Mexican relationship was already one step ahead, and rather than producing a significant transformation, the SP consolidated a relationship

R. Dominguez $(\varangle)$

Suffolk University, Boston, MA, USA

(C) The Author(s), under exclusive license to Springer Nature

Switzerland AG 2021

L. Ferreira-Pereira et al. (eds.), The European Union's Strategic

Partnerships, The European Union in International Affairs, https://doi.org/10.1007/978-3-030-66061-1_12 
where both parties had worked for at least a decade in a coordinated fashion in the international arena.

Based on the numerous questions raised in the introduction of this book, this chapter inquires whether the SP between the EU and Mexico has strengthened the bilateral relationship and produced instruments to enhance the legitimacy of the EU in times of increasing nationalism and nativism (Snyder 2019). To provide elements that answer this question, the chapter is structured in three sections. The first section explains how the EU and Mexico have revisited their bilateral cooperation in the past three decades with the negotiation and implementation of the GA and the SP. The second focuses on the role of the SP in the bilateral relationship and how both parties have aligned their positions to cooperate in promoting multilateralism at the global level and collaboration in the regional agenda in the context of the CFSP agenda on the cases of Colombia, Haiti, Cuba, and Venezuela. The third section examines the performance of the EU-Mexico institutions and mechanisms of dialogue that facilitate the bilateral relationship. The elements provided throughout the chapter lead to the argument that the EU-Mexico SP should be explained in the context of the broader bilateral relationship, which transcends the SP and includes the GA. In this regard, despite the modest volume of their trade relations, the rationale of the EU and Mexico relationship is largely explained by a pragmatic approach that allows both parties to adapt to the changing circumstances, finding in the GA and the SP mechanisms to reinforce their coincidental worldviews in the regional and international arenas. Such a conclusion lends weight to both the external and the identity logics explored in Chapter 2 of this volume.

\section{Pragmatism and Adaptation}

The overarching approach of the international liberal institutionalist agenda that the EU and Mexico share today has been subject to contestations and conflicts in the past, particularly in the areas of the economy, democracy, rule of law and human rights. After embracing the importsubstitution model for several decades and developing an authoritarian political system, Mexico shifted to a political and economic transformation in the early 1990s that converged with the goals of the EU and gradually paved the way to develop a shared perceptions of "likemindedness" (Atanassova-Cornelis and Hellendorff, this volume). This 
coincidental juncture (Kavalski 2016; Kavalski, this volume) aligned the interests of the EU and Mexico to enhance their relationship. ${ }^{l}$ The Administration of Carlos Salinas de Gortari (1988-1994) cemented Mexico's economic liberalization by embracing the open regionalism model, in which the central principles were opening new markets for Mexican products and attracting foreign investment (Villarreal 2017). For Europe, Mexico became more critical, not only due to the size of its economy and its relevance as the second largest EU trade partner in Latin America but also because Mexico was shifting its economic and political strategies. In the economic area, Mexico shared the EU vision in favour of free trade and the multilateral rules-based system of the World Trade Organization (WTO). In the realm of democratization, in the negotiation process of the GA, Mexico was reluctant to adopt the Democratic Clause, which is standard in EU international agreements. Only when Mexico accepted the Democratic Clause in 1996, could the EU and Mexico continue negotiations to conclude the GA (Whitehead 1997). To reinforce liberal practices, under the Administration of Vicente Fox (2000-2006), Mexico signed most of the international instruments for protecting human rights. After 2006, even though levels of violence related to organized crime increased in Mexico, procedural practices of democracy have become the norm in the political system, which still faces challenges in the area of rule of law. In sum, the political and economic transformations in Mexico have facilitated embracing the rules and norms embedded in the GA.

The GA is more than a free trade agreement. With a mandate to institutionalize political dialogue, enhance trade and economic relations, and deepen cooperation, it has marked the EU-Mexico relationship for two decades. The GA has led to substantial increases in trade volume, regular dialogues, and political cooperation. In contrast to the North

\footnotetext{
${ }^{1}$ Framed in a context where the global order was facing deep transformations after the end of the Cold War, the EU and Mexico revisited the best strategies for inserting themselves in the wave of globalization in the 1990s. Their responses were the Treaty of Maastricht and the North American Free Trade Agreement (NAFTA), respectively, and the subsequent questions were whether or not to reinvigorate the EU-Mexico relationship. The 1995 Paris Declaration outlined an ambitious plan to intensify EU-Mexico relations, and the Council of the EU adopted the directive of negotiation for a new agreement in June 1996. The EU and Mexico signed the GA, in Brussels, in December 1997. The European Parliament approved the GA in May of 1999, as did the EU Council, in September of 2000. The Mexican Senate approved it in March 2000 and the Agreement officially entered into force in October 2000.
} 
American Free Trade Agreement (NAFTA), one of the crucial innovations of the GA is the creation of institutions: The Joint Council, the Joint Committee, and other appointed Special Committees. On the other hand, trade relations have grown more than $300 \%$ since the EU-Mexico FTA, one of the three components of the GA, was established in 2000, with bilateral trade reaching a record of $€ 65.3$ billion in 2018 , and trade volume growing each year since 2014 . The EU represented $8.6 \%$ of Mexico's total trade in 2018 and was its third largest trade partner, after the United States (62.3\%) and China (10.2\%) (DG Trade 2019). From the European perspective, Mexico was the twelfth largest trade partner of the EU and represented only $1.7 \%$ of its total trade. The trade balance has been consistently in favour of the European Union-between $€ 7.1$ billion in 2003 and $€ 13.3$ billion in 2018. In the case of services, EU exports amounted to $€ 9.8$ billion and imports to $€ 5$ billion in 2016 (DG Trade 2019).

While the EU-Mexico GA was being implemented, the EU was in the process of designing the SPs as a frame for conducting EU's relationships with regional and global powers. Noticeably, and in contrast to the GA, the SP bears a symbolic value but no legal weight (Renard 2015). The 2003 European Security Strategy (ESS) initially acknowledged Canada, China, India, Japan, Russia, and the United States as key partners. In 2008, the Report on the Implementation of the ESS incorporated South Africa and Brazil but again did not mention Mexico (Council of the European Union 2008). From official statements, there is no evidence that the negotiation of an SP with Mexico was planned in comparison to other SPs, which is understandable due to the bilateral GA. Instead, it seems that it was an adaptation in the design of the EU SPs. Mexico signed the SP in 2008, right after the EU signed the SP with Brazil, and South Korea was identified as a strategic partner to complete ten SPs in 2010 (FerreiraPereira and Guedes Vieira 2016). From the Mexican perspective, the SP added a political tool that contributes to reinforcing existing mechanisms of cooperation and comprehensively stimulated bilateral dialogues, while the GA and its modernization have been the main driving force of the bilateral relationship.

With the duo of the GA and the SP as pillars of the EU-Mexico relationship, a second coincidental juncture emerged in the 2010s. Mexico and the EU revisited the alternatives to explore how to deal with the challenges of the post-2008 financial crisis and the increasing role of China in global trade. Other events such as Brexit, the election of Donald Trump, 
and the renegotiation of NAFTA accelerated the start of negotiations for modernizing the EU-Mexico GA. The EU and Mexico decided to explore the possibilities for a comprehensive update to their GA, and in particular, its trade pillar, in the context of the first CELAC-EU Summit in Santiago de Chile, in 2013. The modernization of the GA is significant because it reflects the political will of the EU and Mexico to provide an updated legal framework for areas of common interest that (1) were not included in the GA; $(2)$ were contemplated in a limited way; and (3) needed to be adapted to internal transformations in Mexico, the EU, and the international arena (Del Río and Saavedra Cinta 2018).

The EU-Mexico relationship responded and adapted to the new circumstances of the regional and international environment between 2016 and 2018 with the conclusion of the modernized EU-Mexico agreement in 2020. Both parties agreed in principle while some details were still subject to discussion in 2019. All in all, the EU and Mexico have gradually adapted to the changing international circumstances and found common ground for cooperation since the end of the Cold War. Despite significant asymmetries in their levels of political, social, and economic development, the EU-Mexico relationship has been resilient and a catalyst for further cooperation for more than two decades: from the 1997 GA to the 2008 SP and to the 2020 modernized GA.

After preparatory work was completed, formal negotiations to modernize the GA were launched in May 2016, ending in principle April 2018 after nine rounds of negotiation (Rodríguez-Piñero Fernández 2018). From 2018 to May 2020, Mexico and the EU worked on the 2018 agreement in principle and finalized the text of the modernized GA in 2020. In Similar to the negotiation process of the original GA, negotiations were complicated, but not highly contentious. Forty negotiation proposals were submitted by the EU (Harte 2018), with disputes arising in a variety of areas - the members of the European Parliament and civil society organizations repeatedly expressed their concern for Mexico's ability to respect human rights and deter the rising impunity related to drugs and migration. On the other hand, the modernized agreement included new policies and mechanisms of cooperation: such as the Strategic Partnership, the establishment of the Joint Parliamentary Committee (EU-Mexico JPC), the continually expanding scope of High-Level Dialogues (HLD) (Dominguez 2014), and the adoption of the Investment Tribunal System (European Commission 2018). Also, the modernized agreement added the following eight additional items: (1) 
anti-corruption; (2) transparency; (3) trade and sustainable development; (4) technical barriers to trade; (5) trade remedies; (6) small and medium enterprises (SMEs); (7) animal welfare and antimicrobial resistance; and (8) energy and raw materials (Ecorys 2015). All these new additions to the GA expanded the scope of the legal and institutional framework to adapt it to the new circumstances of the twenty-first century.

Among other innovations in the area of trade, the new agreement would remove customs duties on trade in goods resulting in the eventual liberalization of $99 \%$ of tariff lines (including full liberalization of trade in industrial goods). In the area of agricultural goods, more than $85 \%$ of tariff lines would be fully liberalized, while specific sensitive sectors (such as dairy and meat) would remain subject to specific restrictions (including quotas and tariff-rate quotas). The modernized agreement would also protect an additional 340 European Geographical Indications (Bosse and Korosteleva-Polglase 2009) in Mexico. Also included were chapters on rules of origin (including for cars), trade facilitation, trade remedies, technical barriers to trade, and sanitary and phytosanitary rules. On services, the modernized agreement would make it easier for EU firms to do business in Mexico (including in the maritime transport, telecommunications, and financial sectors), while protecting the rights of both parties. In further attempts to enhance transparency and consistency, the modernized agreement included the EU's new Investment Court System (ICS), together with provisions to encourage and protect investment. On public procurement, which represents new opportunities for business and investments, Mexico committed to entering into negotiations with its states to offer greater access for EU bidders.

In the light of the content of the modernized GA, the overall expectation is that the predictability in the EU-Mexico relationship will be reinforced. A Commission Impact Assessment determined that a comprehensive and ambitious modernized Agreement could increase EU GDP by $0.01 \%$ annually by 2028 , as well as render improvements in social and environmental standards (Rodríguez-Piñero Fernández 2018). On the other hand, the GA may contribute to ameliorating the uncertainty of external factors such as the United States, Mexico and Canada Agreement (USMCA). The USMCA is an updated version of the nearly 25-year-old, trillion-dollar NAFTA and includes major changes relating to the auto industry and new policies on labour and environmental standards, intellectual property protections, and some digital trade provisions (Office of 
the United States Trade Representative 2020). The effects on EU companies will be limited and vary from sector to sector and even from company to company; they will also reflect their capacity to adapt to certain USMCA provisions, particularly on rules of origin (higher North American content), geographical indications and voluntary export restraints (competition). The main effects will be for EU companies trading with Mexico, in particular carmakers, food and drink exporters, and dairy producers (Titievskaia and Pietsch 2018).

The modernized GA will very likely reinforce the stability of the Mexican legal framework for the operation of European companies in the trade area, and the shared worldviews of decision-makers in the EU and Mexico. Since the GA came into force, the practices in the bilateral relationship have opened spaces for communicating concerns without causing any major disruption. From the European Parliament to the EU Delegation to Mexico, EU actors have raised their concerns about human rights abuses and impunity in Mexico. However, more important is the fact that the legitimacy of the GA has not been questioned and, from the policy perspective, there is significant evidence that a common understanding has allowed the EU and Mexico to adapt to new circumstances by providing new mechanisms of collaboration and cooperation at the regional and multilateral levels, as will be explained in the following sections.

\section{Strategic Partnership: A Political Framework}

The implementation of the GA opened new and numerous avenues of cooperation between the EU and Mexico. While the GA is one of the most developed and comprehensive mechanisms of EU foreign policy, the SP reinforced the relationship between Mexico and the EU. In contrast to the GA, the SPs are EU instruments designed to deepen cooperation with key partners in efforts to preserve the values and interests of the EU at the global level (Cîlig 2012). In 2008 Mexico became the second country in Latin America, after Brazil, to become a SP of the EU. At the IV Mexico-EU Summit, held in Lima, Peru, in May 2008, the leaders of Mexico and the EU announced their intention to form a SP. On July 15, 2008, the European Commission presented a communication to the European Council and the European Parliament, recommending the establishment of a SP between the EU and Mexico. The Council of the EU issued conclusions on endorsing the partnership on October 13, 
2008, the European Parliament issued its favourable opinion on March 12, 2009, and then Mexico formally became a strategic partner of the EU.

While the main framework of the economic, political, and cooperation relationship is based on the GA, the SP has enhanced bilateral dialogue. In order to guide the EU-Mexico relationship, both parties agreed to the SP Joint Executive Plan in May 2010 (Council of the European Union 2010), which attempts to operationalize the goals of the bilateral agenda at the bilateral, regional, and multilateral levels of common interest. The essence of the concept of the SP is that of a framework that reinforces the political will of the parties to intensify consultations and dialogue and, where appropriate, achieves closer cooperation. From the thematic perspective, the SP EU-Mexico aims at producing greater coordination on global, regional and bilateral issues, and it is based on four axes: (1) Political aspects such as democracy, human rights, the rule of law, cultural dialogue, and regional integration; (2) security aspects such as the fight against terrorism, organized crime, drug, and human trafficking; (3) environmental aspects such as climate change and natural catastrophes; and (4) socio-economic aspects such as investment and social responsibility, innovation and intellectual property rights, open markets, food prices, and maritime policy (Secretaría de Relaciones Exteriores 2019b). From the perspective of the levels of cooperation, the SP Joint Executive Plan focuses on three main areas: multilateral, regional, and bilateral. Given the suggested areas of cooperation by the SP and its Executive Plan, the evaluation of the EU-Mexico relationship in the context of the SP-GA indicates that both parties have worked together on several levels. In the bilateral area, as explained in the previous section, the modernization of the GA provides reinvigorating legal frameworks for the bilateral relationship in the areas of trade, political dialogue, and cooperation. In the area of multilateral cooperation, the first section of the EU-Mexico SP Joint Executive Plan enumerates fourteen areas of collaboration. Through the SP, Mexico and the EU have strengthened their coordination within the framework of multilateral institutions and fora on matters of global importance, especially peace, international security, construction and respect for international law, and climate change (Secretaría de Relaciones Exteriores $2019 \mathrm{~b})$. On the other hand, in the case of regional cooperation, the Joint Executive Plan focused on two main areas: bi-regional dialogue and triangular cooperation in Latin American/Caribbean, African and electoral cooperation (Council of the European Union 2010). 
While mechanisms for collaboration have increased, does this mean that effective EU-Mexico collaboration at the multilateral and regional levels has been enhanced? After the end of the Cold War, EU and Mexican positions in multilateral institutions coincided more and more as Mexico started accepting human rights conventions and implementing market-oriented policies. By the time the SP became part of the bilateral agenda, multilateralism was already a traditional area of intersection and cooperation in the EU-Mexico relationship. The introduction of this book suggests a functional dimension of analysis whereby there is an increasing resort to SPs as a foreign policy instrument to mitigate the effects resulting from the growing affirmation of rising and contesting powers (e.g., Russia and China), as well as from the US drift towards unilateralism. While the positions of the EU and Mexico have traditionally converged regarding the topics of the multilateral agenda, the SP could be seen as an additional bilateral mechanism conducive to promoting regional and global stability.

From the EU perspective, The European Union's Global Strategy Three Years on, Looking Forward indicates that EU has become a point of reference for all those in the world who want to preserve and strengthen multilateralism. Particularly, the document continues, the work of the EU has focused on working with other partners on reforming, investing, implementing, deepening and creating multilateral initiatives (EEAS 2019b). To a large extent, after more than a decade, the EU and Mexico have cooperated to promote multilateralism with concrete actions. Regarding reforming and investing in multilateralism, the EU has stepped up its funding for the UN system at a time when others have reduced or cancelled their contributions (EEAS 2019b), while Mexico supported the resolution that allowed the EU to obtain, in 2011, observer status in the UN General Assembly (Secretaría de Relaciones Exteriores 2019b). In the implementation of multilateralism, the EU has invested significant political capital in the defence of multilateral rules-based solutions, which coincides with the crucial role of multilateralism embedded in the principles of Mexican foreign policy. Mexico has also supported nuclear disarmament and worked together with the EU in brokering the ambitious agreement on climate change in Paris, and the 2030 Agenda Sustainable Development Goals of the UN. In the deepening of multilateralism, the EU and Mexico have reached and modernized political and trade agreements between them (GA, modernized GA, and SP) and with 
other parties. ${ }^{2}$ Lastly, a commitment to multilateralism has also brought the EU and Mexico together in initiatives such as migration, climate, natural resources, and human rights (EEAS 2019b).

Regarding cooperation in the regional arena, policies within the CFSP are very significant components of the SPs (as noted in Chapter 1 of this volume) and some of them fall under the interest of the EU and Mexico. Based on the CFSP Annual Reports, the areas of collaboration and contestation between the EU and Mexico are limited to a few elements of the CFSP agenda. The explanation reflects the premise that the main focus of Mexican foreign policy remains within its immediate neighbourhood, on the one hand, and that Latin American issues play a marginal role in the CFSP agenda, on the other. Against this background, the collaboration or contestation between Mexico and the EU is tangibly identified in the cases of Colombia, Haiti, Cuba, and Venezuela. All four of these cases have been a priority in the CFSP agenda for Latin America and have also been subject to EU policies.

The EU and Mexico have aligned their policies in the cases of Colombia and Haiti in supporting reconciliation and reconstruction, respectively. In Colombia, the EU has played a leading role in supporting the peace process and contributing to peacebuilding efforts, mainly through the Colombia EU Trust Fund. Mexico, on the other hand, is one of the participating States of the Global Initiative for the Demining of Colombia. In Haiti, the EU continues its support to improve the internal situation, notably recovery efforts after Hurricane Matthew hit the country in October 2016. Since 2015, Mexico has been a troop contributor to the United Nations Mission for Stability in Haiti (MINUSTAH), whose objective is to support local institutions in their mission of guaranteeing citizen security and peacekeeping.

The cases of Cuba and Venezuela are more complicated for the implementation of aligned policies from the EU and Mexico due to the polarization of politics in both countries and inevitable disagreements in moments of crises. The concentration of power and difficult economic transition in Cuba have been subject to EU and Mexican policies.

${ }^{2}$ The EU and Mexico have developed a very extensive network of free trade agreements based on international laws that deepen multilateralism. As of 2019, the EU has in place the largest trade network in the world, with 41 trade agreements covering 72 countries (European Commission 2019), while Mexico has signed 13 free trade agreements with 50 countries (Secretaría de Economía 2019). 
Regarding the US embargo on Cuba, the EU and Mexico have formed a common front, particularly against the implementation of Title III of the Helms-Burton Act, which allows US nationals to sue a range of persons and entities that traffic in property expropriated by the Cuban government. Considered by most of the international community as contrary to international law, the EU and Mexico have opposed the unilateral action of the US and the Helms-Burton Act. To support the transition in the Island, the EU and Mexico have followed similar paths, but not necessarily in a coordinated way. The EU adopted the Common Position on Cuba in 1996, and the EU and Cuba signed the Political Dialogue and Cooperation Agreement in 2016. Mexico, on the other hand, has developed a critical policy to Cuba under centre-right administrations in Mexico and a more conciliatory approach under centre-left administrations. In the case of Venezuela, the EU has convened an International Contact Group (ICG) on Venezuela, formed by European and Latin American countries. However, in contrast to the Mexican governments that have been critical of the Venezuelan democratic practices from 2000 to 2018, the administration of President Obrador (since 2018) decided not to participate in the ICG. In the meantime, the EU has mobilized $€ 118$ million since 2018 in humanitarian and development assistance to support UN action in Venezuela (EEAS 2019b).

One of the main differences between the EU-Mexico SP and other SPs is that the GA provides a comprehensive framework of cooperation that predates the wave of negotiations of SPs. From this angle, the analytical challenge in assessing the SP is to determine whether the EU-Mexico SP has been a catalyst of the EU-Mexico relationship or mostly a political framework to reinvigorate it. To make the analysis more complex, a potential question is whether the current cooperation at the multilateral and regional levels would be similar under the hypothetical of not having a bilateral SP. While this hypothetical is difficult to answer, the review of the regional and multilateral EU-Mexico agenda indicates that cooperation is quite dynamic, takes place in a variety of topics and areas, and that very likely regular communication and predictability provided by institutions and practices enhance common understandings. 


\section{Institutional Dimension: The Global Agreement and the Strategic Partnership}

The deepening of the EU-Mexico relationship has demanded regular dialogues between officials from both parties and between legislative bodies and civil societies. This institutional dimension has advanced a platform allowing for further cooperation in various policy areas (as noted for SPs in general in Chapter 1 of this volume). To avoid institutional duplication, the SP Joint Executive Plan indicates that the SP will use the institutional structure of the GA to promote bilateral dialogue rather than produce new structures (Council of the European Union 2010). Hence, while there is institutional continuity with the institutions of the GA, the creation of sectoral dialogues has proliferated after the adoption of the SP Joint Executive Plan. Since 2000, when the GA came into effect, the EU and Mexico have held seven Summits (Presidential level), seven Joint Councils (Ministerial level), twelve Joint Committees (Undersecretary level), and twenty-five Joint Parliamentary Committees. In order to exchange best practices and deepen cooperation at the bilateral, regional, and multilateral levels, both parties have created eleven sectoral dialogues (Secretaría de Relaciones Exteriores 2019c). The sectoral dialogues include the following areas: High-Level Political Dialogue, multilateral affairs, climate change, environment, macroeconomic issues, human rights, security and justice, higher education, digital economy, energy, and cooperation on regional and urban policy.

The high-level political dialogue is the most important type of dialogue featured in the SP, and as of 2019, it had convened five times (SRE 2018). International and regional issues have also been examined in the political dialogue, including exchanges of views about Iran, Syria, the situation in the Middle East, relations with strategic partners, and the EU's and Mexico's regional contexts. In 2019, both parties created the high-level dialogue on multilateral affairs during the visit of High Representative/Vice-President (HRVP) Federica Mogherini to Mexico in September. During the first informal meeting of the high-level dialogue on multilateral affairs, the discussions covered sustainable development; the fight against hate speech and expressions of xenophobia and racism; migration and development; the Global Drug Problem; the rule of law; peace and security; and gender issues (EEAS 2019a).

Each sectoral dialogue is significant in its capacity, but some are more visible due to immediate social needs and difficulty-particularly on behalf 
of the Mexican government-in raising the levels of performance and effectiveness of existing oversight frameworks. The bilateral dialogues in human rights, and security and law enforcement are two examples of sectoral dialogues where Mexico has struggled to make significant progress. Human rights have been an essential and sensitive item on the bilateral agenda for several years. EU annual reports on human rights consistently indicate that Mexico faces considerable challenges in the areas of security and human rights, despite substantial efforts made to further strengthen the country's legislative framework (EEAS 2017a). These challenges include cases of torture, forced disappearances, extrajudicial killings, threats, and attacks against high-ranking diplomats and journalists, femicides, high levels of impunity and corruption, and infiltration of state institutions by organized crime (EEAS 2017b). Structural deficiencies in the justice system are unable to lessen impunity, and Mexico ranks among the countries with the highest levels of impunity, according to the 2017 Global Impunity Index (IGI) (Le Clercq Ortega and Rodríguez Sánchez Lara 2017). The observation of human rights in the EU-Mexico agenda was a priority area even before the implementation of the GA. As of 2019, the dialogue on human rights had held eight annual meetings (EEAS 2018).

Another essential dialogue is on security and justice, which was held for the first time in 2011, within the context of increasing levels of violence in Mexico. During her visit to Mexico in May 2016, HRVP Federica Mogherini attended the second dialogue on security and justice. Her visit was emblematic because it revealed that security and law enforcement is one of the most critical areas of the bilateral relationship. Her remarks during the meeting, while acknowledging the progress made in Mexico, were firm regarding shared security concerns and the urgency to work together in the areas with potential for further cooperation (Delegation of the EU to Mexico 2016).

Beyond the regular meetings between EU and Mexican officials, members of the European Parliament and the Mexican Congress examined the bilateral relationship under the EU-Mexico Joint Parliamentary Committee (JPC). As of 2019, the JPC had celebrated 25 meetings and issued the same number of joint declarations, which often reflect the state of the debate in the bilateral relationship and potential avenues of collaboration between parliamentarians of both sides. For instance, the joint declaration of the 25th JPC, celebrated in Brussels in 2018, addressed the following topics: evaluation of the electoral results in Mexico and 
the European Parliament; the ratification process of the EU-Mexico global agreement; immigration, and exchange of views on security and justice, the fight against corruption, and protection of citizens' rights (EU-Mexico Joint Parliamentary Committee 2018).

Regarding dialogues between civil societies of the EU and Mexico, five meetings took place between 2002 and 2012. However, there has since been no record of further meetings. One of the challenges in continuing the dialogues was to find a symmetrical organizational structure: while EU's civil society has organized itself within the European Economic and Social Committee (EESC), Mexico was still in the process of organizing a similar organ at the federal level. Another emerging mechanism is the Dialogue Initiative between Think Tanks Mexico-European Union, which has celebrated two meetings as of 2019 (EEAS 2019c).

The institutionalization of bilateral dialogues is one of the main features of the EU-Mexico GA, which is quite different from free trade agreements such as NAFTA/USCMA. The creation of institutional dialogues contributes to setting rules for governments, defining rights for individuals, opening spaces for inter-state negotiations, and supplying some of the discursive concepts and resources which are taken up by governments and activists in domestic and international society (Hurd 2019). From the summit mechanisms to the bilateral parliamentary meetings, the EU-Mexico relationship enjoys numerous institutions conducive for deepening cooperation. The review of the bilateral institutional agenda, based on GA and the SP, indicates that both parties have found common fronts in international fora and have adapted to the needs of cooperation in numerous fields. However, the potential effects of bilateral institutions are often contingent on the nature and levels of the interdependence in the relationship itself. Thus, the flow of EU assistance to Mexico is modest and focused on reinforcing the capacity of the Mexican society to improve inclusiveness and ameliorate the crucial problems in areas related to the rule-of-law. Despite the limited effects of EU-Mexican institutions, they represent significant pillars to monitor, discuss and potentially propose innovations to the bilateral relationship.

\section{CONCLUSIONS}

One of the conventional diplomatic statements in each one of the ten capitals of the EU's SPs is that inclusion in the selective group is the recognition of their rising profile in international relations as regional or 
global powers. From the EU perspective, the search for recognition as a normative actor and for legitimacy is also intrinsic to the design of the SPs. Ultimately, as indicated in the introduction of this book, one fundamental reflection is on "whether the evolution of the SPs has strengthened the EU's self-conception as an international actor and thus whether the SPs have crystallized into an instrument to enhance the legitimacy of the EU's global role in times of transition" (see Chapter 1 of this volume: 1-17). In this context, the external and the identity logics set out in Chapter 2 provide valuable analytical purchase, since they emphasize the part played in the formation and development of SPs by external challenges and opportunities, and their interaction with considerations of identity and role.

Taking into consideration the asymmetries, geographical distance and low level of interdependence that characterize the EU-Mexico relationship, the SP and the modernization of the GA have provided evidence that both parties are able to face changing international conditions, focus on improving the performance of bilateral mechanisms, find gains through bilateral negotiations, and be resilient to enhance cooperation. In the particular case of the EU-Mexico SP, the key coincidental juncture of interests occurred when the economic and political redefinition of the Mexico project in the early 1990s aligned with the EU's priorities and goals embedded in the Maastricht Treaty. This coincidental juncture facilitated the negotiations of the GA and the SP.

Another aspect of the EU-Mexico relationship is the innovation of mechanisms for improving the bilateral relationship. This area tends to be problematic because the binary metrics of "achieved or non-achieved" goals conceal numerous variables that go beyond the political and normative nature of the SPs. The SPs set a milieu conducive for cooperation that entails the acknowledgement of mutual deontological goals and values, but which is always subject to discussion and even contestation as to the means to achieve them. However, the shared goals and values embedded in the SPs should be contextualized not only in a broader context of EU foreign policy but should also factor in the changing interest and preferences of EU partners. The evaluation of the SP between the EUMexico is hard to understand without considering the GA that predates it. The creation of bilateral dialogues responds to the changing preferences and willingness of both parties to bring issues to the bilateral agenda for discussion. A contrasting and compelling case is the SP partnership between the EU and Brazil. Emerson and Flores (2013) argue that 
that little or nothing concrete has been accomplished and the resulting picture is one of an uneasy economic bilateral relationship, with diminished prospects for further economic integration. The achievements in the EU-Brazil relationship have stagnated (Emerson and Flores 2013; Ferreira-Pereira, this volume) and this trend is likely to deepen in the light of the contesting views of President Jair Bolsonaro (since 2019) to European policies, mainly related to climate change and France. The comparison of both SPs brings to the forefront the argument that other EU policies as well as changing domestic preferences are quite significant elements to be considered in the evaluation of SPs, which are political and normative instruments.

The rationale motivating the establishment of a given SP has been studied elsewhere (Ferreira-Pereira and Guedes Vieira 2016). From the perspective of this chapter, two elements have been quite significant in the SP with Mexico. The first is the perception of a positive-sum game in an asymmetric relationship (Ferreira-Pereira 2016; Dominguez 2015). In this regard, the EU-Mexico relationship can be considered an exemplar of the absolute gains approach, where both parties pursue differentiated interests that do not necessarily collide nor compete, ultimately incentivizing cooperation. In contrast, the relative gains approach employs the zero-sum game logic where one party wins and the other loses, hence conflict inhibits cooperation (Dominguez 2003). Consistent with the absolute gains approach, when a conflict of perspectives emerges, it can be remedied through bilateral negotiation (Espana Arrieta 2007). The second driver has been the role of the United States in the relations between the EU and Mexico. In the early 1990s, NAFTA was a powerful incentive to strengthen the EU-Mexico relationship not only in trade but also regarding political dialogue and cooperation. After the US invasion of Iraq and the 2008 recession, the EU and Mexico found common ground on which to reinvigorate their bilateral relationship with the SP and the modernization of the GA. After the 2008 recession, the prospects for modernizing the GA gained traction after several sequential events took place in the United States. Among others these included the start (2013) and collapse (2016) of the negotiations for the Transatlantic Trade and Investment Partnership (TTIP) and the demand of the Trump Administration for renegotiating NAFTA, which eventually led to the signature (2018) and ratification (2019-2020) of the United States, Mexico and Canada Agreement (USMCA). 
All in all, the bilateral relationship shows resilience in adapting to the revisionist and contestation-oriented posture adopted not only by rising powers, notably China and Russia but also by the US. Despite geopolitical constraints and differentiated regional priorities, the modernization of the GA and the SP are emblematic of the adaptation of the EU-Mexico relationship to the changing international environment and to the challenges and opportunities it presents. During her last visit to Latin America and Mexico in her post as High Representative of the EU, Federica Mogherini met with Mexican Foreign Secretary, Marcelo Ebrard. After reiterating the shared narrative of values embedded in the SP, both officials were pragmatic in operationalizing the bilateral agenda by focusing on three objectives. The first is the conclusion of the negotiations of the modernized Mexico-EU Global Agreement; as has been explained in this chapter, this is a major driving force of the bilateral agenda. The second and third points of the agenda are a by-product of the unilateral tendencies of the United States under the Trump administration. On the one hand, in addition to the construction of the wall on the US-Mexico border, the US has pressured Mexico to stop the flow of Central American migrants. In support of the Mexican government, the EU has already mobilized 7 million euros to contribute to the Comprehensive Development Plan between El Salvador, Guatemala, Honduras, and Mexico that was presented by the Economic Commission for Latin America and the Caribbean (ECLAC) (Secretaría de Relaciones Exteriores 2019a). On the other hand, in the light of the increasing unilateralism of the United States, the EU and Mexico have focused on strengthening their collaboration for supporting multilateralism in the areas of human rights; the fight against xenophobia, racial discrimination and intolerance; gender equality; the rights of indigenous peoples; migration; the fight against corruption; reform of the WTO; G20-related issues; and steps to address the challenge of climate change (Secretaría de Relaciones Exteriores 2019a).

The institutions and practices in the EU-Mexico relationship have produced common ground for further and deeper cooperation that allows for the recalibration of shared strategies. The coincidence of worldviews, positive-sum game perspectives, and resilience has underpinned a stable relationship that will face two main challenges in the future. In the short term, the main challenge is to finalize the details of the modernized GA and submit it to the approval of the legislative bodies in Mexico and Europe. In the medium term, the continuation of strategies to ameliorate the impact of the increasing nationalism, populism, and nativism 
in regional and global arenas is of the utmost relevance for the two partners. Above all, the relationship will very likely continue a path of stability to address these two challenges based on current shared views and institutional practices between the EU and Mexico.

\section{REFERENCES}

Bosse, G., \& Korosteleva-Polglase, E. (2009). Changing Belarus?: The Limits of EU Governance in Eastern Europe and the Promise of Partnership. Cooperation and Conflict. Journal of the Nordic International Studies Association, $44(2), 143-165$.

Cîrlig, C.-C. (2012, September 26). EU Strategic Partnerships with Third Countries. Library of the European Parliament. Brussels.

Council of the European Union. (2008, December 11). Report on the Implementation of the European Security Strategy-Providing Security in a Changing World. Council of the European Union.

Council of the European Union. (2010). Mexico-European Union Strategic Partnership Joint Executive Plan. Spain: Comillas.

Del Río, F., \& Saavedra Cinta, R. (2018, enero-abril). Modernización de los capítulos de diálogo político y cooperación del Acuerdo Global México-Unión Europea. Revista Mexicana de Politica Exterior, 112, 33-48.

Delegation of the EU to Mexico. (2016). Visit of Federica Mogherini, VicePresident of the EC, to Mexico. Mexico City.

DG Trade. (2019). Mexico. EU Bilateral Trade and Trade with the World. Brussels: European Commission.

Dominguez, R. (2003). The European Union and Mexico: Discovering the new South of North America. Centro de Estudios Europeos-UNAM, I(2).

Dominguez, R. (2014). The Modernisation of the European Union-Mexico 'Global Agreement'. Directorate-General for External Policies of the Union. Brussels: European Parliament.

Dominguez, R. (2015). EU Foreign Policy Towards Latin America. New York: Palgrave.

Ecorys. (2015). Ex-post Evaluation of the Implementation of the EU-Mexico Free Trade Agreement: Interim Technical Report. Rotterdam: ECORYS Nederland BV.

EEAS. (2017a). EU Annual Report on Human Rights and Democracy in the World in 2017. Brussels: EEAS.

EEAS. (2017b). EU Annual Report on Human Rights and Democracy in the World in 2017: Country Reports Compilation. Brussels: EEAS.

EEAS. (2018, October 26). Mexico and the European Union Reaffirm Their Commitment to Human Rights (Joint Press Release). 
EEAS. (2019a, November 14). EU and Mexico hold High Level Meeting on Multilateral Affairs (Press Release).

EEAS. (2019b). The European Union's Global Strategy Three Years on, Looking Forward. Brussels: EEAS.

EEAS. (2019c, November 29). Iniciativa de Diálogo entre Think Tanks de la Unión Europea y México celebra el segundo encuentro. News Stories.

Emerson, M., \& Flores, R. (2013). Enhancing the Brazil-EU Strategic Partnership-From the Bilateral and Regional to the Global. Brussels: Center for European Policy Studies.

Espana Arrieta, O. (2007). El Acuerdo de Asociacion entre Mexico y la Union Europea: Nuevas oportunidades o nuevos retos. In J. Arroyo Alejandre, M. Romero Morett, C. Diaz Barrado, \& O. Espana Arrieta (Eds.), A siete anos de la firma del Acuerdo entre Mexico y la Union Europea (pp. 111-137). Guadalajara: Universidad de Guadalajara.

EU-Mexico Joint Parliamentary Committee. (2018, July 11-12). Joint Declaration of the 25th EU-Mexico Joint Parliamentary Committee.

EU-Mexico JPC. (2013). Draft Minutes of the 16th Meeting of the EU-Mexico JPC. Strasbourg: European Parliament.

European Commission. (2018). New EU-Mexico agreement: The Agreement in Principle and Its Texts. Brussels.

European Commission. (2019, October 14). EU Trade Agreements: Delivering New Opportunities in Times of Global Economic Uncertainties. News Archive. DG Trade.

Ferreira-Pereira, L. C. (2016). The European Union's Partnership Policy Towards Brazil: More Than Meets the Eye. Cambridge Review of International Affairs, 29(1), 55-77.

Ferreira-Pereira, L., \& Guedes Vieira, A. V. (2016). Introduction: The European Union's Strategic Partnerships: Conceptual Approaches, Debates and Experiences. Cambridge Review of International Affairs, 29(1), 3-17.

Harte, R. (2018). Modernisation of the Trade Pillar of the EU-Mexico Global Agreement. In European Parliamentary Research Service (Ed.), Briefing International Agreements in Progress. Brussels: European Parliament.

Hurd, I. (2019). Legitimacy and Contestation in Global Governance: Revisiting the Folk Theory of International Institutions. The Review of International Organizations, 14, 717-729.

Kavalski, E. (2016). The EU-India Strategic Partnership: Neither Very Strategic, Nor Much of a Partnership. Cambridge Review of International Affairs, 29(1), 192-208.

Le Clercq Ortega, J. A., \& Rodríguez Sánchez Lara, G. (2017). Global Impunity Dimensions: Global Impunity Index 2017 (GII-2017). Puebla: Fundacion Universidad de Las Americas. 
Office of the United States Trade Representative. (2020). United States-MexicoCanada Agreement. Washington, DC.

Renard, T. (2015, June 9). The EU's Strategic Partnership Agreements: Balancing Geo-Economics and Geopolitics. Commentaries.

Rodríguez-Piñero Fernández, I. (2018). Legislative train schedule of the European Parliament. Brussels: European Parliamentary Research Service.

Secretaría de Economía. (2019, mayo 8). Comercio Exterior/Países con Tratados y Acuerdos firmados con México. Comercio Exterior.

Secretaría de Relaciones Exteriores. (2019a, September 11). Mexico and EU Reaffirm Commitment to Strategic Partnership. Mexico City.

Secretaría de Relaciones Exteriores. (2019b, December 1). Mexico and the EU as Strategic Partners. Mexico City.

Secretaría de Relaciones Exteriores. (2019c). Mexico-EU Global Agreement. Mexico City.

Snyder, J. (2019, March/April). The Broken Bargain: How Nationalism Came Back. Foreign Affairs.

SRE. (2018). 5th Mexico-EU High-Level Political Dialogue. Mexico City.

Titievskaia, J., \& Pietsch, M. (2018). United States-Mexico-Canada Agreement (USMCA): Potential Impact on EU Companies. At a Glance. Brussels: European Parliamentary Research Service.

Villarreal, M. A. (2017). Mexico's Free Trade Agreements. Washington, DC: Congressional Research Service.

Whitehead, L. (1997). Pobre México, tan lejos de Noordwijk: Las relaciones políticas entre México y la Unión Europea vistas desde Europa. In La Unión Europea y México: La nueva relación política y económica (pp. 35-65). Madrid: IRELA. 


\title{
The EU's Strategic Partnerships with Japan and South Korea: A Comparative Analysis of the Drivers, Outcomes and Limitations
}

\author{
Elena Atanassova-Cornelis and Bruno Hellendorff
}

\section{INTRODUCTION}

The European Union's $(\mathrm{EU})^{1}$ drive to integrate its foreign policy instruments is a product of its own institutional evolution, external circumstances and a growing necessity to satisfy identity needs in times of crises. These three logics (internal, external, identity), as examined in Chapter 2

${ }^{1}$ This chapter uses the EU and Europe interchangeably with reference to the Union. The analysis does not include an examination of the individual MS' relations with Japan and the ROK, which have not been supplanted by the EU's bilateral partnerships with these two countries.

E. Atanassova-Cornelis $(\bowtie)$

University of Antwerp, Antwerp, Belgium

e-mail: elena.atanassova-cornelis@uantwerpen.be

B. Hellendorff

Université Catholique de Louvain, Ottignies-Louvain-la-Neuve, Belgium

(C) The Author(s), under exclusive license to Springer Nature

Switzerland AG 2021

L. Ferreira-Pereira et al. (eds.), The European Union's Strategic

Partnerships, The European Union in International Affairs, https://doi.org/10.1007/978-3-030-66061-1_13 
of this volume, clearly find their expression in how Strategic Partnerships have been imagined, negotiated and implemented by the EU. By exploring the evolution of Europe's partnerships, including with countries in the Asia-Pacific, one can discern changing patterns, consolidating practices and shifting images of EU diplomacy.

With the Treaty of Lisbon, which entered into force in 2009 , the Union received the mandate to negotiate free trade agreements (FTAs), as well as to protect common values and diplomatic interests on a more solid basis than before. From then on, FTAs became a crucial component of the EU's foreign policy portfolio. "New generation" FTAs cover more than just trade. In 2015, the European Commission announced a new trade strategy, one that uses "trade agreements and trade preference programmes as levers to promote around the world values like sustainable development, human rights, fair and ethical trade, and the fight against corruption" (DG Trade 2015). The first of these so-called new generation FTAs was signed with South Korea (Republic of Korea, ROK) in 2011. The biggest trade agreement, and the first to include a commitment to the Paris Climate agreement, was signed with Japan in 2018. With both Japan and Korea, accompanying agreements on political cooperation (as well as security cooperation with the ROK) have been negotiated and signed.

The EU's partnerships with Japan and the ROK are emblematic of some important changes that the Union's strategic partnerships have gone through. They both represent a strong signal that Europe has risen to contemporary global geoeconomic challenges. Strategic partnerships are also an expression of the EU's diplomacy, which has grown more convincing and successful in harnessing the bloc's political strength. Equally important, they show that identity imperatives are shaping strategic partnerships in a way that is increasingly cross-cutting and value-based. At the time of their signing, the deals reached with Japan and South Korea were the most visible embodiments of the EU's Global Strategy ambition to develop a "more joined up" external action and, more specifically, a "politically rounded approach to Asia" (European External Action Service 2016: 11, 38).

Admittedly, diverging perspectives and policy interests have also been part of the EU-Japan and EU-ROK partnerships, and in neither case was the negotiation of such ambitious agreements easy. The flagship deals they each gave birth to emerged in large part due to a fast-changing strategic environment, both in the Asia-Pacific and globally. Behind the veneer 
of "like-mindedness" - a term used to characterise both the EU-Japan and EU-ROK partnerships (European Council 2018; European External Action Service 2019) - there is therefore a need to consider their drivers, as much as their outcomes and limitations, in order to assess the images of the EU's strategic partnerships in Asia and the world.

This chapter sets out to do just that, examining in a comparative manner the EU's partnerships with Japan and South Korea, with a particular focus on security cooperation from 2009 (the entry into force of the Lisbon Treaty) to 2019. It builds upon the existing academic literature on the EU's strategic partnerships, while adding two new and critical elements: firstly, few comparative analyses have been published on the EU's strategic partnerships, especially with the so-called "like-minded" partners. Secondly, this chapter capitalises on conversations with policymakers in Brussels, Tokyo and Seoul; it, therefore, examines not only foreign policy choices, but also the perspectives of those who negotiated the actual agreements. Both elements offer together a striking image of the EU's Asia policy and its reception in a region that is becoming ever more central in both great power rivalry and global economic relations.

Finally, this chapter reinforces the argument that strategic partnerships, while institutionalising cooperation at the highest level and introducing common language in specific relationships, are neither straightforward nor self-sustaining. Indeed, as the drivers of the different partnerships vary from country to country, strategic partnerships evidently evolve in "differing ways and to differing degrees" (Ferreira-Pereira and Guedes Vieira 2016: 2). The EU's strategic partnerships with Japan and South Korea are an illustration of this.

\section{Drivers of "STRATEgising”}

\section{The EU, Japan and ROK: A Comparison of Critical Drivers}

From the perspective of the EU, a strategic partnership is characterised by a normative congruence, is built upon common interests, and is multidimensional-it includes both politico-security and economic objectives, and has a strong regional/global impact (Reiterer 2013). Brussels' strategic partnerships with Japan and South Korea are firmly anchored in their mutual perceptions of "like-mindedness" in terms of shared values, such as democracy and the rule of law, as well as common interests related to global peace and stability (EU-Japan Summit, EU-ROK 
Summit, various years). Indeed, there are abundant references in the EU's official documents and statements to Japan and the ROK, respectively, as "like-minded" countries. As the shared liberal democratic principles provide "an external confirmation of internal [European] values" (Kelly 2012: 112), these two strategic partnerships may be regarded as an opportunity for the EU to strengthen its global identity as a normative power and leverage that into performance of a specific set of roles in the global arena.

Increased concerns about European stability, in both the economic and security areas, have become a defining feature of the thinking of Brussels' strategists from 2010 onwards, leading to the growing importance of strategic partnerships in the EU's foreign policy (Ferreira-Pereira and Guedes Vieira 2016). EU's strategic anxieties became explicit in the 2016 Global Strategy, manifesting themselves in the Union's perception of being "under threat", due to "violation" of the European security order "to the East" (European External Action Service 2016: 7), most notably by Russia. The 2014 Russian annexation of Crimea and the ongoing conflict in Ukraine, as well as the instability in North Africa and the Middle East, have exposed the fragility of the European neighbourhood. The debate in Europe has increasingly focused on the existing means to prevent and respond to violations of international legal standards, and the possible partners to engage with in defending the established norms and rules (Raine and Small 2015). It is in this context that the strategic partnerships with both Japan and the ROK have come to occupy a higher place on the EU's foreign policy agenda since 2010.

Additionally, at the global level, developments such as China's Belt and Road Initiative (BRI), announced in 2013, which emphasised foreign investments in infrastructure development, put a premium on economic cooperation as part of a wider effort aimed at reconfiguring governance rules at different levels (bilateral, regional, global). The pledge of the People's Republic of China (PRC) to commit close to a US\$1 trillion in foreign investments to recreate the ancient "Silk Roads" has attracted considerable international attention, including in Europe. In particular, Beijing's BRI served as an additional push for Brussels to re-evaluate the Union's overall foreign policy agenda and external partnerships, with a renewed focus on Asia (see, e.g., Biscop 2019; Hellendorff 2019; Cottey in this volume). 
For Brussels, the EU-ROK and EU-Japan partnerships provide an opportunity to bolster its political and security credentials in the AsiaPacific, as the EU's image in that part of the world still remains largely defined in economic terms. Indeed, the Union's perception of itself as a "strategic player" in Asia diverges from the way many Asian players, including Japan and the ROK, perceive the EU (Atanassova-Cornelis 2015 b , 2019). With both countries, the EU also sees vast potential to cooperate as like-minded partners on a range of issues, both regional and global, politico-security and economic. These include, notably, engaging China and ensuring its rise as a status-quo player, working to achieve a peaceful resolution of the Democratic People's Republic of Korea (DPRK) nuclear issue, countering the US trade war narrative, promoting multilateralism and a rules-based international order. ${ }^{2}$

For their part, Tokyo and Seoul have each sought to upgrade their respective partnerships with Brussels, as since the late 2000s both have diversified their foreign and security policies due to growing perceptions of being in a "fragile" position in Asia's security environment. This is related, in particular, to strategic uncertainties associated with the future of their respective military alliances with the US, notably the sustainability of Washington's security commitments, as well as China's regional ambitions and the shifting regional balance of power, more broadly (Richey 2017; O'Hanlon 2018; Atanassova-Cornelis 2019; Atanassova-Cornelis and Sato 2019).

Security and economic overreliance on America and the PRC, respectively, intensifying US-China rivalry and major shifts in the DPRK-US relations under Donald J. Trump have driven Japan's and Korea's search for alternative partners. Although the EU is not able to replace the US as a security provider, a partnership with Brussels is nevertheless seen in both Tokyo and Seoul as an opportunity to diversify their respective foreign policies away from the US (Richey 2017; Atanassova-Cornelis 2019). Equally important is the perceived necessity to reduce their economic overdependence on the PRC — an important component of both Japan's and the ROK's strategic thinking on the EU. However, as will be demonstrated later in this chapter, the specific policy preferences of Tokyo and Seoul vary, even though the "strategic" dimension of their respective relationships with Brussels is similar in origin.

\footnotetext{
2 Authors' discussions with European policymakers under the Chatham House rules, Brussels, September-October 2019.
} 


\section{Japan: Strategic Considerations}

In the first place, China's rise has been perceived in Japan as a multi-dimensional and long-term challenge to Japan's strategic interests, namely, in the geoeconomic, political and security dimensions (Atanassova-Cornelis 2018). With the relative decline of the US, Japan's concerns about the continuity of America's defence commitments to Japan (and the security of the Asia-Pacific region more broadly) have intensified. Therefore, Japan has prioritised in its foreign policy, in addition to its alliance with Washington, the establishment of new, or the reinforcement of the existing, strategic partnerships both in Asia and beyond (Wallace 2013; Atanassova-Cornelis 2019). Secondly, Japan saw a stabilisation of the domestic political situation during Prime Minister Shinzo Abe's second term in office (2012-2020). ${ }^{3}$ Japan articulated and pursued a clear foreign policy and economic agenda, the latter known as Abenomics. With regard to Japan's foreign policy, Abe promoted a policy of "pro-active contribution to peace" (Prime Minister of Japan and His Cabinet 2013). The justification for Japan's move towards security activism included the so-called severe security environment that Japan faced and the Abe administration's belief that the international community expected Japan to step up its role as a provider of global peace and stability.

Finally, and related to the above, the tackling of various security challenges at the regional and global level necessitates, from Tokyo's perspective, a coordinated and multilateral approach, as they can not be dealt with by a single country alone (Ministry of Defence, Japan 2018). These include, at the regional level in Asia, the nuclear and ballistic missile (BM) developments of the DPRK, and the strict enforcement of the UNSC sanctions; the implications of China's rise, seen in its "unilateral, coercive attempts to alter the status quo" in the East China Sea, the maritime territorial disputes in the South China Sea with associated concerns about the stability of the Sea Lines of Communication (SLOCs); and the preservation of the rules-based maritime order in the IndoPacific. At the global level, terrorism, environment and climate change are seen as priority challenges by Japan. Against the above background,

\footnotetext{
${ }^{3}$ Abe's first term in office was in 2006-2007. Between 2006 and 2012, there were six prime ministers in Japan. Each of them stayed in office between 9 and 12 months. Abe resigned in September 2020 and was succeeded by Yoshihide Suga.
} 
the EU is perceived as a partner that both appreciates Japan's expanded international security role and assists Japan in its pursuit of global responsibilities, while also engaging with Tokyo in the joint preservation of the rules-based international order (Atanassova-Cornelis 2019).

\section{ROK: Strategic Considerations}

Strategic considerations in the ROK have long focused on the country's volatile regional environment and trade-reliant (especially on China) economy, requiring a strong security relationship with the US (Snyder 2018). As observed by O'Hanlon (2018: 105), geopolitical considerations associated with a possible "abandonment" by its US ally, which would leave Korea alone "next to a country with 20 times the population and 40 times the size of even a reunified peninsula", reinforce the longterm value to Seoul of the ROK-US alliance. A good relationship with the US is also seen as necessary not only to face China, but also in the context of Korea's difficult political relationship with Japan. While Seoul is indeed concerned about Beijing's assertive behaviour in the region, it does not perceive the PRC as a strategic threat to the extent that Japan does (Sakaki and Nishino 2018). Instead, historical grievances vis-a-vis Japan continue to weigh against any meaningful trilateral security cooperation with Washington and Tokyo. Despite the PRC's ambivalent position on the issue of future reunification of the two Koreas, for the ROK, which remains preoccupied with the DPRK's military threat and the divided peninsula, the PRC is seen primarily as an indispensable player on the Korean Peninsula (Sakaki and Nishino 2018).

At the same time, as South Korea's economy is heavily dependent on China, the implications of China's macroeconomic policy represent a growing source of concern. In a South Korean diplomat's words, as long as Korea-China relations were based on economic co-prosperity, Seoul was not very concerned about them, but "now, this is a different era" and "the China issue is becoming more important". 4 The possibility of Beijing resorting to policies of economic coercion vis-a-vis Seoul was strikingly illustrated in 2017 when China retaliated against the ROK's decision to allow the deployment of the US Terminal High Altitude Area Defence (THAAD) missile defence system in South Korea. Chinese

\footnotetext{
4Authors' conversation with a South Korean diplomat, Brussels, November 2019.
} 
authorities adopted punitive economic measures such as massive cancellation of Chinese tour groups visits to the ROK. The South Korean retail giant Lotte, which had heavily invested in the Chinese market, was hit by punitive measures in reaction to its decision to cede the land where the THAAD missile defence system would be based. The losses incurred by Lotte were so high that the conglomerate all but left the Chinese market (Lee 2019; Asia News Network 2019).

Predating these developments, already in the 2000s there had been support in South Korea for a diversification of its economic partnerships to maintain the country's growth. The conservative Lee Myung-bak administration (2008-2012) was intent on pursuing a chaebol-friendly "Global Korea" strategy and developing partnerships worldwide (Sakaki and Nishino 2018), including with the EU.

Another key driver of South Korea's strategic thinking is the DPRK's weapons of mass destruction (WMD) programme. In 2016 and 2017, Pyongyang took dramatic steps to anchor its self-professed nuclear power status in reality: it conducted a series of ballistic missile tests, including intercontinental missiles, as well as nuclear tests. In this context, SeoulBrussels security discussions had as a priority the implementation of UN Security Council (UNSC) sanctions and applying pressure on North Korea.

Overall, strategic considerations in the ROK included the position of the EU as a major market for its exports, an economic powerhouse and a diplomatic partner. With new provocations from the DPRK and a growing anxiety over the course of China's rise came new opportunities for a strategic rapprochement. These opportunities were seized over the course of more than a decade, with the result being a considerable strengthening of EU-Korea relations since the 2008 global financial crisis.

\section{From Cooperation to Strategic Partnership}

\section{The EU-Japan Case: Evolution and the Role of Conjuncture}

Among the EU's strategic partnerships in Asia, this bilateral partnership is the most institutionalised. Indeed, the political dialogue was institutionalised back in 1991 with the signing of the Joint Declaration on Relations Between the European Community and Its Member States and Japan. In addition to the growing trade relations, and differently from Europe's 
partnership with the ROK, since the 1990s Japan and the EU have developed substantial security cooperation. This is primarily in non-traditional or "soft" security areas, such as development, climate change, and conflict prevention and peace-building.

For example, since 2010 Japan and the EU have been holding a Development Policy Dialogue. The dialogue seeks to achieve a better bilateral coordination on aid and development effectiveness, and places a special emphasis on regional development issues in Africa and Asia. Tokyo and Brussels have also cooperated in non-military crisis management and postconflict reconstruction based on their shared view of the need for a comprehensive approach in this area (Atanassova-Cornelis 2019). Some of their initiatives since the 2000s include joint promotion of the peace process in Sri Lanka, as well as the rebuilding of the Western Balkans, especially Bosnia-Herzegovina and Kosovo. More recently, the two have cooperated in capacity building missions in Mali and Congo, and for security improvement in Niger. Cooperation in Somalia has been identified as a possible future area. In 2014, Japan and the EU carried out their first joint counter-piracy exercise between deployed units of the EU's Naval Force (EU NAVFOR) Somalia-Operation ATALANTA and Japan's Self-Defence Forces. Against this background, maritime security, especially capacity building and anti-piracy collaboration, has emerged as a promising future area for EU-Japan security cooperation.

Regional geopolitical issues in Asia and Europe have become more prominent on the EU-Japan agenda from 2013 onwards. While China is not mentioned explicitly, the Joint Statements underscore shared EUJapan concerns about instability in "East Asia's maritime areas" and about "unilateral actions that change the status quo and increase tensions", stressing that maritime disputes should be resolved peacefully and in accordance with international law (EU-Japan Summit 2013, 2014, 2015). The EU's tensions with Russia are emphasised as well: it is argued that Tokyo and Brussels "remain determined never to recognise the illegal annexation of Crimea by the Russian Federation" (EU-Japan Summit 2015).

Given the substantial level of EU-Japan security cooperation, which has been built on solid political and economic ties, it is not surprising that Tokyo and Brussels have referred to each other as "strategic partners" since the early 2000s. However, the actual drive to "codify" this in a binding agreement emerged in the 2010s and negotiations commenced in 2013. Compared to the EU-ROK negotiations (discussed below), the 
process took much longer. Hurdles between Brussels and Tokyo were numerous, related, among others, to domestic sectors in Japan (such as agriculture) and divergences in specific areas (such as over the death penalty).

The signing in 2018 of the two EU-Japan partnership agreements-a political, Strategic Partnership Agreement (SPA) and an Economic Partnership Agreement (EPA), i.e. an FTA-has been more a product of conjuncture than in the case of the EU-ROK partnership. Since 2017 Japan has found itself somewhat isolated in Asia. The reasons for this are primarily geopolitical and geoeconomic in nature. They include the uncertainties of the Trump administration's Asia policy, developments on the Korean peninsula, Tokyo's souring relations with Seoul and the challenges brought about by China's BRI on Japan's regional standing. This has been in addition to the mixed results of the "Abenomics" programme. The fear of further regional marginalisation, as well as the perceived danger of America's protectionist policies, have provided a strong impetus for Tokyo to reach out to the EU. ${ }^{5}$ The main catalyst for the finalisation of the negotiations in 2018 was Trump's decision to pull the US out of the Trans-Pacific Partnership (TPP) agreement in early 2017 and his "trade war" threats, more broadly. Hence the agreement came later than the one with the ROK.

In the security area, Tokyo has continued to invest substantial resources in the reinforcement of its alliance with Washington and has increased its burden-sharing within the alliance, not least in response to Trump's pressure on America's allies (in both Europe and Asia) (Atanassova-Cornelis and Sato 2019). Japan under Abe also prioritised the strengthening of its relations with countries in Asia that share Tokyo's concern about China's strategic rise, such as India, Vietnam and Australia. From Japan's perspective, Europe pursues a one-sided engagement policy towards the PRC (Atanassova-Cornelis 2019). The Union's primarily trade-based approach towards Asia, largely driven by the "China opportunity" perception, hinders Europe's relevance for Japan as a strategic partner; indeed, despite the shared interests and democratic values (Atanassova-Cornelis 2015a)

Although the EU approached its relations with Japan with more caution, ${ }^{6}$ it was happy to finally sign these long-awaited deals with one of

5 Authors' personal communication with Japanese policy-makers.

${ }^{6}$ Authors' personal communication with EU policy-makers. 
its most important (economically and politically) strategic partners. While both Brussels and Tokyo stressed their shared commitment to a fair, rulesbased international order, their long collaboration on political, security and economic issues of common interest, and the natural evolution of their partnership towards this kind of agreement, ultimately, conjuncture played an important role in the actual signing of their strategic partnership. Although European strategy played a rather minimal role, it cannot be asserted that the EU was simply reactive in this process either. By and large, it is the managerial image of the strategic partnership (as detailed in Chapter 2 of this volume) that has emerged from a specific conjunction of factors in this case.

\section{The EU-ROK Case: A Matter of Strategic Choice and Negotiation}

In 2007, the European Commission was authorised by the EU member states to begin negotiations with South Korea on an FTA. In 2010, the EU and South Korea agreed to a Framework Agreement (FA) that would consolidate their political relationship, which was then elevated to a strategic partnership. In 2011, they agreed to an ambitious FTA, which scrapped almost $99 \%$ of duties on both sides. ${ }^{7}$ The $2008-2009$ financial and economic crisis had played an important role in bringing Seoul closer to Brussels with a view to facilitating trade and upholding a shared global liberal agenda. A mere three years later, the FA entered into force, covering many areas of cooperation including human rights, nonproliferation, combating terrorism, energy, climate change, agriculture. Finally, in 2014, they signed another agreement, destined to facilitate South Korea's participation in European crisis management missions: the Framework Participation Agreement (FPA). By 2017, the South Korean Navy had contributed a destroyer to the EU's anti-piracy operations off the coast of Somalia, EU NAVFOR Somalia-Operation Atalanta. Together, the FTA, FA and FPA constitute the triad of agreements that the EU is negotiating with strategic partners in the post-Lisbon Treaty era (Minard 2014).

With all three agreements signed, this EU-Korea strategic partnership is in many respects trailblazing. The main catalyst was the EU's and ROK's shared willingness to sign an ambitious, first-of-a-kind

${ }^{7}$ The EU-ROK FTA was provisionally applied from 2011 and officially entered into force in 2015 . 
deal. Progress was faster than in the EU-Japan case and bilateral EUROK negotiations encountered fewer hiccups. This pleads for a greater weight of internal factors as shaping forces in the EU-ROK relationship (compared to the EU's partnership with Japan), and a more strategic image of the partnership. At the same time, the managerial image of EU diplomacy was not completely absent from the process either: several bilateral issues of common interest such as trade, development, climate change, human rights and non-proliferation made the negotiations smoother. Although the ROK was interested primarily in engaging the EU on trade, it was also motivated by the growing potential for collaboration with Europe on issues of global concern.

For the Park Geun-hye administration (2013-2017) implementation of the FTA was a priority. The Moon Jae-in administration defends a similar agenda, but it also fights an uphill battle to create jobs and improve wages at home (Kim and Roh 2018). This partly explains why outstanding issues remain in terms of implementation, notably pertaining to South Korea's delays in ratifying fundamental International Labour Organisation Conventions. Despite pressure from the EU to further upgrade the FTA, appetite for new negotiations in Korea appears limited. ${ }^{8}$

The analysis illustrates that the EU-ROK partnership is largely rooted in shared structural interests These include external drivers, such as upholding a rules-based international order, promoting free trade and deepening security collaboration. At the same time, the relevance of internal factors should not be underestimated either. These include a strong appetite by policymakers and diplomats, backed up by adequate legislative and administrative means, to reinforce bilateral cooperation.

The ROK was eager to conclude these agreements with the EU as they were in line with the government's political line. For the EU, on the other hand, it was critical to reach an ambitious agreement with an Asian partner and demonstrate that it could leverage its economic weight for political and diplomatic gains. However, political evolutions have since made the partnership less straightforward: for instance, with the thawing inter-Korean relations in 2018 and 2019, and the major effort exerted by the South Korean Presidency to support a diplomatic solution to the current impasse, disagreements over priorities and methods

\footnotetext{
${ }^{8}$ Authors' conversations with European and South Korean diplomats, Brussels, September 2019, Seoul, November 2019.
} 
emerged with the EU. ${ }^{9}$ When President Moon Jae-in visited Brussels for a Summit in October 2018, he appeared surprised that he could not convince European countries to adopt a flexible stance on sanctions against North Korea (Ryall 2018). A surprise that appeared "surprising" to European diplomats, who had long warned their South Korean counterparts that the DPRK issue was a question of principle for the EU. ${ }^{10}$ An issue that was attributed by some observers to the perceived suspicion of the Moon administration vis-à-vis conservative institutions such as the Foreign Ministry (see, e.g., Green 2019). This shows the prevalence of the third logic in driving the strategic partnership: identity (Chapter 2 in this volume). Both the EU and the ROK have used their partnership to feed a distinct political narrative, and reinforce an international identity they each have conceived of as being a "constructive member of the international community".

\section{Agreements: SignificAnce AND Limitations}

\section{Significance of the Strategic Partnerships}

As this chapter demonstrates, a convergence of views and interests between the EU and its two strategic partners in Asia has resulted since the early 2010s in the signature of much-anticipated EU-Japan and EU-ROK comprehensive agreements.

The EU-Japan agreements are more recent, yet have a greater scope. To be sure, the industry and political actors on both sides are very hopeful. The SPA is perceived as an important aspect of the bilateral partnership, especially on the EU side (the same as in the EU-ROK case) (Hellendorff 2018). By and large, however, it is the managerial image of the partnership that has gained most momentum: the EU's relationship with Japan evolved from an overall understanding of each other's perspectives and divergence in specific sectors to a close alignment of policy interests and shared concerns. A partnership on connectivity-the first of its kind-was signed on the occasion of Prime Minister Abe's visit to

\footnotetext{
9 Authors' conversations with European and South Korean diplomats under the Chatham House rules, Brussels, February, September and October 2019; Seoul, November 2019.

${ }^{10}$ Conversations of the authors with European diplomats under the Chatham House rules, Brussels, October 2019.
} 
Brussels in October 2019, heralding more cooperation on infrastructure development (and other sectors). A potential FPA between Japan and the EU, along the lines of the EU's agreement with South Korea, would likely provide a further boost to the existing EU-Japan security collaboration, enabling Japanese Self-Defence Forces to participate in CSDP's civilian (and possibly military) missions and operations. At the moment, however, neither Tokyo nor Brussels seems to see an urgency in formalising such an arrangement.

It is likely that the political agreement between Japan and the EU will be more important at the global level, especially in relation to upholding the rules-based international order and non-traditional security cooperation, than at the regional level in the Asia-Pacific where, as mentioned earlier, the EU is not perceived by Japan as a major security player (Atanassova-Cornelis 2019). The driver of the bilateral Japan-EU FTA has been at the global level, too. Indeed, this agreement institutes a trading bloc of global significance and represents a more important symbol of liberal policy in a global environment where protectionist trends, most notably manifested in Trump's trade policies, have been on the rise.

Of the three EU-ROK agreements, the FTA is by far the most meaningful, in that it represents the first "new generation" agreement negotiated by the EU and the first of this kind signed with an Asian partner. Similarly, the FPA is another first for the Union, and the only one with an Asian country to allow participation in CSDP's missions (Richey 2017).

The EU-Korea FTA has been considered "an economic success story for both sides" (EEAS 2018). It included wide-ranging provisions on tariffs and non-tariff barriers, and effectively boosted trade: between 2010 and 2018, EU exports of goods to Korea increased by $43 \%$ to $€ 49.2$ billion while Korean exports of goods to the EU rose from $€ 39.5$ billion to $€ 51$ billion (Civic and Ifo 2018). Supply chains have also become much more integrated. Lots of tariffs (quasi all) and non-tariff barriers have been abolished. For their part, the political and framework agreements are perceived as an important signal of deepening EU-Korea cooperation, and one to update, given the recent developments in Asia and the world (not least trade war threats coming from Washington). Sectoral cooperation is pretty much on track, with little impatience to drastically change the framework, or to do much more than is already the case. 
In the security area, however, the bilateral EU-ROK relationship has moved from a close alignment, on issues such as the DPRK's nuclear programmes, to a growing divergence, notably related to the Union's determination (similarly to that of the US and Japan) to keep the UNSC sanctions in place. This stands in contrast to the EU-Japan relationship, where strategic convergence on the DPRK and shared concerns about the rules-based (maritime) order have facilitated cooperation, despite the lack of a formal security agreement. In Seoul, Europe's policy is more and more seen as diverging from the Moon administration's focus on engagement of the DPRK. Moon's approach brings Korea closer to China, as Beijing has continued to emphasise policies of engagement towards Pyongyang and has supported the gradual lifting of the UNSC sanctions. Again, this shows the importance of the logic of identity as a shaping force in these processes.

An important last point is that cooperation with Japan and South Korea in multilateral forums has been very productive in the last few years, and the agreements that underpin both strategic partnerships have played a role in facilitating this convergence. For instance, in the framework of the Asia-Europe Meeting (ASEM) or the ASEAN Regional Forum (ARF), EU, South Korean and Japanese diplomats typically find their interests aligned and sometimes even meet informally—alongside others-as "likeminded" partners. ${ }^{11}$ Here, too, this shows that a specific image has taken more room than the others in defining the form of the EU's two Strategic Partnerships in Asia: the managerial image.

\section{Limitations of the Strategic Partnerships}

Having established external, internal and identity factors as key determinants of the EU's Strategic partnerships in Asia, and their relative importance, it is now possible to look at the potential evolution of the EU's strategic partnerships with Japan and South Korea. In all, the likelihood of them moving beyond the economic and declaratory politics to include security cooperation that would be perceived as "strategic" by Japan and the ROK is likely to face important constraints in the years to come.

${ }^{11}$ Authors' experience with ASEM and ARF meetings, 2017-2019. 
Both Tokyo and Seoul will remain preoccupied with Asian-Pacific geopolitical issues: for Japan, these are the rise of China and the DPRK's military threat, while for the ROK-the divided Korean peninsula and related concerns about peninsular instability. Japan and South Korea will, therefore, each continue to prioritise their respective alliances with the US, which will evidently limit the diplomatic and military resources that Tokyo and Seoul will be willing, as well as able, to devote to their respective partnerships with Brussels.

Equally important will be the EU-associated limitations. These constraints include deficiencies in hard power projection capabilities and the Union's limited involvement in Asia's core areas of geopolitical tension, notably, the Korean Peninsula, and the maritime territorial disputes in the East and South China Seas-theatres of geostrategic importance for Japan and South Korea. Indeed, the Asia-Pacific is not a main geographical area of Brussels' foreign policy. Understandably, this means that Europe is not willing and/or able to divert military and diplomatic resources away from areas "closer to home" (such as the Mediterranean, North Africa or the Middle East). Additionally, there are institutional constraints related to the Union's inability to speak "with one voice". These constraints are reinforced by Europe's prudent approach towards such sensitive, for China, issues as cross-Strait relations between China and Taiwan, the South China Sea disputes, or Beijing's repressive measures adopted in Xinjiang and Hong Kong-where democracy-related protests of unprecedented scale and duration erupted in 2019 in reaction to the introduction by the city government of a bill allowing extradition to the mainland.

The EU's position on the maritime territorial disputes in Asia is one of "principled neutrality" with an emphasis on encouraging dispute resolution in accordance with international law (Council of the EU 2012: 19). The EU's reluctance to be more outspoken on these issues reflects the "China factor" in its Asia policies. It is Brussels' relationship with Beijing, as argued by Richey (2017: 6), that is "the big obstacle" to the Union's more substantial contribution to Asian security and regional order. Indeed, many Asian observers tend to agree that fears of negative implications for European business interests in China are the actual driver of the EU's perceived “timidity" (Berkofsky 2014) on Asian geopolitical issues. This reinforces the long-standing argument that, for the EU in Asia, its economic interests trump geopolitical ones (Atanassova-Cornelis 2019). 
The EU's response to the 2016 international arbitration ruling on the "Philippines versus China arbitration case" is illustrative of the above-mentioned limitations. After three days of internal disagreements among EU members states, Brussels succeeded in issuing only a carefully worded statement on the South China Sea. There was no mentioning of China and the Union merely "acknowledged" the court's decision. This outcome was largely due to the unwillingness of countries such as Hungary and Greece, which rely on trade and investments from China, as well as Croatia and Slovenia, which have their own maritime dispute, to criticise Beijing and bring about possible retaliatory measures by the PRC.

While the EU has since reviewed its China strategy, and has become more strategic in its outlook towards both China and the Asia-Pacific region (Hellendorff 2019), its perceived "timidity" has raised questions in Tokyo (and in various Asian capitals) about the EU's ability and willingness to support the integrity of the rules-based international order, but, more critically, of the Union's value as a "strategic partner". From Tokyo's perspective, therefore, the likelihood of the EU-Japan partnership's "strategic" impact in the Asia-Pacific in the foreseeable future, a region characterised by power politics, is rather low (Atanassova-Cornelis 2019). This, alongside Japan's existing limitations on military force projection, can help in explaining why, despite extensive bilateral security cooperation, the EU-Japan strategic partnership does not (yet) include an FPA. The SPA with the EU is unlikely to become a foreign policy priority for Japan. This does not, however, minimise the importance to Japan of the economic and soft security dimension of their bilateral cooperation, especially at the global level. The ongoing COVID-19 pandemic provides one such opportunity for strengthened EU-Japan cooperation.

For Korea, the picture is more mixed. On the one hand, a strong convergence of views has led to early successes. From 2011 onwards, the implementation of existing agreements has been a priority in the relationship, trumping any meaningful addition to the strategic partnership. Several factors have kept Korea focused on its immediate neighbourhood and alliance with the US, thus limiting the resources that Seoul has been able to allocate to developing partnerships with distant players such as the EU. These factors include a complicated and deteriorating relationship with Tokyo (including historical grievances), territorial disputes (with Japan, China and the DPRK) and, of course, changing inter-Korean relations. Since 2018, the Moon administration has displayed signs of 
frustration over the EU's strong views on sanctions implementation against North Korea. Additionally, the South Korean political landscape has experienced a meaningful swing with the election of Moon Jae-in, resulting in a somewhat different outlook on economic reforms, diplomacy and alliances. The EU appeared, in this context, as less of a priority, and more of a partner to seek diplomatic support from, as President Moon has continued with his perilous balancing act between Pyongyang and Washington. Such a perception gap can at least partly explain why the EU signed a connectivity partnership with Japan before Korea, despite the latter's similarly great interest in infrastructure development.

With a European support perceived to be less straightforward than expected, and a foreign policy agenda focused on inter-Korean relations, the South Korean government related to its strategic partnership with the EU more as a diplomatic acquis than as an operational platform. Whether a drastic change in outlook vis-à-vis North Korea, or political changes in either Brussels or Seoul can bring both partners closer to each other, remains to be seen.

\section{ConCLusions}

Japan and Korea exhibit similarities in terms of geopolitical and geoeconomic interests and concerns, which have largely driven their respective overtures to the EU. Both are core US allies, highly dependent on Washington for security protection. Both have been increasingly concerned about America's possible disengagement from Asia, hence, seeking to diversify their foreign and security policies. Japan and Korea also share similar anxieties related to their economic overdependence on China, as the PRC is their largest trading partner. They have been eager to maintain a rules-based international order and have been dissatisfied with America's turn away from economic multilateralism under Trump. So a strengthened political and economic partnership with the EU has been seen in both countries as a means to address these challenges.

At the same time, as demonstrated in this chapter, the rationale for the actual institutionalisation of the strategic partnership has differed. While Japan and the EU started to refer to each other as "strategic partners" in the early 2000s, on the back of growing bilateral politicosecurity cooperation, they only formalised their partnership in 2018. This arguably reflected an evolutionary process, although conjuncture played a key role. With South Korea, on the other hand, the partnership seemed 
to be more a matter of negotiation and a strategic choice. The institutionalisation of the EU-ROK strategic partnership moved faster (than was the case of the EU-Japan partnership) and was completed by the mid-2010s, even though the mutual EU-Korea perception as "strategic partners" was apparently less forthright. Not surprisingly, the dynamics of EU-Japan and EU-ROK relations have experienced different trajectories since the conclusion of the strategic partnership. Indeed, Brussels' cooperation with Seoul has remained largely focused on implementation issues. Cooperation with Tokyo, on the other hand, has been re-energised. A manifestation of this was the decision by the EU and Japan to initiate a partnership, dedicated to the relatively new and transversal issue of "connectivity", merely seven months after the entry into force of their EPA. All in all, despite the above-mentioned differences, the EU-Japan and EU-ROK strategic partnerships each highlight the relevance of the institutional dimension in the EU's partnership policy, as one of the four key dimensions discussed in Chapter 1 of this volume.

As the EU scrambles to have a strategic role in Asia (and Northeast Asia is key to this), lessons from this comparative case study will surely be useful to both academics and policy-makers. Indeed, for the EU, Japan and the ROK are "like-minded" partners, and so collaboration with them is perceived by Brussels as key to both consolidating the EU's own acquis (post-Lisbon Treaty) and upholding a rules-based international order where it is most challenged: in the Asia-Pacific.

However, the EU-Japan and EU-ROK agreements are unlikely to lead to substantial changes in the strategic equation that both Japan and Korea find themselves in. These agreements are arguably more useful (in political terms) to Brussels. The importance of these partnerships to both Tokyo and Seoul is mainly economic and is likely to remain so in the foreseeable future.

All in all, the formal extension of economically significant and diplomatically convenient partnerships to the political and strategic realm is still facing considerable obstacles. These are associated with the EU's limited strategic footprint in Asia, as well as with Japan's and the ROK's respective strategic concerns, and hence their resistance to endorse the Union's claim to a "strategic" role in the region. 


\section{REFERENCES}

Asia News Network. (2019, March 13). South Korea's Lotte Seeks to Exit China After Investing \$9.6 Billion, as Thaad Fallout Ensues. The Straits Times. www.straitstimes.com/asia/east-asia/south-koreas-lotte-seeksto-exit-china-after-investing-96-billion.

Atanassova-Cornelis, E. (2015a). Constraining or Encouraging? US and EU Responses to China's Rise in East Asia. Central European Journal of International and Security Studies, 9(4), 6-27.

Atanassova-Cornelis, E. (2015b). How Important Is Northeast Asia for China and the EU? Economic Convergence, Geopolitical Divergence. In J. Wouters, J. C. Defraigne, \& M. Burnay (Eds.), China, the EU and the Developing World (pp. 63-88). Edward Elgar.

Atanassova-Cornelis, E. (2018). Reconceptualising the Asia-Pacific Order: Japan's Response to Strategic Uncertainties in the Era of Trump. Special Issue: Trump and the Post-American World Order, Interdisciplinary Political Studies, $4(1), 153-183$.

Atanassova-Cornelis, E. (2019). Shifting Constraints, Evolving Opportunities and the Search for the 'Strategic' in the EU-Japan Bilateral Partnership. In W. Song \& J. Wang (Eds.), The European Union in the Asia Pacific: Rethinking Europe's Strategies and Policies (pp. 164-183). Manchester: Manchester University Press.

Atanassova-Cornelis, E., \& Sato, Y. (2019). The US-Japan Alliance Dilemma in the Asia-Pacific: Changing Rationales and Scope. The International Spectator, 54(4), 78-93.

Berkofsky, A. (2014). The European Union in Asian Security: Actor with a Punch or Distant Bystander? Asia-Pacific Review, 21(2), 61-85.

Biscop, S. (2019, March 15). The EU, the US and China: A Middle Way to Approach the Middle Kingdom. Egmont Commentary. http://www.egmont institute.be/external-action-the-eu-the-us-and-china/.

Civic \& Ifo. (2018, May). Evaluation of the Implementation of the Free Trade Agreement Between the EU and Its Member States and the Republic of Korea. Brussels: European Commission, DG Trade. https://trade.ec.europa.eu/doc lib/docs/2019/march/tradoc_157716.pdf.

Council of the European Union. (2012, June 15). Guidelines on the EU's Foreign and Security Policy in East Asia. www.eeas.europa.eu/asia/docs/gui delines_eu_foreign_sec_pol_east_asia_en.pdf/.

DG Trade. (2015, October). Trade for All: Towards a More Responsible Trade and Investment Policy. https://trade.ec.europa.eu/doclib/docs/2015/ october/tradoc_153846.pdf.

European Council. (2018, October). EU-Republic of Korea Summit, 19 October 2018. Brussels. https://www.consilium.europa.eu/en/meetings/int ernational-summit/2018/10/19/. 
European External Action Service. (2016, June). Shared Vision, Common Action: A Stronger Europe. A Global Strategy for the European Union's Foreign and Security Policy. https://eeas.europa.eu/sites/eeas/files/eugs_review_web_0. pdf.

European External Action Service. (2018, January 23). 7th Meeting of the Trade Committee of the EU-Korea Free Trade Agreement (FTA). https://eeas.eur opa.eu/headquarters/headQuarters-homepage/38576/7th-meeting-tradecommittee-eu-korea-free-trade-agreement-fta_ko.

European External Action Service. (2019, October 18). EU-Japan Relations. https://eeas.europa.eu/headquarters/headquarters-homepage_en/48463/ EU-Japan\%20relations.

EU-Japan Summit. (various years, 2013-2015). Joint Press Statement. https:// eeas.europa.eu/archives/delegations/japan/en/tag/day-eu-summit-talk/ index.html.

Ferreira-Pereira, L. C., \& Guedes Vieira, A. V. (2016). Introduction: The European Union's Strategic Partnerships: Conceptual Approaches, Debates and Experiences. Cambridge Review of International Affairs, 29(1), 3-17.

Green, M. (2019, November 5). The Japan-Korea Impasse and the Security of Northeast Asia, Nippon. https://www.nippon.com/en/in-depth/a06403/ the-japan-korea-impasse-and-the-security-of-northeast-asia.html.

Hellendorff, B. (2018, April 10). Waiting for New Deliverables: Can the EUJapan Strategic Partnership Measure up to Global and Regional Challenges? (EPC Policy Brief). Brussels: EPC. http://www.epc.eu/en/Publications/Wai ting-for-new-deliverables-Can-the-EU-Japan-strategic-partnership-m 208c08.

Hellendorff, B. (2019, September 27). Is Europe Equipped to Face a Global China? ISPI Commentary. https://www.ispionline.it/en/pubblicazione/eur ope-equipped-face-global-china-23997.

Kelly, R. E. (2012). Korea-European Union Relations: Beyond the FTA? International Relations of the Asia-Pacific, 12(1), 101-132.

Kim, C., \& Roh, J. (2018, August 24). South Korea's “Jobs President" Faces Policy Roll-Back over Employment Uproar. Reuters. https://www.reuters. com/article/us-southkorea-economy-moon-analysis/south-koreas-jobs-presid ent-faces-policy-roll-back-over-employment-uproar-idUSKCNIL906I.

Lee, J.-H. (2019, May 2). China Ends Sanctions on Lotte Two Years After South Korean Retailer Cedes Land to US Missile Defences. South China Morning Post. www.scmp.com/news/china/diplomacy/article/300 8576/china-ends-sanctions-lotte-two-years-after-south-korean.

Minard, P. (2014, September 18). The EU, Japan and South Korea: Mutual Recognition Between Different Partners. GRIP Analysis Note. https://www. grip.org/en/node/1365. 
Ministry of Defence, Japan. (2018, December 18). National Defense Program Guidelines for FY 2019 and Beyond. https://www.mod.go.jp/j/approach/ agenda/guideline/2019/pdf/20181218_e.pdf.

O'Hanlon, M. (2018). The Long-Term Basis for a U.S.-Korea Alliance. The Washington Quarterly, 41(4), 103-116.

Prime Minister of Japan and His Cabinet. (2013, December 17). National Security Strategy. http://japan.kantei.go.jp/96_abe/documents/2013/_ics Files/afieldfile/2013/12/18/NSS.pdf.

Raine, S., \& Small, A. (2015, May 22). Waking Up to Geopolitics: A New Trajectory to Japan-Europe Relations. Paper Series. Washington, DC: The German Marshall Fund of the United States. https://www.gmfus.org/publications/ waking-geopolitics-new-trajectory-japan-europe-relations/.

Ryall, J. (2018, October 24). South Korean President Falls Short Lobbying for Pyongyang in Europe. Deutsche Welle. https://www.dw.com/en/south-kor ean-president-falls-short-lobbying-for-pyongyang-in-europe/a-46019592.

Sakaki, A., \& Nishino, J. (2018). Japan's South Korea Predicament. International Affairs, 94(4), 735-754.

Snyder, S. (2018). South Korea at the Crossroads: Autonomy and Alliance in an Era of Rival Powers. Columbia: Columbia University Press.

Reiterer, M. (2013). The Role of "Strategic Partnerships" in the EU's Relations with Asia. In T. Christiansen, E. Kirchner, \& P. Murray (Eds.), The Palgrave Handbook of EU-Asia Relations (pp. 75-89). Basingstoke: Palgrave Macmillan.

Richey, M. (2017, May). EU-South Korea Security Relations: The Current State of Play (Security Policy Brief No. 87). Brussels: Egmont: Royal Institute for International Relations.

Wallace, C. J. (2013). Japan's Strategic Pivot South: Diversifying Dual Hedge. International Relations of the Asia-Pacific, 13, 479-517. 


\title{
Conclusions: The Rise and Fall of an Idea
}

\author{
Thomas Renard
}

So much has been written on the EU's foreign policy, and yet so little on the so-called strategic partnerships. EU strategic partnerships have been largely ignored in the academic literature, with a few notable exceptions cited in this volume, and rarely studied in depth. This lack of interest partly reflects a critical take on what most scholars and observers perceived as a mere new "label", largely artificial and unconvincing as a new foreign policy concept, notably in the light of the lack of clear definition or purpose for these partnerships. At the same time, the near-absence of analysis of a concept that was presented as central to the EU's foreign policy in the late 2000s, certainly in EU documents and rhetoric, constitutes a clear gap in our understanding of the EU's foreign policy (and of its making).

In the light of this relative neglect from academia, this volume is a welcome contribution. It combines a reflection on the concept of strategic partnership, its definition, its purpose and institutional functioning, with an extensive analysis of all ten individual partnerships in a historical and

\section{T. Renard $(\bowtie)$}

Egmont, Royal Institute for International Relations, Brussels, Belgium e-mail: t.renard@egmontinstitute.be

(C) The Author(s), under exclusive license to Springer Nature Switzerland AG 2021

L. Ferreira-Pereira et al. (eds.), The European Union's Strategic

Partnerships, The European Union in International Affairs, https://doi.org/10.1007/978-3-030-66061-1_14 
comparative perspective. In fact, more than just an assessment of the EU's strategic partnerships, this volume is a broader review of the evolution of the EU's foreign policy over the past two or three decades, and more specifically of the EU's relationship with the main powers of this world.

In this final chapter, it seems opportune to first go back to the notion of "strategic partnership" as a foreign policy concept of a certain era. To do so, it is interesting to look at the EU strategic partnerships in the broader perspective of the proliferation of strategic partnerships worldwide, in the 1990s and 2000s. During almost two decades, strategic partnerships were concluded at an increasing pace, including by the EU. The proliferation of strategic partnerships heralded a new era, marked by the emergence of new powers and the challenge to the established liberal order. However, by the mid-2010s, strategic partnerships seemed to have largely disappeared from the headlines. The causes of this progressive disinterest are multiple, but they are most likely linked at least partly to the global economic slowdown, increasing geopolitical competition, the underperformance of emerging powers, or rising nationalism. The concept of strategic partnership seems to have lived its course, and it has now largely disappeared from the foreign policy narrative of most countries.

\section{The Globalisation of Partnership Diplomacy}

The concept of "strategic partnership" in modern international relations seems to have emerged at the end of the Cold War. According to Kay (2000), the notion of strategic partnership was first advanced by the Soviets in their bilateral discussions with the Americans, with a view to managing post-Cold War security on the European continent. By the end of the 1990s, a number of strategic partnerships had been concluded. For instance, China and Russia announced their resolve to develop a "strategic partnership of equality, mutual confidence and mutual coordination for the twenty-first century" in a joint statement following the visit of Boris Yeltsin to China's President Jiang Zemin, a statement that was then circulated to all UN members. ${ }^{1}$ Other early instances of such partnerships include the 1993 China-Brazil strategic partnership, or the 1998 US-Turkey strategic partnership.

${ }^{1}$ Joint Declaration by the People's Republic of China and the Russian Federation, Beijing, 25 April 1996. Available online: https://undocs.org/pdf?symbol=en/A/51/127. 
With the beginning of the twenty-first century, strategic partnerships became even more popular among established and emerging powers alike. The first decade of the years 2000 witnessed the conclusion of many new strategic partnerships, including major ones such as between China and Pakistan (2005) or between the US and India (2004). As a result, the number of these partnerships grew dramatically, from a few in the 1990s to more than a hundred in the 2000s. Whereas China had established just two strategic partnerships by the end of the twentieth century, it had concluded 20 by 2005 , and the number had reached 49 by the end of 2014 (Zhongping and Huang 2014).

Nowadays, there are probably more than 200 of these arrangements worldwide (see Map 14.1), although no study or database has ever attempted - or been able - to provide an exact account. China has established more than 50 strategic partnerships; India, Brazil and Russia have each signed more than 20 strategic partnerships, whereas the United States (US) has concluded 31 of them, in addition to its many alliances.

Partnership diplomacy emerged thus in the post-Cold War context, at a time of political openings, economic opportunities and shifting alignments. China, Russia and the US were at the origins of this new concept. To a large extent, this had to do with their power status. As the "lonely superpower", the US was courted by a number of former Soviet states willing to redefine their relationship with Washington and, by extension, with the West. This was notably the case of Ukraine and Romania, with which the US established strategic partnerships in 1996 and 1998, respectively. China and Russia were also willing to redefine their relations with the West. Russia wanted to start relations on a new basis, following the demise of the Soviet Union, whereas China was looking to normalise its relations with the world after the Tiananmen incident. Both China and Russia were also showing great power aspirations and a willingness to participate in the shaping of a new world order, as illustrated by the 1997 Russian-Chinese Joint Declaration on a Multipolar World and the Establishment of a New International Order. ${ }^{2}$

The proliferation of partnerships in the 2000s may be the result, at least in part, of a form of emulation of the instrument, one partnership

${ }^{2}$ Russian-Chinese Joint Declaration on a Multipolar World and the Establishment of a New International Order, Moscow, 23 April 1997. Available online: http://www.fas.org/ news/russia/1997/a52--153en.htm. 

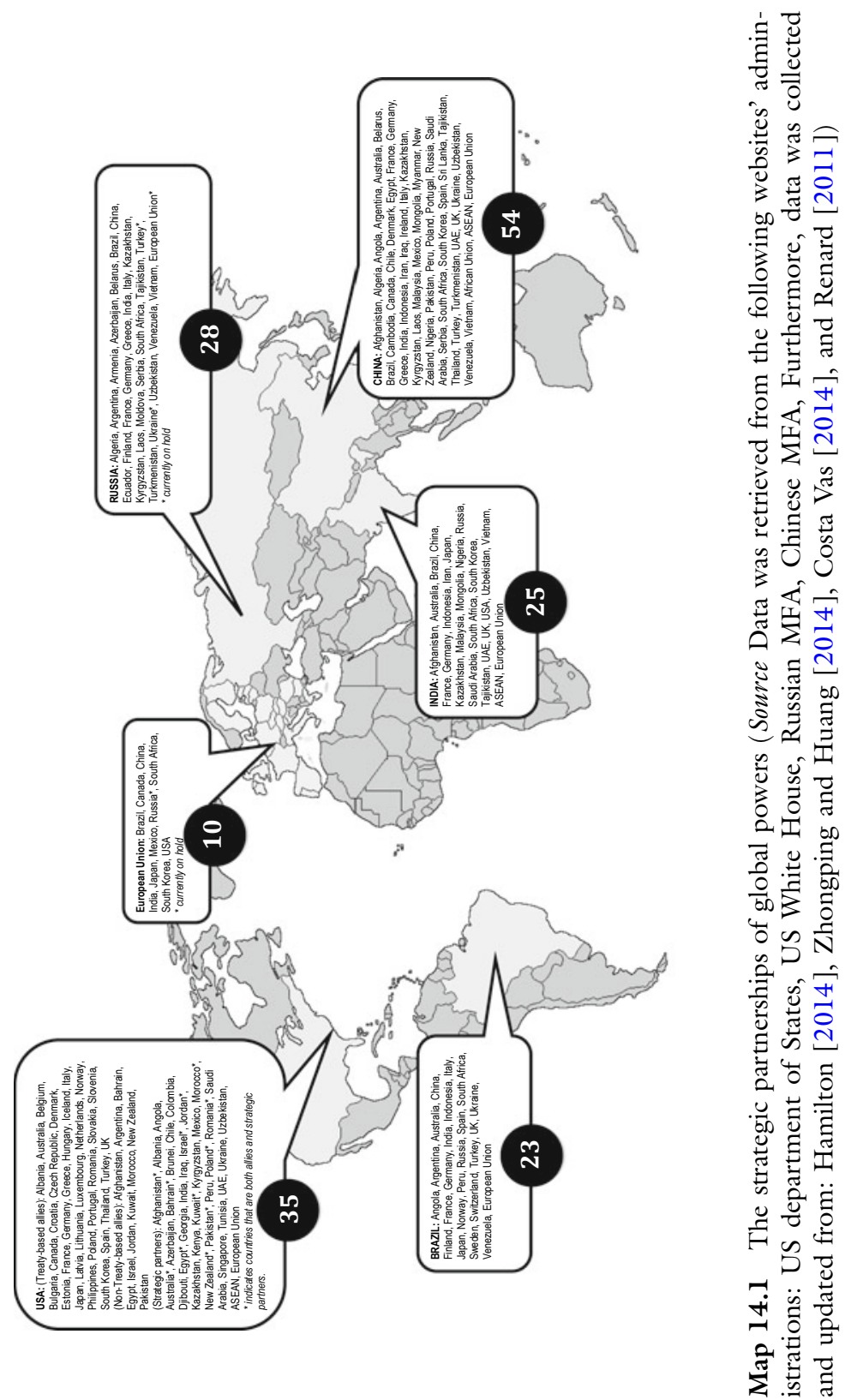
leading to another one. Yet, this does not mean that these partnerships were entirely meaningless, or that major powers did not envision a greater role for them. For instance, former US Secretary of State Hillary Clinton referred to a "multi-partner world" based on "partnerships aimed at solving problems" in 2009, whereas Chinese President Xi Jinping expressed his ambition in 2014 to create a "global network of partnerships" as a foundation of its foreign policy, during a major speech (Clinton 2009; Huang 2014). However, most scholars suggest that these partnerships have rarely been pursued or developed in a strategic manner, that is with a clear sense of purpose (see for instance Renard 2011; Hamilton 2014; Zhongping and Huang 2014; Costa Vaz 2014). In other words, every strategic partnership had its own reason, logic and goal, but there was not a coherent purpose or consistent features across all partnerships.

Already in 2000, Sean Kay wondered "what is a strategic partnership?" observing the growing use of this instrument by the US administration, and warning against the dangers of confusing its allies and competitors about its foreign policy objectives through such inflated rhetoric (Kay 2000). While there have been several interesting reflections on the definition of strategic partnerships, ${ }^{3}$ it is perhaps more fundamental to ask "what are strategic partnerships for?", that is what is their purpose? In this regard, strategic partnerships can be conceived either as a form of "alignment", which needs to be distinguished from other types of alignment, such as alliances or coalitions, or as a form of "engagement", according to which these partnerships can participate to a foreign policy strategy of balancing, containment or hedging.

Firstly, strategic partnerships must be distinguished from more traditional alliances or coalitions. Similarly to an alliance, a strategic partnership is a form of international cooperation between two parties that go beyond mere diplomatic contacts. However, an alliance is generally more limited in its agenda, to military and security issues, whereas strategic

\footnotetext{
${ }^{3}$ Parameswaran (2014: 263-264) offers perhaps the most concise definition of a strategic partnership as "a loose but structured framework of collaboration between parties to address common challenges and to seize opportunities in several areas". Wilkins (2008: 360-361) considers that strategic partnerships are (1) organised around a 'system principle', that is a general purpose, rather than a specific task; (2) based primarily on common interests and not always underwritten by shared values; (3) essentially goal-driven rather than threat-driven; (4) informal and with low commitment costs; (5) driven mostly by economic and security concerns.
} 
partnerships are generally more wide-ranging, encompassing all kinds of challenges such as economic or environmental ones. Furthermore, the level of commitment expected among formal allies is higher than among strategic partners. Conversely, with lower expectations, a strategic partnership is more flexible than an alliance, and its level of cooperation can vary over time and across policy areas. Overall, a strategic partnership can go through political ups and downs over time, as domestic and international contexts evolve, without necessarily questioning the founding principles of the partnership. In short, strategic partnerships provide "maximum diplomatic, political, and economic flexibility and minimum commitments from involved parties" (Nadkarni 2010: 17).

While very different from alliances, strategic partnerships may be more akin to a form of coalition, defined as "a grouping of like-minded states that agree on the need for joint action on a specific problem at a particular time with no commitment to a durable relationship" (Pierre 2002: 2 ). However, the main difference between these concepts is that strategic partnerships are generally bilateral agreements, whereas coalitions have a broader membership, whether they take the form of "bloc-type coalitions" (like the BRICS, IBSA or the G7, for instance), or of "issue-based coalitions" (like the G77 on development issues, or the US-led anti-ISIS coalition in counter-terrorism).

Secondly, beyond the nature of the agreement, strategic partnerships can be analysed through the prism of IR theory, as a form of balancing, containment or hedging. For instance, according to Hughes, Japan's quest to strike strategic partnerships globally, from Asia to the MiddleEast, Europe and Africa, can be seen as a form of "soft containment", to curb Chinese influence and "encumber China's free projection of its power outside East Asia” (Hughes 2009: 855). Strategic partnerships can also be described as a strategy of hedging from a number of states confronted with geopolitical uncertainty. This is certainly the case in Asia, where Goh (2007) called "omni-enmeshment" the tangled web of engagement strategies in Southeast Asia, resulting from states' hedging behaviours between the US and China. The proliferation of strategic partnerships over the past two decades suggest that omni-enmeshment may be a strategy of global relevance, beyond Asia.

Overall, strategic partnerships can be seen as instruments of flexibility and pragmatism in times of geopolitical uncertainty. In a more fluid and contested international order, defined by co-existing elements of "partnership and rivalry" (Patrick 2010: 46), partnership diplomacy can be 
seen as a way to strengthen cooperation while managing competition between great and regional powers. As Michael Cox concluded almost a decade ago, "we no longer live in a world composed of clearly specified friends and well-defined enemies, but rather in one where partnership has become a necessity" (Cox 2012: 381, emphasis added). There would be in this regard "partnerships of choice", i.e. with like-minded countries, and "partnerships of necessity", i.e. with potential competitors (Grevi 2012).

To some extent, strategic partnerships can also be seen as a structured approach for countries to gather "followership" at the regional or global level, which determines in turn the true global powers, i.e. those who can actually shape the global agenda (Schirm 2010). For countries that do not have formal alliances, like China, strategic partnerships offer a decent alternative to signal a form of political and economic rapprochement with other states. This is probably why China, as the challenging superpower in need of followers, still continues to maintain a network of strategic partnerships.

In spite of the inherent flexibility of the concept, which made it popular and "handy" for diplomacy during over two decades (Hamilton 2014: 21), strategic partnerships have now lost traction. The use of strategic partnerships in foreign policy doctrines and discourses has drastically declined compared to several years ago, except perhaps for China. The reasons for this lacklustre performance are multiple. Of course, this is probably at least partly the result of the ambiguity of the concept. With no clear meaning or purpose, the declaratory power of establishing a strategic partnership eventually runs its course and may even possibly backfire when the partnership does not live up to the expectations. It could also be the result of competition increasingly outweighing cooperation at the global level, particularly in the light of the rising rivalry between the US and China, driven by new forms of nationalism, and the declining influence of multilateral institutions. As the stakes become higher, open alignment with either the US or China, even in the diluted form of a strategic partnership, becomes a headache for every country, particularly those investing on a hedging strategy.

\section{Europe's Way: Partnering Without Pattern}

The development of the EU's own strategic partnerships, as explained in this book, largely matches the evolution described above. Although the first mention of a "strategic partnership" in EU documents goes back to 
the late 1990s, in the context of EU-Russia relations, it is really in 2003 that the EU claimed its intention to develop its relations with "strategic partners" (then listed as the US, Russia, Japan, Canada, China and India), in its European Security Strategy (ESS)-a key foreign policy document. The drivers of the EU's strategic partnerships were therefore very much alike most other global strategic partnerships: it was about rethinking and restructuring political relations with Russia, the US and emerging powers in the post-Cold War and post-US "unilateral moment" era. The ESS also reflected a major internal development, as the EU sought to assert itself as a global actor, more active and united on foreign and defence policy (notably as the document was drafted in the aftermath of the 2003 US invasion of Iraq, which had deeply divided European countries). The EU's strategic partnerships came to complement other layers of the EU's foreign policy agenda, forming a sort of "triptych", composed of three concentric circles of influence: the enlargement policy, the neighbourhood policy, and global partnerships (Kempin and Lippert 2013).

Following the 2003 ESS, the EU progressively widened its list of strategic partners to reach a group of ten strategic partners in 2010: Brazil, Canada, China, India, Japan, Mexico, Russia, South Africa, South Korea and the US. What was particularly remarkable during this phase was the lack of attention and interest this instrument received, both inside and outside EU policy circles. In my earlier research, I spoke with more than a dozen EU officials in 2009-2010, and none of them was able to name the full list of EU strategic partners, nor to explain the logic of these partnerships (Renard 2011). Most of these countries seemed to have become strategic partners "by accident" (Renard 2011), and EU officials seemed unaware of the difference, if any, between a strategic partner and a nonstrategic partner. As explained in the first chapter of this volume, it appears that some EU member states played an important role in establishing some of these partnerships. It could also be that the EU had been influenced by the flourishing of strategic partnerships worldwide, as discussed above, thus emulating a label more than seeking to establish a new foreign policy instrument.

Following the widening phase came a phase of deepening of the existing strategic partnerships. This phase started in 2010, in the aftermath of the Copenhagen climate summit fiasco, as recalled in the second chapter of this volume. Herman Van Rompuy, the new President of the European Council, came back from Copenhagen with the firm intention to avoid similar failures in the future, making full use of the Lisbon 
Treaty in external relations, on the one hand, and initiating a reflection on strategic partnerships, on the other hand. In the opening to the September 2010 European Council, he famously said "we have strategic partnerships, now we need a strategy" (Van Rompuy 2010). Following this meeting, the EU High Representative Catherine Ashton was tasked to assess the EU strategic partnerships in so-called progress reports, which she did in late 2010 and early 2011. These confidential reports sought notably to identify the EU's main objectives vis-à-vis each partner, what are the shared interests, and what kind of tradeoffs could be reached (Renard 2011).

With hindsight, the few months following the Copenhagen wake-up call were really the apex of the reflection (and use) of strategic partnerships by the EU. There was a momentum created by the convergence of the three logics presented in the second chapter of this volume: the EU's internal logic (more foreign policy powers, following the Lisbon Treaty), the external logic (the EU sidelined in Copenhagen, as a sign of a return to geopolitics), and the identity logic (the EU wanted to become a more strategic global actor). At the time, it seemed that strategic partnerships could become much more central to the EU's foreign policy, and certainly that they would remain high on the agenda of the High Representative. ${ }^{4}$ However, that moment was only short-lived. Only six out of ten progress reports were produced (Canada, Japan, South Korea and Mexico were never covered), and the existing reports were quickly shelved to never see the light again. No significant breakthrough was achieved under Catherine Ashton regarding strategic partnerships, whether in terms of internal thinking and management, or in terms of bilateral relations.

When Federica Mogherini became the EU's new High Representative in 2014, she suggested that strategic partnerships would remain a topic on her agenda. However, even before she took office, Russia had already been unofficially suspended from the list of EU strategic partners, following its annexation of Crimea. In the following years, relations with other partners, notably Brazil, India, China and even the US (under the Trump administration), proved increasingly challenging for the EU, with little progress achieved on major issues. In fact, Mogherini came to develop a much more pragmatic approach to strategic partnerships. The 2016 EU Global Strategy is a good indicator of this new approach:

\footnotetext{
${ }^{4}$ Interview with a European diplomat, Brussels, 13 December 2010.
} 
it put "partnership" as a central element of the EU's foreign policy approach, but barely mentioned "strategic partners" or "strategic partnerships". In line with the principle of "principled pragmatism", the emphasis seemed to be more on working either with "like-minded partners" (which excludes a number of strategic partners de facto) or with partners in an ad hoc manner, based on specific issues and objectives. In other words, issuebased cooperation came to be favoured over fixed partnerships, as flexible as these can be. Equally telling of the lacklustre image of the concept, is its almost total absence from the website of the EU's External Action Service (EEAS), or from most EU official speeches and documents. As noted by Schade in this volume, there is "very little evidence that the concept of strategic partnerships receives any ongoing and regular attention whatsoever, either in the form of formulating goals and aims, providing a framework for cooperation, or by facilitating institutional exchanges on the strategic partnerships". In short, while strategic partnerships have not entirely disappeared from EU's vocabulary, they appear to be more a reminiscence of a past ambition than evidence of their centrality in foreign policy making.

\section{Assessing the EU's Strategic Partnerships}

In the introduction to this volume, the editors raised a number of questions about EU strategic partnerships. The first of these questions was: are strategic partnerships still alive? From the reading of this book's chapters, the answer seems to be leaning towards "no". It was always clear that the EU's strategic partnerships were uneven, fulfilling different purposes and having different levels of ambition (Renard 2011). It was also understood that these partnerships were "work in progress" in the early 2010s (Grevi 2012). However, ten years after Van Rompuy's call for truly strategic partnerships, there is little sign of any positive development.

At the global level, strategic partnerships were once considered as a tool to promote "effective multilateralism". However, it is unclear to what extent the EU has managed to leverage its partnerships to defend or promote multilateralism. More fundamentally, the whole multilateral system that has formed the backbone of the so-called liberal order seems to be increasingly challenged. This doesn't mean that multilateralism is dead, or partnering in a multilateral context impossible, but the ambition to develop strategic partnerships that could "structure" global governance 
(Grevi 2012) has been downscaled to a more selective and pragmatic form of multilateralism and partnership.

At the bilateral level, most partnerships have not lived up to their promises. Russia is no longer considered a strategic partner but a "strategic challenge" (EEAS 2016: 33), and China has been relabelled a "systemic rival" and "strategic competitor" (European Commission and HR/VP 2019: 1, 5). The transatlantic partnership with the US is deeply tested under the Trump administration, albeit arguably "there has not been and may never be a comprehensive EU-US strategic partnership" as Smith concludes in this volume, whereas the partnership with Brazil is "on hold" according to Ferreira-Pereira in this volume and the partnership with India characterised by "mutual neglect" according to Kavalski. This is a stark reminder that "a simple declaration of "strategic partnership' does not necessarily render a partnership strategic" (Hamilton 2014: 21).

At the EU's internal level, strategic partnerships have been presented as a tool to increase strategic thinking and improve foreign policy coordination within EU institutions and among EU member states (Grevi 2012). Here again, there is little sign of progress. The EU's communication around strategic partnerships remains unclear and confusing. It is not clear who is still a strategic partner in 2020 or what the purpose of these partnerships is. To some extent, this volume illustrates this confusion as some authors focussed on the substance of the bilateral relationship between the EU and its partner, whereas others focussed more-or exclusively - on the formal aspects of these partnerships, notably the so-called strategic partnership agreements. Finally, as highlighted in some chapters, the EU remains divided or undecided on some key foreign policy issues when confronted with a powerful strategic partner, particularly China.

The second key question raised in the introduction of this volume was: do strategic partners perceive the EU as a strategic actor? Here as well, the various authors in this volume suggest a negative answer. AtanassovaCornelis and Hellendorff explain, for instance, how Japan and South Korea question the EU's "value as a strategic partner", whereas countries like Brazil or India consider the relationship with the EU of a "secondary place" at best, in the words of Ferreira-Pereira. The fact is that the EU is not a great power (except commercially, arguably) and is not considered as a major player in the geopolitical environment of its strategic partners. In Asia, South Korea and Japan do not see the EU as a viable third way to escape the US-China confrontation. In North America, Mexico and 
Canada are so deeply interlinked with the US, that it leaves little room for wide-ranging engagement with the EU.

The introduction of this volume presented four themes that guided the following chapters: functional, policy-related, institutional and rolerelated aspects of strategic partnerships. This book suggests overall that strategic partnerships have failed or under-delivered in all these aspects. In spite of clear efforts to find a purpose for strategic partnerships, and to develop an institutional architecture to consolidate them, these partnerships have not fundamentally reshaped any of these bilateral relationships, nor have they become a cornerstone of the EU's foreign policy.

To conclude, strategic partnerships were once regarded as a promising instrument to structure and strengthen the EU's foreign policy, but this ambition has now faded and the concept is mostly history. It remains to be seen whether the rising confrontation between the US and China will trigger a reactivation of this concept, or whether the COVID19 crisis (economically, socially, politically) will transform international relations to the extent that something akin to strategic partnerships become needed again. Strategic partnerships could be a way to re-create an "international society" post-COVID-19, or to build the EU's "strategic autonomy" in the midst of the US-China rivalry, but key questions would remain nonetheless: partnering with whom, and what for? For the foreseeable future, the EU is more likely to operate on the basis of ad hoc, flexible, issue-based partnerships. To say it differently, strategic partnering has replaced strategic partnerships.

\section{REFERENCES}

Clinton, H. R. (2009, 15 July). A Multi-Partner World. Speech at the Council on Foreign Relations, New York City.

Costa Vaz, A. (2014). Brazil's Strategic Partnerships: Origins, Agendas and Outcomes (ESPO Working Paper 9). Brussels: European Strategic Partnerships Observatory (Egmont Institute and FRIDE).

Cox, M. (2012). Power Shifts, Economic Change and the Decline of the West? International Relations, 26(4), 369-388.

EEAS. (2016). Shared Vision, Common Action: A Stronger Europe: A Global Strategy for the European Union's Foreign and Security Policy. Brussels: European External Action Service.

European Commission \& HR/VP. (2019, 12 March). EU-China-A Strategic Outlook. Joint Communication to the European Parliament, the European Council and the Council. 
Goh, E. (2007). Great Powers and Hierarchical Order in Southeast Asia: Analyzing Regional Security Strategies. International Security, 32(3), 113157.

Grevi, G. (2012). Why EU Strategic Partnerships Matter (ESPO Working Paper 1). Brussels: European Strategic Partnerships Observatory (Egmont Institute and FRIDE).

Hamilton, D. (2014). The American Way of Partnership (ESPO Working Paper 6). Brussels: European Strategic Partnerships Observatory (Egmont Institute and FRIDE).

Huang, K. L. (2014, 30 November). President Xi Jinping Puts 'Network of Partners' on Foreign Policy Agenda. South China Morning Post.

Hughes, C. W. (2009). Japan's Response to China's Rise: Regional Engagement, Global Containment, Dangers of Collision. International Affairs, 85(4), 837856.

Kay, S. (2000). What Is a Strategic Partnership? Problems of Post-Communism, $47(3), 5-24$.

Kempin, R., \& Lippert, B. (2013). Membership, Neighbourhood, Partnership: The EU's Foreign Policy Triptych Needs Remodelling (SWP Working Paper). Berlin: Stiftung Wissenschat und Politik.

Nadkarni, V. (2010). Strategic Partnerships in Asia: Balancing Without Alliances. Abingdon: Routledge.

Parameswaran, P. (2014). Explaining US Strategic Partnerships in the Asia-Pacific Region: Origins, Developments and Prospects. Contemporary Southeast Asia, $36(2), 262-289$.

Patrick, S. (2010). Irresponsible Stakeholders? The Difficulty of Integrating Rising Powers. Foreign Affairs, 89(6), 44-53.

Pierre, A. J. (2002). Coalitions: Building and Maintenance. Washington, DC: Georgetown University.

Renard, T. (2011). The Treachery of Strategies: A Call for True EU Strategic Partnerships (Egmont Paper 45). Brussels: Egmont Institute.

Schirm, S. (2010). Leaders in Need of Followers: Emerging Powers in Global Governance. European Journal of International Relations, 16(2), 197-221.

Van Rompuy, H. (2010, 14 September). We Have Strategic Partners, Now We Need a Strategy. Video Message of President Van Rompuy in the Run-Up to the European Council.

Wilkins, T. (2008). Russo-Chinese Strategic Partnership: A New Form of Security Cooperation? Contemporary Security Policy, 29(2), 358-383.

Zhongping, F., \& Huang, J. (2014). China's Strategic Partnership Diplomacy: Engaging with a Changing World (ESPO Working Paper 8). Brussels: European Strategic Partnerships Observatory (Egmont Institute and FRIDE). 


\section{INDEX}

A

Afghanistan, 31, 103, 104, 107, 236

Africa, 10, 26, 31, 63, 157, 170, 224, $227,236,245,248,250,251$, 254, 255, 257, 260, 262, 297, 316

African Renaissance, 252

Agenda Sustainable Development

Goals, 277

Albright, Madeleine, 101

Alliance(s)/allies, 25, 75, 107, 109,

$134,140,157,165,203$,

$227,229,231,235,252,262$,

293, 294, 298, 304-306, 313, 315-317

Ambiguity, constructive, 180, 181, $186,191,193,194,317$

'America First', 109, 111

Amsterdam Treaty, 25

Anti-piracy, 297, 299

Apartheid, 245, 251, 252, 262

Arab Spring, 107

Article 370, 200, 207
Ashton, Catherine, 4, 27, 52, 319

Asia-Pacific, 290, 293, 294, 302, 304, 305,307

Association Agreement, 55, 56, 61

Association of South-East Asian Nations (ASEAN), 10, 81, 231-233

'Atlantic Community', 98, 114, 190

'Atlantic Partnership', 98

Australia, 57, 59, 78, 121, 130, 213, $214,227,232,298$

Authoritarianism, 7, 227, 238

B

Balkans

Western Balkans, 206

Ballistic missile (BM), 294, 296

Barroso, José Durão, 27

Belt and Road Initiative (BRI), 167, 292

'Berlin Plus', 102

Bharatiya Janata Party (BJP), 213

(C) The Editor(s) (if applicable) and The Author(s), under exclusive

license to Springer Nature Switzerland AG 2021

L. Ferreira-Pereira et al. (eds.), The European Union's Strategic

Partnerships, The European Union in International Affairs, https://doi.org/10.1007/978-3-030-66061-1 
Bologna Policy Forum, 84

Bolsonaro, Jair, 165, 169, 171, 284

Botswana, Lesotho, Namibia and

Swaziland (BLNS), 246, 247,

256, 257, 259

Brazil, 3, 4, 10, 11, 14, 24, 28,

$31,55,58,59,63,70,72,77$,

$81-86,89,90,151-171,313$,

$318,319,321$

Brazil, Russia, India, China and South

Africa (BRICS), 4, 13, 23, 37,

$76,81,164,165,169,252,262$, 263,316

Brexit/Brexit process, 4, 11, 33, 80, $110,142,152,153,161,162$, $167,171,192,228,252,261$, 272

British referendum, 4, 30, 33, 164 Bush, George W. (President) and Administration, 99, 103-105

C

Canada, 3, 4, 10, 13, 23, 26, 54, $56-58,60,63,65,76,77$,

121-124, 126-132, 134, 135,

137-142, 154, 208, 213, 272,

$318,319,322$

CELAC-EU Summit, 273

Central America, 285

Central and Eastern European

Countries (CEECs), 168

China, 3, 4, 7, 9-12, 14, 15, 23, $24,26,28,29,31,37,40,42$, $54,63,65,73,76,77,79,80$, $104,111,112,122,134,137$, $138,157,161,163,168,169$, 190, 192, 200, 202, 208, 209, 211-214, 221-239, 262, 272, 277, 285, 292-298, 303-306, $312,313,316-319,321,322$

Citizenship Amendment Bill (CAB), 199, 200, 207
Climate change, $8,27,102,153,155$, $164,165,222,224,229,230$, 235-238, 248, 255, 276, 277, 280, 284, 285, 294, 297, 299, 300

Clinton, Bill (President) and Administration, 102

Coalitions, 165, 170, 208, 236, 315, 316

Coincidental juncture, 271, 272, 283

Cold War, 97, 98, 112, 123, 128, 140, 141, 154, 201, 206, 221-223, 226, 228, 233, 237, 238, 269, 271, 273, 277, 312

Common Foreign and Security Policy (CFSP), 3, 8, 12, 22, 26, 30, 35, $37,52,60,61,101,112,132$, $133,155,169,206,224,234$, $237,238,270,278$

Common Market for Eastern and Southern Africa (COMESA), 258

Common neighbourhood (between the EU and Russia), 87, 178-181, 183, 191, 192

Common Security and Defence Policy (CSDP), 33, 35, 101, 102, 112, $133,135,167,236,302$

Common strategies, $3,25,26,37$, 178

Common Strategy on Russia (CSR), $25,26,81,178,187$

Common Strategy on Ukraine, 29

Competition, 4, 7, 42, 97, 99, 100, $103,106,108,111,116,157$, $168,183,192,222,228,229$, $259,275,312,317$

'Competitive interdependence', 107

Comprehensive Economic and Trade Agreement (CETA), 122, 124, $126,133-136,139-142$

Conditionality, 181, 186, 210 
Conference on Security and Cooperation in Europe (CSCE), 129

Constitutional treaty, 36, 132

Containment, 315, 316

Convention on the future of the $\mathrm{EU}$, 132

Cooperation, 2, 7, 9, 10, 13, 14, 24, $28,33,34,38,43,51,53-61$, $65,74,78,79,82,84,86,88$, $91,98,100,104,105,111$, $112,122,123,125-130,134$, $136,140,152-154,158,159$, $165-168,171,179,181,188$, 203-205, 209, 212, 214, 222, 224, 225, 229, 231-233, 235, $237,246,248,254,255,260$, 270-273, 275-285, 290-292, 295, 297, 299, 300, 302, 303, 305-307, 315-317, 320

Corruption, 163, 253, 261, 262, 281, $282,285,290$

Council Conclusions, 4

Council of the EU/Council, 25, 26,

$52,54,57,58,60-65,82,87$, $88,91,122,133,138,159,183$, $184,190,211,223,246,251$, $272,275,276,280,304$

Crimea, annexation of, 7, 29, 32, 71, $72,152,179,210,228,292$, 297,319

D

Declaration on Transatlantic Relations between the European Community and its Member States and Canada (1990), 127

Democratic Clause, 271

Democratic People's Republic of Korea (DPRK, North Korea), 293-296, 301, 303-305

Developing country, 245, 259, 262
Diplomacy, 10, 13, 22, 30, 34, 40, $41,44,65,71,73,78,88,91$, $99,108,109,156,170,171$, 202, 213, 231, 263, 264, 290, $300,306,317$

Directorate General (DG), 61, 62

Directorate General for Education, Culture, Youth and Sports (DG EAC), 69, 70, 72, 74, 76, 77, $79,80,82,87$

Directorate General for European

Neighbourhood and Enlargement

Negotiations (DG NEAR), 76, $77,79,82,87$

Directorate General for International

Cooperation and Development

(DG DEVCO), 76, 77, 79, 82, 85

Doha Development Round, 36, 106

Doha Round, 132, 155, 157, 160

'Domesticism', 109

Drug trafficking, 276

Duty Free and Quota Free (DFQF), 247,259

$\mathrm{E}$

East African Community (EAC), 258 East China Sea, 294

Economic and Monetary Union (EMU), 36, 103, 129

2008 economic crisis, 28, 153, 170

Economic/financial crisis, 4, 24, 31, $32,37,106,161,248,261,272$, 296

Economic Partnership Agreement (EPA), 98, 232, 246, 248, 249, $251,253,256,258-260,263$

Education, 70, 71, 73-75, 77, 79, 80, $82-89,91,158,255,261$

Effective multilateralism, $3,10,12$, $14,22,29,151,190,320$

Emerging country, 245 
Emerging powers, 2, 9, 104, 134, $171,207,312,313,318$

Endogenous factors, 72, 122, 124

Engagement, 32, 35, 36, 39-41, 70, $72,79,88,91,101,107,114$, $153,165,171,179,184,194$, 214, 222, 226-229, 233, 237, $251,252,263,298,303,315$, 316,322

Erasmus Alumni, 70, 81

Erasmus/Erasmus+, 13, 69-72, 74-78, 80-83, 85-91

Erasmus Generation, 74

Erasmus Impact Study, 74

Erasmus Mundus, 69, 76, 82, 83

Erasmus Mundus Joint Master Degrees, 76, 77, 85, 87

Erasmus+ National Agency, 75-77

Erasmus+ Office, 77, 87

EU Alumni Engagement Initiative, 80

EU-Brazil Sector Dialogues Support Facility (SDSF), 84, 85

EU-Brazil Summit(s), 24, 58, 84, $154,159,160,162,163,169$, 171

EU-Canada Partnership Agenda (2004), 122, 126, 131, 135

EU-Community of Latin American and Caribbean States (EU-CELAC), 85, 86, 165

EU-Cuba Political Dialogue and Cooperation Agreement, 279

EU external action, 7, 10, 13, 14, 22, $26,33-35,38,39,42,43,50$, $71-73,79,85,90,91,104,113$, $115,192,210$

EU foreign policy, 50-52, 59, 60, 62, 65

EU Global Strategy (EUGS), 53, 134, 212, 231, 290, 292, 319

EU-India strategic partnership, 200-202
EU-Japan Economic Partnership Agreement (EPA), 298, 307

EU-Japan Strategic Partnership Agreement (SPA), 298, 301, 305

EU-LAC Common Area of Higher Education, 85

EU-Mercosur association agreement, $58,155,158,169$

EU Naval Force (EU NAVFOR) Somalia, 297, 299

EU neighbourhood, 71, 76, 77, 82

EU-Republic of Korea Framework Agreement (FA), 299, 302

EU-Republic of Korea Framework Participation Agreement (FPA), 299, 302, 305

EU-Republic of Korea Free Trade Agreement (FTA), 290, 298-300, 302

Europe Agreements, 182

European Bank for Reconstruction and Development (EBRD), 129

European Commission/Commission, $26,29,32,51,52,54,55,57$, 59-62, 64, 65, 72, 76, 78-80, $83,85-91,111,128,131,132$, $135,154,155,159,169,170$, 181-184, 204, 205, 208, 209, $211-213,223,224,238,273$, $275,278,290,299,321$

European Council, 4, 23-27, 29, 49, $50,53,78,131,178,208,210$, $211,275,291,318,319$

2010 European Council Conclusions, 27

European External Action Service (EEAS), 7, 11, 12, 29, 30, 32, $40,52,53,57,59-65,69,70$, 72, 74, 76, 78-82, 84, 88, 91, $106,110,113,135,152,165$, $169,170,183,184,211,212$, 
224, 233, 236, 238, 277-282, 290-292, 302, 320, 321

European foreign policy, 2, 3, 7, 9, $23,25,71,79,112,134,171$, $189,211,225,234,238,275$, 283

European Geographical Indications, 274

European Higher Education Area, $85-87$

European Neighbourhood Policy (ENP), 26, 137, 182, 207, 210 European Parliament (EP), 29, 32, $52,61,63,64,71,78,87,88$, $133,138,155,159,200,211$, 226, 271, 273, 275, 276, 281, 282

European Security and Defence Policy (ESDP), 157, 206

European Security Strategy (ESS), 3, $9,12,22-24,26,29,39,81$, $104,112,122,131,140,157$, $169,208,210,272,318$

European Union (EU), xi, xiii-xvii, $\mathrm{xx}, 1-14,21-44,50-62,64$, $65,70-92,97-116,121-142$, 151-171, 178-194, 199-215, 221-239, 245-249, 253-264, 269-286, 289-307, 311, 312, 317-322

European Union Delegation (EUD), $77,81,82,84,87$

EU-Russia Civil Society Forum, 88 Exogenous factors, 122, 124, 141

\section{F}

Ferrero-Waldner, Benita, 185

Fisheries war, 123

Foreign policy, 3, 4, 7, 12, 14, 26, $36,49,51-53,99,105,109$, $111,130,135,137,155,156$, 163-166, 168, 169, 171, 190,
206-208, 212-215, 222, 229, $237,252,256,277,289-292$, 294, 304-306, 311, 312, 315, 317-322

Foreign policy concept, 311,312

Former Yugoslavia, 100, 236

Four Common Spaces, 185, 187

Framework Agreement for Commercial and Economic Co-operation between the European Communities and Canada (1976), 122, 125

France, 24, 107, 108, 110, 168, 225, $230,246,284$

Free Trade Agreement (FTA), 13, 55, $56,58,107,122,131,132,137$, $139,141,165,169,199,213$, $231,232,251,256,271,272$, $278,282,299$

G

G20/G-20, 27, 106, 136, 248, 254, 285

General Agreement on Tariffs and Trade (GATT), 125, 126, 130

Geopolitics, 38, 111, 113, 161, 192, $226,230,231,319$

Germany, 24, 90, 108, 110, 130, $138,139,166,168,230,261$

Global Agreement (GA), 14, 155, $235,269-277,279-283,285$

Global South, 156, 164

Global Strategy, 7-10, 12, 22, 29, 30, $32-34,38-40,53,70,73,76$, $80,88-91,110,112,113,152$, $153,162,166,168-171,231$

Great power, 9, 185, 192, 212, 222, 226-228, 237, 238, 291, 313, 321

Great power politics, 237 
$\mathrm{H}$

Hard power, 73, 102, 107, 211, 214, 304

Hedging, 203, 315-317

Helms-Burton Act, 279

Higher education, 69-75, 77, 82-84, $86,87,89,90,126,188,280$

High-Level Dialogues (HLD), 24, $152,159,165,273,280$

High Representative for Foreign

Affairs and Security Policy/Vice-

President of the Commission

(HRVP), 4, 7, 26, 27, 30, 52-55,

$57,60,61,63-65,74,88,106$,

$108,280,281,319$

Hong Kong, 73, 78, 230, 304

Human rights, 36, 38, 54, 57, 70, $109,136,158-160,163,164$, $186,208,209,212,225,230$, 234, 249, 254, 255, 270, 271, 273, 275-278, 280, 281, 285, $290,299,300$

\section{I}

IBSA, 165, 316

Identity, 4, 13, 22, 23, 35, 37, 38, $42,44,51,74,89,90,99,100$, $112,115,140,170,192,214$, $215,222,237,239,246,264$, 270, 283, 289, 290, 292, 301, 303,319

Image, $2,4,13,22,31,34,38-42$, $44,50,52,80,89,115,152$, $161,171,191,215,239,261$, 262, 290, 291, 293, 299-301, 303,320

India, 3, 4, 10, 23, 24, 26, 63, 77, 79, $122,134,138,169,199-201$, 203-215, 231, 232, 262, 272, 298, 313, 318, 319, 321

Indo-Pacific region, 108, 215
International Contact Group (ICG) on Venezuela, 279

International Credit Mobility (ICM), $77,78,85,87,90$

International Criminal Court, 102

Iran nuclear agreement, 111

Iran (nuclear weapons), 103, 111, 156,229

Iraq, 3, 31, 104, 107, 190, 284, 318 Iraq war, 37, 190

Joined-up approach, 76, 167

Joint Parliamentary Committee (EU-Mexico JPC), 273, 280-282

Joint Political Declaration on EUCanada Relations (1996), 125, 127,130

K

Kargil War, 206, 207

Korean peninsula, 63, 295, 298, 304

Kosovo war, 190, 206

Kyoto Protocol, 102, 164

L

Latin America, 11, 63, 77, 86, 155, 163, 167, 168, 227, 271, 275, 278,285

Lavrov, Sergey, 188

Least developed country (LDC), 258, 259

Liberal international order, 108, 222, $226,228,237,238$ 
Liberal order, 12, 109, 111, 222, 312,320

Libya, 107, 162, 236

Lisbon Joint Statement, 152

1975 Lomé Convention, 204, 253, 257,258

Luís Inácio Lula da Silva, 156

M

Macron, Emmanuel, 184, 188, 231

Mandela, Nelson (President), 251, 252,256

Mbeki, Thabo (President), 252

Mercosur, 55, 58, 64, 156, 158

Mexico, 2-4, 10, 11, 14, 24, 32, 55, $63,76,77,79,85,86,160$, 269-286, 318, 319, 321

Mexico-EU Summit, 275

Mgobagoba Dialogue, 254, 255

Middle income country, 250

Mid-Term EU Strategy (of Russia), 187

Millennium Development Goals, 157

Model Power Europe, 70

Modernization Global Agreement, 273-276, 283-285

Modi, Narendra, 208, 213

Mogherini, Federica, 7, 30, 74, 78, $79,184,280,281,285,319$

Monnet, Jean, 75, 78-80, 83, 85, 87, 121

Moralpolitik, 208

Multilateralism, 23, 30, 38, 108, 134, $136,141-143,158,160,163$, 190, 191, 209, 229, 230, 234, $235,255,270,277,278,285$, $293,306,320,321$

Multilevel crisis, 12, 31, 152, 153, 160,170

Multilevel governance, 123, 137

Mutual recognition agreements (MRAs), 98, 101
$\mathbf{N}$

Navalny, Alexei, 191

New generation FTAs, 138, 290

New Transatlantic Agenda and Action Plan (1995), 98, 99, 101

Nice Treaty, 35

Non-alignment, 207

Non-traditional security, 302

Normative power, 36, 38, 105, 109, 200, 207, 214, 215, 292

'Normative power Europe', 99

North American Free Trade Agreement (NAFTA), 123, 138, 269, 271-274, 282, 284

North Atlantic Treaty Organisation (NATO), 23, 32, 33, 98, 100-102, 104, 107, 123, 129, $136,141,166,189,228,230$, 231, 236

Northern Dimension, 188

Novichok (nerve agent), 191

\section{O}

Obama, Barack (President) and Administration, 99, 108, 228

Official development assistance (ODA), 249-251, 257

Organisation for Economic Cooperation and Development (OECD), 136

Organisation for Security and Cooperation in Europe (OSCE), 136

$\mathbf{P}$

Paris Climate Accords, 110, 111

Paris Climate agreement, 290

Partnership and Cooperation Agreement PCA (with Russia), 178, $181,182,185,226,232$ 
Partnership diplomacy, 7, 12, 22, 25, $34,38-41,65,215,313,316$

Partnership for Modernisation (P4M), 187

Partnership Instrument (PI), 78-82, $84,87-90$

Partnership policy, 2, 3, 9, 11, 12, 30, 307

Peacekeeping, 10, 38, 129, 222, 236, 278

People's Republic of China (PRC), 221, 223, 292, 293, 295, 298, 305,306

People-to-people contacts, $70,78-80$, $83,86,88,91,184,188$

Permanent Partnership Council (PPC), 187

Permanent Structured Cooperation (PESCO), 33, 38

Political dialogue, 3, 8, 24, 25, 28, $62,65,128,160,164,166,170$, 171, 224, 246, 258, 271, 276, $280,284,296$

Portugal, 24, 31, 154

Power, 4, 7, 9, 11, 12, 14, 23, 26, 27, $29,33,37,43,63,97,98,103$, $104,106,109,111,114,115$, $133,138,139,141,142,151$, $152,155-158,161-163,186$, 192, 203, 204, 207, 222-224, 226-229, 231-235, 245, 255, 260, 262-264, 272, 277, 278, $283,285,293,296,305,312$, $313,315-317,319$

Principled pragmatism, 212, 320

Proliferation of the fuzzy, 180, 181 Putin, Vladimir, 179, 181, 185, 186, 188, 190, 191, 227

Q

Quadrennial Diplomacy and Development Review, 108
$\mathbf{R}$

Ramaphosa, Cyril (President), 250, $252,262,263$

Ratification, 58, 122, 131, 133, 136, $138-140,142,282,284$

Realpolitik, 9, 38, 208

Recognition, 2-4, 23, 29, 77, 83, 85, $155,156,191,209,215,224$, $235,237,248,254,282,283$

Report on the Implementation of the European Security Strategy, 4, 24,29

Republic of Korea (ROK, South Korea), 56, 57, 63, 289, 290, 292, 293, 295-301, 303, 304, 307

Role, 2, 8-11, 13, 14, 22, 23, 28, $30,38,42,44,49,51,52$, $56,57,59,61,63,64,70-74$, $78,99,100,107,110,111$, $115,123,124,129,133,140$, $154-160,163,165,167,183$, $184,189,190,192,194,201$, 206, 211-213, 222, 224, 231, $238,239,248,251,252,255$, 256, 260, 263, 264, 270, 272, 277, 278, 283, 284, 294, 295, $299,303,306,307,315,318$, 322

Rousseff, Dilma, 84, 152, 162-164, 170

Rules-based order, 111, 293-295, 299, 300, 302, 303, 305-307

Russia, 3, 4, 9-12, 15, 23, 25, 26, $28,29,32,37,54,63,70,72$, $77,79,81,82,86-90,112$, 178-194, 202, 210, 213, 222, 226-228, 230, 231, 235-237, 272, 277, 285, 292, 297, 312, $313,318,319,321$ 
$S$

\section{SA-EU SP, 253}

Sea Lines of Communication (SLOCs), 294

Sectoral dialogues, 83, 84, 159, 209, $224,225,280,281$

Security Council, UN, 156, 163, 168, 190, 227, 236, 296

Self-Defense Force (SDF), 297, 302

Service for Foreign Policy Instruments (FPI), 78, 79, 82, 87

Social constructivism, 43, 222, 237, 238

Soft power, 13, 69-74, 76, 79-81, $89,90,92,102,105,134$

Solana, Javier, 183

South Africa, 3, 4, 10, 14, 24, 28, 63, $77,79,81,138,245-264,272$, 318

South America, 154-157, 166, 169

South American Defense Council (SADC), 156, 167, 256, 258

South China Sea, 225, 228, 233, 234, 239, 294, 304, 305

Southern African Customs Union (SACU), 250, 253, 256-260

Southern African Development Community (SADC), 247, 253, 256, 258, 263

South Korea, 3, 4, 10, 11, 14, 24, 32, $56,63,76,78,138,231,272$, 290, 291, 295, 296, 299, 300, 302-304, 306, 318, 319, 321

Soviet Union, 23, 97, 140, 223, 313

Spain, 31

Strategic autonomy, 33, 39, 110, 212, 322

Strategic partner(s), 2-4, 7-11, $23-25,27-30,32,33,49-51$, $53,55-57,59-65,71,72$, 75-82, 86, 87, 89-91, 102, 113, $115,122,138,153,155,157$,
$162,169,170,178,179,181$, 193, 194, 201, 208, 211, 213, $214,225,238,247,254,255$, 272, 276, 280, 297-299, 305, $316,318-321$

Strategic partnership (SPs), 2, 3, 10, $13,14,21-23,25-27,29,30$, $32-34,36-44,50-65,70,71$, $75,78,82,83,86,98-104,106$, $111-115,122,131-133,135$, 138-141, 151, 153-155, 158, $160-162,170,171,178-180$, $189,191,193,194,200-202$, 208, 211, 221, 222, 224, 229-231, 233, 237-239, 246$248,250,251,254,260,263$, $269,273,280,290-292,294$, 296, 299, 301, 303, 305-307, $311-313,315-322$

Strategic partnership agreement (SPA), 56-61, 65, 122-124, 126, $132-140,142,232,321$

Strategy, 12, 22, 26, 33, 39, 40, 49-52, 54, 55, 59, 64, 65, $73,81,104,115,129,154$, $156,167,171,178,187,191$, 211-213, 227, 228, 232, 271, 285, 290, 296, 305, 315-317, 319

Study in Europe, 82, 87

Summits, EU-Russia, 182

Syria, 31, 162, 227, 236, 280

$\mathrm{T}$

Taiwan, 78, 227, 239, 304

Temer, Michel, 164, 166

Terminal High Altitude Area Defence (THAAD), 295, 296

Third option, 127

Tindemans Report, 115

Trade, 222, 223, 225, 229, 230, 234, $235,237,238$ 
Trade and Cooperation Agreement (TCA), 188

Trade and Investment Enhancement Agreement (TIEA), 131

Trade, Development and Cooperation Agreement (TDCA), 246-248, 251, 256-259

Transatlantic Business Dialogue (TABD), 101

Transatlantic Declaration (1990), 98

Transatlantic dialogue, 101, 114, 136

Transatlantic Economic Partnership (TEP), 99, 101, 105

Transatlantic Trade and Investment

Partnership (TTIP), 99, 106, $107,134,284$

Trans-European Mobility Programme for University Studies

(TEMPUS), 77, 86, 87

Transition, 13, 33, 49-52, 60, 62, 63, $182,185,212,250,278,279$, 283

Transnational terrorism, 8, 102, 104, 164,169

Trans-Pacific Partnership (TPP), 107, 163, 298

Treaty of Lisbon/Lisbon Treaty, $2,22,26,33,36,49-52,56$, 60-63, 104, 106, 112, 133, 135, $141,151,167,211,290,291$, 319

Trump, Donald (President) and Administration, 7, 11, 32, 99, $109,110,113,152,161,165$, $171,228,229,235,284,285$, 298, 319, 321

Trump, Donald, US President, 109, $111,142,228,229,272,293$, 298, 302, 306

'Trumpism', 109

Turkey, 7, 75, 101, 206, 312

Two-level game (Putnam), 183
$\mathrm{U}$

Ukraine, 25, 29, 30, 32, 54, 59, 89, $108,161,178,181,183,188$, $189,191,192,210,228,292$, 313

Ukraine conflict, 14, 178-180, 184, $188,189,191,194,231$

UNESCO, 84, 110

Union of South American Nations (UNASUR), 156, 167

United Kingdom (UK), 4, 11, 33, $107,108,110,129,130,139$, $142,152,161,201,228,230$, 252, 261

United Nations (UN), 9, 30, 38, 104, $107,136,155,163,167,234$, $236,255,277,279,312$

United Nations Mission for Stability in Haiti (MINUSTAH), 278

United States (US)/USA, 3, 4, 7, 9-13, 15, 23, 28, 30, 32, 33, $40,41,63,76,78,79,97-115$, $123,124,127,130,131$, $134,135,137,140-142,154$, $155,157,161,164-167,189$, 190, 192, 200, 202, 211, 213, 222-225, 227-230, 235-238, 253, 262, 272, 277, 279, 284, 285, 293-295, 303-306, 313, 315-319, 321, 322

United States, Mexico and Canada Agreement (USMCA), xxii, 274, 275,284

UN peacekeeping mission in Haiti (MINUSTAH), 156

UN Permanent Security Council, 156 US-ROK alliance, 295

USSR, 185,188

V

Van Rompuy, Herman, 4, 23, 26, 27, $49,50,53,65,211,318-320$ 
W

War in Georgia, 179

Weapons of Mass Destruction (WMD), 157, 209, 296

Workers' Party, 164, 166, 167

World Trade Organisation (WTO), $36,106,155,157,163,235$, $247,248,257-259,271,285$

X

Xinjiang, 230, 304
Y

Yeltsin, Boris, 185, 312

Youth, 73, 75, 83, 85, 87, 91, 126, 249

Youth in External Action, 91

Z

Zuma, Jacob (President), 252, 261, 262 